\title{
Structure-function relationship of atrial fibrillation waves in goat and man
}

Citation for published version (APA):

Maesen, B. (2015). Structure-function relationship of atrial fibrillation waves in goat and man. [Doctoral Thesis, Maastricht University]. Maastricht University. https://doi.org/10.26481/dis.20151030bm

Document status and date:

Published: 01/01/2015

DOI:

10.26481/dis.20151030bm

Document Version:

Publisher's PDF, also known as Version of record

\section{Please check the document version of this publication:}

- A submitted manuscript is the version of the article upon submission and before peer-review. There can be important differences between the submitted version and the official published version of record.

People interested in the research are advised to contact the author for the final version of the publication, or visit the DOI to the publisher's website.

- The final author version and the galley proof are versions of the publication after peer review.

- The final published version features the final layout of the paper including the volume, issue and page numbers.

Link to publication

\footnotetext{
General rights rights.

- You may freely distribute the URL identifying the publication in the public portal. please follow below link for the End User Agreement:

www.umlib.nl/taverne-license

Take down policy

If you believe that this document breaches copyright please contact us at:

repository@maastrichtuniversity.nl

providing details and we will investigate your claim.
}

Copyright and moral rights for the publications made accessible in the public portal are retained by the authors and/or other copyright owners and it is a condition of accessing publications that users recognise and abide by the legal requirements associated with these

- Users may download and print one copy of any publication from the public portal for the purpose of private study or research.

- You may not further distribute the material or use it for any profit-making activity or commercial gain

If the publication is distributed under the terms of Article $25 \mathrm{fa}$ of the Dutch Copyright Act, indicated by the "Taverne" license above, 


\section{Structure-Function Relationship of Atrial Fibrillation Waves in Goat and Man}


Copyright (C) Maesen Bart, Maastricht, the Netherlands, 2015

ISBN/EAN 978-90-8590-063-4

All rights reserved. No part of this book may be reproduced, stored in a database or retrieval system, or published in any form or by any means, without prior permission in writing by the author.

Cover by Dashville.be

Layout by D\&L graphics

Printed by Schrijen-Lippertz MediaNova BV

Financial support by Atricure, Stichting Hartsvrienden Rescar te Maastricht and Biosemi BV for lay-out and publication of this thesis is gratefully acknowledged.

Further financial support granted by Maquet Netherlands BV, Cardiac Care BV, Covidien Nederland BV, Krijnen Medical Innovations BV, Heart Medical Europe BV, Sorin Group Nederland NV, Vascutek Nederland, QP\&S NV, Terumo Europe NV and St. Jude Medical Nederland BV is gratefully acknowledged. 


\section{Structure-Function Relationship of Atrial Fibrillation Waves in Goat and Man}

\section{PROEFSCHRIFT}

Ter verkrijging van de graad van doctor aan de Universiteit Maastricht, op gezag van de Rector Magnificus, Prof. dr. L.L.G. Soete volgens het besluit van het College van Decanen, in het openbaar te verdedigen op vrijdag 30 Oktober 2015 om 12.00 uur

door

\section{Bart Maesen}




\section{Promotores}

Prof. dr. U. Schotten

Prof. dr. J.G. Maessen

\section{Copromotor}

Dr. S. Verheule

\section{Beoordelingscommissie}

Prof. dr. F.W. Prinzen (voorzitter)

Prof. dr. T. Delhaas

Prof. dr. M. Duytschaever, UZ Gent

Prof. dr. F. Rega, UZ Leuven

This research is supported by CARIM (Cardiovascular Research Institute Maastricht), ZonMw and EUTRAF (European Network for Translational Research in Atrial Fibrillation)

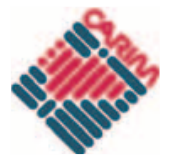


Making the simple complicated is commonplace;

making the complicated simple, awesomely simple, that's creativity.

Charles Mingus 



\section{Contents}

\section{Chapter I}

Introduction - Mechanistic Insights from Mapping of Atrial Fibrillation

and Implications for Ablation Strategies

\section{Chapter II}

Postoperative Atrial Fibrillation - A Maze of Mechanisms

\section{Chapter III}

Rearrangement of Atrial Bundle Architecture and Consequent Changes

77 in Anisotropy of Conduction Constitute the 3D Substrate for Atrial Fibrillation

\section{Chapter IV}

Electrical and Structural Substrates in Patients with Acute, Paroxysmal and Persistent Atrial Fibrillation

\section{Chapter V}

Indices of Bipolar Complex Fractionated Atrial Electrograms Correlate

Poorly with Each Other and Atrial Fibrillation Substrate Complexity

\section{Chapter VI}

Automated Quantification of Atrial Fibrillation Complexity by

Probabilistic Electrogram Analysis and Fibrillation Wave Reconstruction

\section{Chapter VII}

General Discussion 

Chapter 1

Introduction

Mechanistic Insights from

Mapping of Atrial Fibrillation

and Implications for Ablation

Strategies 
Chapter 1 


\section{Introduction}

Atrial fibrillation (AF) is an arrhythmia characterized by rapid and irregular electrical activity in both atria, as opposed to normal sinus rhythm where, originating from the sinus node, homogenous activation of both atria takes place. As a consequence of the chaotic conduction from the atria to the AV node, also ventricular depolarization and contraction are irregular. This underlies one of the main AF symptoms in patients, palpitations. The first written record of AF probably dates back to approximately 1187, when rabbi, physician, and philosopher Moses Maimonides for the first time described 'a totally irreg-

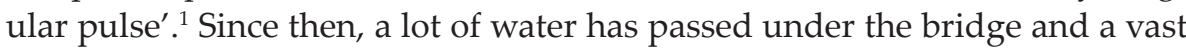
amount of research has been performed and published. As of today, however, the exact pathophysiological mechanisms of AF are still not fully understood. This knowledge gap is probably one of the main reasons why AF remains so fascinating today.

AF is the most common sustained cardiac arrhythmia in humans, affecting 1 to $2 \%$ in the general population, and the number of people with AF is likely to increase the next 50 years. ${ }^{2} \mathrm{AF}$ often progresses from paroxysmal to persistent forms of the arrhythmia. ${ }^{3,4}$ Most of the time AF is detected when AF-related symptoms occur. It should be noted that also asymptomatic AF occurs in 5\% to $20 \%$ in unselected patient groups. ${ }^{5}$ In the elderly, asymptomatic (persistent) $\mathrm{AF}$ is often associated with aortic stenosis or mitral valve regurgitation and enlarged atria. ${ }^{6}$ The first episodes of AF are commonly short and self-limiting, followed by initially short episodes of AF interrupted by longer episodes of sinus rhythm ('paroxysmal $\mathrm{AF}^{\prime}$ ), but with a slowly increasing duration of the arrhythmia episodes. ${ }^{3}$ When AF is recurrent and sustained for more than 7 days, it is labeled 'persistent $\mathrm{AF}^{\prime} .{ }^{7}$ If $\mathrm{AF}$ is continuous or the episode lasts for more than 1 year it is called 'longstanding persistent $\mathrm{AF}^{\prime} .^{7}$ Finally, the term 'permanent $\mathrm{AF}^{\prime}$ is sometimes used, but this term represents merely a therapeutic intention (joined decision of the patient and a physician to cease further attempts to restore and/or maintain sinus rhythm). ${ }^{7}$ A schematic overview of the natural history of AF is depicted in Figure 1. In this Figure, the chaotic pattern of AF episodes alternated with time in sinus rhythm is depicted. Different underlying pathophysiological mechanisms have been attributed to these different classifications of AF. In this chapter, mechanistic insights of experimental and human mapping studies will be discussed. 


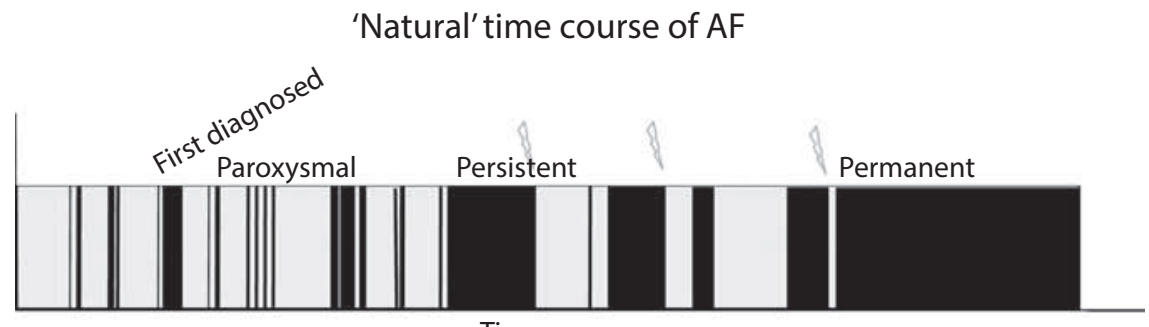

Time

Figure 1. The natural history of AF. Normal sinus rhythm is depicted in light gray; AF episodes are depicted in black. Flashes indicate electrical cardioversions. AF progresses from undiagnosed to first diagnosed, paroxysmal, persistent, and finally to permanent $A F{ }^{3}$

Reprinted from Kirchhof et al., with permission from Oxford University Press.

\section{Mechanistic Insights from Experimental Mapping Studies}

Mechanisms driving and perpetuating AF can be classified as 'hierarchical' or 'anarchical' ${ }^{8}$ From a mechanistic point of view, an hierarchical organization means that a single source drives $\mathrm{AF} .{ }^{4}$ Contrary to hierarchical AF, anarchical AF indicates that multiple non-localized sources act anarchically to drive AF. ${ }^{4}$ As depicted in Figure 2, a single source can be an automatic focus, one mother wave, a fixed or a moving rotor. Multiple sources may consist of multiple foci, unstable circuits, multiple wavelets or a combination of those.

The multiple wavelet hypothesis, introduced by Moe and coworkers, is a classic example of anarchical AF. ${ }^{10}$ In this conceptual model, AF is sustained by the coexistence of multiple wavelets meandering over both atria, given that the atria are big enough (atrial mass) and the refractory period short enough. ${ }^{10,11}$ In 1985, Allessie et al. mapped AF in isolated canine atria infused with acetylcholine and were able to demonstrate the presence of circulating random reentrant wavelets during AF. ${ }^{12}$ In a variety of experimental studies, the findings of multiple reentrant activity during AF was confirmed. For example, Wang et al. studied the effect of flecainide in a canine model of vagally induced AF. ${ }^{13}$ They reported multiple small zones of reentry which after flecainide administration progressively increased in size and decreased in number, with slowing of the frequency of atrial activation until the arrhythmia terminated. ${ }^{13}$ Another example is the optical mapping study by Gray et al in the right atrium of the Langendorff-perfused sheep heart. ${ }^{14}$ During AF, propagation patterns were characterized by a combination of incomplete re- 


\section{Single Source}

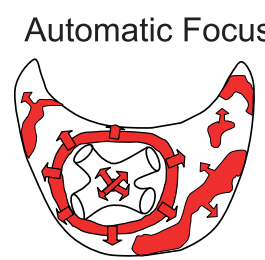

1

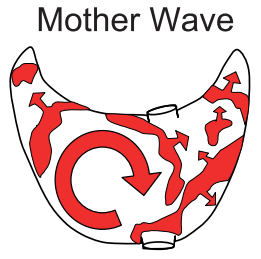

2

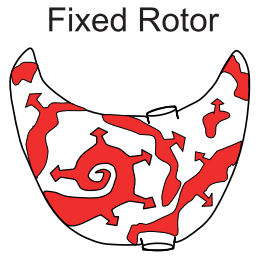

3

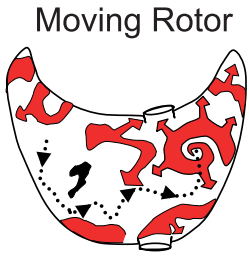

4

\section{Multiple Sources}

Multiple Foci

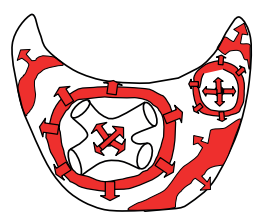

5
Unstable Circuits

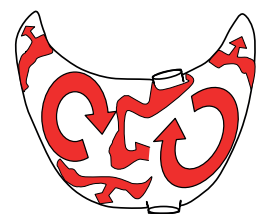

6

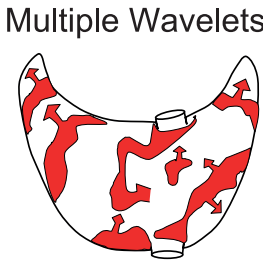

7
Focus

Multiple Wavelets

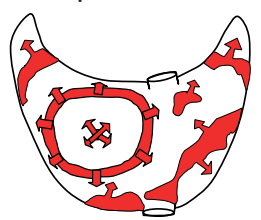

8

Figure 2. Anarchical versus hierarchical organization of AF. In anarchical AF, the arrhythmia is driven and sustained by a single source (e.g. automatic focus, mother wave, fixed rotor, or a moving rotor). In hierarchical AF, multiple sources are present (e.g. multiple foci, unstable circuits, multiple wavelets or a combination).

Reprinted from Eckstein et al., with permission from Elsevier.

entry, breakthrough patterns, and wave collisions. ${ }^{14}$ In this model, conduction block and especially breakthroughs were related to the underlying anatomy in a way suggestive of endo-epicardial conduction. ${ }^{14}$ In an elegant canine model of AF and atrial flutter created in the lab of Waldo et al. ${ }^{15}, \mathrm{AF}$ is induced by sterile talc injection in the pericardium. In this model, Kumagai et al reported multiple unstable reentrant circuits in both atria. ${ }^{16,17}$ During high-density mapping in a rapid atrial pacing model of AF in the goat, Verheule et al. found simultaneously propagating fibrillation waves and 'breakthroughs' (newly appearing waves) during AF. ${ }^{18}$ Moreover, they showed an increase in the number of fibrillation waves and breakthroughs with the duration of AF. ${ }^{18}$ In the same model, Eckstein et al. performed simultaneous endo- and epicardial mapping by using a clamp-like mapping device and demonstrated dissociation of endocardial and epicardial mapped fibrillation waves. ${ }^{8}$ This endo-epicardial dissociation of electrical activity produces more functional surfaces for 


\section{Chapter 1}

fibrillation wavelets to coexist is, providing the condition for transmural conduction by reactivation of the atrial myocardium in the opposite layer and thereby producing a 3-dimensional (3D) substrate for AF (see also Figure 3). ${ }^{8}$ Continued analysis of the breakthrough events in the same data set demonstrated that most of these newly appearing waves were due to transmural conduction rather than ectopic activity. ${ }^{19}$ Finally, in a comparable tachypacing goat model of AF, Kirubakaran at al. recently showed comparable increase in fibrillation waves and electrogram fractionation resulting from conduction block. ${ }^{20}$ It should be noted that the presence of multiple wavelets during AF does not rule out the (co-existence) of other sources in the atria.

Next to multiple reentrant circuits, also other sources sustaining AF have been reported. The group of Jalife ${ }^{21-23}$ studied AF in acetylcholine-infused isolated sheep hearts. By using frequency sampling and optical mapping, stable local-

Dissociated
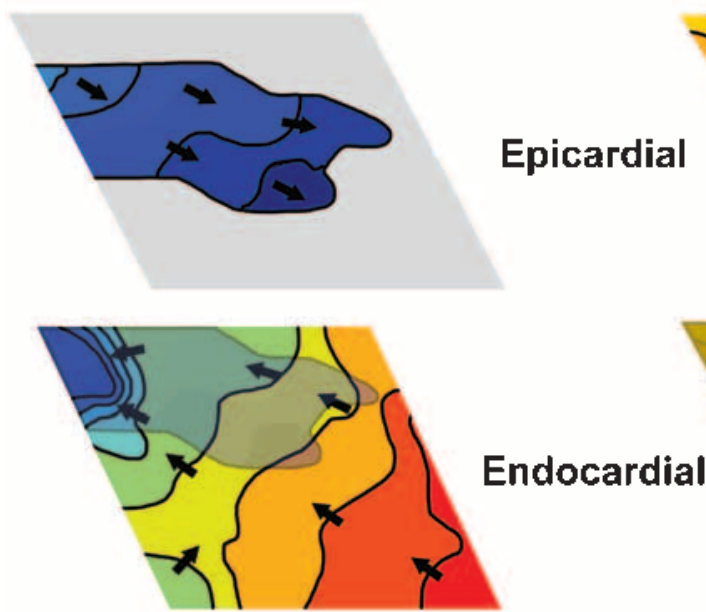

\section{Oms}

Epicardial
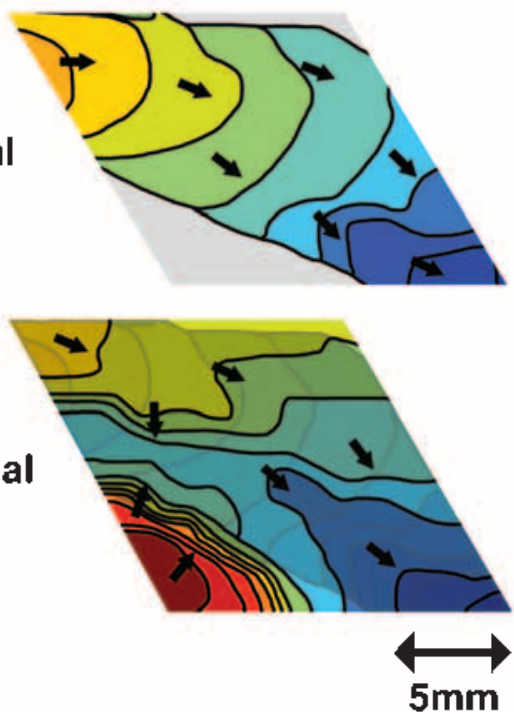

Figure 3. Example of a dissociated epicardial wave (left) and a non-dissociated epicardial wave (right) during simultaneous endo-epicardial mapping in goat left atria. Endo-epicardial dissociation of electrical activity is a conditio sine qua non for transmural conduction and thus the occurrence of breakthrough.

Reprinted from Eckstein et al., ${ }^{19}$ with permission from Wolters Kluwer Health, Inc. 
ized (microreentrant) sources were identified in the posterior left atrium during AF. ${ }^{21}$ The mechanism of this periodicity was attributed to (functional) reentry in the epicardial plane (epicardial rotors) and transmural reentry (breakthroughs). ${ }^{22}{ }^{23}$ In this concept, rapidly rotating activation patterns would drive fibrillatory conduction in the rest of the atria. ${ }^{9}$ The mechanism of transmural reentry was further studied in a simultaneous endo- and epicardial optical mapping in the sheep model. ${ }^{24}$ Yamazaki et al suggested the presence of transmural rotors around a filament spanning through the full atrial wall as the primary activation pattern during AF ${ }^{24}$ Contrary to other studies, ${ }^{18}$ a lower incidence of 'breakthroughs' in persistent AF compared to acutely induced AF was reported..$^{24,25}$ Further study of the mechanisms of microreentry was performed in the sleeves of canine pulmonary veins, where zones of activation delay were identified. ${ }^{26}$ Consequent to this slow conduction, local microreentry could occur ${ }^{27}$ however complete reentry circuits were not observed. ${ }^{26}$ In addition to reentry mechanisms, also multiple foci have been found to drive AF. In a high-density multisite mapping study in a vagal nerve stimulated canine model of AF, Lee et al. mapped multiple foci widely distributed over the atria, with no role for random or stable reentry. ${ }^{28}$ It should be noted that this was a model of acutely induced AF in atria with no remodeling whatsoever. ${ }^{28}$ As such, this might not represent the complexity of AF in fully remodeled atria.

In summary, data derived from animal mapping studies are not unequivocal regarding the mechanism underlying persistence of AF. Next to multiple wavelets meandering over both atria, also stable and less stable rotors - both structural and functional - and multiple foci have been reported. There is however clear evidence that stabilization of AF is related to a 3D substrate of AF..$^{8,14,19}$ The mechanistic heterogeneity might be due to differences in the AF models studied: different species and variations in AF induction and AF duration, different processing algorithms and discrepancies in electrode resolution. In this context, the study of Everett et al. is interesting. ${ }^{29}$ They studied AF mechanisms in different canine models (congestive heart failure, rapid atrial pacing, mitral regurgitation and methylcholine) and showed differences in the type of atrial remodeling and in the mechanism and characteristics of the resulting AF, ranging from multiple wavelets to focal activation and reentry. ${ }^{29}$ In addition there is also diversity in the mapping methods used. For example, unlike direct contact mapping, optical mapping requires the use of excitation-contraction uncouplers and only visualizes electrical conduction in the outer layer of the atrial wall. On the other hand, stable microreentries out- 


\section{Chapter 1}

side the mapping array may give rise to multiple wavelets in the recording area. Finally, experimental AF by definition is artificial. It is based on a variety of AF induction methods with relatively rapid onset of different types of remodeling. Therefore animal studies are not able to precisely identify the exact mechanism that is responsible for onset and sustainment of AF in patients, with far slower remodeling processes diseasing both atria.

\section{Mechanistic Insights from Human Mapping Studies}

Insights on AF mechanisms in human both emerge from studies mapping propagation patterns during AF and studies exploring treatment options for AF. A selection of important studies is summarized here.

In the early 1980s, the only interventional treatment for AF was ablation of the atrioventricular node and implantation of a ventricular pacemaker. ${ }^{30}$ The Cox-Maze procedure (see Figure 4) was the first curative attempt in AF treatment and was performed for the first time on 25 September 1987 at the Barnes Hospital in St. Louis, USA by dr. James Cox. ${ }^{32}$ The operation consisted of an extensive cut-and-sew incision set in both atria with the goal of blocking macroreentrant conduction and directing propagation from the sinoatrial node throughout both atria. ${ }^{33}$ The concept of the procedure was based on epicardial mapping in patients with paroxysmal AF who were undergoing surgical correction of the Wolff-Parkinson-White syndrome. ${ }^{34}$ In this study, Cox et al. demonstrated that, during human AF, mainly multiple wave fronts and macroreentrant circuits occur. ${ }^{34}$ The numerous atrial transections were designed in such way that macroreentrant circuits no longer could prevail. ${ }^{35}$ In this context, success of this procedure could support the hypothesis of multiple wave fronts and macroreentrant circuits driving AF. There are, however, two drawbacks concerning the support of the multiple wavelet hypothesis: (1) although a high success rate was reported, true freedom of AF and the incidence of asymptomatic AF might have been underestimated due to the method of follow-up ${ }^{36}$ and (2) electrical isolation of the pulmonary veins and the posterior left atrial wall (box lesion) was a part of the surgical procedure. ${ }^{31}$ As isolation of the left atrial posterior wall also would prevent other mechanisms driving AF (e.g. ectopic activity in or adjacent to the pulmonary veins, left atrial stable and unstable rotors, etc.), success of the Cox-Maze procedure as such does not precludes these mechanisms. 


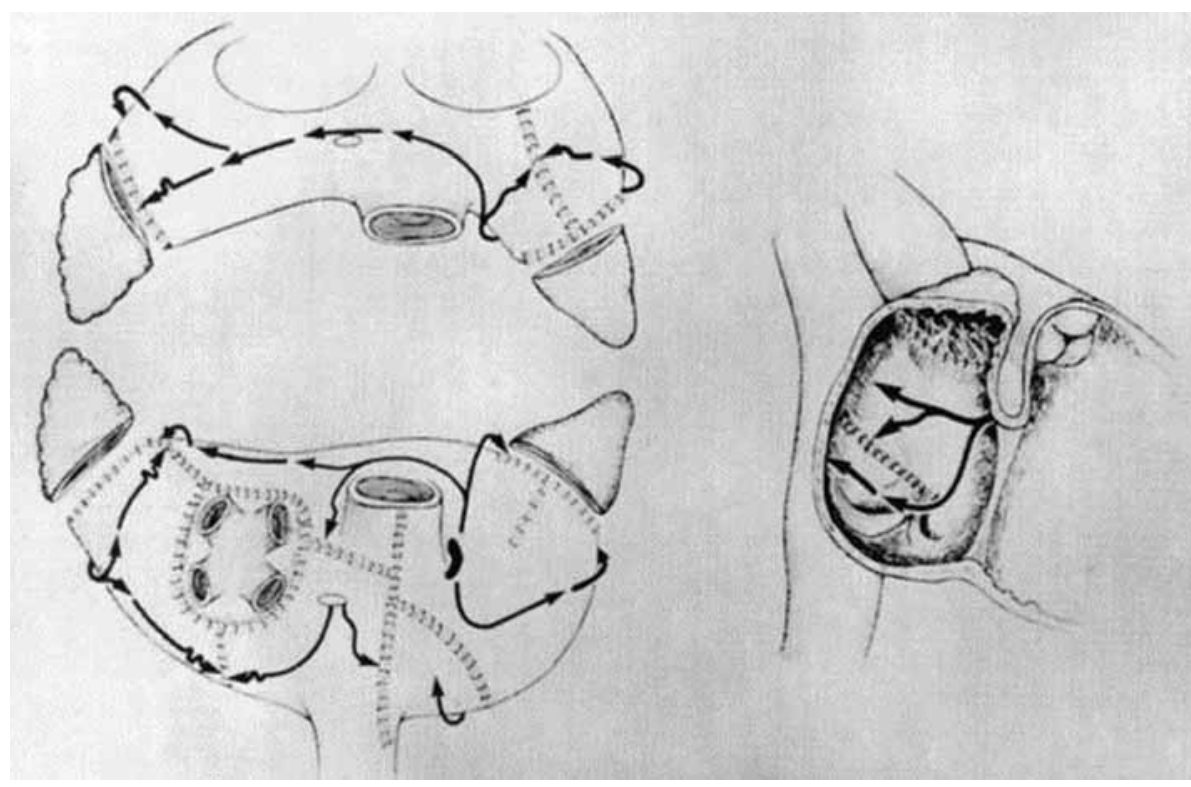

Figure 4. Two-dimensional representation of the Cox-Maze III procedure. Schematic drawings of both atria as seen from posterior (left) and of the surface of the right atrial septum (right) are depicted. Dotted lines represent cut-and-sew incisions. Arrows indicate direction of electrical propagation during sinus rhythm. Both atrial appendages are excised and the pulmonary veins are isolated.

Reprinted from Cox et al., ${ }^{31}$ with permission from Elsevier.

In 1994, Konings et al. performed epicardial mapping during AF, induced by rapid atrial pacing, on the right atrial free wall using a spoon-shaped electrode with 244 unipolar electrodes in 25 patients undergoing surgery for accessory pathways. ${ }^{37}$ Three different types of AF were determined based on the pattern of activation ranging from single broad wave fronts without significant conduction delay (type I) to complex patterns with multiple reentering wavelets (type III). ${ }^{37}$ Both in the study of Cox et $\mathrm{al}^{34}$ and Konings et al ${ }^{37}$, patients were young and had no history of AF or were known with paroxysmal AF. The majority of mapped AF patterns were characterized by uniform wave fronts possibly part of a larger reentrant circuit, with only $28 \%$ having type III AF in the study of Konings et al. ${ }^{37}$ Furthermore, no relation was found between the type of mapped AF and the incidence of documented AF history. ${ }^{37}$ This suggests that the complexity in AF propagation is not much different between acutely induced AF and paroxysmal AF. 


\section{Chapter 1}

In 1998, the pioneering work of Haïssaguerre et al. resulted in a worldwide rush into catheter-based pulmonary vein isolation for curing $\mathrm{AF}^{38}$ In this study, the authors showed that the pulmonary veins harbor ectopic beats (see Figure 5), initiating frequent paroxysms of $\mathrm{AF}$, and that these foci respond well to radio-frequency (RF) ablation. ${ }^{38}$ Later, it was shown that the ectopic activity presumably was a consequence of microreentry promoted by the presence of heterogeneity in refractoriness and anisotropic conduction at the atrial junction with the pulmonary veins and within the pulmonary veins. ${ }^{39,40}$ These findings have important implications: as frequent discharges of a few focal sources can lead to progressive pathologic changes in the atrial substrate, ${ }^{41}$ thereby entraining $\mathrm{AF}^{42}$ and ablation of these foci suppresses the trigger and
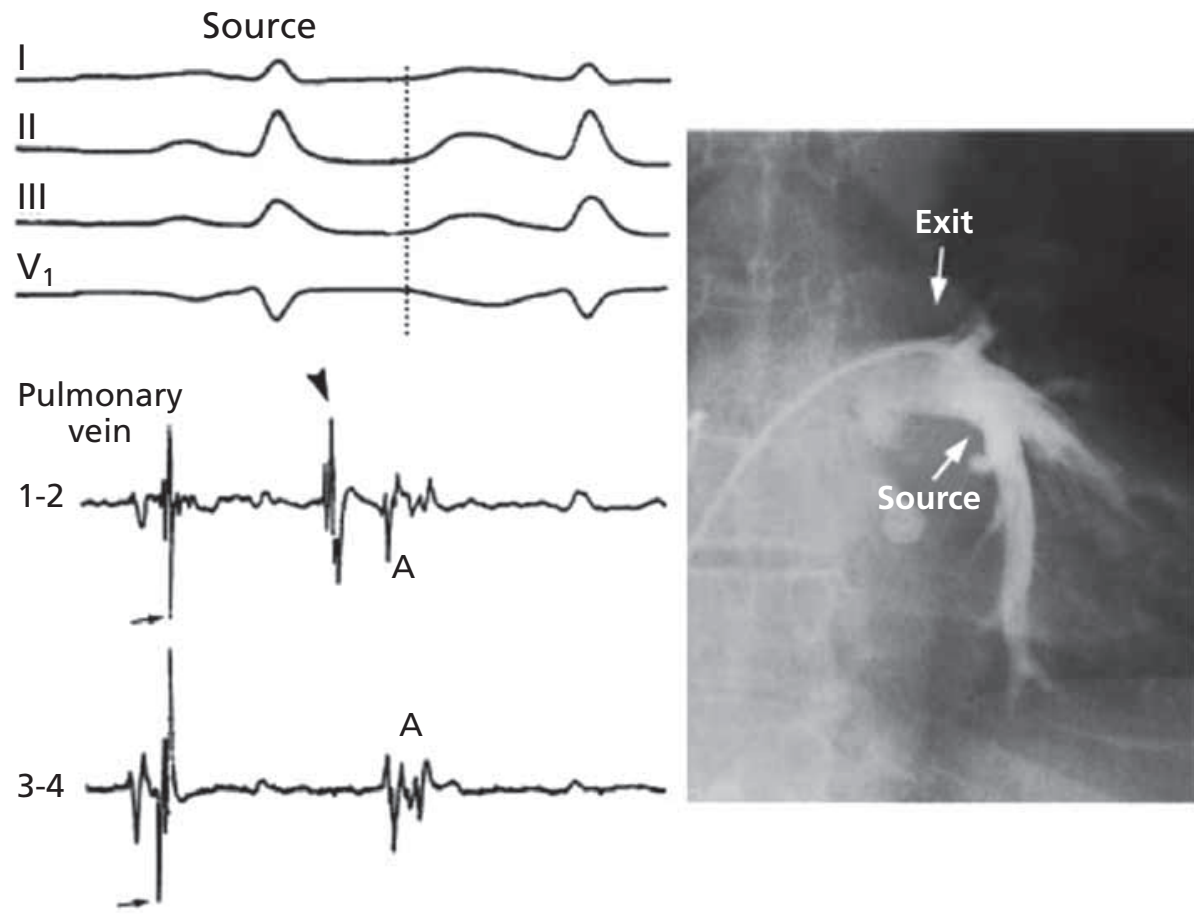

Figure 5. Ectopic activity in the pulmonary veins.

Left: During sinus rhythm, the spike in the pulmonary vein (small arrows) is recorded progressively later. During ectopic activity, the spike in the pulmonary vein is recorded earlier (arrowhead). Right: angiogram of the left inferior pulmonary vein depicting the source of ectopic activity. Reproduced and adapted with permission from Haïssaguerre et al. ${ }^{38}$ Copyright Massachusetts Medical Society. 
reduces the potential degeneration of the atrial substrate, ${ }^{38}$ the underlying mechanism driving human paroxysmal AF seems to be that of multiple foci adjacent to or in the pulmonary veins (Figure 1, cartoon 5). ${ }^{7}$

In persistent $\mathrm{AF}$, on the contrary, the underlying mechanism of $\mathrm{AF}$ maintenance is not fully understood and might be due to (1) cellular proarrhythmic mechanisms, like automaticity or triggers; (2) spiral wave reentry or rotors; (3) multiple wavelet reentry where the fibrillation process is actually driven by waves and no localized sources of AF exist; or (4) a combination of all, different in each patient. ${ }^{4}$

Is persistent AF driven by triggers? There are two indirect arguments against foci driving persistent AF. The first argument is that not the same characteristics are found in paroxysmal and persistent $\mathrm{AF}$, and indeed several endocardial mapping studies identified more complex AF conduction characteristics in persistent $\mathrm{AF}$ than in paroxysmal $\mathrm{AF} .{ }^{43-48}$ The second argument is that the same therapy does not work, and indeed pulmonary vein isolation by RF ablation is highly effective in patients with paroxysmal AF, but not in persistent AF. ${ }^{49,50}$

Be that as it may, some studies do suggest an important role for foci in persistent AF. For example, Nitta et al. performed epicardial mapping on both atria in patients with longstanding persistent AF undergoing mitral valve surgery ${ }^{51}$ Multiple left atrial focal activations with fibrillatory conduction and right atrial focal or reentrant activations were reported as the mechanisms driving AF. ${ }^{51}$ However, repetitive activation was considered as proof of focal activity while no direct mapping of the pulmonary veins was performed and a lower electrode resolution was used to be able to cover the whole atrium. ${ }^{51}$ Sahadevan et al. used dominant frequency analysis of bipolar electrograms and considered regular rapid activity as evidence for the presence of a "driver" of AF. ${ }^{52}$ No reliable sequences of activation maps could be reconstructed..$^{52}$ In both studies, the fibrillatory conduction in the right atrium was considered as a bystander of the focal activity in the left atrium. ${ }^{51,52}$

Is persistent AF due to multiple wavelet reentry? There are several studies supporting Moe's multiple wavelet hypothesis in human AF. ${ }^{10}$ First, Allessie and coworkers performed high-density epicardial mapping of AF on both atria in patients with longstanding persistent $\mathrm{AF}$ and patients without a history of AF. ${ }^{53,54}$ The authors introduced a novel algorithm that, for the first time, enabled separating the fibrillation process into its individual elements (waves). ${ }^{53}$ 


\section{Chapter 1}

During AF, many narrow wavelets propagated simultaneously over both atria. ${ }^{53}$ Also new wavelets appearing in the middle of the mapping area, 'breakthroughs', were quantified. ${ }^{54}$ Interestingly, both the number of peripheral waves and breakthroughs was much higher in persistent AF compared to acute $\mathrm{AF}$, and higher in the left than in the right atrium (see Figure 6). ${ }^{53,54}$ Furthermore, based on variety in location, lack of repetition and electrogram characteristics, transmural conduction (epicardial breakthrough of sources propagating in deeper layers of the atrial wall), rather than a focal mechanism, was attributed as the responsible mechanism underlying breakthrough. ${ }^{54}$ Complete reentrant circuits (rotors) in the epicardial plane were extremely rare. ${ }^{53,54}$ The authors concluded that an increase in longitudinal dissociation (and thus the

\section{Acute AF}

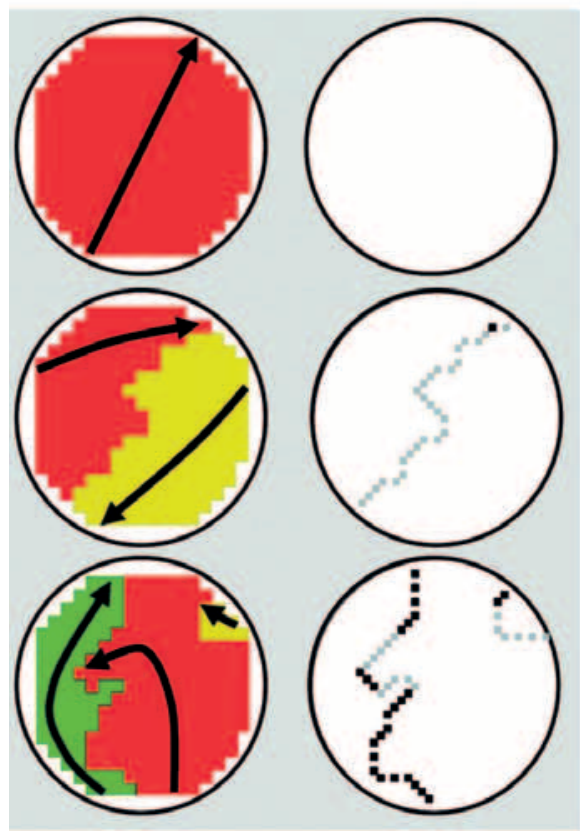

Persistent AF

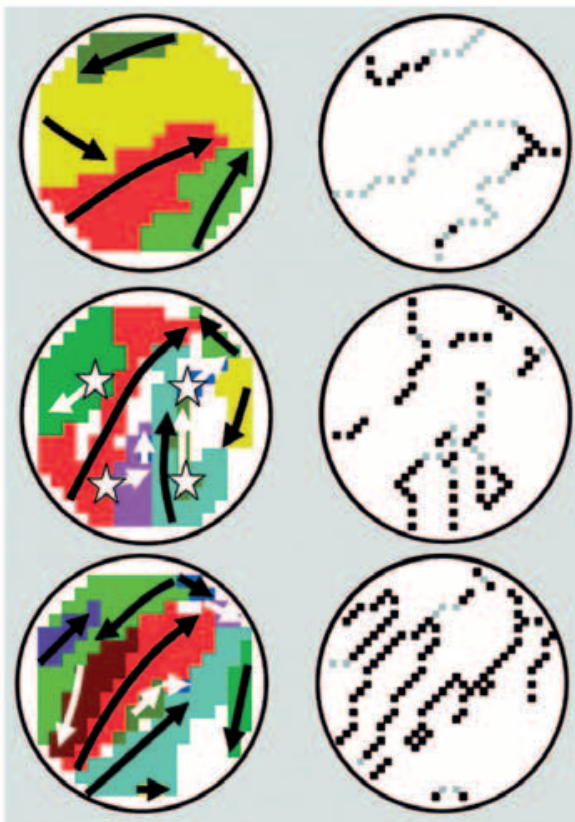

Figure 6. Increase in AF complexity with AF duration.

Separate fibrillation waves (color-coded) and their main trajectories (arrows) of 3 patients with acute AF and 3 patients with persistent AF are depicted. Asterisks indicate epicardial breakthrough. Next to the wave maps, the boundaries between the waves are plotted. (gray = interwave time differences of $\leq 12 \mathrm{~ms}$, black = conduction block).

Reprinted from Allessie et al., ${ }^{53}$ with permission from Wolters Kluwer Health, Inc. 
number of wavelets) and endo-epicardial dissociation of electrical activity form the substrate of persistent AF in humans. ${ }^{53,54}$ Also, a relation between the underlying structure and the conduction pattern was suggested by the correspondence of the conduction block along the borders of wavelets to the location of the pectinate muscles on the right atrial free wall..$^{53}$ Roberts-Thomson et al. reported a similar relationship between conduction slowing and the underlying anatomy in the posterior left atrium leading to circuitous wavefront propagation..$^{5,56}$

Another example supporting the multiple wavelet reentry is the noninvasive imaging of biatrial epicardial activation sequences of AF performed by Cuculich et al. ${ }^{57}$ The authors found multiple wavelets and multilocal foci driving AF, and both increased with the duration of AF. ${ }^{57}$ Whether these 'focal events' were due to local triggers or transmural conduction could not be determined, but similar with the findings of Allessie et al, they were increasing with $\mathrm{AF}$ duration and multilocal. ${ }^{54,57}$ Since patients with paroxysmal and persistent AF were studied, these focal events might represent a mixture of pulmonary vein triggers and transmural conduction. Also in this study, 'rotor activity' was rare, with rotors almost never sustaining more than 1 rotation..$^{57}$

Finally, in a recent report of Lee et al., biatrial epicardial mapping of long-lasting persistent human AF was performed. ${ }^{58}$ Propagation patterns during AF consisted predominantly of multiple unstable wavefronts and disorganized activity, with only the occasional occurrence of rotor activity (3/18 patients) and no sustained focal activity. ${ }^{58}$ Importantly, rotational activity was transient and rotational circuits had a size consistent with that of macroreentry. ${ }^{58}$

Is persistent AF driven by rotors? To date, no epicardial high-density mapping study has been able to document the existence of long-lasting rotors during human AF. ${ }^{34,37,53,54,58}$ In 2012, Narayan et al. unmasked sustained electrical rotors and/or repetitive focal activation in 97\% of mapped human AF (combination of paroxysmal and persistent $\mathrm{AF}$ ) by using a 64-pole basket catheter and a novel algorithm that produces a video of the computed activation process (see Figure 7). ${ }^{60}$ These localized sources were low in number, stable in position, mostly located in the left atrium and they controlled surrounding fibrillatory conduction. ${ }^{61}$ Catheter ablation at the center of these localized sources terminated or consistently slowed persistent or paroxysmal AF in $86 \%$ of patients and significantly improved long-term freedom of AF. ${ }^{61,62}$ Moreover, in a multicenter trial using the same software, the finding of focal sources 
Chapter 1

A. LA Basket Fluoroscopy

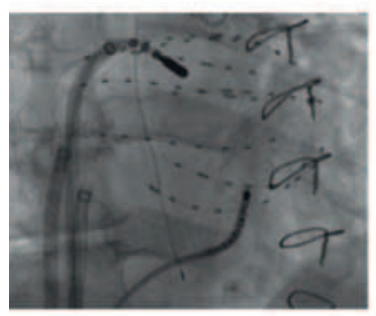

B. LA Rotor in AF

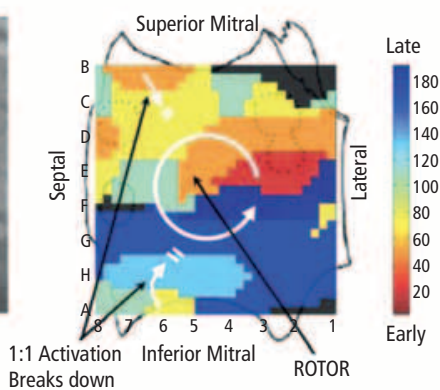

C. Electrograms at LA Rotor

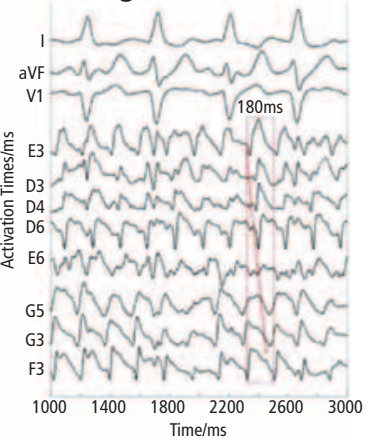

Figure 7. Left atrial basket mapping and identification of a stable rotor.

A. fluoroscopy image showing the endocardial basket catheter.

B. Cartoon depicting the reconstructed counterclockwise rotor in midposterior left atrium based on phase mapping.

C. Corresponding electrograms around the LA rotor.

Reprinted from Narayan et al., ${ }^{59}$ with permission from Elsevier.

and rotors driving different types of AF was confirmed. ${ }^{63}$ Of notice, in a recent extension of that report, more rotors and less focal sources were reported compared to earlier reports, ${ }^{60,61}$ which the authors attributed to 'improved software', among other things. ${ }^{64}$ This might reflect a high dependence on a special software algorithm enabling the detection of rotors driving human AF.

Even more recently, Haïssaguerre et al. used electrograms generated by body surface mapping and biatrial geometry relative from a computed tomography (CT) scan to reconstruct the propagation pattern of fibrillating atria in a noninvasive way. ${ }^{65}$ Signal-analysis processing combining filtering, wavelet transform, and phase mapping was used to identify drivers (focal or reentrant activity) in 103 patients with persistent AF. ${ }^{66}$ Contrary to Narayan et al., ${ }^{60,61}$ the authors reported more driver locations, substantial meandering, and periodic occurrence of unstable reentries requiring statistical density maps to identify them. ${ }^{66}$ Also here, RF ablation at the driver location resulted in acute AF termination in $75 \%$ of persistent $\mathrm{AF}$ and $15 \%$ of long-lasting $\mathrm{AF}$ patients. ${ }^{66}$ No long-term differences in freedom of AF were reported between this novel 'driver targeting ablation' and historically matched patients undergoing the conventional ablation strategy. ${ }^{66}$

Since the unmasking of rotors by Narayan et al, ${ }^{60,61}$ rotor detection has drawn the world attention of the experimental and clinical EP community. It almost 
seems that if currently an era of 'learning by burning' has arrived, 'driving' detailed AF mapping out of the field of studying mechanisms underlying persistence of AF. For example, Nademanee et al. identified areas with bipolar complex fractionated electrograms (CFAE) as AF target sites, ${ }^{67}$ based on the earlier described finding by Konings et al. that unipolar CFAE are found in regions of conduction slowing and conduction block. ${ }^{37}$ Following this finding, one would expect that CFAE should be 'fleeting', as reentrant wavelets are expected to meander. ${ }^{10,37,53,54}$ Nevertheless, Nademanee et al. reported that the distribution and location of CFAEs remained relatively constant. ${ }^{67}$ Despite this mechanistic uncertainty, ablation of this CFAE sites was performed and reported to result in AF termination in 115 of 121 patients (95\%) ${ }^{67}$ Consequent to this report, ${ }^{67} \mathrm{CFAE}-$ ablation was widely adopted and performed in treating persistent AF. However, in 2009 Oral et al. randomized between CFAE and no CFAE ablation and reported that "...up to $2 \mathrm{~h}$ of additional ablation of CFAEs after pulmonary vein isolation does not appear to improve clinical outcomes...". ${ }^{68}$

Equal to CFAE ablation, novel rotor and other driver ablation techniques are being performed without thorough understanding of the underlying mechanism that is visualized by sophisticated software. The difference of mechanisms in persistence AF as detected by direct contact mapping compared to novel techniques, using signal processing techniques as phase mapping, might be explained by a different visualization (or resolution) of the same propagation processes. Indeed, driver patterns reported by Haïssaguerre et al. might resemble multiple reentrant wavelets with transmural 'breakthrough'-conduction if mapped with high-density direct contact mapping. Novel techniques should always be embraced, especially if they go hand in hand with good clinical results. However, more randomized trials are needed to confirm the reported results, and even more importantly, more mechanistic studies have to be performed to understand what really drives AF. Finally, there is a necessity of transparency in this field of research. It is important to stress that exchange of data between different research groups and analysis of data sets by different software algorithms currently used might help us get into the right direction. Moreover, the scientific community has it in its own hands whether or not it accepts research of which the respective algorithms are not in the public domain.

It is remarkable that after almost 35 years of studying and mapping $\mathrm{AF}$, the true nature of the arrhythmia is still not understood. An illustrating example is the STAR AF $2 .{ }^{69}$ In this trial 589 patients, recruited from 48 experienced 
ablation centers in 12 countries, were randomized to pulmonary vein isolation alone, pulmonary vein isolation plus ablation of CFAE or pulmonary vein isolation plus linear ablation lines. ${ }^{69}$ Additional CFAE or linear lines ablation increased procedural time (which may increase risks) but produced no benefit in reducing the AF burden. ${ }^{69}$

In summary, in contrast to the strong indications that paroxysmal AF is trigger driven, the underlying mechanisms driving persistence AF remain unclear. Detailed epicardial mapping using high-density direct contact electrodes reveal multiple reentrant wavelets and possibly 3D conduction as the sustaining mechanisms of AF. Recently, novel software algorithms analyzing electrical activity recorded with low(er)-resolution endocardial or body surface electrodes report rotors and multiple foci (stable and non-stable) driving persistent AF.

\section{Mechanistic Insights provided by this Thesis}

In this thesis, we will focus on different aspects of pathophysiological mechanisms driving AF to give more insights into the complex puzzle of AF mechanisms. In chapter 2 , the maze of mechanisms driving postoperative AF - a specific form of AF occurring primarily after cardiac surgery - is discussed and opportunities for the unmasking of a 'pre-existent substrate of $\mathrm{AF}^{\prime}$ are explored. Chapters 3 and 4 focus on the interrelation between the atrial anatomy and pathology on the fibrillatory conduction process. In chapter 3 , the relation between the complex 3D atrial anatomy and the behavior of fibrillation waves is studied. Chapter 4 provides a detailed study of the electrical and structural remodeling processes in human paroxysmal AF (compared to patients without a history of AF and patients with persistent AF). Chapters 5 and 6 present algorithms and techniques for a comprehensive, objective and transparent analysis of fibrillation electrograms. In chapter 5, CFAE algorithms, used in daily clinical practice, are evaluated against AF substrate complexity measures following fibrillation wave reconstruction derived from unipolar AF electrograms. In chapter 6, a new automated algorithm for analysis of high-density activation maps of AF is presented and validated using manually annotated AF electrograms. Finally, the mechanistic insights provided by the data presented in chapter 2 to 6 are summarized in chapter 7 . 


\section{Mechanistic Insights from AF mapping}

\section{References}

1. Prystowsky EN. The history of atrial fibrillation: the last 100 years. Journal of cardiovascular electrophysiology. 2008;19:575-82.

2. European Heart Rhythm A, European Association for Cardio-Thoracic S, Camm AJ, Kirchhof P, Lip GY, Schotten U, Savelieva I, Ernst S, Van Gelder IC, Al-Attar N, Hindricks G, Prendergast B, Heidbuchel H, Alfieri O, Angelini A, Atar D, Colonna P, De Caterina R, De Sutter J, Goette A, Gorenek B, Heldal M, Hohloser SH, Kolh P, Le Heuzey JY, Ponikowski P, Rutten FH and Guidelines ESCCfP. Guidelines for the management of atrial fibrillation: the Task Force for the Management of Atrial Fibrillation of the European Society of Cardiology (ESC). Europace. 2010;12:1360-420.

3. Kirchhof P, Auricchio A, Bax J, Crijns H, Camm J, Diener HC, Goette A, Hindricks G, Hohnloser S, Kappenberger L, Kuck KH, Lip GY, Olsson B, Meinertz T, Priori S, Ravens U, Steinbeck G, Svernhage E, Tijssen J, Vincent A and Breithardt G. Outcome parameters for trials in atrial fibrillation: executive summary. European heart journal. 2007;28:2803-17.

4. Schotten U, Verheule S, Kirchhof P and Goette A. Pathophysiological mechanisms of atrial fibrillation: a translational appraisal. Physiol Rev. 2011;91:265-325.

5. Israel CW, Gronefeld G, Ehrlich JR, Li YG and Hohnloser SH. Long-term risk of recurrent atrial fibrillation as documented by an implantable monitoring device: implications for optimal patient care. Journal of the American College of Cardiology. 2004;43:47-52.

6. Urena M, Hayek S, Cheema AN, Serra V, Amat-Santos IJ, Nombela-Franco L, Ribeiro HB, Allende R, Paradis JM, Dumont E, Thourani VH, Babaliaros V, Francisco Pascual J, Cortes C, Del Blanco BG, Philippon F, Lerakis S and Rodes-Cabau J. Arrhythmia burden in elderly patients with severe aortic stenosis as determined by continuous electrocardiographic recording: toward a better understanding of arrhythmic events after transcatheter aortic valve replacement. Circulation. 2015;131:469-77.

7. Calkins H, Kuck KH, Cappato R, Brugada J, Camm AJ, Chen SA, Crijns HJ, Damiano RJ, Jr., Davies DW, DiMarco J, Edgerton J, Ellenbogen K, Ezekowitz MD, Haines DE, Haissaguerre M, Hindricks G, Iesaka Y, Jackman W, Jalife J, Jais P, Kalman J, Keane D, Kim YH, Kirchhof P, Klein G, Kottkamp H, Kumagai K, Lindsay BD, Mansour M, Marchlinski FE, McCarthy PM, Mont JL, Morady F, Nademanee K, Nakagawa H, Natale A, Nattel S, Packer DL, Pappone C, Prystowsky E, Raviele A, Reddy V, Ruskin JN, Shemin RJ, Tsao HM and Wilber D. 2012 HRS/EHRA/ECAS Expert Consensus Statement on Catheter and Surgical Ablation of Atrial Fibrillation: recommendations for patient selection, procedural techniques, patient management and follow-up, definitions, endpoints, and research trial design. Europace. 2012; 14:528-606.

8. Eckstein J, Maesen B, Linz D, Zeemering S, van Hunnik A, Verheule S, Allessie M and Schotten U. Time course and mechanisms of endo-epicardial electrical dissociation during atrial fibrillation in the goat. Cardiovasc Res. 2011;89:816-24. 


\section{Chapter 1}

9. Eckstein J, Verheule S, de Groot NM, Allessie M and Schotten U. Mechanisms of perpetuation of atrial fibrillation in chronically dilated atria. Prog Biophys Mol Biol. 2008;97:435-51.

10. Moe GK and Abildskov JA. Atrial fibrillation as a self-sustaining arrhythmia independent of focal discharge. Am Heart J. 1959;58:59-70.

11. Lee AM, Aziz A, Didesch J, Clark KL, Schuessler RB and Damiano RJ, Jr. Importance of atrial surface area and refractory period in sustaining atrial fibrillation: testing the critical mass hypothesis. J Thorac Cardiovasc Surg. 2013;146:593-8.

12. Allessie MA LW, Bonke FIM, HollenJ.; 1985. . Experimental evaluation of moe's multiple wavelet hypothesis of atrial fibrillation. Zipes DP, Jalife J (Ed) Cardiac arrhythmias New York: Grune \& Stratton. 1985:256-276.

13. Wang Z, Page P and Nattel S. Mechanism of flecainide's antiarrhythmic action in experimental atrial fibrillation. Circulation research. 1992;71:271-287.

14. Gray RA, Pertsov AM and Jalife J. Incomplete reentry and epicardial breakthrough patterns during atrial fibrillation in the sheep heart. Circulation. 1996;94:2649-61.

15. Page PL, Plumb VJ, Okumura K and Waldo AL. A new animal model of atrial flutter. Journal of the American College of Cardiology. 1986;8:872-9.

16. Kumagai K, Khrestian C and Waldo AL. Simultaneous Multisite Mapping Studies During Induced Atrial Fibrillation in the Sterile Pericarditis Model: Insights Into the Mechanism of its Maintenance. Circulation. 1997;95:511-521.

17. Kumagai K, Uno K, Khrestian C and Waldo AL. Single site radiofrequency catheter ablation of atrial fibrillation: studies guided by simultaneous multisite mapping in the canine sterile pericarditis model. Journal of the American College of Cardiology. 2000;36:917-23.

18. Verheule S, Tuyls E, van Hunnik A, Kuiper M, Schotten U and Allessie M. Fibrillatory conduction in the atrial free walls of goats in persistent and permanent atrial fibrillation. Circ Arrhythm Electrophysiol. 2010;3:590-9.

19. Eckstein J, Zeemering S, Linz D, Maesen B, Verheule S, van Hunnik A, Crijns H, Allessie MA and Schotten U. Transmural Conduction is the Predominant Mechanism of Breakthrough during Atrial Fibrillation: Evidence from Simultaneous Endo-epicardial High Density Activation Mapping. Circ Arrhythm Electrophysiol. 2013;6:334-341.

20. Kirubakaran S, Chowdhury RA, Hall MCS, Patel PM, Garratt CJ and Peters NS. Fractionation of electrograms is caused by colocalized conduction block and connexin disorganization in the absence of fibrosis as AF becomes persistent in the goat model. Heart Rhythm. 2015;12:397-408.

21. Mandapati R, Skanes A, Chen J, Berenfeld O and Jalife J. Stable microreentrant sources as a mechanism of atrial fibrillation in the isolated sheep heart. Circulation. 2000;101:194-9.

22. Kalifa J, Tanaka K, Zaitsev AV, Warren M, Vaidyanathan R, Auerbach D, Pandit S, Vikstrom KL, Ploutz-Snyder R, Talkachou A, Atienza F, Guiraudon G, Jalife J and Berenfeld O. Mechanisms of wave fractionation at boundaries of high-frequency excitation in the posterior left atrium of the isolated sheep heart during atrial fibrillation. Circulation. 2006;113: 626-33. 


\section{Mechanistic Insights from AF mapping}

23. Skanes AC, Mandapati R, Berenfeld O, Davidenko JM and Jalife J. Spatiotemporal periodicity during atrial fibrillation in the isolated sheep heart. Circulation. 1998;98:1236-48.

24. Yamazaki M, Mironov S, Taravant C, Brec J, Vaquero LM, Bandaru K, Avula UM, Honjo H, Kodama I, Berenfeld $\mathrm{O}$ and Kalifa J. Heterogeneous atrial wall thickness and stretch promote scroll waves anchoring during atrial fibrillation. Cardiovasc Res. 2012;94:48-57.

25. Eckstein J and Schotten U. Rotors and breakthroughs as three-dimensional perpetuators of atrial fibrillation. Cardiovascular research. 2012;94:8-9.

26. Hocini M, Ho SY, Kawara T, Linnenbank AC, Potse M, Shah D, Jais P, Janse MJ, Haissaguerre $\mathrm{M}$ and de Bakker JM. Electrical Conduction in Canine Pulmonary Veins: Electrophysiological and Anatomic Correlation. Circulation. 2002;105:2442-2448.

27. Koura T, Hara M, Takeuchi S, Ota K, Okada Y, Miyoshi S, Watanabe A, Shiraiwa K, Mitamura H, Kodama I and Ogawa S. Anisotropic Conduction Properties in Canine Atria Analyzed by High-Resolution Optical Mapping: Preferential Direction of Conduction Block Changes From Longitudinal to Transverse With Increasing Age. Circulation. 2002;105: 2092-2098.

28. Lee S, Sahadevan J, Khrestian CM, Durand DM and Waldo AL. High Density Mapping of Atrial Fibrillation During Vagal Nerve Stimulation in the Canine Heart: Restudying the Moe Hypothesis. J Cardiovasc Electrophysiol. 2012;24:328-335.

29. Everett Iv TH, Wilson EE, Hulley GS and Olgin JE. Transmural characteristics of atrial fibrillation in canine models of structural and electrical atrial remodeling assessed by simultaneous epicardial and endocardial mapping. Heart Rhythm. 2010;7:506-517.

30. Ad N. The Cox-Maze procedure: history, results, and predictors for failure. Journal of interventional cardiac electrophysiology: an international journal of arrhythmias and pacing. 2007;20: 65-71.

31. Cox JL, Boineau JP, Schuessler RB, Jaquiss RD and Lappas DG. Modification of the maze procedure for atrial flutter and atrial fibrillation. I. Rationale and surgical results. J Thorac Cardiovasc Surg. 1995;110:473-84.

32. Cox JL. The surgical treatment of atrial fibrillation. IV. Surgical technique. J Thorac Cardiovasc Surg. 1991;101:584-92.

33. Cox JL, Schuessler RB, D'Agostino HJ, Jr., Stone CM, Chang BC, Cain ME, Corr PB and Boineau JP. The surgical treatment of atrial fibrillation. III. Development of a definitive surgical procedure. J Thorac Cardiovasc Surg. 1991;101:569-83.

34. Cox JL, Canavan TE, Schuessler RB, Cain ME, Lindsay BD, Stone C, Smith PK, Corr PB and Boineau JP. The surgical treatment of atrial fibrillation. II. Intraoperative electrophysiologic mapping and description of the electrophysiologic basis of atrial flutter and atrial fibrillation. J Thorac Cardiovasc Surg. 1991;101:406-26.

35. Cox JL, Jaquiss RD, Schuessler RB and Boineau JP. Modification of the maze procedure for atrial flutter and atrial fibrillation. II. Surgical technique of the maze III procedure. J Thorac Cardiovasc Surg. 1995;110:485-95. 


\section{Chapter 1}

36. Prasad SM, Maniar HS, Camillo CJ, Schuessler RB, Boineau JP, Sundt TM, 3rd, Cox JL and Damiano RJ, Jr. The Cox maze III procedure for atrial fibrillation: long-term efficacy in patients undergoing lone versus concomitant procedures. J Thorac Cardiovasc Surg. 2003; 126:1822-8.

37. Konings KT, Kirchhof CJ, Smeets JR, Wellens HJ, Penn OC and Allessie MA. High-density mapping of electrically induced atrial fibrillation in humans. Circulation. 1994;89:1665-80.

38. Haissaguerre M, Jais P, Shah DC, Takahashi A, Hocini M, Quiniou G, Garrigue S, Le Mouroux A, Le Metayer P and Clementy J. Spontaneous initiation of atrial fibrillation by ectopic beats originating in the pulmonary veins. N Engl J Med. 1998;339:659-66.

39. Kumagai K, Ogawa M, Noguchi H, Yasuda T, Nakashima H and Saku K. Electrophysiologic properties of pulmonary veins assessed using a multielectrode basket catheter. Journal of the American College of Cardiology. 2004;43:2281-9.

40. Lee G, Spence S, Teh A, Goldblatt J, Larobina M, Atkinson V, Brown R, Morton JB, Sanders P, Kistler PM and Kalman JM. High-density epicardial mapping of the pulmonary vein-left atrial junction in humans: insights into mechanisms of pulmonary vein arrhythmogenesis. Heart Rhythm. 2012;9:258-64.

41. de Bakker JM, Ho SY and Hocini M. Basic and clinical electrophysiology of pulmonary vein ectopy. Cardiovascular research. 2002;54:287-94

42. Wijffels MCEF, Kirchhof CJHJ, Dorland R and Allessie MA. Atrial Fibrillation Begets Atrial Fibrillation : A Study in Awake Chronically Instrumented Goats. Circulation. 1995;92:19541968.

43. Zrenner B, Ndrepepa G, Karch MR, Schneider MA, Schreieck J, Schomig A and Schmitt C. Electrophysiologic characteristics of paroxysmal and chronic atrial fibrillation in human right atrium. Journal of the American College of Cardiology. 2001;38:1143-9.

44. Fiala M, Wichterle D, Chovancik J, Bulkova V, Wojnarova D, Nevralova R and Januska J. Left atrial voltage during atrial fibrillation in paroxysmal and persistent atrial fibrillation patients. Pacing Clin Electrophysiol. 2010;33:541-8.

45. Ndrepepa G, Karch MR, Schneider MA, Weyerbrock S, Schreieck J, Deisenhofer I, Zrenner B, Schomig A and Schmitt C. Characterization of paroxysmal and persistent atrial fibrillation in the human left atrium during initiation and sustained episodes. Journal of cardiovascular electrophysiology. 2002;13:525-32.

46. Stiles MK, Brooks AG, Kuklik P, John B, Dimitri H, Lau DH, Wilson L, Dhar S, RobertsThomson RL, Mackenzie L, Young GD and Sanders P. High-density mapping of atrial fibrillation in humans: relationship between high-frequency activation and electrogram fractionation. Journal of cardiovascular electrophysiology. 2008;19:1245-53.

47. Solheim E, Off MK, Hoff PI, Schuster P, Ohm OJ and Chen J. Characteristics and distribution of complex fractionated atrial electrograms in patients with paroxysmal and persistent atrial fibrillation. Journal of interventional cardiac electrophysiology : an international journal of arrhythmias and pacing. 2010;28:87-93. 


\section{Mechanistic Insights from AF mapping}

48. Teh AW, Kistler PM, Lee G, Medi C, Heck PM, Spence SJ, Sparks PB, Morton JB and Kalman JM. Electroanatomic remodeling of the left atrium in paroxysmal and persistent atrial fibrillation patients without structural heart disease. Journal of cardiovascular electrophysiology. 2012;23:232-8.

49. Oral H, Knight BP, Tada H, Ozaydin M, Chugh A, Hassan S, Scharf C, Lai SW, Greenstein R, Pelosi F, Jr., Strickberger SA and Morady F. Pulmonary vein isolation for paroxysmal and persistent atrial fibrillation. Circulation. 2002;105:1077-81.

50. Gaita F, Riccardi R, Caponi D, Shah D, Garberoglio L, Vivalda L, Dulio A, Chiecchio A, Manasse E and Gallotti R. Linear cryoablation of the left atrium versus pulmonary vein cryoisolation in patients with permanent atrial fibrillation and valvular heart disease: correlation of electroanatomic mapping and long-term clinical results. Circulation. 2005;111: $136-42$.

51. Nitta T, Ishii Y, Miyagi Y, Ohmori H, Sakamoto S and Tanaka S. Concurrent multiple left atrial focal activations with fibrillatory conduction and right atrial focal or reentrant activation as the mechanism in atrial fibrillation. J Thorac Cardiovasc Surg. 2004;127:770-8.

52. Sahadevan J, Ryu K, Peltz L, Khrestian CM, Stewart RW, Markowitz AH and Waldo AL. Epicardial mapping of chronic atrial fibrillation in patients: preliminary observations. Circulation. 2004;110:3293-9.

53. Allessie MA, de Groot NM, Houben RP, Schotten U, Boersma E, Smeets JL and Crijns HJ. Electropathological substrate of long-standing persistent atrial fibrillation in patients with structural heart disease: longitudinal dissociation. Circ Arrhythm Electrophysiol. 2010;3:606-15.

54. de Groot NM, Houben RP, Smeets JL, Boersma E, Schotten U, Schalij MJ, Crijns H and Allessie MA. Electropathological substrate of longstanding persistent atrial fibrillation in patients with structural heart disease: epicardial breakthrough. Circulation. 2010;122:1674-82.

55. Roberts-Thomson KC, Stevenson IH, Kistler PM, Haqqani HM, Goldblatt JC, Sanders P and Kalman JM. Anatomically Determined Functional Conduction Delay in the Posterior Left Atrium: Relationship to Structural Heart Disease. J Am Coll Cardiol. 2008;51:856-862.

56. Roberts-Thomson KC, Stevenson I, Kistler PM, Haqqani HM, Spence SJ, Goldblatt JC, Sanders P and Kalman JM. The role of chronic atrial stretch and atrial fibrillation on posterior left atrial wall conduction. Heart Rhythm. 2009;6:1109-17.

57. Cuculich PS, Wang Y, Lindsay BD, Faddis MN, Schuessler RB, Damiano RJ, Jr., Li L and Rudy Y. Noninvasive characterization of epicardial activation in humans with diverse atrial fibrillation patterns. Circulation. 2010;122:1364-72.

58. Lee G, Kumar S, Teh A, Madry A, Spence S, Larobina M, Goldblatt J, Brown R, Atkinson V, Moten S, Morton JB, Sanders P, Kistler PM and Kalman JM. Epicardial wave mapping in human long-lasting persistent atrial fibrillation: transient rotational circuits, complex wavefronts, and disorganized activity. European heart journal. 2014;35:86-97.

59. Narayan SM, Patel J, Mulpuru S and Krummen DE. Focal impulse and rotor modulation ablation of sustaining rotors abruptly terminates persistent atrial fibrillation to sinus rhythm with elimination on follow-up: a video case study. Heart Rhythm. 2012;9:1436-9. 


\section{Chapter 1}

60. Narayan SM, Krummen DE and Rappel WJ. Clinical mapping approach to diagnose electrical rotors and focal impulse sources for human atrial fibrillation. Journal of cardiovascular electrophysiology. 2012;23:447-54.

61. Narayan SM, Krummen DE, Shivkumar K, Clopton P, Rappel WJ and Miller JM. Treatment of atrial fibrillation by the ablation of localized sources: CONFIRM (Conventional Ablation for Atrial Fibrillation With or Without Focal Impulse and Rotor Modulation) trial. Journal of the American College of Cardiology. 2012;60:628-36.

62. Narayan SM, Baykaner T, Clopton P, Schricker A, Lalani GG, Krummen DE, Shivkumar K and Miller JM. Ablation of rotor and focal sources reduces late recurrence of atrial fibrillation compared with trigger ablation alone: extended follow-up of the CONFIRM trial (Conventional Ablation for Atrial Fibrillation With or Without Focal Impulse and Rotor Modulation). Journal of the American College of Cardiology. 2014;63:1761-8.

63. Shivkumar K, Ellenbogen KA, Hummel JD, Miller JM and Steinberg JS. Acute termination of human atrial fibrillation by identification and catheter ablation of localized rotors and sources: first multicenter experience of focal impulse and rotor modulation (FIRM) ablation. Journal of cardiovascular electrophysiology. 2012;23:1277-85.

64. Miller JM, Kowal RC, Swarup V, Daubert JP, Daoud EG, Day JD, Ellenbogen KA, Hummel JD, Baykaner T, Krummen DE, Narayan SM, Reddy VY, Shivkumar K, Steinberg JS and Wheelan KR. Initial Independent Outcomes from Focal Impulse and Rotor Modulation Ablation for Atrial Fibrillation: Multicenter FIRM Registry. Journal of Cardiovascular Electrophysiology. 2014;25:921-929.

65. Haissaguerre M, Hocini M, Shah AJ, Derval N, Sacher F, Jais P and Dubois R. Noninvasive Panoramic Mapping of Human Atrial Fibrillation Mechanisms: A Feasibility Report. Journal of Cardiovascular Electrophysiology. 2013;24:711-717.

66. Haissaguerre M, Hocini M, Denis A, Shah AJ, Komatsu Y, Yamashita S, Daly M, Amraoui S, Zellerhoff S, Picat MQ, Quotb A, Jesel L, Lim H, Ploux S, Bordachar P, Attuel G, Meillet V, Ritter P, Derval N, Sacher F, Bernus O, Cochet H, Jais P and Dubois R. Driver domains in persistent atrial fibrillation. Circulation. 2014;130:530-8.

67. Nademanee K, McKenzie J, Kosar E, Schwab M, Sunsaneewitayakul B, Vasavakul T, Khunnawat $C$ and Ngarmukos T. A new approach for catheter ablation of atrial fibrillation: mapping of the electrophysiologic substrate. Journal of the American College of Cardiology. 2004;43:2044-53.

68. Oral H, Chugh A, Yoshida K, Sarrazin JF, Kuhne M, Crawford T, Chalfoun N, Wells D, Boonyapisit W, Veerareddy S, Billakanty S, Wong WS, Good E, Jongnarangsin K, Pelosi F, Jr., Bogun F and Morady F. A randomized assessment of the incremental role of ablation of complex fractionated atrial electrograms after antral pulmonary vein isolation for longlasting persistent atrial fibrillation. Journal of the American College of Cardiology. 2009;53:782-9.

69. Verma A, Jiang CY, Betts TR, Chen J, Deisenhofer I, Mantovan R, Macle L, Morillo CA, Haverkamp W, Weerasooriya R, Albenque JP, Nardi S, Menardi E, Novak P, Sanders P and 
Mechanistic Insights from AF mapping

Investigators SAI. Approaches to catheter ablation for persistent atrial fibrillation. $N$ Engl J

Med. 2015;372:1812-22. 



\section{Chapter 2}

Postoperative

Atrial Fibrillation -

A Maze of Mechanisms

Bart Maesen, Jan Nijs, Jos Maessen, Maurits Allessie and Ulrich Schotten. Published in Europace. 2012 Feb;14(2):159-74. 


\section{Chapter 2}

\section{Abstract}

Postoperative atrial fibrillation (POAF) is one of the most frequent complications of cardiac surgery and an important predictor of patient morbidity as well as of prolonged hospitalization. It significantly increases costs for hospitalization. Insights into the pathophysiological factors causing POAF have been provided by both experimental and clinical investigations and show that POAF is 'multi-factorial'.

Facilitating factors in the mechanism of the arrhythmia can be classified as acute factors caused by the surgical intervention and chronic factors related to structural heart disease and ageing of the heart. Furthermore, some proarrhythmic mechanisms specifically occur in the setting of POAF. For example, inflammation and beta-adrenergic activation have been shown to play a prominent role in POAF, while these mechanisms are less important in non-surgical AF. More recently, it has been shown that atrial fibrosis and the presence of an electrophysiological substrate capable of maintaining AF also promote the arrhythmia, indicating that POAF has some proarrhythmic mechanisms in common with other forms of AF.

The clinical setting of POAF offers numerous opportunities to study its mechanisms. During cardiac surgery, biopsies can be taken and detailed electrophysiological measurements can be performed. Furthermore, the specific time course of POAF, with the delayed onset and the transient character of the arrhythmia, also provides important insights into its mechanisms.

This review discusses the mechanistic interaction between predisposing factors and the electrophysiological mechanisms resulting in POAF and their therapeutic implications. 


\section{Introduction}

Atrial arrhythmias and atrial fibrillation (AF) in particular are well known complications after cardiac surgery with a reported incidence between $10 \%$ and $60 \%{ }^{1-17}$ The incidence is higher in patients undergoing valve surgery than in patients undergoing coronary artery bypass surgery (CABG). $1,2,7,8,10,11,17,18$ Postoperative atrial arrhythmias also occur after non-cardiac surgery, especially after esophagectomy, ${ }^{19}$ lung surgery ${ }^{20-24}$ and large abdominal surgery. ${ }^{25-27}$ The incidence after non-cardiac surgery is, however, lower with incidences ranging from $0.3 \%$ to $29 \% .22,28,29$ Postoperative atrial arrhythmias are associated with a prolonged hospital stay, with hemodynamic instability, with an increased risk of stroke, and increased mortality. ${ }^{2-4,6,10,12,13,24,28,30-33}$

The exact pathophysiological mechanisms responsible for the onset and perpetuation of postoperative atrial arrhythmias are incompletely understood. Factors facilitating postoperative AF (POAF) can be classified in acute factors directly related to surgery (e.g. adrenergic stimulation) and factors which are reflecting a chronic and progressive process of remodeling or ageing of the heart (e.g. left atrial enlargement). ${ }^{14,15}$ These predisposing factors can on the one hand provoke triggers able to initiate the arrhythmia and on the other hand enhance the development of a substrate capable of perpetuating AF.

The association of POAF with specific kinds of surgery and the time course of the arrhythmia can help to better understand its mechanisms. First, the association of POAF with cardiac surgery and degree of structural heart disease suggests a direct role for cardiac surgical trauma and pre-existing cardiac pathology in the occurrence of POAF. Secondly, the arrhythmia follows a specific time course. In most studies, the incidence peaks on the second day after surgery and rapidly declines to around $2 \%$ at discharge, ${ }^{32}$ suggesting that some of the proarrhythmic mechanisms require some time to become operative. Furthermore, the transient nature of the arrhythmia suggests a reversible mechanism, caused by factors which come into play shortly after surgery, but seem to subside on the long run.

This review discusses the mechanistic interaction between predisposing factors, alterations in intracellular signaling, and the electrophysiological mechanisms of POAF. 


\section{Epidemiology}

The incidence of POAF after cardiac surgery varies considerably between different studies (Table 1). This variation in incidence is due to differences in patient demographics, techniques for rhythm monitoring and criteria for diagnosis. ${ }^{5}, 34$ Mathew et al. found diverging POAF incidences according to different regions. ${ }^{3}$ The authors reported a similar POAF incidence among patients in the United States (33.7\%), Canada (36.6\%), Europe (34\%) and the Middle East (41.6\%), but a lower POAF incidence in South America $(17.4 \%)$ and Asia (15.7\%). ${ }^{3}$ Another example that stresses the importance of patient demographics is the identification of Caucasian race as an independent predictor of POAF in several studies. ${ }^{17,34}$ Fluctuation in reported POAF incidence due to differences in rhythm follow-up is illustrated by the comparison of the following three studies. Siebert et al. found an incidence as low as $9.8 \%$ after isolated CABG. However, only AF occurrence during stay on the intensive care unit was studied, with a mean period of 2.3 days. ${ }^{11}$ In another example, Leitch et al. found an incidence of $17.2 \%$ after isolated CABG. Again, only during the first 48 hours AF and atrial flutter (AFL) were detected by continuous electrocardiogram (ECG) monitoring. After these 48 hours, AF and AFL were solely identified if clinical symptoms occurred. ${ }^{9}$ On the other hand, in a large retrospective study Shen et al. found an incidence of $29 \%$ after isolated CABG. ${ }^{17}$ In this report, all patients received continuous 24-hour telemetry with arrhythmia-detection algorithms during their entire hospital stay. The difference in reported POAF incidence between these studies emphasizes that a more systematic ECG monitoring results in a better identification and thus a higher incidence of the arrhythmia. ${ }^{17}$ Finally, the definition of POAF also influences its incidence. For example, in one study POAF is defined as any documented AF longer than 5 minutes, while in another study only episodes of more than 10 minutes are counted.7, 16

Despite the methodical differences between studies, the incidence of POAF could be shown to be strongly determined by the kind of surgery. In general, the reported incidence of POAF after CABG ranges between 16\% and 50\%., 6, 8, 9, 11-17 The incidence is higher after valve surgery and highest after combination of CABG and valve surgery. ${ }^{1,2,7,10,11,17,18}$ Remarkably, after heart transplantation the incidence of postoperative atrial arrhythmias is reported to be very low $(4 \%) .{ }^{35}$ However, due to the surgical cut and sew lines in the atria during heart transplantation, the atrial surface is strongly reduced and the pulmonary veins are isolated. 
In the group of non-cardiac surgery, the incidence of POAF is higher after thoracic surgery than after non-thoracic surgical procedures. ${ }^{36,37}$ In non-cardiac, non-thoracic surgery, POAF occurs relatively infrequently $(0.37 \%$ for ophthalmic surgery up to $13 \%$ for large colorectal surgery). ${ }^{25-30}$ After thoracic surgery POAF is more frequent, with reported incidences of $9 \%$ up to $29 \% .{ }^{20}$. $21,23,24,38-42$ Some studies report no differences in incidence between more invasive and less invasive types of thoracic surgical procedures, ${ }^{20,21}$ although other studies do. ${ }^{22,38-40}$

The time course of the onset of POAF after cardiac surgery is very typical, with $70 \%$ of the patients developing POAF in the first 4 postoperative days and only $6 \%$ developing AF after the $6^{\text {th }}$ day. ${ }^{4,7,43}$ POAF has its peak incidence on the $2^{\mathrm{e}}$ postoperative day and recurrence of POAF is highest on the $3^{\text {th }}$ postoperative day, with only $22 \%$ of the patients experiencing more than 2 episodes of POAF. ${ }^{3,8}$

Different risk factors for development of POAF after cardiac surgery have been identified. The strongest predictor of POAF is advancing age. ${ }^{1,2,4,6-9,15-18,44-48}$ Association with other risk factors shows a large degree of variability between different studies (Table 2). For example, Zacharias et al. found body mass index (BMI) to be an important determinant of $\mathrm{POAF}^{47}$ while other studies failed to show this. ${ }^{6,7,15}$ Furthermore, left atrial enlargement is a predictor for POAF is some studies. ${ }^{15,46}$ However, sometimes left atrial enlargement is not predictive even when mitral valve surgery in the same study is a risk factor. This might indicate a role for tissue trauma as a consequence of a more invasive procedure during mitral valve repair/replacement. ${ }^{3,48}$

In 2002, Ferguson et al. confirmed the wide-spread perception among cardiac surgeons that the population of patients currently referred for isolated CABG are older, sicker, and have a higher surgical risk than a decade ago. ${ }^{49}$ As age represents an important risk factor for the onset of POAF, one would expect an increase in incidence of POAF over time which indeed in one study has been reported. ${ }^{1}$ Other studies, however, failed to identify an increase or even reported a trend towards a decreasing prevalence., 10, 17, 50,51 Whether the lack of increase in POAF incidence over the past years is due to more frequent use of beta-blockers or amiodarone is currently unknown. In the study of Shen et al., the annual percentage of aortic and mitral valve procedures increased over two decades. Considering that these surgical procedures are associated with a higher risk of POAF, and that the incidence remained approximately $30 \%$, the authors concluded that some progress in treating POAF has been made. ${ }^{17}$ 
Chapter 2

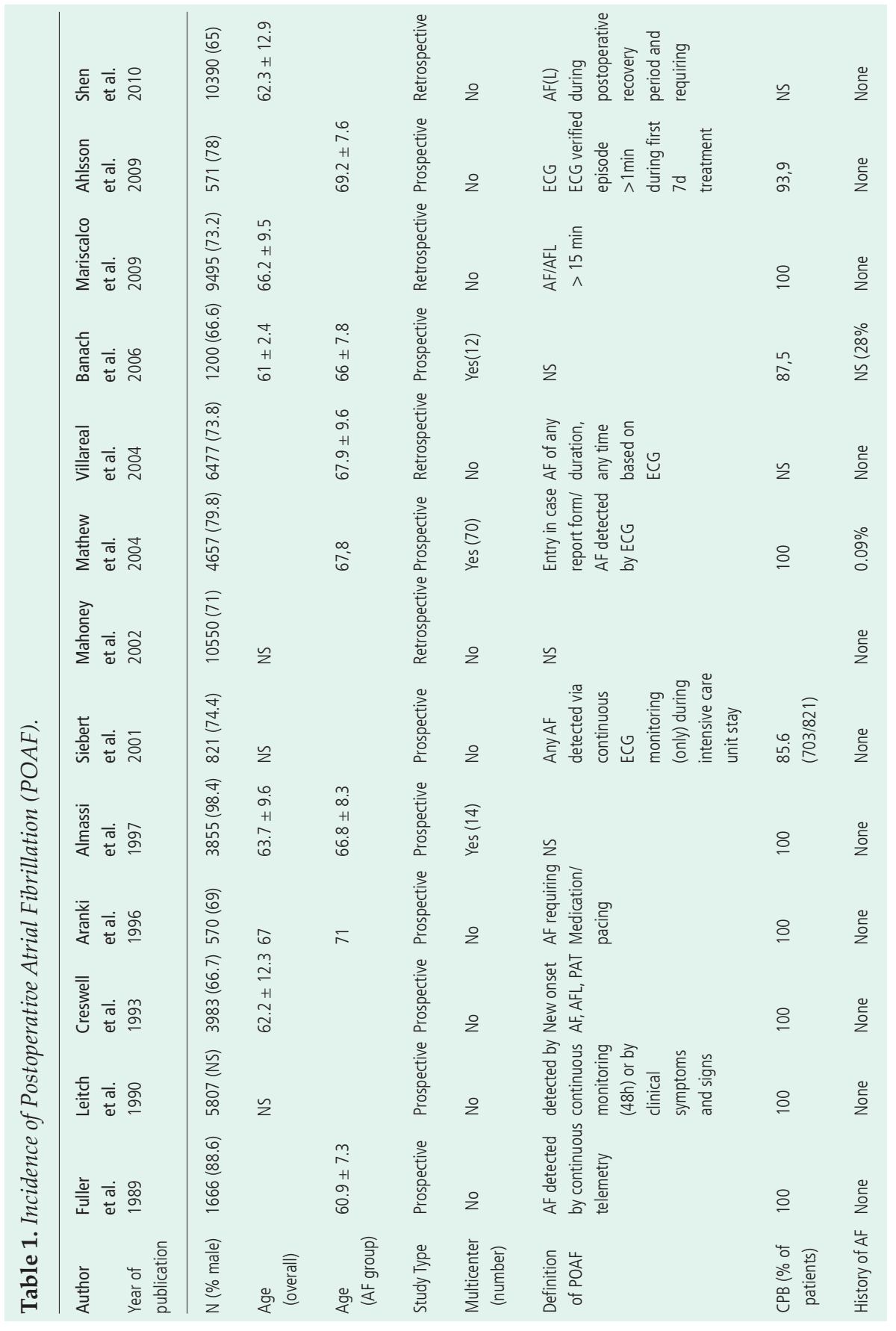


POAF, a Maze of Mechanisms

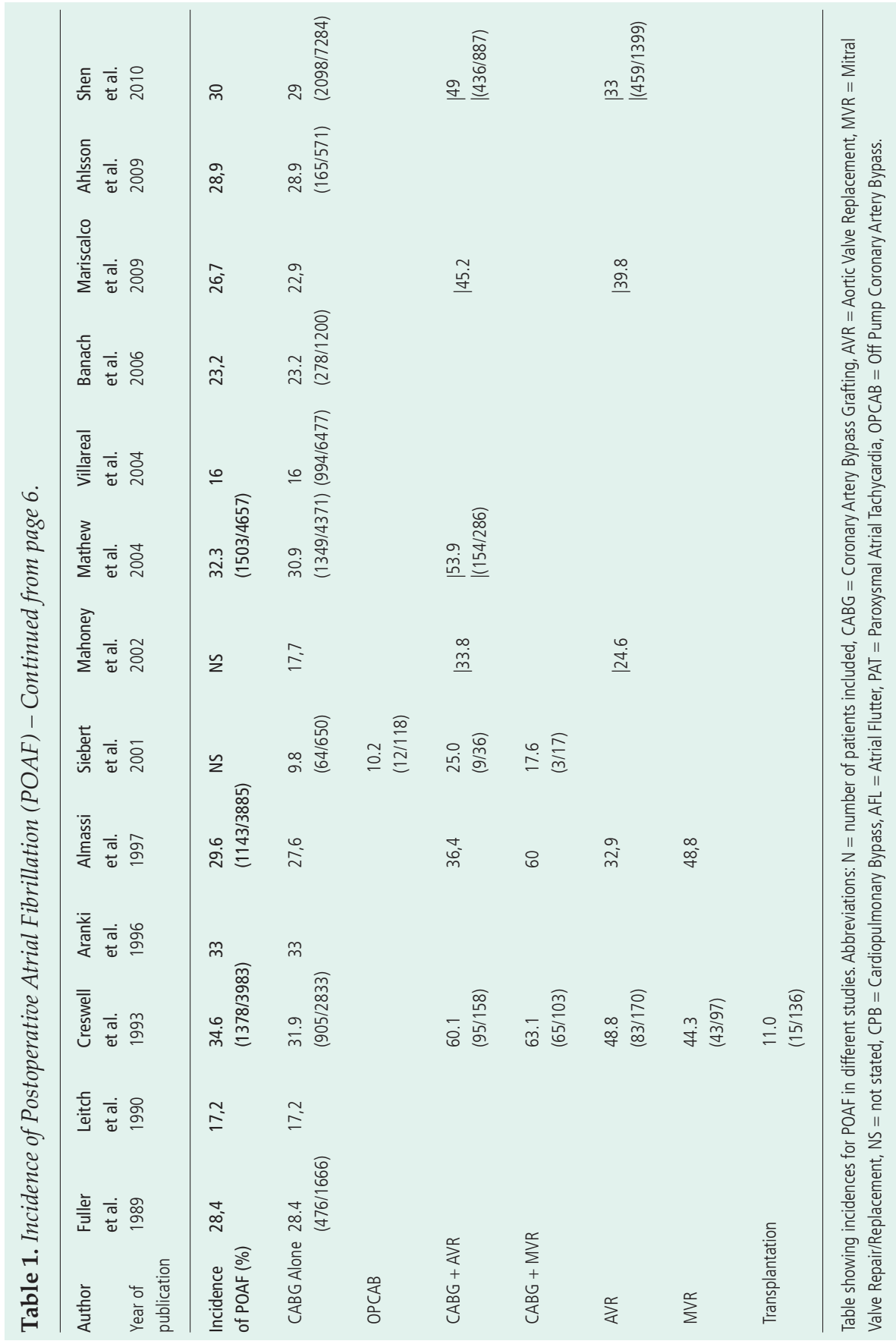




\section{Chapter 2}

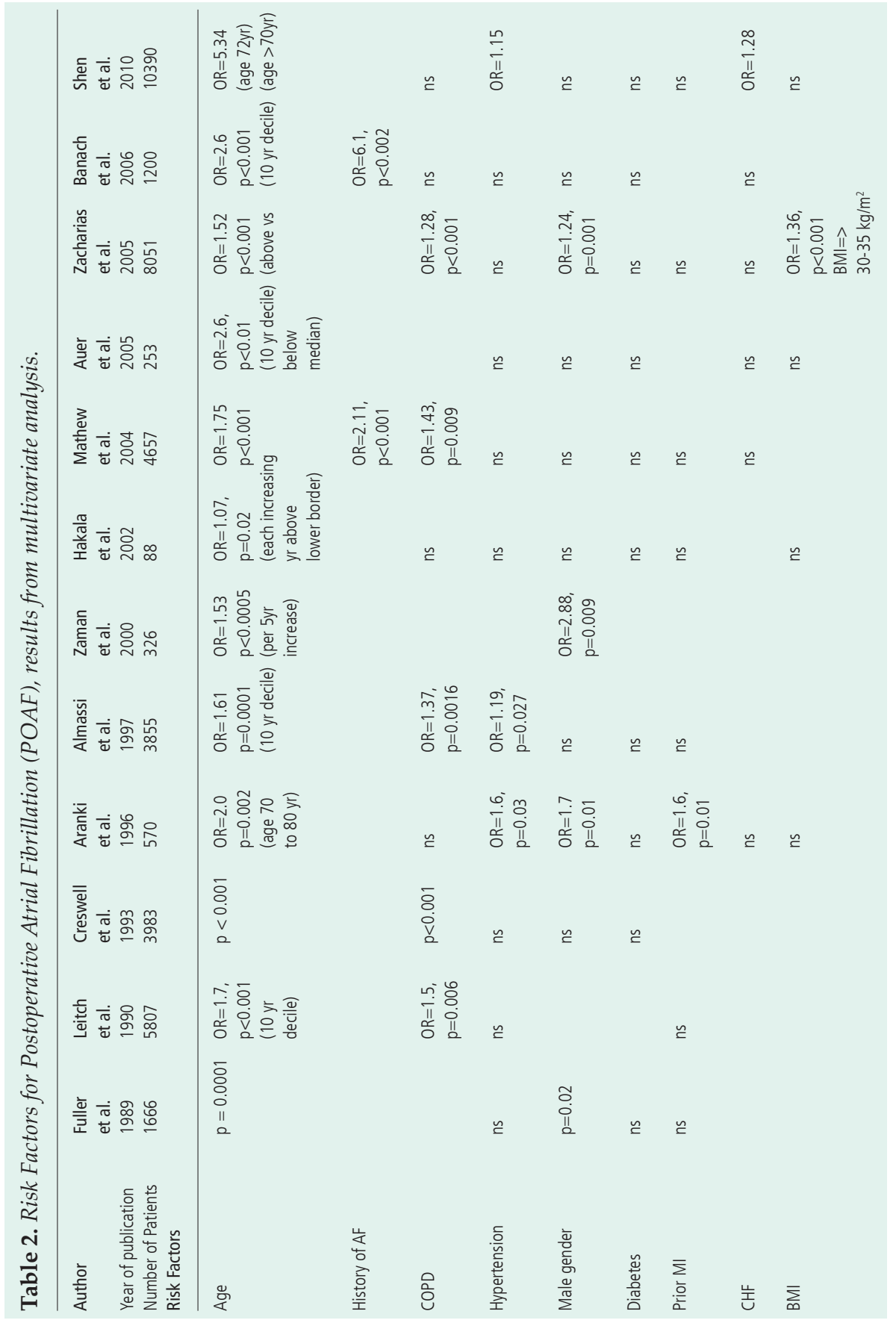


POAF, a Maze of Mechanisms

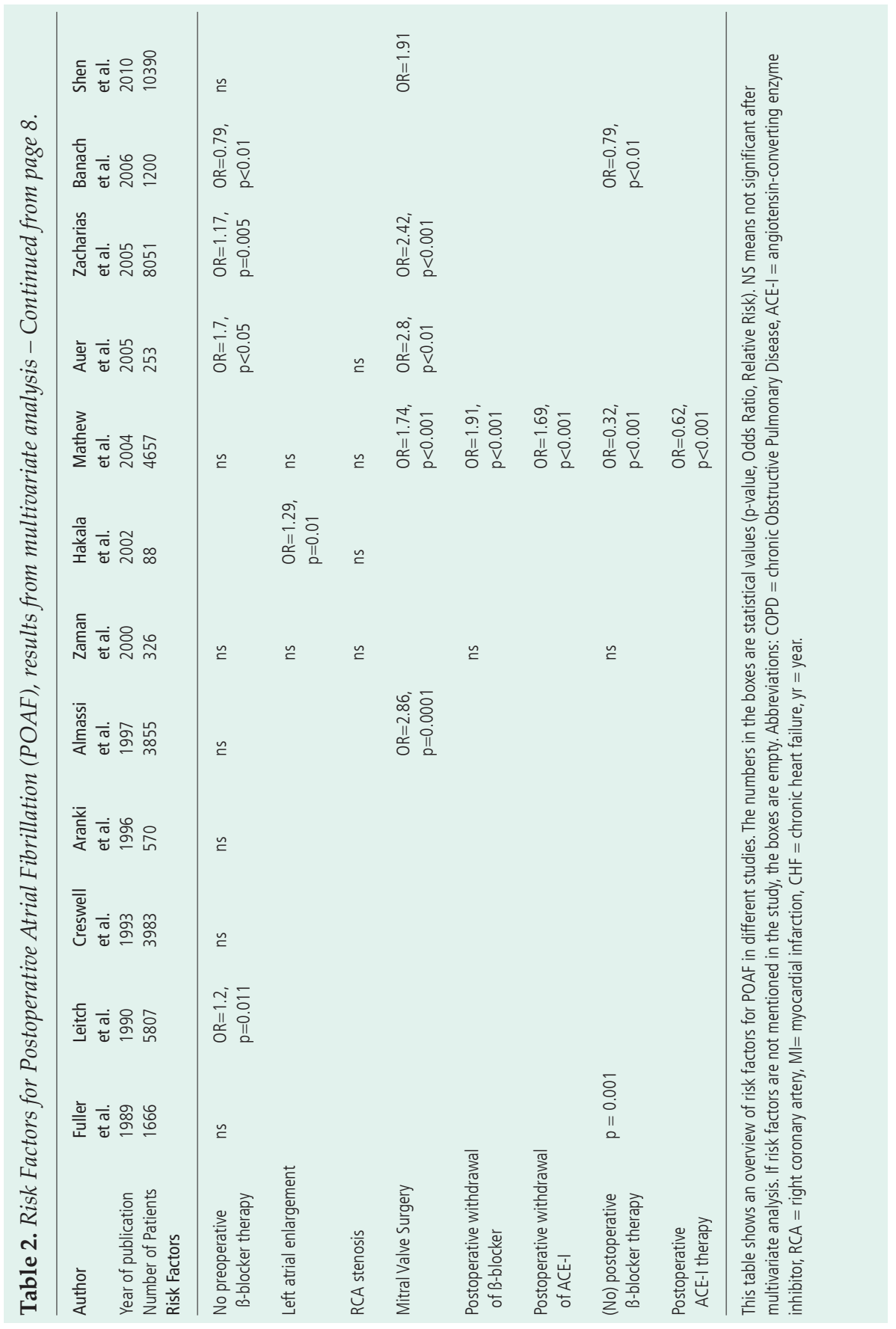


Chapter 2

\section{Mechanisms based on acute factors}

\subsection{Inflammation}

The similarity between the time course of AF occurrence after cardiac surgery and the activation of the complement system with the release of pro-inflammatory cytokines suggests an inflammatory component in the mechanism triggering POAF. ${ }^{52-57}$ Complement activation during cardiac surgery with cardiopulmonary bypass (CPB) occurs in two steps. The first phase occurs during $\mathrm{CPB}$, results from interaction of blood with the surface of the extracorporeal circuit, and is mediated via the "alternative pathway" involving tumor necrosis factor $\alpha$. The second phase acts via the "classical pathway" which is initiated by protamine usually administered after CPB. Interestingly, fever and POAF do not occur before the first postoperative days and thus coincide with the second phase rather than with the first. Their time course corresponds to changes in activity of markers indicating complement activation and inflammation, such as c-reactive protein (CRP), complement-CRP complexes, ${ }^{52}$ interleukin-2, ${ }^{58}$ interleukin- $6 .^{53}$ The similarity in the postoperative time course of POAF incidence and CRP is illustrated in Figure 1. Also, a more pronounced increase in postoperative white blood cell count as a marker of inflammatory response independently predicts development of postoperative AF in some studies, but not in others. ${ }^{56,59}$ Furthermore, patients developing POAF have upregulated monocyte activation and higher monocyte and neutrophil levels post CPB. ${ }^{60,61}$

Besides the systemic inflammatory reaction caused by use of $\mathrm{CPB}$, also local inflammation caused by surgical incision contributes to the occurrence of POAF. It is known that the degree of atrial inflammation increases with the invasiveness of surgery, but even after pericardiotomy alone the atrium becomes mildly inflamed. This transient sterile pericarditis, which is part of the healing process, might help to explain the temporal occurrence of POAF. Comparison of AF incidence after off-pump and on-pump surgery facilitates to distinguish the importance of systemic inflammation from that of surgical incision and manipulation. As such, off-pump CABG (OPCAB) is believed to elicit less systemic inflammation than on-pump surgery because of reduced cytokine responses and less myocardial injury. ${ }^{62}$ However, several studies failed to show statistical association between OPCAB and a lower incidence of POAF. ${ }^{11,63-68}$ This lack of association suggests that surgical stress as such is a more important determinant than systemic inflammation in triggering POAF. It has to be noted, however, that some of these studies are limited by their 


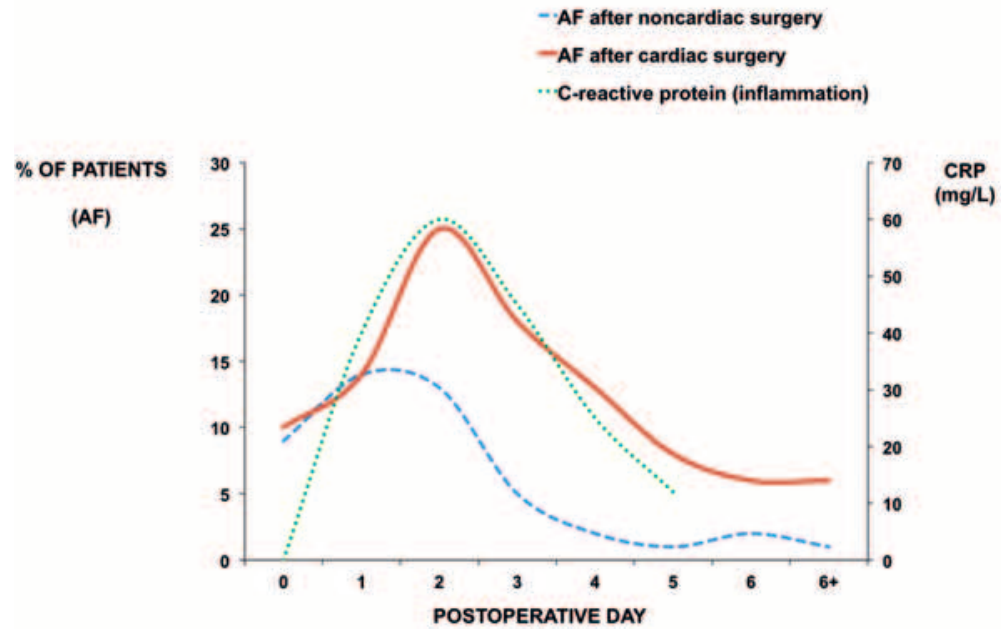

Figure 1. Time course of atrial fibrillation incidence after cardiac and non-cardiac surgery and time course of C-reactive protein after cardiac surgery. Atrial fibrillation incidence after non-cardiac surgery peaks at post-operative day 1 and then rapidly declines to $2 \%$ at day 6 , while atrial fibrillation incidence after cardiac surgery peaks at post-operative day 2 and slowly declines to around $6 \%$ at day 6 . This suggests a 'cardiac factor', related to the specific setting of cardiac surgery. The time course of C-reactive protein is surprisingly similar to that of atrial fibrillation incidence after cardiac surgery, supporting the role for inflammation in the mechanism of post-operative atrial fibrillation (modified from references $4,30,52$ ).

retrospective nature and sample size, and that they all showed at least a nonsignificant trend towards lower AF incidence in off-pump surgery. Other controlled randomized studies do reveal CPB in combination with cardioplegic arrest as the main predictor of POAF, especially in elderly and high-risk individuals. ${ }^{69-72}$ For example, Panesar et al. performed an extensive meta-analysis including 4921 patients of $70 \mathrm{yrs}$ and older and reported a significantly lower AF incidence in the OPCAB group compared to on-pump surgery. ${ }^{73}$ It could be argued that the influence of on-pump surgery compared to offpump surgery on AF occurrence is rather small and that this effect only emerges in the older patient population, where the risk of POAF is known to be higher. ${ }^{1-4}$ Furthermore, minimal invasive off-pump CABG resulted in lower AF incidence compared to conventional, more extensive off-pump CABG in one study, but surprisingly failed to reach significance in another. ${ }^{74,75}$ This might indicate that the trauma and the successive inflammation of the pericardium that easily spreads within the pericardial sac rather than the manipulation of the myocardial tissue itself renders the atria more prone to AF. 


\section{Chapter 2}

Several experimental and clinical studies have been undertaken to explore how inflammation enhances AF susceptibility of atrial tissue. A prominent example of involvement of inflammation in the development of $\mathrm{AF}$ is the study by Frustaci et al., showing lymphomononuclear infiltrates compatible with atrial myocarditis in atrial tissue of $66 \%$ of patients with lone AF. ${ }^{76}$ Also Chen et al. found CD45-positive cells to be independently and significantly higher in right atrial appendages of patients with AF compared to patients with sinus rhythm. ${ }^{77}$ An excellent experimental model to study postoperative AF/AFL is the canine sterile pericarditis model of Page et al. ${ }^{78}$ In this model, sterile pericarditis is created by epicardial application of sterile talcum. The time course of atrial arrhythmias in patients after open heart surgery is consistent with inducibility of AF/AFL in this model, both peaking between day 2 and 4 after surgery. ${ }^{79}$ In response to sterile pericarditis, proliferation and activation of epicardial fibroblasts takes place in the atria, with loss of epicardial myocytes and altered distribution of connexins 40 and $43 .{ }^{80}$ These changes are associated with nonuniform slowing of conduction and promote induction and maintenance of AF/AFL. The causative association between inflammation and postoperative AF/AFL was further studied in the canine pericarditis model by suppression of the inflammatory response with steroids and HMGCoA reductase inhibitors (statins). ${ }^{81,82}$ Administration of prednisone inhibited tissue inflammation and reduced serum CRP and AF inducibility. ${ }^{81}$ Also atorvastatine, an HMG-CoA reductase inhibitor, significantly reduced CRP levels and AF duration, and attenuated perimyocarditis. ${ }^{82}$ Finally, the use of n-3 polyunsaturated fatty acids in the sterile pericarditis model was associated with lower levels of inflammatory markers, a reduction in AF inducibility and AF duration, prolongation of the refractory period and shortening of intra-atrial conduction times. ${ }^{83}$

Atrial inflammation is known to cause conduction disturbances. For example, in a study with mongrel canines, Ishii et al. measured myeloperoxidase activity and neutrophil cell infiltration in atrial myocardium. The degree of atrial inflammation was associated with a proportional increase in the inhomogeneity of atrial conduction after experimental cardiac surgery and increased the incidence and duration of $\mathrm{AF} .{ }^{84}$ In another canine study, acute inflammation provoked by arachidonic acid produced slowing and enhanced anisotropy of conduction but did not affect atrial refractoriness. ${ }^{85}$

In several clinical trials, drugs with anti-inflammatory effects have shown to be effective in lowering AF incidence after CABG and/or valve surgery. Corti- 
costeroids reduce the incidence of new-onset POAF by inhibition of cytokine release (tumor necrosis factor $\alpha$ and interleukin-6), thereby reducing complement activation. ${ }^{86,87} \mathrm{~A}$ recent meta-analysis of 17643 patients undergoing cardiac surgery suggests that preoperative use of statins significantly reduces POAF incidence. ${ }^{88}$ The exact mechanism by which statins lower POAF incidence is, however, likely pleiotropic. Preoperative statin therapy is, besides its lipid-lowering effect, known to decrease inflammation markers, ${ }^{89}$ but also to attenuate myocardial reperfusion injury after cardiac surgery. ${ }^{90}$ According to the European guidelines, corticosteroids (class IIb recommendation) may be and statins (class IIa recommendation) should be considered for prevention of POAF after CABG and/or valve surgery. ${ }^{91}$ Treatment with n-3 polyunsaturated fatty acids to prevent POAF has been reported with success in some studies, ${ }^{92,93}$ however placebo controlled, double-blinded, randomized trials have failed to reproduce this protective effect of fish oil..$^{94,95}$

Finally, it is known that chronic inflammation in patients can cause atrial structural remodeling. CRP is associated with and predicts patients at risk for developing future non-surgical AF. ${ }^{54,55}$ This chronic inflammation might also predispose to the occurrence of POAF. Some studies found elevated preoperative CRP levels to be associated with an increased risk of the arrhythmia after CABG. ${ }^{32,96}$ Others, on the contrary, failed to find an association between preoperative CRP and POAF, ${ }^{60,97,98}$ This controversy suggests that the induction of inflammation during surgery, rather than a pre-existing inflammation process, contributes to the development of the arrhythmia.

\subsection{Sympathetic Activation}

In the heart, sympathetic stimulation is mediated by $\beta$-adrenoreceptors and leads to an increase in frequency and contractile force, but also to enhanced excitability and automaticity. ${ }^{99}$ Several findings support a role for sympathetic activation in the pathogenesis of atrial arrhythmias after cardiac surgery. First, advanced age, the most important risk factor for POAF, is associated with increasing circulating norepinephrine levels. ${ }^{100}$ Secondly, patients who develop $\mathrm{POAF}$ also have significantly elevated norepinephrine levels postoperatively compared to patients without POAF. ${ }^{14}$ This association is further reflected by the fact that the onset of POAF is preceded by an increase in sinus rate and atrial ectopic activity. Third, studies on postoperative heart rate variability (HRV) show an increase in time- and frequency-domain parameters of $\mathrm{HRV}$ prior to the onset of POAF, consistent with increasing sympathetic activ- 


\section{Chapter 2}

ity. ${ }^{101,102}$ However, controversy remains if this sympathetic activation is accompanied by increased activity or loss of vagal tone. ${ }^{101-103}$ Finally, sympathetic activation has been reported to shorten atrial refractoriness non-uniformly, thereby favoring the perpetuation of the arrhythmia. ${ }^{104}$ On the other hand, there is a slight discrepancy between the peak of sympathetic activation, which occurs within $24 \mathrm{~h}$ postoperatively, and the onset of POAF, mostly developing between $48 \mathrm{~h}$ and $72 \mathrm{~h}$ after surgery. ${ }^{105}$

If sympathetic activation plays an important role in onset of POAF, one would expect that cardiac denervation reduces the incidence of the arrhythmia. This was first studied by Melo et al. ${ }^{106}$ They performed ventral cardiac denervation in 207 patients undergoing low-risk CABG, and indeed found that this intervention significantly reduced the incidence and severity of POAF. ${ }^{106}$ It should be noted, however, that only $15 \%$ of the patients in their study underwent telemetric monitoring and some patients with asymptomatic AF might not have been identified. Other studies failed to show the benefit of cardiac denervation or found even an increase in POAF. ${ }^{107-109}$ These findings, however, do not exclude a role for sympathetic activation in the arrhythmia substrate, as both sympathetic and parasympathetic activation alter atrial refractoriness. ${ }^{109,110}$ Hogue et al. detected a higher HRV in some patients, but a lower HRV in others in the hour before onset of POAF, suggesting the possibility of divergent autonomic conditions shortly before onset of the arrhythmia. ${ }^{103}$ Cardiac denervation obviously interrupts both sympathetic and parasympathetic regulation of heart function.

Drugs mimicking sympathetic activation are also pro-arrhythmic. Administration of milrinone, a phosphodiesterase inhibitor that increases cardiac cyclic adenosine monophosphate (cAMP), dobutamine and dopamine, both binding on the $\beta$-adrenoreceptor, is associated with an increased incidence of POAF. ${ }^{111-113}$ Activation of protein kinase A by cAMP can lead to stimulation of multiple cardiac currents, including the L-type calcium current $\left(I_{C a L}\right)$, thereby promoting the occurrence of early and delayed afterdepolarizations. ${ }^{114}, 115$ Mechanisms by which inotropic drugs can promote POAF consist of abbreviation of atrial refractoriness (presumably due to activation of the slowly activating delayed rectifier current $\left(\mathrm{I}_{\mathrm{Ks}}\right)$ ) and ectopic activity. ${ }^{114-116}$

In theory, blocking the sympathetic activation by $\beta$-adrenoreceptor blocking drugs should reduce the incidence of POAF. Indeed, patients receiving $\beta$-blockers postoperatively have less episodes of AF compared to patients receiving placebo..$^{50,117,118}$ However, these results must be interpreted with caution as 
arrhythmia detection varies between studies and some of the patients, assigned to the placebo group, were withdrawn from their preoperative $\beta$-blocker therapy. ${ }^{105}$ The withdrawal of preoperative $\beta$-blockade after CABG is associated with a more than twofold increase in POAF. ${ }^{119}$ The peak effect of this rebound phenomenon correlates well with the time course of POAF, suggesting that the continuity of preoperative $\beta$-blocking therapy after surgery has a stronger effect on POAF incidence than $\beta$-blocking treatment started de novo after surgery. ${ }^{14}$ The increase in POAF incidence after $\beta$-blocker withdrawal might be due to the synergistic effect of the rebound phenomenon and the higher sympathetic tone postoperatively.

Workman et al. found preoperative $\beta$-blockade to be associated with significant prolongation of atrial cell action potential duration (APD) and atrial effective refractory period (AERP) in isolated cells of patients undergoing open heart surgery. ${ }^{50,120}$ The authors called this adaptive response 'pharmacological remodeling', as it appeared to be caused by the previous exposure to but not by the acute presence of $\beta$-blocker. Contribution of this prolongation of refractoriness to the anti-arrhythmic effect of $\beta$-blockers can act via lengthening the minimum pathlength for reentry. In their study, however, this $\beta$-blocker induced AERP prolongation was identical between patients who did and did not developed POAF. ${ }^{50}$ The authors concluded that, as preoperative $\beta$-blockade did reduce POAF incidence in their study without involvement of $\beta$-blocker induced AERP prolongation, mechanisms as attenuation of triggered atrial extrasystoles also underlie the antiarrhythmic effect of $\beta$-blockers. ${ }^{50}$

In conclusion, it seems that sympathetic activation, by altering atrial refractoriness and promoting ectopic activity, contributes to the onset of POAF. The fact that $\beta$-blockade does not abolish all episodes of POAF once more stresses the multifactorial etiology of POAF. ${ }^{121}$ However, oral $\beta$-blocker therapy started at least 1 week before surgery remains the first choice in preventing POAF after cardiac surgery. ${ }^{91}$

\subsection{Oxidative Stress}

Oxidative stress occurs from an imbalance between pro-oxidants and antioxidants in favor of pro-oxidants. The use of CPB in cardiac surgery involves controlled ischemia followed by reperfusion of the heart. During reperfusion, increased production of reactive oxygen species takes place, leading to myocardial stunning, tissue damage and cell death. ${ }^{122,123}$ 


\section{Chapter 2}

The interaction between oxidative stress and electrical remodeling has been studied in experimental studies. In a canine rapid atrial pacing (RAP) model of AF, pacing induced reduction of AERP was attenuated by ascorbate, a potent antioxidant. ${ }^{124}$ First, production of atrial peroxynitrite, a free radical, was enhanced while endogenous atrial ascorbate levels were diminished during RAP. Secondly, supplementation of vitamin $C$ prevented atrial tissue ascorbate depletion and the increased peroxynitrite formation. These results suggest a direct effect of oxidative stress on early electrical remodeling (24 to 48 hours after RAP). ${ }^{124}$ In another canine RAP study, AF promotion after 7-days of RAP was attenuated by simvastatine but not by antioxidant vitamins $C$ and E. ${ }^{125}$ The dosages in both studies were comparable. Therefore, these results might indicate that vitamin $\mathrm{C}$ can attenuate AF promotion in very early remodeling, but that it loses its protective effect during later stages of the electrical remodeling process. The fact that simvastatine attenuated AF promotion can be partly due to an anti-inflammatory mechanism. As discussed before, statins posses antioxidant as well as anti-inflammatory properties. ${ }^{126}$

Atrial myocytes of patients with persistent AF show oxidative damage following cardiac production of peroxynitrite, which oxidizes cellular lipids, proteins and DNA and promotes death of cardiomyocytes via necrosis/apoptosis. ${ }^{127}$ This oxidation contributes to the loss of fibrillar protein function and thus to atrial contractile dysfunction. Moreover, atrial nicotinamide adenine dinucleotide phosphate (NADPH) oxidase activity is increased in right atrial appendages of patients with non-surgical forms of AF compared to patients without AF. ${ }^{128}$ NADPH oxidase is known to be an important source of reactive oxygen species in human atrial myocytes. ${ }^{128}$ Direct measurement of free radicals in atrial tissue of patients during episodes of POAF is impossible. Therefore, evidence for oxidative stress has been obtained by measuring concentrations of antioxidants as lipid peroxidation products and by administering antioxidant substances. ${ }^{129,130}$

Indications that oxidative stress plays a role in the occurrence of POAF can be summarized as follows. First of all, reperfusion of patients undergoing CABG results in oxidative stress and the amount of oxidative stress depends on the severity of the ischemic period and left ventricular ejection fraction (LVEF). ${ }^{129,130}$ Secondly, Ramlawi et al. confirmed that patients with POAF, compared to patients without the arrhythmia, have a larger increase in systemic oxidative stress as well as at the myocardial level. ${ }^{131}$ Third, in a follow-up study Kim et al. measured NADPH oxidase activity in right atrial appendage samples from 
patients undergoing CABG. ${ }^{132}$ The authors identified NADPH oxidase activity as the most important independent predictor of POAF. Surprisingly, in their preliminary data there was no difference in NADPH oxidase activity before $\mathrm{CPB}$ and after reperfusion. They hypothesized that the perioperative inflammatory response, rather than ischemia and reperfusion, stimulates atrial NADPH oxidase activity, thereby increasing oxidative stress. Interestingly, also Clermont et al. argue that oxidative stress related to myocardial ischemia/ reperfusion might be overwhelmed by systemic radical activation, which is due to activation of neutrophils and high oxygen tension level during $\mathrm{CPB} .{ }^{133}$

The involvement of oxidative stress in the multifactorial mechanism of POAF has been further studied by administrating antioxidant drugs to patients undergoing heart surgery. Indeed, antioxidant drugs are reported to lower the incidence of POAF after cardiac surgery involving CPB use. For example, Carnes et al. showed that administration of ascorbate to patients undergoing CABG decreased the incidence of POAF. ${ }^{124}$ Moreover, combination of ascorbic acid and $\beta$-blockers seems to be more effective than $\beta$-blockers alone in reducing post-CABG AF. ${ }^{134}$ Another example is the administration of the antioxidant $\mathrm{N}$-acetylcysteine. $\mathrm{N}$-acetylcysteine lowered the incidence of POAF after CABG and/or valve surgery significantly. ${ }^{135}$ By scavenging reactive oxygen species with $\mathrm{N}$-acetylcysteine, myocardial oxidative stress is attenuated in patients undergoing $\mathrm{CABG}$ with $\mathrm{CPB}$ and cardioplegic arrest. ${ }^{136}$ Furthermore, nitric oxide (NO) gas has been reported to significantly inhibit oxidative stress when administered to patients undergoing CABG. ${ }^{137}$ Sodium nitroprusside (SNP), an NO donor, significantly lowered incidence and duration of postCABG AF in a recent pilot study ${ }^{138}$ Finally, also statins are known to lower the incidence of POAF, presumably in part through their antioxidative properties. $^{88}$

Another argument supporting a causative relation between oxidative stress and POAF is the higher occurrence of the arrhythmia in the elderly. ${ }^{4}$ Ageing hearts are more susceptible for ischemia/reperfusion injury. ${ }^{139}$ It can be hypothesized that cellular damage due to oxidation is more important in older patients undergoing cardiac surgery and that this, in part, explains the higher incidence of POAF in this population.

Finally, the relation between the specific setting of off-pump surgery and oxidative stress has also been studied. Off-pump surgery not only permits to avoid ischemia/reperfusion, but also has been associated with a reduced sys- 


\section{Chapter 2}

temic inflammatory reaction. ${ }^{62}$ Furthermore, inflammation seems to be at least as important as ischemia/reperfusion in producing oxidative radicals during on-pump surgery. ${ }^{132,133}$ Indeed, some studies indicate that off-pump surgery is associated with less oxidative stress. For example, Fontaine et al. reported that only plasmas isolated after on-pump, but not after off-pump CABG, induce superoxide generation in the vascular wall of rat aorta, leading to oxidative stress. ${ }^{140}$ Moreover, levels of oxidative stress markers (lipid hydroperoxides, protein carbonyls and nitrotyrosine) in peripheral plasma of patients undergoing CABG were significantly lower in OPCAB compared to on-pump CABG. ${ }^{141}$ In another study, Orhan et al. found reduced systemic inflammation in patients undergoing OPCAB compared to on-pump CABG. ${ }^{142}$ However, they failed to show a reduction in myocardial oxidative stress in the off-pump group. ${ }^{142}$

\section{Mechanisms based on pre-existing factors}

\subsection{Presence of a substrate}

Besides AF promotion by acute, surgery-induced factors (Table 3), also the pre-existence of a substrate for AF can predispose to onset of the arrhythmia in the postoperative setting (Table 4). Development of such an AF substrate can involve (A) ion channel alterations resulting in shortening and/or enhanced dispersion of atrial refractoriness and (B) heterogeneities in conduction due to interstitial alterations like for example accumulation of collagen fibers, inflammatory infiltration or amyloidosis. Both mechanisms and their relationship with POAF will be separately discussed.

\subsubsection{Alterations in electrical ion channels as predisposing factor for POAF}

The question as to whether propensity to POAF can be explained by pre-existing alterations of ion-channel function in these patients has been addressed by several investigators.

Calcium $\left(\mathrm{Ca}^{2+}\right)$ influx through the L-type $\mathrm{Ca}^{2+}$ channels is the main current to produce the plateau phase of the atrial action potential. High atrial rates as they occur during AF or RAP are known to downregulate $I_{C a L}$ which contributes to shortening of atrial refractoriness as a consequence of AF. ${ }^{143}$ Some studies have investigated whether changes of this current can also predispose to AF in the setting of cardiac surgery. In a study by Van Wagoner et al., $I_{C a L}$ in isolated atrial myocytes of non-AF patients was larger in patients developing POAF 
Table 3. Overview of Studies with Important Findings Regarding the Role of Acute SurgeryInduced Factors in the Mechanism of POAF.

\begin{tabular}{|c|c|c|c|}
\hline Author, year & Acute Factor & Species & Main Finding \\
\hline White, 1984 & Adrenergic Activation & Human & $\begin{array}{l}\text { Prophylactic use of timolol after CABG decreases } \\
\text { frequency and severity of supraventricular } \\
\text { arrhythmias. }\end{array}$ \\
\hline Kalman, 1995 & Adrenergic Activation & Human & $\begin{array}{l}\text { Significant association between norepinephrine } \\
\text { levels and the development of POAF. }\end{array}$ \\
\hline Bruins, 1997 & Inflammation & Human & $\begin{array}{l}\text { The second phase of complement activation during } \\
\text { CPB involves CRP and is associated with POAF. }\end{array}$ \\
\hline Frustaci, 1997 & Inflammation & Human & $\begin{array}{l}\text { Lymphomononuclear infiltrates compatible with } \\
\text { atrial myocarditis in atrial tissue of } 66 \% \text { of } \\
\text { patients with lone AF. }\end{array}$ \\
\hline Carnes, 2001 & Oxidative Stress & $\begin{array}{l}\text { Canine/ } \\
\text { Human }\end{array}$ & $\begin{array}{l}\text { Ascorbate attenuates rapid pacing-induced atrial } \\
\text { ERP shortening and decreases the incidence of } \\
\text { POAF after CABG. }\end{array}$ \\
\hline Kumagai, 2004 & $\begin{array}{l}\text { Inflammation/ } \\
\text { Oxidative Stress }\end{array}$ & Canine & $\begin{array}{l}\text { Atorvastatine prevents AF by inhibiting inflamma- } \\
\text { tion in the sterile pericarditis model. }\end{array}$ \\
\hline $\begin{array}{l}\text { Shiroshita- } \\
\text { Takeshita, } 2004\end{array}$ & $\begin{array}{l}\text { Oxidative Stress/ } \\
\text { Inflammation }\end{array}$ & Canine & $\begin{array}{l}\text { AF promotion by atrial tachycardia is attenuated } \\
\text { by simvastatin, but not by antioxidant vitamins. }\end{array}$ \\
\hline Ishii, 2005 & Inflammation & Canine & $\begin{array}{l}\text { Atrial inflammation after cardiac surgery is } \\
\text { associated with inhomogeneity of atrial conduction. }\end{array}$ \\
\hline Workman, 2006 & Adrenergic Activation & Human & $\begin{array}{l}\text { Chronic B-blocker therapy is associated with } \\
\text { reduced POAF incidence, unrelated to preoperative } \\
\text { ERP-prolonging. }\end{array}$ \\
\hline Kim, 2008 & Oxidative Stress & Human & $\begin{array}{l}\text { NADPH oxidase activity in right atrial appendage is } \\
\text { the most important independent predictor of POAF. }\end{array}$ \\
\hline Fleming, 2008 & Adrenergic Activation & Human & $\begin{array}{l}\text { Perioperative milrinone use is associated with an } \\
\text { increased incidence of POAF. }\end{array}$ \\
\hline Ozaydin, 2008 & Oxidative Stress & Human & $\begin{array}{l}\text { Treatment with N-acetylcysteine, an antioxidant, } \\
\text { decreases the incidence of POAF. }\end{array}$ \\
\hline Ho, 2009 & Inflammation & Human & $\begin{array}{l}\text { Corticosteroid prophylaxis is effective in reducing } \\
\text { the risk of atrial fibrillation. }\end{array}$ \\
\hline
\end{tabular}




\section{Chapter 2}

Table 4. Overview of Studies with Important Findings Regarding the Pre-Existence of a Substrate in the Mechanism of POAF.

\begin{tabular}{|c|c|c|c|}
\hline Author, year & Substrate Factor & Species & Main Finding \\
\hline Steinberg, 1993 & Structural Alteration & Human & $\begin{array}{l}\text { Signal averaged surface P-wave duration is a potent, } \\
\text { accurate and independent predictor of POAF. }\end{array}$ \\
\hline $\begin{array}{l}\text { Von Wagoner, } \\
1999\end{array}$ & $\begin{array}{l}\text { Alteration in } \\
\text { Ion Channels }\end{array}$ & Human & $\begin{array}{l}\text { Positive correlation between } I_{\text {CaL }} \text { measured at the } \\
\text { time of surgery and the occurrence of POAF. }\end{array}$ \\
\hline Brandt, 2000 & $\begin{array}{l}\text { Alteration in } \\
\text { Ion Channels }\end{array}$ & Human & $\begin{array}{l}\text { No difference in } I_{\text {to }} \text { and a nonsignificant trend } \\
\text { towards a decrease in } I_{\text {kur }} \text { between patients with } \\
\text { and without POAF. }\end{array}$ \\
\hline$d, 2$ & Structural Alteration & Human & $\begin{array}{l}\text { Atrial Myolysis and lipofuscin levels identified as } \\
\text { independent histologic finding associated with } \\
\text { POAF. }\end{array}$ \\
\hline Goette, 2002 & Structural Alteration & Human & $\begin{array}{l}\text { Amount of atrial fibrosis in association with } \\
\text { prolongation of the surface P-wave or ageing } \\
\text { correlates with POAF. }\end{array}$ \\
\hline Dobrev, 2002 & $\begin{array}{l}\text { Alteration in } \\
\text { Ion Channels }\end{array}$ & Human & $\begin{array}{l}\text { Atrial myocytes of patients developing POAF have } \\
\text { no alterations in } I_{K 1} \text { and } I_{K, A c h} \text {. }\end{array}$ \\
\hline Ak, 2005 & Structural Alteration & Human & $\begin{array}{l}\text { Degree of atrial myolisis and increased apoptotic } \\
\text { pattern are significant predictors for development } \\
\text { POAF. }\end{array}$ \\
\hline Mariscalco, 2006 & Structural Alteration & Human & $\begin{array}{l}\text { Atrial histology is similar in patients undergoing } \\
\text { on- or off-pump surgery and is similar before and } \\
\text { after CPB. }\end{array}$ \\
\hline Workman, 2006 & $\begin{array}{l}\text { Alteration in } \\
\text { Ion Channels }\end{array}$ & Human & $\begin{array}{l}\text { No differences in } I_{\text {Cat }^{\prime}} I_{\text {to }} I_{\mathrm{K} 1} \text { and } I_{\text {sus }} \text { in right atrial } \\
\text { biopsies of patients who do and do not develop } \\
\text { POAF. }\end{array}$ \\
\hline $\begin{array}{l}\text { Kanagaratnam, } \\
2008\end{array}$ & Structural Alteration & nan & $\begin{array}{l}\text { Only patients with sustained induced AF develop } \\
\text { POAF and have prolonged unipolar electrograms. }\end{array}$ \\
\hline
\end{tabular}

compared to those without the arrhythmia. ${ }^{144}$ Also, a higher sympathetic tone after surgery ${ }^{14}$ will further increase calcium influx through L-type $\mathrm{Ca}^{2+}$ channels. Enhanced calcium load might elicit triggered activity (e.g. delayed afterdepolarizations) potentially initiating POAF. ${ }^{144}$ However, a more recent and very detailed study by Workman et al. could not confirm any differences in $I_{C a L}$ between patients with and without POAF. ${ }^{50}$ This recent study and the significant overlap in the $\mathrm{Ca}^{2+}$ current density data for most patients in the earlier 
report ${ }^{144}$ suggest that changes in L-type $\mathrm{Ca}^{2+}$ channel might have contributed to POAF initiation in some patients, but certainly not in all.

Potassium $\left(\mathrm{K}^{+}\right)$channels, which are altered in patients with persistent $\mathrm{AF}$, are apparently not involved in the occurrence of POAF. First, Brandt et al. reported that the ultra-rapid delayed rectifier $\mathrm{K}^{+}$current $\left(I_{\text {Kur }}\right)$ is reduced in human persistent AF. ${ }^{145}$ In non-AF patients developing AF after cardiac surgery, however, only a non-significant trend towards a decrease in $I_{K u r}$ and no difference in the transient outward $\mathrm{K}^{+}$current $\left(I_{t_{0}}\right)$ were detected compared to patients without POAF. ${ }^{145}$ Dobrev et al. found the larger basal inward rectifying $\mathrm{K}^{+}$ current in patients with persistent AF to consist of increased activity of the inward rectifier $\mathrm{K}^{+}$current $\left(I_{K 1}\right)$ and constitutive activity of the acetylcholineactivated $\mathrm{K}^{+}$current $\left(I_{K, A C H}\right) \cdot{ }^{146,147}$ Again, both $I_{K 1}$ and $I_{K, A C H}$ were not altered in non-AF patients developing POAF compared to patients not having AF after surgery. Third, Workman et al. found no differences in $I_{t 0^{\prime}}$ in $I_{K 1^{\prime}}$ or in the sustained outward $\mathrm{K}^{+}$current $\left(I_{\text {sus }}\right)$ between patients who did and did not develop POAF. ${ }^{50}$ These findings are consistent with unaltered APD or ERP in their study ${ }^{50}$ and with results in other reports. ${ }^{145,147}$ Finally, a recent study of Swartz et al. confirmed the lack of difference in $\mathrm{K}^{+}$channels in atrial biopsies of patients who did and did not develop AF after cardiac surgery. ${ }^{148}$

All together, these data suggest that, unlike in persistent AF, preoperative changes in cellular $\mathrm{Ca}^{2+}$ and $\mathrm{K}^{+}$channels do not play an important role in the occurrence of POAF.

\subsubsection{Alterations of the atrial interstitium and extracellular matrix predisposing to POAF}

Ageing is an important risk factor for POAF and slowing of conduction is known to occur as atria structurally remodel with age. Spach et al. were the first to report that progressive electrical uncoupling of the side-to-side connections between parallel-orientated atrial fibers occurs in atrial muscle with advancing age. This uncoupling results in a decrease of transverse conduction and enhances anisotropy of conduction velocity. ${ }^{149}$ Such an alteration in conduction is often associated with the presence of extensive collagenous septa and favors reentry. ${ }^{149}$ The relationship between this age-dependent remodeling and the occurrence of POAF is strengthened by several studies. First, Ad et al. reported that the severity of preoperative atrial myolysis in right atrial biopsies of non-AF patients undergoing CABG correlated well with the occurrence of POAF. ${ }^{150}$ In this study and in a study by Mariscalco et al., ${ }^{151}$ no histo- 
logical differences were noted in atrial specimens before and after $\mathrm{CPB}$. This suggests that any contribution of CPB to POAF must be independent from histological changes. Secondly, Ak et al. found that preoperative morphologic alterations like atrial myocardial vacuolization and increased myocardial apoptosis may constitute a pathologic substrate for POAF. ${ }^{152}$ Third, a study of Goette et al. further strengthens this role for pre-existent structural alterations. In this report, the incidence of POAF increased with the amount of fibrosis in right atrial appendages of patients undergoing cardiac surgery. ${ }^{153}$ Moreover, atrial fibrosis was not only age-dependent, but also correlated with P-wave duration suggesting macroscopic slowing of conduction. ${ }^{153}$ Finally, a larger amount of fibrosis was found in left atria of patients developing POAF. ${ }^{148}$ On the other hand, one study reported no differences in right atrial histology between patients who do and do not develop POAF. ${ }^{154}$

By comparing POAF incidences between different types of cardiac surgery, the important contribution of atrial structural alterations to the mechanisms of POAF is further supported. For example, Anné et al. found more profound structural changes in patients with mitral valve disease than in patients undergoing CABG: larger atria, hypertrophied cells, more interstitial fibrosis and signs of cellular degeneration. ${ }^{155}$ Left atrial fibrosis was more pronounced in patients undergoing mitral valve surgery compared to patients undergoing CABG, independently of the underlying heart rhythm. It appears reasonable to assume that the higher AF incidence after mitral valve surgery is due to these structural alterations. Also, Asher et al. found left atrial enlargement to be a independently associated with POAF in patients undergoing only valve surgery. ${ }^{156}$

Other studies more directly demonstrate the pre-existence of an arrhythmogenic substrate in patients who do develop POAF. For example, Lowe et al. screened patients at risk for developing POAF by electrical stimulation of the mid right atrium during surgery. ${ }^{45}$ Of a total of 36 patients in whom AF was inducible, 17 patients developed POAF. One patient was not inducible, but did develop POAF. Another example is the study by Kanagaratnam et al., where AF was induced during cardiac surgery by burst pacing in patients without a history of AF. ${ }^{157}$ Only patients with sustained induced AF developed any episodes of POAF. ${ }^{157}$ Also in the same study, patients with sustained AF had prolonged unipolar electrograms compared to patients not able to sustain AF and this prolongation was more marked in the region of the crista terminalis than in the trabeculated right atrium. The authors stated that this 
prolongation of local electrograms is suggestive of microscopic conduction abnormalities. ${ }^{157}$ Finally, connexin 40 expression, one of the 3 connexins present in atrial myocytes, is significantly higher in patients who develop POAF compared to sinus rhythm patients. ${ }^{158}$ Cell to cell conduction properties are determined by gap junctions, which are clusters of transmembrane channels built up from connexins. As such, enhanced expression and heterogeneous distribution of connexin 40 could result in local conduction heterogeneities. ${ }^{158}$ Some indirect evidence for the existence of a structural substrate for AF comes from studies investigating surface-ECG parameters in patients with POAF. In a study of Steinberg et al., measurement of P-wave duration on the standard ECG was longer in patients with POAF, but this did not reach significance. ${ }^{159}$ In the same study, however, signal-averaged P-wave duration proved to be a independent predictor of AF after cardiac surgery. ${ }^{159}$ In another study, increase in P-wave dispersion postoperatively predicted POAF after CABG. ${ }^{160}$

The concept of a pre-existing substrate for $\mathrm{AF}$ as an important predictor of POAF is also supported by a study of Ahlsson et al. who recently published the remarkable finding that one-fourth of patients with POAF developed AF of any form during a follow-up of 5 years. ${ }^{12} \mathrm{~A}$ possible explanation is that these patients already had a pre-existing substrate for AF at the time of surgery, that this substrate was unmasked by occurrence of acute factors increasing the activity of proarrhythmic factors in the perioperative period and eventually led to a non-surgical form of AF later on. The hypothetical relationship between acute and chronic factors is illustrated in Figure 2. In this figure, the time course of two fictive patients is depicted. Both patients have no AF history at the time of surgery and undergo on-pump CABG at the same age. In patient 1, acute surgery related factors enhance the AF susceptibility, but the 'AF threshold ${ }^{\prime 161}$ is not reached and sinus rhythm is maintained in the postoperative phase. In patient 2, synergistic interaction of acute, surgery induced factors and the pre-existence of a substrate for $\mathrm{AF}$ due to structural heart disease enhances $\mathrm{AF}$ susceptibility that much that the 'AF threshold'161 is exceeded. In this sense, the post-operative setting can be regarded as a 'stress test' for the propensity to the arrhythmia.

\subsection{Risk Factors for POAF and the development of an AF Substrate}

After having discussed the mechanisms predisposing to POAF this section describes the relation between these mechanisms and clinical risk factors for $\mathrm{AF}$ and POAF. 
Chapter 2

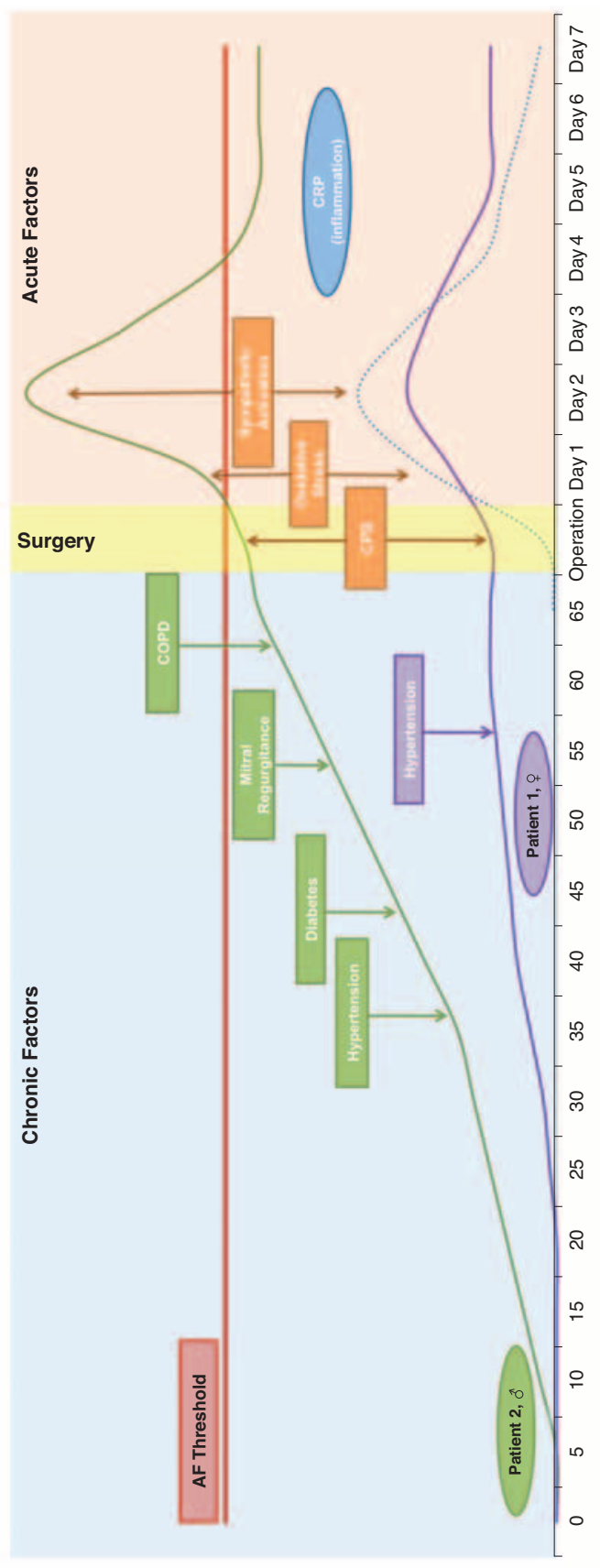

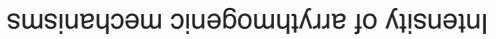

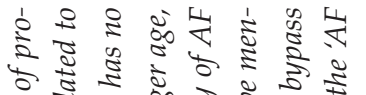
क ज

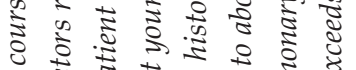

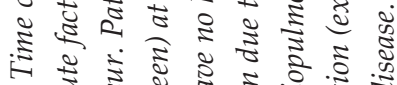

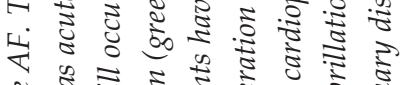
.

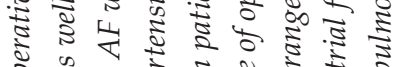

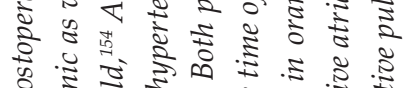

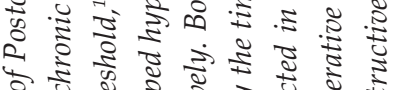

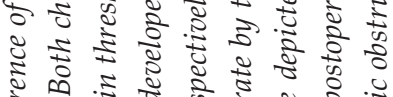

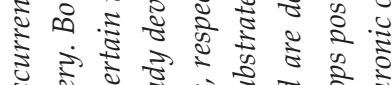

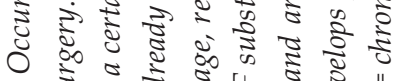

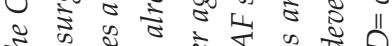

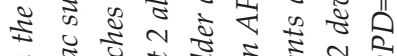

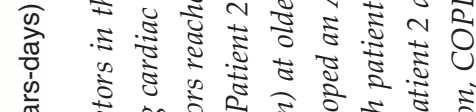

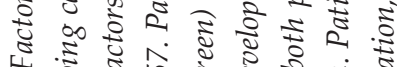

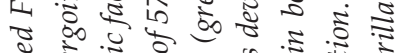

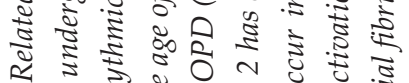

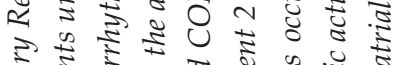

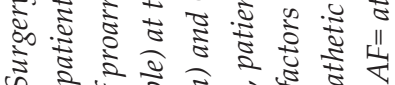

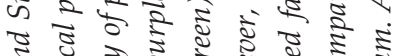

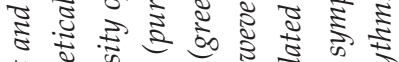

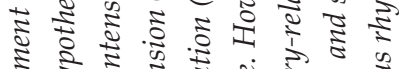

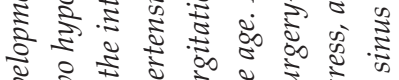

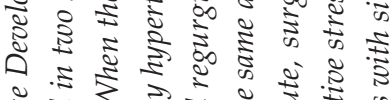

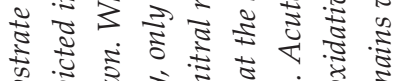

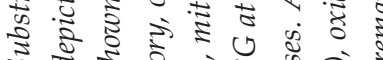

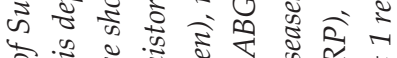
गे.

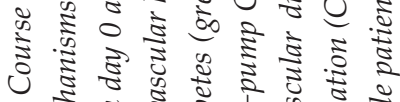

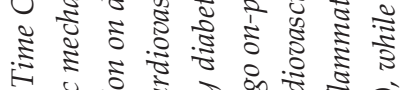

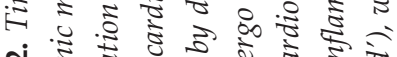

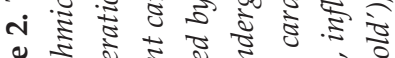

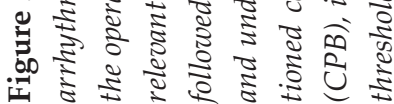


Age

Advancing age correlates strongly with the occurrence of new onset $\mathrm{AF}^{162,163}$ and POAF. 1, 2, 4, 6-9, 15-18, 44-48 Moreover, several arguments support that ageing enhances the development of a substrate capable of perpetuating AF. ${ }^{149}$ As discussed above, ageing goes along with fibrosis ${ }^{151,153,164}$ and is associated with slowing of conduction. ${ }^{165}$ Surprisingly, in one study endocardial AF inducibility in patients without any AF history did not increase with age and even decreased in elderly patients $(>70 \mathrm{yr}) .{ }^{166}$ These older patients had a significant longer AERP compared to younger patients (40yr). However, as wavelength, measured as the product of conduction velocity and ERP, is a more reliable predictive index for induction of atrial arrhythmias than conduction velocity or ERP alone, ${ }^{167}$ the proarrhyhtmic effect of slowing of conduction likely outweighs the protective effect of prolongation of atrial refractoriness.

\section{Structural heart disease}

Left atrial enlargement, mitral valve disease, congestive heart failure (CHF) and hypertension are well known risk factors for non-surgical AF. ${ }^{162}, 163,168$ Atrial structural remodeling consequent to these risk factors can predispose to the onset of POAF. Indeed, in large epidemiological studies, ${ }^{2,4}, 17$ these risk factors are also associated with the incidence of POAF. This suggests that underlying mechanisms enhance the propensity to AF similarly in cardiac surgery patients as in patients not undergoing cardiac surgery. However, it appears that the association of structural heart disease with POAF is weaker than with persistent non-surgical AF. ${ }^{18,9,47}$ It can be hypothesized that in the case of non-surgical AF, structural alterations enhanced the development of an $\mathrm{AF}$ substrate so far that $\mathrm{AF}$ occurs 'spontaneously'. In the setting of POAF however, superimposition of acute surgery induced factors is required to exceed the 'AF threshold'. As such, a weaker association would be expected between these risk factors and $\mathrm{POAF}$ incidence compared to non-surgical $\mathrm{AF}$ incidence.

\section{i. Left atrial enlargement and mitral valve disease}

Chronic structural alterations in the left atrium, rather than changes in ion channels, seem responsible for the higher POAF susceptibility in patients with enlargement of the left atrium. First, in non-AF patients with mitral regurgitance, prolongation rather than shortening of AERP is seen in the left atrium. ${ }^{169}$ Moreover, a line of conduction block runs vertically between the pulmonary veins in the posterior left atrium. ${ }^{170}$ In patients with greater left atrial enlargement, this line of block is more extensive compared to 'unremodeled' 
patients. Furthermore, complex fractionated electrograms, which can be found at a line of block, are relatively stable in this region and thus most likely related to the underlying architecture of the atrial wall. ${ }^{169}$ Finally, also experimental data support this rationale. In a canine study of chronic left atrial dilatation due to mitral regurgitation, persistence of induced AF went hand in hand with the degree of left atrial dilatation. ${ }^{171}$ Histological analysis of these atria revealed areas of chronic inflammation and increased interstitial fibrosis. ${ }^{171}$

\section{ii. Congestive Heart Failure}

Congestive heart failure is known to cause (1) left atrial dilatation due to increased atrial filling pressures secondary to decreased ventricular function, (2) increased atrial fibrosis and (3) regional conduction abnormalities. ${ }^{172,173}$

\section{iii. Hypertension}

Elevated blood pressure causes left ventricular hypertrophy, left atrial dilatation and modifications of atrial mechanical function, all promoting AF. ${ }^{174} \mathrm{How}$ ever, administration of angiotensin converting enzyme inhibitor or angiotensin receptor blocker has not yet been clearly associated with a decrease in POAF incidence. ${ }^{91,175,176}$

\section{History of $A F$}

High propensity to POAF in patients with previous episodes of $\mathrm{AF}^{3,6}$ is not surprising. The fact that spontaneous episodes of AF already occurred shows that the activity of proarrhythmic mechanisms in these patients exceeded the 'AF threshold'. ${ }^{161}$ Superimposition of acute surgery-induced factors will only facilitate new episodes of the arrhythmia. On the other hand, AF itself might have contributed to the development of an AF substrate secondary to electrical and structural remodeling of the atria.

\section{Risk factors for AF but not for POAF}

Some but not all studies identified diabetes as independent risk factor for AF. ${ }^{162,163,177,178}$ Also in POAF, the predictive value of diabetes for the incidence of the arrhythmia is low. ${ }^{1-4,6-8,15,17,47}$ In a recent meta-analysis reviewing 100,217 patients no difference in POAF incidence was found between patients with and without diabetes. ${ }^{179}$ Furthermore, men have a 1.5 greater likelihood of developing new onset AF compared to women. ${ }^{162}$ The mechanism behind the higher AF susceptibility remains unclear. In POAF, male gender fails to reach significance in many studies, ${ }^{1-3,6,7,15,17}$ and in studies that find male gender to be associated with POAF, the number of women included is often low. $4,8,47,48$ 
Association between chronic obstructive pulmonary disease (COPD) and new onset $\mathrm{AF}$ is still under discussion. ${ }^{162,178}$ COPD has been identified as an independent predictor of AF progression. ${ }^{180}$ In the occurrence of POAF, COPD is often identified as a risk factor. ${ }^{1-3,9,47}$ The pathogenesis of AF in patients with COPD is unclear, ${ }^{3}$ but pulmonary hypertension, inflammation, hypoxia, acidosis and right atrial and ventricular dilatation might contribute to the formation of a substrate for AF in these patients. ${ }^{181}$

\section{Conclusions}

From the numerous experimental and epidemiological studies addressing the mechanisms of POAF several conclusions can be drawn.

1. Both transient factors related to surgery as well as factors developing slowly and progressively contribute to the occurrence of POAF.

The time course of $\mathrm{POAF}^{4,7,43}$ unmasks the importance of temporary surgeryinduced factors as inflammation, sympathetic stimulation and oxidative stress. However, transient factors cannot be the only responsible mechanism for the occurrence of the arrhythmia, as many patients in whom one or even several of these factors are clearly operative do not develop POAF.

2. Among the transient predisposing mechanisms of POAF, sympathetic activation appears to be more relevant than inflammation and oxidative stress.

Withdrawal from and treatment with $\beta$-blockers has been shown to largely affect POAF incidence, ${ }^{50,117-119}$ while reducing oxidative stress ${ }^{124,135}$ or inflammation ${ }^{86,87}$ were less effective. In line with this the 2010 ESC guidelines recommend $\beta$-blocker treatment as first line therapy of POAF. ${ }^{91}$

3. Occurrence of POAF is strongly determined by the pre-existence of an AF substrate.

Despite the importance of transient surgery induced factors, the majority of POAF cases occur in atria with a pre-existing AF substrate due to a long-lasting structural remodeling process. Moreover, patients developing POAF have an eightfold increased risk of developing AF in the future. ${ }^{12}$ If transient factors were the only cause of onset of POAF, AF after surgery would not be expected to be associated with occurrence of AF later on. This emphasizes the important role for more chronic factors, not directly related to surgery. 
Chapter 2

4. AF after cardiac surgery and non-surgical AF have common clinical risk factors.

Patients developing AF after surgery have preoperatively increased intraatrial conduction times (longer SAPWD) ${ }^{159}$ and more profound atrial structural changes like fibrosis ${ }^{148,153}$ compared to patients who maintain sinus rhythm after surgery. This presence of structural 'remodeling' of atria before the onset of POAF is very similar to the setting of non surgical AF. In agreement with this hypothesis, the risk factors for POAF are surprisingly similar to the classical risk factors identified for AF as such.

5. Susceptibility to AF after surgery is not to due to changes in ionic currents. In non-surgical $\mathrm{AF}$, alterations in ion channels as a consequence of $\mathrm{AF}$ enhance the perpetuation of AF..$^{143,145-147}$ However, the function of these ion channels is not altered in preoperative atrial biopsies of patients developing AF after cardiac surgery. ${ }^{50,145,147,148}$

6. Progress in the preventive treatment of POAF has been made during the past decade.

As age is the strongest risk factor for POAF $^{1,2,4,6-9,15-18,44-48}$ and cardiac surgery nowadays is performed in older patients, ${ }^{49}$ one would expect POAF incidence to rise over time. The fact that recent epidemiological studies ${ }^{10,17}$ were not able to confirm this trend suggests significant progress in preventive treatment of POAF.

Reviewing mechanisms predisposing to the occurrence of AF after cardiac surgery clearly reveals that the pathogenesis of POAF is multifactorial. Therefore, subclassification of POAF based on these mechanisms does not appear adequate. Identifying leading mechanisms in individual patients, however, might improve treatment in the future. The clinical setting of POAF offers numerous opportunities to study not only mechanisms of POAF but also of $\mathrm{AF}$ in general, as cardiac surgery enables direct access to the heart. This opportunity appears to be underused so far. 


\section{References}

1. Creswell LL, Schuessler RB, Rosenbloom M, Cox JL. Hazards of postoperative atrial arrhythmias. Ann Thorac Surg. 1993;56:539-49.

2. Almassi GH, Schowalter T, Nicolosi AC, Aggarwal A, Moritz TE, Henderson WG, Tarazi R, Shroyer AL, Sethi GK, Grover FL, Hammermeister KE. Atrial fibrillation after cardiac surgery: a major morbid event? Annals of surgery. 1997;226:501-11;discussion 11-3.

3. Mathew JP, Fontes ML, Tudor IC, Ramsay J, Duke P, Mazer CD, Barash PG, Hsu PH, Mangano DT. A multicenter risk index for atrial fibrillation after cardiac surgery. JAMA .2004;291:1720-9.

4. Aranki SF, Shaw DP, Adams DH, Rizzo RJ, Couper GS, VanderVliet M, Collins JJ, Jr., Cohn LH, Burstin HR. Predictors of atrial fibrillation after coronary artery surgery. Current trends and impact on hospital resources. Circulation. 1996;94:390-7.

5. Frost L, Molgaard H, Christiansen EH, Hjortholm K, Paulsen PK, Thomsen PE. Atrial fibrillation and flutter after coronary artery bypass surgery: epidemiology, risk factors and preventive trials. Int J Cardiol. 1992;36:253-61.

6. Banach M, Rysz J, Drozdz JA, Okonski P, Misztal M, Barylski M, Irzmanski R, Zaslonka J. Risk factors of atrial fibrillation following coronary artery bypass grafting: a preliminary report. Circ J. 2006;70:438-41.

7. Auer J, Weber T, Berent R, Ng CK, Lamm G, Eber B. Risk factors of postoperative atrial fibrillation after cardiac surgery. J Card Surg. 2005;20:425-31.

8. Fuller JA, Adams GG, Buxton B. Atrial fibrillation after coronary artery bypass grafting. Is it a disorder of the elderly? J Thorac Cardiovasc Surg. 1989;97:821-5.

9. Leitch JW, Thomson D, Baird DK, Harris PJ. The importance of age as a predictor of atrial fibrillation and flutter after coronary artery bypass grafting. J Thorac Cardiovasc Surg. 1990; 100:338-42.

10. Mariscalco G, Engstrom KG. Postoperative atrial fibrillation is associated with late mortality after coronary surgery, but not after valvular surgery. Ann Thorac Surg. 2009;88:1871-6.

11. Siebert J, Anisimowicz L, Lango R, Rogowski J, Pawlaczyk R, Brzezinski M, Beta S, Narkiewicz M. Atrial fibrillation after coronary artery bypass grafting: does the type of procedure influence the early postoperative incidence? Eur J Cardiothorac Surg. 2001;19:455-9.

12. Ahlsson A, Fengsrud E, Bodin L, Englund A. Postoperative atrial fibrillation in patients undergoing aortocoronary bypass surgery carries an eightfold risk of future atrial fibrillation and a doubled cardiovascular mortality. Eur J Cardiothorac Surg. 2010;37:1353-59.

13. Villareal RP, Hariharan R, Liu BC, Kar B, Lee VV, Elayda M, Lopez JA, Rasekh A, Wilson JM, Massumi A. Postoperative atrial fibrillation and mortality after coronary artery bypass surgery. J Am Coll Cardiol. 2004;43:742-8.

14. Kalman JM, Munawar M, Howes LG, Louis WJ, Buxton BF, Gutteridge G, Tonkin AM. Atrial fibrillation after coronary artery bypass grafting is associated with sympathetic activation. Ann Thorac Surg. 1995;60:1709-15. 


\section{Chapter 2}

15. Hakala T, Hedman A, Turpeinen A, Kettunen R, Vuolteenaho O, Hippelainen M. Prediction of atrial fibrillation after coronary artery bypass grafting by measuring atrial peptide levels and preoperative atrial dimensions. Eur J Cardiothorac Surg. 2002;22:939-43.

16. Zangrillo A, Landoni G, Sparicio D, Benussi S, Aletti G, Pappalardo F, Fracasso G, Fano G, Crescenzi G. Predictors of atrial fibrillation after off-pump coronary artery bypass graft surgery. J Cardiothorac Vasc Anesth. 2004;18:704-8.

17. Shen J, Lall S, Zheng V, Buckley P, Damiano Jr RJ, Schuessler RB. The persistent problem of new-onset postoperative atrial fibrillation: A single-institution experience over two decades. J Thorac Cardiovasc Surg. 2011;141:559-70.

18. Mahoney EM, Thompson TD, Veledar E, Williams J, Weintraub WS. Cost-effectiveness of targeting patients undergoing cardiac surgery for therapy with intravenous amiodarone to prevent atrial fibrillation. Journal of the American College of Cardiology. 2002;40:737-45.

19. Ma JY, Wang Y, Zhao YF, Wu Z, Liu LX, Kou YL, Yang JJ. Atrial fibrillation after surgery for esophageal carcinoma: clinical and prognostic significance. World J Gastroenterol. 2006;12: 449-52.

20. Amar D, Zhang H, Heerdt PM, Park B, Fleisher M, Thaler HT. Statin Use Is Associated With a Reduction in Atrial Fibrillation After Noncardiac Thoracic Surgery Independent of C-Reactive Protein*. Chest. 2005;128:3421-27.

21. Passman RS, Gingold DS, Amar D, Lloyd-Jones D, Bennett CL, Zhang H, Rusch VW. Prediction Rule for Atrial Fibrillation After Major Noncardiac Thoracic Surgery. The Annals of Thoracic Surgery. 2005;79:1698-703.

22. Curtis JJ, Parker BM, McKenney CA, Wagner-Mann CC, Walls JT, Demmy TL, Schmaltz RA. Incidence and predictors of supraventricular dysrhythmias after pulmonary resection. Ann Thorac Surg. 1998;66:1766-71.

23. Lanza LA, Visbal AI, DeValeria PA, Zinsmeister AR, Diehl NN, Trastek VF. Low-dose oral amiodarone prophylaxis reduces atrial fibrillation after pulmonary resection. Ann Thorac Surg. 2003;75:223-30;discussion 30.

24. Amar D, Roistacher N, Burt M, Reinsel RA, Ginsberg RJ, Wilson RS. Clinical and echocardiographic correlates of symptomatic tachydysrhythmias after noncardiac thoracic surgery. Chest. 1995;108:349-54.

25. Walsh SR, Oates JE, Anderson JA, Blair SD, Makin CA, Walsh CJ. Postoperative arrhythmias in colorectal surgical patients: incidence and clinical correlates. Colorectal Dis. 2006;8: 212-6.

26. Batra GS, Molyneux J, Scott NA. Colorectal patients and cardiac arrhythmias detected on the surgical high dependency unit. Ann R Coll Surg Engl. 2001;83:174-6.

27. Siu CW, Tung HM, Chu KW, Jim MH, Lau CP, Tse HF. Prevalence and predictors of new-onset atrial fibrillation after elective surgery for colorectal cancer. Pacing Clin Electrophysiol. 2005;28 Suppl 1:S120-3.

28. Christians KK, Wu B, Quebbeman EJ, Brasel KJ. Postoperative atrial fibrillation in noncardiothoracic surgical patients. The American Journal of Surgery. 2001;182:713-15. 
29. Kahn RL, Hargett MJ, Urquhart B, Sharrock NE, Peterson MG. Supraventricular tachyarrhythmias during total joint arthroplasty. Incidence and risk. Clin Orthop Relat Res. 1993:265-9.

30. Brathwaite D, Weissman C. The new onset of atrial arrhythmias following major noncardiothoracic surgery is associated with increased mortality. Chest. 1998;114:462-8.

31. Auer J, Weber T, Berent R, Ng CK, Lamm G, Eber B. Postoperative atrial fibrillation independently predicts prolongation of hospital stay after cardiac surgery. The Journal of cardiovascular surgery. 2005;46:583-8.

32. Lo B, Fijnheer R, Nierich AP, Bruins P, Kalkman CJ. C-reactive protein is a risk indicator for atrial fibrillation after myocardial revascularization. Ann Thorac Surg. 2005;79:1530-5.

33. Lahtinen J, Biancari F, Salmela E, Mosorin M, Satta J, Rainio P, Rimpiläinen J, Lepojärvi M, Juvonen T. Postoperative atrial fibrillation is a major cause of stroke after on-pump coronary artery bypass surgery. The Annals of Thoracic Surgery. 2004;77:1241-44.

34. Nazeri A, Razavi M, Elayda MA, Lee V-V, Massumi A, Wilson JM. Race/ethnicity and the incidence of new-onset atrial fibrillation after isolated coronary artery bypass surgery. Heart Rhythm;7:1458-63.

35. Vaseghi M, Boyle NG, Kedia R, Patel JK, Cesario DA, Wiener I, Kobashigawa JA, Shivkumar K. Supraventricular tachycardia after orthotopic cardiac transplantation. J Am Coll Cardiol. 2008;51:2241-9.

36. Goldman L. Supraventricular tachyarrhythmias in hospitalized adults after surgery. Clinical correlates in patients over 40 years of age after major noncardiac surgery. Chest. 1978;73:450-4.

37. Rogers WR, Wroblewski F, Ladue JS. Supraventricular tachycardia complicating surgical procedures;a study of the contributing causes, course, and treatment of this complication in fifty patients. Circulation. 1953;7:192-9.

38. Vaporciyan AA, Correa AM, Rice DC, Roth JA, Smythe WR, Swisher SG, Walsh GL, Putnam JB, Jr. Risk factors associated with atrial fibrillation after noncardiac thoracic surgery: analysis of 2588 patients. J Thorac Cardiovasc Surg. 2004;127:779-86.

39. Asamura H, Naruke T, Tsuchiya R, Goya T, Kondo H, Suemasu K. What are the risk factors for arrhythmias after thoracic operations? A retrospective multivariate analysis of 267 consecutive thoracic operations. J Thorac Cardiovasc Surg. 1993;106:1104-10.

40. Harpole JDH, Liptay MJ, DeCamp JMM, Mentzer SJ, Swanson SJ, Sugarbaker DJ. Prospective analysis of pneumonectomy: Risk factors for major morbidity and cardiac dysrhythmias. The Annals of Thoracic Surgery. 1996;61:977-82.

41. Materazzo C, Piotti P, Mantovani C, Miceli R, Villani F. Atrial fibrillation after non-cardiac surgery: P-wave characteristics and Holter monitoring in risk assessment. Eur J Cardiothorac Surg. 2007;31:812-6.

42. Park BJ, Zhang H, Rusch VW, Amar D. Video-assisted thoracic surgery does not reduce the incidence of postoperative atrial fibrillation after pulmonary lobectomy. J Thorac Cardiovasc Surg. 2007;133:775-79.

43. Auer J, Weber T, Berent R, Puschmann R, Hartl P, Ng CK, Schwarz C, Lehner E, Strasser U, Lassnig E, Lamm G, Eber B. A comparison between oral antiarrhythmic drugs in the pre- 


\section{Chapter 2}

vention of atrial fibrillation after cardiac surgery: the pilot study of prevention of postoperative atrial fibrillation (SPPAF), a randomized, placebo-controlled trial. Am Heart J. 2004;147: 636-43.

44. Butler J, Chong JL, Rocker GM, Pillai R, Westaby S. Atrial fibrillation after coronary artery bypass grafting: a comparison of cardioplegia versus intermittent aortic cross-clamping. Eur J Cardiothorac Surg. 1993;7:23-5.

45. Lowe JE, Hendry PJ, Hendrickson SC, Wells R. Intraoperative identification of cardiac patients at risk to develop postoperative atrial fibrillation. Annals of surgery. 1991;213:388-91; discussion 91-2.

46. Ducceschi V, D'Andrea A, Liccardo B, Alfieri A, Sarubbi B, De Feo M, Santangelo L, Cotrufo M. Perioperative clinical predictors of atrial fibrillation occurrence following coronary artery surgery. European Journal of Cardio-Thoracic Surgery. 1999;16:435-39.

47. Zacharias A, Schwann TA, Riordan CJ, Durham SJ, Shah AS, Habib RH. Obesity and risk of new-onset atrial fibrillation after cardiac surgery. Circulation. 2005;112:3247-55.

48. Zaman AG, Archbold RA, Helft G, Paul EA, Curzen NP, Mills PG. Atrial Fibrillation After Coronary Artery Bypass Surgery: A Model for Preoperative Risk Stratification. Circulation. 2000;101:1403-08.

49. Ferguson TB, Jr., Hammill BG, Peterson ED, DeLong ER, Grover FL. A decade of change risk profiles and outcomes for isolated coronary artery bypass grafting procedures, 19901999: a report from the STS National Database Committee and the Duke Clinical Research Institute. Society of Thoracic Surgeons. Ann Thorac Surg. 2002;73:480-9;discussion 89-90.

50. Workman AJ, Pau D, Redpath CJ, Marshall GE, Russell JA, Kane KA, Norrie J, Rankin AC. Post-operative atrial fibrillation is influenced by beta-blocker therapy but not by preoperative atrial cellular electrophysiology. J Cardiovasc Electrophysiol. 2006;17:1230-8.

51. Olshansky B. Management of atrial fibrillation after coronary artery bypass graft. Am J Cardiol. 1996;78:27-34.

52. Bruins P, te Velthuis H, Yazdanbakhsh AP, Jansen PG, van Hardevelt FW, de Beaumont EM, Wildevuur CR, Eijsman L, Trouwborst A, Hack CE. Activation of the complement system during and after cardiopulmonary bypass surgery: postsurgery activation involves C-reactive protein and is associated with postoperative arrhythmia. Circulation. 1997;96: 3542-8.

53. Gaudino M, Andreotti F, Zamparelli R, Di Castelnuovo A, Nasso G, Burzotta F, Iacoviello L, Donati MB, Schiavello R, Maseri A, Possati G. The -174G/C interleukin-6 polymorphism influences postoperative interleukin-6 levels and postoperative atrial fibrillation. Is atrial fibrillation an inflammatory complication? Circulation. 2003;108 Suppl 1:II195-9.

54. Chung MK, Martin DO, Sprecher D, Wazni O, Kanderian A, Carnes CA, Bauer JA, Tchou PJ, Niebauer MJ, Natale A, Van Wagoner DR. C-Reactive Protein Elevation in Patients With Atrial Arrhythmias: Inflammatory Mechanisms and Persistence of Atrial Fibrillation. Circulation. 2001;104:2886-91. 
55. Aviles RJ, Martin DO, Apperson-Hansen C, Houghtaling PL, Rautaharju P, Kronmal RA, Tracy RP, Van Wagoner DR, Psaty BM, Lauer MS, Chung MK. Inflammation as a Risk Factor for Atrial Fibrillation. Circulation. 2003;108:3006-10.

56. Abdelhadi RH, Gurm HS, Van Wagoner DR, Chung MK. Relation of an exaggerated rise in white blood cells after coronary bypass or cardiac valve surgery to development of atrial fibrillation postoperatively. Am J Cardiol. 2004;93:1176-8.

57. Anselmi A, Possati G, Gaudino M. Postoperative Inflammatory Reaction and Atrial Fibrillation: Simple Correlation or Causation? The Annals of Thoracic Surgery. 2009;88:326-33.

58. Hak Ł, Myśliwska J, Wickiewicz J, Szyndler K, Siebert J, Rogowski J. Interleukin-2 as a Predictor of Early Postoperative Atrial Fibrillation After Cardiopulmonary Bypass Graft (CABG). Journal of Interferon \& Cytokine Research. 2009;29:327-32.

59. Lamm G, Auer J, Weber T, Berent R, Ng C, Eber B. Postoperative White Blood Cell Count Predicts Atrial Fibrillation After Cardiac Surgery. Journal of Cardiothoracic and Vascular Anesthesia. 2006;20:51-56.

60. Fontes ML, Mathew JP, Rinder HM, Zelterman D, Smith BR, Rinder CS. Atrial Fibrillation After Cardiac Surgery/Cardiopulmonary Bypass Is Associated with Monocyte Activation. Anesthesia \& Analgesia. 2005;101:17-23.

61. Gibson PH, Cuthbertson BH, Croal BL, Rae D, El-Shafei H, Gibson G, Jeffrey RR, Buchan KG, Hillis GS. Usefulness of neutrophil/lymphocyte ratio as predictor of new-onset atrial fibrillation after coronary artery bypass grafting. Am J Cardiol;105:186-91.

62. Wan S, Izzat MB, Lee TW, Wan IYP, Tang NLS, Yim APC. Avoiding cardiopulmonary bypass in multivessel CABG reduces cytokine response and myocardial injury. The Annals of Thoracic Surgery. 1999;68:52-56.

63. Enc Y, Ketenci B, Ozsoy D, Camur G, KayacIoglu I, Terzi S, Cicek S. Atrial fibrillation after surgical revascularization: is there any difference between on-pump and off-pump? European Journal of Cardio-Thoracic Surgery. 2004;26:1129-33.

64. Siebert J, Lewicki L, Mlodnicki M, Rogowski J, Lango R, Anisimowicz L, Narkiewicz M. Atrial fibrillation after conventional and off-pump coronary artery bypass grafting: two opposite trends in timing of atrial fibrillation occurrence? Med Sci Monit 2003;9:CR137-41.

65. van Dijk D, Nierich AP, Jansen EWL, Nathoe HM, Suyker WJL, Diephuis JC, van Boven W-J, Borst C, Buskens E, Grobbee DE, Robles de Medina EO, de Jaegere PPT. Early Outcome After Off-Pump Versus On-Pump Coronary Bypass Surgery: Results From a Randomized Study. Circulation. 2001;104:1761-66.

66. Legare J-F, Buth KJ, King S, Wood J, Sullivan JA, Friesen CH, Lee J, Stewart K, Hirsch GM. Coronary Bypass Surgery Performed off Pump Does Not Result in Lower In-Hospital Morbidity Than Coronary Artery Bypass Grafting Performed on Pump. Circulation. 2004; 109:887-92.

67. Zamvar V, Williams D, Hall J, Payne N, Cann C, Young K, Karthikeyan S, Dunne J. Assessment of neurocognitive impairment after off-pump and on-pump techniques for coronary artery bypass graft surgery: prospective randomised controlled trial. BMJ. 2002;325:1268. 


\section{Chapter 2}

68. Czerny M, Baumer H, Kilo J, Zuckermann A, Grubhofer G, Chevtchik O, Wolner E, Grimm M. Complete revascularization in coronary artery bypass grafting with and without cardiopulmonary bypass. The Annals of Thoracic Surgery. 2001;71:165-69.

69. Ascione R, Caputo M, Calori G, Lloyd CT, Underwood MJ, Angelini GD. Predictors of Atrial Fibrillation After Conventional and Beating Heart Coronary Surgery: A Prospective, Randomized Study. Circulation. 2000;102:1530-35.

70. Murphy GJ, Ascione R, Caputo M, Angelini GD. Operative factors that contribute to postoperative atrial fibrillation: insights from a prospective randomized trial. Card Electrophysiol Rev. 2003;7:136-9.

71. Boyd WD, Desai ND, Del Rizzo DF, Novick RJ, McKenzie FN, Menkis AH. Off-pump surgery decreases postoperative complications and resource utilization in the elderly. The Annals of Thoracic Surgery. 1999;68:1490-93.

72. Van Belleghem Y, Caes F, Maene L, Van Overbeke H, Moerman A, Van Nooten G. Offpump coronary surgery: surgical strategy for the high-risk patient. Cardiovascular Surgery. 2003;11:75-79.

73. Panesar SS, Athanasiou T, Nair S, Rao C, Jones C, Nicolaou M, Darzi A. Early outcomes in the elderly: a meta-analysis of 4921 patients undergoing coronary artery bypass grafting comparison between off-pump and on-pump techniques. Heart. 2006;92:1808-16.

74. Stamou SC, Dangas G, Hill PC, Pfister AJ, Dullum MKC, Boyce SW, Bafi AS, Garcia JM, Corso PJ. Atrial fibrillation after beating heart surgery. The American Journal of Cardiology. 2000;86:64-67.

75. Scherer M, Sirat A, Dogan S, Aybek T, Moritz A, Wimmer-Greinecker G. Does Totally Endoscopic Access for Off-pump Cardiac Surgery Influence the Incidence of Postoperative Atrial Fibrillation in Coronary Artery Bypass Grafting? A Preliminary Report. Cardiovascular Engineering. 2006;6:118-21.

76. Frustaci A, Chimenti C, Bellocci F, Morgante E, Russo MA, Maseri A. Histological Substrate of Atrial Biopsies in Patients With Lone Atrial Fibrillation. Circulation. 1997;96:1180-84.

77. Chen M-C, Chang J-P, Liu W-H, Yang C-H, Chen Y-L, Tsai T-H, Wang Y-H, Pan K-L. Increased Inflammatory Cell Infiltration in the Atrial Myocardium of Patients With Atrial Fibrillation. The American Journal of Cardiology. 2008;102:861-65.

78. Page PL, Plumb VJ, Okumura K, Waldo AL. A new animal model of atrial flutter. J Am Coll Cardiol. 1986;8:872-9.

79. Kumagai K, Khrestian C, Waldo AL. Simultaneous Multisite Mapping Studies During Induced Atrial Fibrillation in the Sterile Pericarditis Model: Insights Into the Mechanism of its Maintenance. Circulation. 1997;95:511-21.

80. Ryu K, Li L, Khrestian CM, Matsumoto N, Sahadevan J, Ruehr ML, Van Wagoner DR, Efimov IR, Waldo AL. Effects of sterile pericarditis on connexins 40 and 43 in the atria: correlation with abnormal conduction and atrial arrhythmias. Am J Physiol Heart Circ Physiol. 2007;293:H1231-41. 
81. Goldstein RN, Ryu K, Khrestian C, van Wagoner DR, Waldo AL. Prednisone prevents inducible atrial flutter in the canine sterile pericarditis model. J Cardiovasc Electrophysiol. 2008;19:74-81.

82. Kumagai K, Nakashima H, Saku K. The HMG-CoA reductase inhibitor atorvastatin prevents atrial fibrillation by inhibiting inflammation in a canine sterile pericarditis model. Cardiovascular Research. 2004;62:105-11.

83. Zhang Z, Zhang C, Wang H, Zhao J, Liu L, Lee J, He Y, Zheng Q. n-3 polyunsaturated fatty acids prevents atrial fibrillation by inhibiting inflammation in a canine sterile pericarditis model. International Journal of Cardiology. 2010;Sep, 8.

84. Ishii Y, Schuessler RB, Gaynor SL, Yamada K, Fu AS, Boineau JP, Damiano RJ, Jr. Inflammation of atrium after cardiac surgery is associated with inhomogeneity of atrial conduction and atrial fibrillation. Circulation. 2005;111:2881-8.

85. Tselentakis EV, Woodford E, Chandy J, Gaudette GR, Saltman AE. Inflammation effects on the electrical properties of atrial tissue and inducibility of postoperative atrial fibrillation. J Surg Res. 2006;135:68-75.

86. Ho KM, Tan JA. Benefits and Risks of Corticosteroid Prophylaxis in Adult Cardiac Surgery: A Dose-Response Meta-Analysis. Circulation. 2009;119:1853-66.

87. Bourbon $\mathrm{A}$, Vionnet $\mathrm{M}$, Leprince $\mathrm{P}$, Vaissier $\mathrm{E}$, Copeland $\mathrm{J}$, McDonagh $\mathrm{P}$, Debré $\mathrm{P}$, Gandjbakhch I. The effect of methylprednisolone treatment on the cardiopulmonary bypass-induced systemic inflammatory response. European Journal of Cardio-Thoracic Surgery. 2004;26:932-38.

88. Liakopoulos OJ, Choi Y-H, Kuhn EW, Wittwer T, Borys M, Madershahian N, Wassmer G, Wahlers T. Statins for prevention of atrial fibrillation after cardiac surgery: A systematic literature review. J Thorac Cardiovasc Surg. 2009;138:678-86.e1.

89. Chello M, Anselmi A, Spadaccio C, Patti G, Goffredo C, Di Sciascio G, Covino E. Simvastatin Increases Neutrophil Apoptosis and Reduces Inflammatory Reaction After Coronary Surgery. The Annals of Thoracic Surgery. 2007;83:1374-80.

90. Wagner AH, Kohler T, Ruckschloss U, Just I, Hecker M. Improvement of Nitric OxideDependent Vasodilatation by HMG-CoA Reductase Inhibitors Through Attenuation of Endothelial Superoxide Anion Formation. Arterioscler Thromb Vasc Biol. 2000;20:61-69.

91. Developed with the special contribution of the European Heart Rhythm A, Endorsed by the European Association for Cardio-Thoracic S, Authors/Task Force M, Camm AJ, Kirchhof P, Lip GYH, Schotten U, Savelieva I, Ernst S, Van Gelder IC, Al-Attar N, Hindricks G, Prendergast B, Heidbuchel H, Alfieri O, Angelini A, Atar D, Colonna P, De Caterina R, De Sutter J, Goette A, Gorenek B, Heldal M, Hohloser SH, Kolh P, Le Heuzey J-Y, Ponikowski P, Rutten FH, Guidelines ESCCfP, Vahanian A, Auricchio A, Bax J, Ceconi C, Dean V, Filippatos G, Funck-Brentano C, Hobbs R, Kearney P, McDonagh T, Popescu BA, Reiner Z, Sechtem U, Sirnes PA, Tendera M, Vardas PE, Widimsky P, Document R, Agladze V, Aliot E, Balabanski T, Blomstrom-Lundqvist C, Capucci A, Crijns H, Dahlöf Br, Folliguet T, 


\section{Chapter 2}

Glikson M, Goethals M, Gulba DC, Ho SY, Klautz RJM, Kose S, McMurray J, Perrone Filardi P, Raatikainen P, Salvador MJ, Schalij MJ, Shpektor A, Sousa Jo, Stepinska J, Uuetoa $\mathrm{H}$, Zamorano JL, Zupan I. Guidelines for the management of atrial fibrillation. Europace; 12:1360-420.

92. Calò L, Bianconi L, Colivicchi F, Lamberti F, Loricchio ML, de Ruvo E, Meo A, Pandozi C, Staibano M, Santini M. N-3 Fatty Acids for the Prevention of Atrial Fibrillation After Coronary Artery Bypass Surgery: A Randomized, Controlled Trial. Journal of the American College of Cardiology. 2005;45:1723-28.

93. Mariscalco G, Sarzi Braga S, Banach M, Borsani P, Bruno VD, Napoleone M, Vitale C, Piffaretti G, Pedretti RFE, Sala A. Preoperative n-3 Polyunsatured Fatty Acids Are Associated With a Decrease in the Incidence of Early Atrial Fibrillation Following Cardiac Surgery. Angiology. 2010;61:643-50.

94. Saravanan P, Bridgewater B, West AL, O'Neill SC, Calder PC, Davidson NC. Omega-3 fatty acid supplementation does not reduce risk of atrial fibrillation after coronary artery bypass surgery: a randomized, double-blind, placebo-controlled clinical trial. Circ Arrhythm Electrophysiol. 2010;3:46-53.

95. Heidarsdottir R, Arnar DO, Skuladottir GV, Torfason B, Edvardsson V, Gottskalksson G, Palsson R, Indridason OS. Does treatment with n-3 polyunsaturated fatty acids prevent atrial fibrillation after open heart surgery? Europace. 2010;12:356-63.

96. Kaireviciute D, Blann AD, Balakrishnan B, Lane DA, Patel JV, Uzdavinys G, Norkunas G, Kalinauskas G, Sirvydis V, Aidietis A, Lip GY. Characterisation and validity of inflammatory biomarkers in the prediction of post-operative atrial fibrillation in coronary artery disease patients. Thromb Haemost;104:122-7.

97. Ahlsson AJ, Bodin L, Lundblad OH, Englund AG. Postoperative Atrial Fibrillation is Not Correlated to C-Reactive Protein. The Annals of Thoracic Surgery. 2007;83:1332-37.

98. Gaudino M, Nasso G, Andreotti F, Minniti G, Iacoviello L, Donati M, Schiavello R, Possati G. Preoperative C-reactive protein level and outcome following coronary surgery. Eur J Cardiothorac Surg. 2002;22:521-6.

99. Workman A. Cardiac adrenergic control and atrial fibrillation. Naunyn-Schmiedeberg's Archives of Pharmacology;381:235-49.

100. Hoeldtke RD, Cilmi KM. Effects of aging on catecholamine metabolism. J Clin Endocrinol Metab. 1985;60:479-84.

101. Dimmer C, Tavernier R, Gjorgov N, Van Nooten G, Clement DL, Jordaens L. Variations of autonomic tone preceding onset of atrial fibrillation after coronary artery bypass grafting. The American Journal of Cardiology. 1998;82:22-25.

102. Amar D, Zhang H, Miodownik S, Kadish AH. Competing autonomic mechanisms precedethe onset of postoperative atrial fibrillation. Journal of the American College of Cardiology. 2003;42:1262-68. 
103. Hogue CW, Jr., Domitrovich PP, Stein PK, Despotis GD, Re L, Schuessler RB, Kleiger RE, Rottman JN. RR Interval Dynamics Before Atrial Fibrillation in Patients After Coronary Artery Bypass Graft Surgery. Circulation. 1998;98:429-34.

104. Waldo AL. Mechanisms of atrial fibrillation, atrial flutter, and ectopic atrial tachycardia a brief review. Circulation. 1987;75:III37-40.

105. Hogue CW, Jr., Hyder ML. Atrial fibrillation after cardiac operation: risks, mechanisms, and treatment. Ann Thorac Surg. 2000;69:300-6.

106. Melo J, Voigt P, Sonmez B, Ferreira M, Abecasis M, Rebocho M, Timóteo A, Aguiar C, Tansal S, Arbatli H, Dion R. Ventral cardiac denervation reduces the incidence of atrial fibrillation after coronary artery bypass grafting. J Thorac Cardiovasc Surg. 2004;127:511-16.

107. Alex J, Guvendik L. Evaluation of Ventral Cardiac Denervation As a Prophylaxis Against Atrial Fibrillation After Coronary Artery Bypass Grafting. The Annals of Thoracic Surgery .2005;79:517-20.

108. Cummings JE, Gill I, Akhrass R, Dery M, Biblo LA, Quan KJ. Preservation of the anterior fat pad paradoxically decreases the incidence of postoperative atrial fibrillation in humans. Journal of the American College of Cardiology. 2004;43:994-1000.

109. Omran AS, Karimi A, Ahmadi H, Yazdanifard P, Sheikh Fahtollahi M, Tazik M. Prophylactic ventral cardiac denervation: Does it reduce incidence of atrial fibrillation after coronary artery bypass grafting? J Thorac Cardiovasc Surg. 2010;140:1036-39.

110. Levy MN. Brief Reviews: Sympathetic-Parasympathetic Interactions in the Heart. Circ Res. 1971;29:437-45.

111. Fleming GA, Murray KT, Yu C, Byrne JG, Greelish JP, Petracek MR, Hoff SJ, Ball SK, Brown NJ, Pretorius M. Milrinone use is associated with postoperative atrial fibrillation after cardiac surgery. Circulation. 2008;118:1619-25.

112. Feneck RO, Sherry KM, Withington PS, Oduro-Dominah A. Comparison of the hemodynamic effects of milrinone with dobutamine in patients after cardiac surgery. J Cardiothorac Vasc Anesth. 2001;15:306-15.

113. Argalious M, Motta P, Khandwala F, Samuel S, Koch CG, Gillinov AM, Yared JP, Starr NJ, Bashour CA. "Renal dose" dopamine is associated with the risk of new-onset atrial fibrillation after cardiac surgery. Crit Care Med. 2005;33:1327-32.

114. Sampson KJ, Terrenoire C, Cervantes DO, Kaba RA, Peters NS, Kass RS. Adrenergic regulation of a key cardiac potassium channel can contribute to atrial fibrillation: evidence from an IKs transgenic mouse. The Journal of Physiology. 2008;586:627-37.

115. El-Armouche A, Boknik P, Eschenhagen T, Carrier L, Knaut M, Ravens U, Dobrev D. Molecular Determinants of Altered Ca2+ Handling in Human Chronic Atrial Fibrillation. Circulation. 2006;114:670-80.

116. Patterson E, Yu X, Huang S, Garrett M, Kem DC. Suppression of Autonomic-Mediated Triggered Firing in Pulmonary Vein Preparations, 24 Hours Postcoronary Artery Ligation in Dogs. Journal of Cardiovascular Electrophysiology. 2006;17:763-70. 


\section{Chapter 2}

117. Lamb RK, Prabhakar G, Thorpe JAC, Smith S, Norton R, Dyde JA. The use of atenolol in the prevention of supraventricular arrhythmias following coronary artery surgery. European Heart Journal. 1988;9:32-36.

118. White HD, Antman EM, Glynn MA, Collins JJ, Cohn LH, Shemin RJ, Friedman PL. Efficacy and safety of timolol for prevention of supraventricular tachyarrhythmias after coronary artery bypass surgery. Circulation. 1984;70:479-84.

119. Ali IM, Sanalla AA, Clark V. Beta-blocker effects on postoperative atrial fibrillation. European Journal of Cardio-Thoracic Surgery. 1997;11:1154-57.

120. Workman AJ, Kane KA, Russell JA, Norrie J, Rankin AC. Chronic beta-adrenoceptor blockade and human atrial cell electrophysiology: evidence of pharmacological remodelling. Cardiovascular Research. 2003;58:518-25.

121. Kailasam R, Palin CA, Hogue CW, Jr. Atrial fibrillation after cardiac surgery: an evidencebased approach to prevention. Semin Cardiothorac Vasc Anesth. 2005;9:77-85.

122. Epstein FH, McCord JM. Oxygen-Derived Free Radicals in Postischemic Tissue Injury. New England Journal of Medicine. 1985;312:159-63.

123. Carmeliet E. Cardiac Ionic Currents and Acute Ischemia: From Channels to Arrhythmias. Physiol Rev. 1999;79:917-1017.

124. Carnes CA, Chung MK, Nakayama T, Nakayama H, Baliga RS, Piao S, Kanderian A, Pavia S, Hamlin RL, McCarthy PM, Bauer JA, Van Wagoner DR. Ascorbate attenuates atrial pacing-induced peroxynitrite formation and electrical remodeling and decreases the incidence of postoperative atrial fibrillation. Circ Res. 2001;89:E32-8.

125. Shiroshita-Takeshita A, Schram G, Lavoie J, Nattel S. Effect of simvastatin and antioxidant vitamins on atrial fibrillation promotion by atrial-tachycardia remodeling in dogs. Circulation. 2004;110:2313-9.

126. Shishehbor MH, Brennan M-L, Aviles RJ, Fu X, Penn MS, Sprecher DL, Hazen SL. Statins Promote Potent Systemic Antioxidant Effects Through Specific Inflammatory Pathways. Circulation. 2003;108:426-31.

127. Mihm MJ, Yu F, Carnes CA, Reiser PJ, McCarthy PM, Van Wagoner DR, Bauer JA. Impaired myofibrillar energetics and oxidative injury during human atrial fibrillation. Circulation. 2001;104:174-80.

128. Kim YM, Guzik TJ, Zhang YH, Zhang MH, Kattach H, Ratnatunga C, Pillai R, Channon KM, Casadei B. A Myocardial Nox2 Containing NAD $(\mathrm{P}) \mathrm{H}$ Oxidase Contributes to Oxidative Stress in Human Atrial Fibrillation. Circ Res. 2005;97:629-36.

129. Ferrari R, Alfieri O, Curello S, Ceconi C, Cargnoni A, Marzollo P, Pardini A, Caradonna E, Visioli O. Occurrence of oxidative stress during reperfusion of the human heart. Circulation. 1990;81:201-11.

130. De Vecchi E, Pala MG, Di Credico G, Agape V, Paolini G, Bonini PA, Grossi A, Paroni R. Relation between left ventricular function and oxidative stress in patients undergoing bypass surgery. Heart. 1998;79:242-47. 
131. Ramlawi B, Otu H, Mieno S, Boodhwani M, Sodha NR, Clements RT, Bianchi C, Sellke FW. Oxidative Stress and Atrial Fibrillation After Cardiac Surgery: A Case-Control Study. The Annals of Thoracic Surgery. 2007;84:1166-73.

132. Kim YM, Kattach H, Ratnatunga C, Pillai R, Channon KM, Casadei B. Association of atrial nicotinamide adenine dinucleotide phosphate oxidase activity with the development of atrial fibrillation after cardiac surgery. J Am Coll Cardiol. 2008;51:68-74.

133. Clermont G, Vergely C, Jazayeri S, Lahet JJ, Goudeau JJ, Lecour S, David M, Rochette L, Girard C. Systemic free radical activation is a major event involved in myocardial oxidative stress related to cardiopulmonary bypass. Anesthesiology. 2002;96:80-7.

134. Eslami M, Badkoubeh RS, Mousavi M, Radmehr H, Salehi M, Tavakoli N, Avadi MR. Oral ascorbic acid in combination with beta-blockers is more effective than beta-blockers alone in the prevention of atrial fibrillation after coronary artery bypass grafting. Tex Heart Inst J. 2007;34:268-74.

135. Ozaydin M, Peker O, Erdogan D, Kapan S, Turker Y, Varol E, Ozguner F, Dogan A, Ibrisim E. N-acetylcysteine for the prevention of postoperative atrial fibrillation: a prospective, randomized, placebo-controlled pilot study. European Heart Journal. 2008;29:625-31.

136. Tossios P, Bloch W, Huebner A, Raji MR, Dodos F, Klass O, Suedkamp M, Kasper S-M, Hellmich M, Mehlhorn U. N-acetylcysteine prevents reactive oxygen species-mediated myocardial stress in patients undergoing cardiac surgery: results of a randomized, doubleblind, placebo-controlled clinical trial. Journal of Thoracic and Cardiovascular Surgery. 2003; 126:1513-20.

137. Elahi MM, Worner M, Khan JS, Matata BM. Inspired nitric oxide and modulation of oxidative stress during cardiac surgery. Curr Drug Saf. 2009;4:188-98.

138. Cavolli R, Kaya K, Aslan A, Emiroglu O, Erturk S, Korkmaz O, Oguz M, Tasoz R, Ozyurda U. Does Sodium Nitroprusside Decrease the Incidence of Atrial Fibrillation After Myocardial Revascularization?: A Pilot Study. Circulation. 2008;118:476-81.

139. Lesnefsky EJ, Lundergan CF, Hodgson JM, Nair R, Reiner JS, Greenhouse SW, Califf RM, Ross AM. Increased left ventricular dysfunction in elderly patients despite successful thrombolysis: The GUSTO-I angiographic experience. Journal of the American College of Cardiology. 1996;28:331-37.

140. Fontaine D, Pradier O, Hacquebard M, Stefanidis C, Carpentier Y, de Canniere D, Fontaine J, Berkenboom G. Oxidative stress produced by circulating microparticles in on-pump but not in off-pump coronary surgery. Acta Cardiol. 2009;64:715-22.

141. Matata BM, Sosnowski AW, Galiñanes M. Off-pump bypass graft operation significantly reduces oxidative stress and inflammation. The Annals of Thoracic Surgery. 2000;69:785-91.

142. Orhan G, Sargin M, Senay S, Yuksel M, Kurc E, Tasdemir M, Ozay B, Aka SA. Systemic and myocardial inflammation in traditional and off-pump cardiac surgery. Tex Heart Inst J. 2007; 34:160-5. 


\section{Chapter 2}

143. Yue L, Feng J, Gaspo R, Li G-R, Wang Z, Nattel S. Ionic Remodeling Underlying Action Potential Changes in a Canine Model of Atrial Fibrillation. Circ Res. 1997;81:512-25.

144. Van Wagoner DR, Pond AL, Lamorgese M, Rossie SS, McCarthy PM, Nerbonne JM. Atrial L-type Ca2+ currents and human atrial fibrillation. Circ Res. 1999;85:428-36.

145. Brandt MC, Priebe L, Böhle T, Südkamp M, Beuckelmann DJ. The Ultrarapid and the Transient Outward K+Current in Human Atrial Fibrillation. Their Possible Role in Postoperative Atrial Fibrillation. Journal of Molecular and Cellular Cardiology. 2000;32:1885-96.

146. Dobrev D, Friedrich A, Voigt N, Jost N, Wettwer E, Christ T, Knaut M, Ravens U. The G Protein-Gated Potassium Current IK,ACh Is Constitutively Active in Patients With Chronic Atrial Fibrillation. Circulation. 2005;112:3697-706.

147. Dobrev D, Wettwer E, Kortner A, Knaut M, Sch $\tilde{A}^{1 / 4}$ ler S, Ravens U. Human inward rectifier potassium channels in chronic and postoperative atrial fibrillation. Cardiovascular Research. 2002;54:397-404.

148. Swartz MF, Fink GW, Lutz CJ, Taffet SM, Berenfeld O, Vikstrom KL, Kasprowicz K, Bhatta L, Puskas F, Kalifa J, Jalife J. Left versus right atrial difference in dominant frequency, K(+) channel transcripts, and fibrosis in patients developing atrial fibrillation after cardiac surgery. Heart Rhythm. 2009;6:1415-22.

149. Spach MS, Dolber PC. Relating extracellular potentials and their derivatives to anisotropic propagation at a microscopic level in human cardiac muscle. Evidence for electrical uncoupling of side-to-side fiber connections with increasing age. Circ Res. 1986;58:356-71.

150. Ad N, Snir E, Vidne BA, Golomb E. Histologic atrial myolysis is associated with atrial fibrillation after cardiac operation. The Annals of Thoracic Surgery. 2001;72:688-93.

151. Mariscalco G, Engström KG, Ferrarese S, Cozzi G, Bruno VD, Sessa F, Sala A. Relationship between atrial histopathology and atrial fibrillation after coronary bypass surgery. J Thorac Cardiovasc Surg. 2006;131:1364-72.

152. Ak K, Akgun S, Tecimer T, Isbir CS, Civelek A, Tekeli A, Arsan S, Cobanoglu A. Determination of Histopathologic Risk Factors for Postoperative Atrial Fibrillation in Cardiac Surgery. The Annals of Thoracic Surgery. 2005;79:1970-75.

153. Goette A, Juenemann G, Peters B, Klein HU, Roessner A, Huth C, Rocken C. Determinants and consequences of atrial fibrosis in patients undergoing open heart surgery. Cardiovasc Res. 2002;54:390-6.

154. Cosgrave J, Foley JB, Flavin R, O'Briain DS, Fitzpatrick E, Bennett K, Young V, Tolan M, McGovern E. Preoperative atrial histological changes are not associated with postoperative atrial fibrillation. Cardiovascular Pathology;15:213-17.

155. Anné W, Willems R, Roskams T, Sergeant $P$, Herijgers $P$, Holemans $P$, Ector H, Heidbüchel $\mathrm{H}$. Matrix metalloproteinases and atrial remodeling in patients with mitral valve disease and atrial fibrillation. Cardiovascular Research. 2005;67:655-66.

156. Asher CR, Miller DP, Grimm RA, Cosgrovelii DM, Chung MK. Analysis of risk factors for development of atrial fibrillation early after cardiac valvular surgery. The American Journal of Cardiology. 1998;82:892-95. 
157. Kanagaratnam P, Kojodjojo P, Peters NS. Electrophysiological abnormalities occur prior to the development of clinical episodes of atrial fibrillation: observations from human epicardial mapping. Pacing Clin Electrophysiol. 2008;31:443-53.

158. Dupont E, Ko Y, Rothery S, Coppen SR, Baghai M, Haw M, Severs NJ. The gap-junctional protein connexin40 is elevated in patients susceptible to postoperative atrial fibrillation. Circulation. 2001;103:842-9.

159. Steinberg JS, Zelenkofske S, Wong SC, Gelernt M, Sciacca R, Menchavez E. Value of the P-wave signal-averaged ECG for predicting atrial fibrillation after cardiac surgery. Circulation. 1993;88:2618-22.

160. Chandy J, Nakai T, Lee RJ, Bellows WH, Dzankic S, Leung JM. Increases in P-Wave Dispersion Predict Postoperative Atrial Fibrillation After Coronary Artery Bypass Graft Surgery. Anesthesia E Analgesia. 2004;98:303-10.

161. Schotten U, Verheule S, Kirchhof P, Goette A. Pathophysiological Mechanisms of Atrial Fibrillation: A Translational Appraisal. Physiological Reviews. 2011;91:265-325.

162. Benjamin EJ, Levy D, Vaziri SM, D'Agostino RB, Belanger AJ, Wolf PA. Independent Risk Factors for Atrial Fibrillation in a Population-Based Cohort: The Framingham Heart Study. JAMA. 1994;271:840-44.

163. Schnabel RB, Sullivan LM, Levy D, Pencina MJ, Massaro JM, D'Agostino Sr RB, NewtonCheh C, Yamamoto JF, Magnani JW, Tadros TM, Kannel WB, Wang TJ, Ellinor PT, Wolf PA, Vasan RS, Benjamin EJ. Development of a risk score for atrial fibrillation (Framingham Heart Study): a community-based cohort study. The Lancet. 2009;373:739-45.

164. Nakai T, Chandy J, Nakai K, Bellows WH, Flachsbart K, Lee RJ, Leung JM. Histologic Assessment of Right Atrial Appendage Myocardium in Patients with Atrial Fibrillation after Coronary Artery Bypass Graft Surgery. Cardiology. 2007;108:90-96.

165. Kojodjojo P, Kanagaratnam P, Markides V, Davies DW, Peters N. Age-Related Changes in Human Left and Right Atrial Conduction. Journal of Cardiovascular Electrophysiology. 2006;17:120-27.

166. Brembilla-Perrot B, Burger G, Beurrier D, Houriez P, Nippert M, Miljoen H, Andronache M, Khaldi E, Popovic B, De La Chaise AT, Louis P. Influence of Age on Atrial Fibrillation Inducibility. Pacing and Clinical Electrophysiology. 2004;27:287-92.

167. Rensma PL, Allessie MA, Lammers WJ, Bonke FI, Schalij MJ. Length of excitation wave and susceptibility to reentrant atrial arrhythmias in normal conscious dogs. Circ Res. 1988;62: 395-410.

168. Vaziri SM, Larson MG, Benjamin EJ, Levy D. Echocardiographic predictors of nonrheumatic atrial fibrillation. The Framingham Heart Study. Circulation. 1994;89:724-30.

169. Roberts-Thomson KC, Stevenson I, Kistler PM, Haqqani HM, Spence SJ, Goldblatt JC, Sanders P, Kalman JM. The role of chronic atrial stretch and atrial fibrillation on posterior left atrial wall conduction. Heart Rhythm. 2009;6:1109-17. 


\section{Chapter 2}

170. Roberts-Thomson KC, Stevenson IH, Kistler PM, Haqqani HM, Goldblatt JC, Sanders P, Kalman JM. Anatomically Determined Functional Conduction Delay in the Posterior Left Atrium: Relationship to Structural Heart Disease. Journal of the American College of Cardiology. 2008;51:856-62.

171. Verheule S, Wilson E, Everett TIV, Shanbhag S, Golden C, Olgin J. Alterations in Atrial Electrophysiology and Tissue Structure in a Canine Model of Chronic Atrial Dilatation Due to Mitral Regurgitation. Circulation. 2003;107:2615-22.

172. Barasch E, Gottdiener JS, Aurigemma G, Kitzman DW, Han J, Kop WJ, Tracy RP. Association Between Elevated Fibrosis Markers and Heart Failure in the Elderly/CLINICAL PERSPECTIVE. Circulation: Heart Failure. 2009;2:303-10.

173. Li D, Fareh S, Leung TK, Nattel S. Promotion of Atrial Fibrillation by Heart Failure in Dogs: Atrial Remodeling of a Different Sort. Circulation. 1999;100:87-95.

174. L'Allier PL, Ducharme A, Keller P-F, Yu H, Guertin M-C, Tardif J-C. Angiotensin-converting enzyme inhibition in hypertensive patients is associated with a reduction in the occurrence of atrial fibrillation. Journal of the American College of Cardiology. 2004;44:159-64.

175. Shariff N, Zelenkofske S, Eid S, Weiss M, Mohammed M. Demographic determinants and effect of pre-operative angiotensin converting enzyme inhibitors and angiotensin receptor blockers on the occurrence of atrial fibrillation after CABG surgery. BMC Cardiovascular Disorders;10:7.

176. White CM, Kluger J, Lertsburapa K, Faheem O, Coleman CI. Effect of preoperative angiotensin converting enzyme inhibitor or angiotensin receptor blocker use on the frequency of atrial fibrillation after cardiac surgery: a cohort study from the atrial fibrillation suppression trials II and III. European Journal of Cardio-Thoracic Surgery. 2007;31:817-20.

177. Kannel WB, Wolf PA, Benjamin EJ, Levy D. Prevalence, incidence, prognosis, and predisposing conditions for atrial fibrillation: population-based estimates. The American Journal of Cardiology. 1998;82:2N-9N.

178. Buch P, Friberg J, Scharling H, Lange P, Prescott E. Reduced lung function and risk of atrial fibrillation in The Copenhagen City Heart Study. European Respiratory Journal. 2003;21:1012-16.

179. Zhang X, Wu Z, Peng X, Wu A, Yue Y, Martin J, Cheng D. Prognosis of Diabetic Patients Undergoing Coronary Artery Bypass Surgery Compared With Nondiabetics: A Systematic Review and Meta-analysis. Journal of Cardiothoracic and Vascular Anesthesia. 2010.

180. de Vos CB, Pisters R, Nieuwlaat R, Prins MH, Tieleman RG, Coelen R-JS, van den Heijkant AC, Allessie MA, Crijns HJGM. Progression From Paroxysmal to Persistent Atrial Fibrillation: Clinical Correlates and Prognosis. Journal of the American College of Cardiology;55: 725-31.

181. Lopez CM, House-Fancher MA. Management of atrial fibrillation in patients with chronic obstructive pulmonary disease. J Cardiovasc Nurs. 2005;20:133-40. 
POAF, a Maze of Mechanisms 



\section{Chapter 3}

Rearrangement of Atrial

Bundle Architecture and

Consequent Changes in

Anisotropy of Conduction

Constitute the 3-Dimensional

Substrate for Atrial Fibrillation

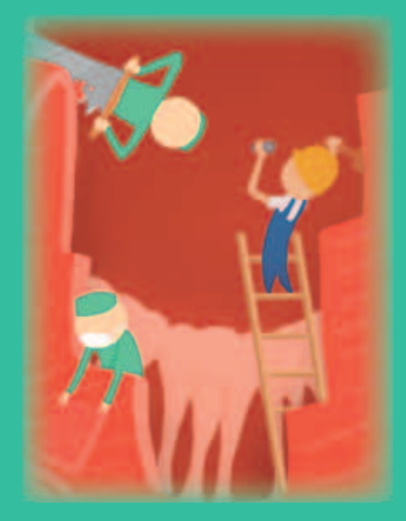

Bart Maesen, Stef Zeemering, Carlos Afonso, Jens Eckstein, Rebecca A.B. Burton, Arne van Hunnik, Daniel J Stuckey, Damian Tyler, Jos Maessen, Vicente Grau, Sander Verheule, Peter Kohl, and Ulrich Schotten.

Published in Circ Arrhythm Electrophysiol. 2013 Oct;6(5):967-75. 


\section{Chapter 3}

\section{Abstract}

Background: Anisotropy of conduction facilitates reentry and is therefore a key determinant of the stability of atrial fibrillation (AF). Little is known about the effect of AF on atrial bundle architecture and consequent changes in anisotropy of conduction and maintenance of AF.

Methods and Results: Direct contact mapping was performed in left atria of goats with acute $(\mathrm{aAF}, \mathrm{n}=6)$ or persistent $\mathrm{AF}$ (persAF, $\mathrm{n}=5)$. Degree and direction of anisotropic conduction were analyzed. Mapped tissue regions were imaged by high-resolution MRI for identification of endocardial and epicardial bundle directions. Correlation between endo- and epicardial bundle directions and between bundle directions and anisotropic conduction were quantified. In persAF, epicardial bundles were oriented more perpendicularly to endocardial bundles than in aAF ( $\%$ angles below $20^{\circ}$ between epicardial and endocardial bundle direction were $7.63 \%$ and $21.25 \%$ respectively, $P<0.01$ ). In aAF, direction of epicardially-mapped anisotropic conduction correlated with endocardial but not with epicardial bundles. In persAF, direction of anisotropic conduction correlated better with epicardial than with endocardial bundle direction ( $\%$ angles below $20^{\circ}$ between direction of anisotropic conduction and bundle direction were $28.77 \%$ and $18.45 \%$ respectively $P<0.01$ ).

Conclusions: During AF, atrial bundle rearrangement manifests itself in more perpendicular orientation of epicardial to endocardial bundles. Propagation of fibrillation waves is dominated by endocardial bundles in aAF and by epicardial bundles in persAF. Together with loss of endo-epicardial electrical connections, rearrangement of atrial bundles underlie endo-epicardial dissociation of electrical activity and the development of a three-dimensional AF substrate. 


\section{Introduction}

Mechanisms perpetuating atrial fibrillation (AF) are incompletely understood. Both in experimental and clinical studies, persistent $\mathrm{AF}$ is sustained by multiple wavelets propagating throughout the atria, ${ }^{1-6}$ but also ectopic focal discharges and localized rotors have been proposed as a dominant activation pattern during AF. ${ }^{7-10}$

In general, heterogeneity in electrophysiological properties promotes multiple wavelet reentry ${ }^{6,11,12}$ In particular, non-uniform anisotropy of conduction facilitates unidirectional block and can cause heterogeneity and local slowing of conduction. ${ }^{11,12}$ Both factors reduce the pathlength for reentry and facilitate initiation and perpetuation of AF. ${ }^{13-17}$ At macroscopic scales, anisotropy of conduction velocity $(\mathrm{CV})$ is surprisingly low both in right $(\mathrm{RA})^{18-21}$ and left atria (LA) ${ }^{22}$ (anisotropy ratio ranges from 1.2 to 3.2). At the microscopic scale, however, conduction is highly anisotropic. ${ }^{11}$ In atrial muscle bundles isolated from young individuals an anisotropy ratio of $\approx 4.5$ was reported which even increased twofold when older patients were studied. ${ }^{13}$

Atrial architecture is highly complex. It not only shows three-dimensional (3D) arrangements of circumferentially and longitudinally orientated muscle bundles, but also sudden transitions in fiber architecture from the endocardial to the epicardial layer. ${ }^{23,24}$ Such transitions may promote conduction block and reentry, especially in the presence of tissue fibrosis. ${ }^{25}$

The exact effects of the atrial bundle architecture on conduction anisotropy during $\mathrm{AF}$, and its changes due to structural remodeling, have not yet been determined. It is important to distinguish anisotropy of conduction velocity (which is based on CV in the various propagation directions) from anisotropy of conduction likelihood (i.e. a parameter based on most frequently encountered propagation direction). The direction of the fastest conduction tends to correspond to local fiber orientation. However, the most frequently encountered propagation direction does not necessarily align with highest CV. In fact, anisotropy of conduction likelihood may reflect not only local fiber orientation, but also the surrounding tissue architecture. Here, we have studied changes in endocardial and epicardial bundle orientation after 7 months of AF in goat LA and their relation to the anisotropic behavior of fibrillation waves. 
Chapter 3

\section{Methods}

\subsection{Open chest experiments and tissue harvesting}

Sham-operated goats with acutely induced $\mathrm{AF}(\mathrm{aAF}, \mathrm{n}=6)$ and goats with $\mathrm{AF}$ persisting for 7 months (persAF, $n=5$ ) were studied (see online supplement for detail). ${ }^{2,45}$ After electrical cardioversion, LA effective refractory periods (AERP) were determined. A square contact mapping array (256 channels, interelectrode distance $1.5 \mathrm{~mm}$, Supplemental Figure 1A) was positioned on the LA wall and conduction during epicardial pacing outside the mapping area near the 4 corners was recorded. AF was re-induced and fibrillation electrograms were recorded for $30 \mathrm{~s}$ (sampling rate $1 \mathrm{kHz}$; filtering bandwidth $0.5-500 \mathrm{~Hz}$ ). Immediately after recording, the mapping array was mechanically fixed exactly at the recording site and tissue deformation was prevented by application of a frame (Figure 1A, see online supplement for detailed description). The sample was stored in Karnovky's fast-acting chemical fixative. ${ }^{26}$

\subsection{Analysis of MRI images}

Original high-resolution 3D magnetic resonance imaging (MRI) data-sets (acquisition details and example movie in online supplement) were reconstructed to yield a stack of $2 \mathrm{D}$ images in a plane parallel to the epicardial recording surface (Figure 1B) and used to determine the direction of endocardial bundles and epicardial fibers (Figure 1C+D). A 16x16 grid, spaced to contain one recording electrode each in the center of any grid-square, was overlaid on these $2 \mathrm{D}$ reconstructions. For each electrode position, the orientation of the endocardial and epicardial bundle within that square was determined. Squares not containing tissue were excluded from analysis. Only MRI images located within less than $220 \mu \mathrm{m}$ of the epicardial boundary were used for epicardial bundle identification.

\subsection{Quantification of anisotropy}

\section{Anisotropy of conduction during $A F$}

Epicardial unipolar fibrillation electrogram recordings (4s) were analyzed using a wave mapping algorithm (see online supplement) described previously. ${ }^{1,3,4}$ Anisotropic behavior is defined as 'the property of being directiondependent'. In order to study anisotropic conduction of fibrillation waves, two types of anisotropy were distinguished. 

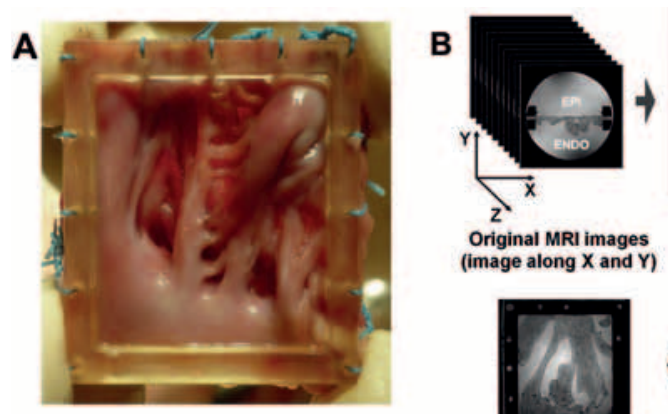

Original MRI images
(image along $X$ and $Y$ )
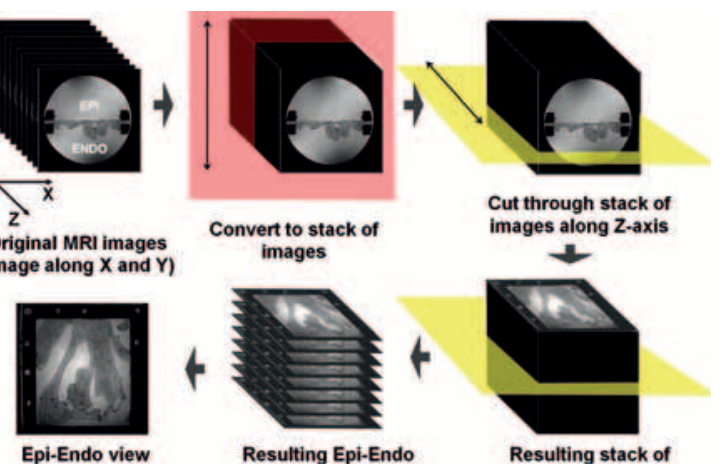
images along $\mathrm{Z}$-axis images
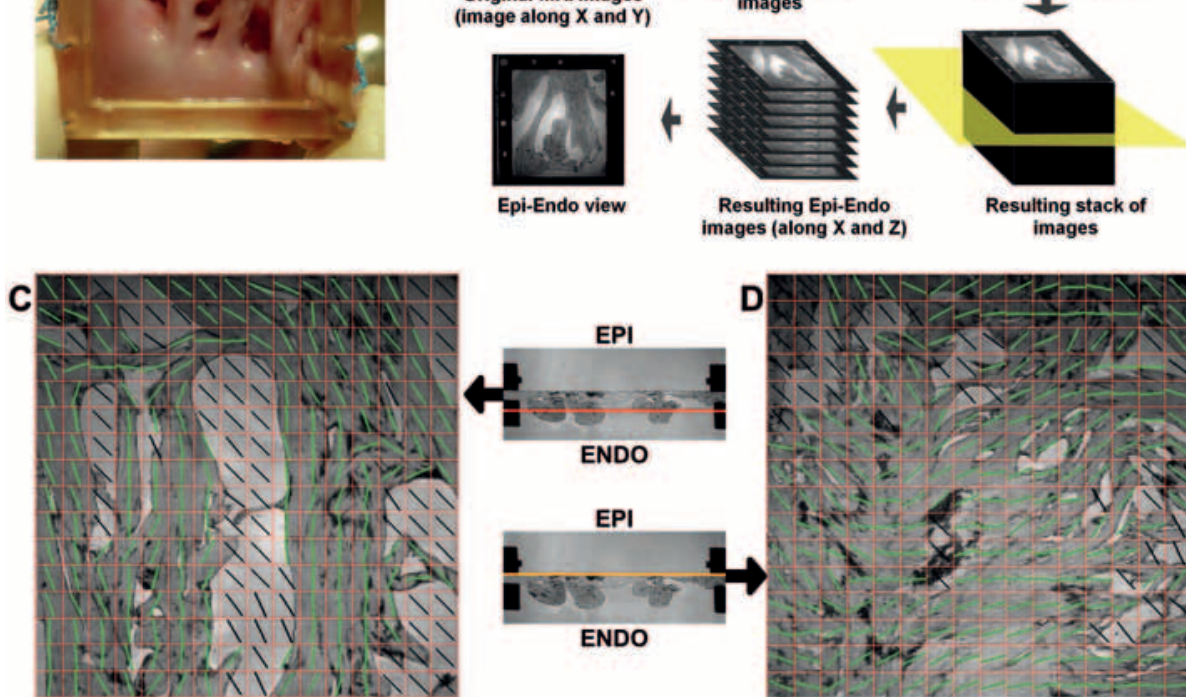

Figure 1.

A. Endocardial aspect of the recording location of the mapping array. Atrial tissue is mechanically fixed between transparent frame and counter-frame via sutures (blue). Note the endocardial bundle network.

B. Processing of MRI images. Original MRI images are converted to a stack of images, allowing reconstruction of an epicardial to endocardial view.

C, D. Identification of endocardial and epicardial bundle direction. Grid (red) represents the mapping array, each square within the grid represents 1 electrode. In each square, a green marker line indicates endocardial or epicardial bundle direction. Black lines indicate that no direction can be determined or no structure is defined for that square. Large in-plane image sections through the MRI data are used for determination of endocardial (C) and epicardial (D) bundle direction. Small images indicate the plane through the endocardial and epicardial region used for analysis.

First, we determined anisotropy of $C V$ (i.e. fastest versus slowest propagation direction). This was characterized by degree of anisotropy CV (i.e. the ratio between the long axis and the short axis of the ellipse fitted through local conduction vectors) and direction of anisotropy CV (i.e. the direction of fastest 


\section{Chapter 3}

propagation). Secondly, we determined anisotropy of conduction likelihood (i.e. the most frequent versus the least frequent propagation direction). This was characterized by degree of anisotropy of conduction likelihood (i.e. the degree of spread of propagation directions) and direction of anisotropy of conduction likelihood (i.e. the most frequently observed propagation direction). See online supplement for a detailed description of anisotropy calculation.

\section{Anisotropy of conduction during pacing}

Pacing (200ms cycle length) was performed outside each of the 4 corners of the mapping array. Due to hemodynamic instability, pacing was not possible in 1 persAF goat. For each pacing site $(n=4), 4$ consecutive beats were analyzed. All analyzed beats $(n=16)$ were merged per goat and the degree and direction of anisotropy of CV was determined by ellipse fitting. Because the pacing location dictated the conduction direction, the degree of anisotropy of conduction likelihood was not calculated.

\section{Heterogeneity of conduction anisotropy and of bundle orientation}

To quantify and compare the organization of the two types of anisotropy, a heterogeneity index (HI) was calculated. For each electrode, the mean absolute angle difference between the direction of anisotropy of CV or anisotropy of conduction likelihood at that electrode and the directions of anisotropy of CV or anisotropy of conduction likelihood at its 8 surrounding electrodes was determined. The HI was calculated as the mean of all absolute angle differences. The same HI calculation was used to quantify organization of epicardial and endocardial bundle orientation.

\subsection{Directional coherence between electrophysiological and structural data}

To assess the relationship between electrophysiological and structural data, directions of anisotropy of $\mathrm{CV}$ and anisotropy of conduction likelihood were compared with the directions of endocardial bundles and epicardial fibers, both in aAF and persAF. For quantitative analysis, angle differences were pooled within the aAF group and within the persAF group. Only absolute angle differences between 2 directions were used for analysis, so that the minimal and maximal angle difference between two compared directions equal $0^{\circ}$ and $90^{\circ}$, respectively. For each comparison, the mean angle difference was calculated. As a metric, the ratio $\left[\mathbf{R}_{\mathrm{N}}=\mathrm{N}_{\text {SMall angle differences }\left(0^{\circ}-20^{\circ}\right)} /\left(\mathrm{N}_{\text {SMall angle differences }\left(0^{\circ}-20^{\circ}\right)}\right.\right.$ $\left.+\mathrm{N}_{\text {LARGE ANGLe DifferenCes }\left(70^{\circ}-90^{\circ}\right)}\right)$ ] was calculated to quantify directional correlation. 


\subsection{Statistical analysis}

Data are expressed as mean \pm SD. Significance of differences in means between aAF and persAF was assessed using an unpaired Student's $t$-test. As angle differences were pooled for aAF and persAF, a mixed-effect analysis of variance was performed to test for significance of differences in mean angle differences, using a linear model with fixed effect aAF or persAF and random effect the goat the angle difference belonged to. To test for the presence of a uniform distribution of angle differences between two directions $\left(P_{\text {uniform }}\right)$, a Kolmogorov-Smirnov test was used. There was no adjustment for multiple comparisons. $P$-values $<0.05$ were considered statistically significant.

\section{Results}

\subsection{AF substrate complexity}

AERP (at cycle lengths above 250ms, Figure 2) as well as AFCL (Table 1) were significantly shorter in persAF than in aAF. Further electrophysiological parameters characterizing the AF substrate are listed in table 1 . As expected, ${ }^{4,5}$ the number of fibrillation waves and breakthroughs per second were higher in persAF compared to aAF, while $\mathrm{CV}$ and width of the fibrillation waves were lower. Figure 3 shows representative wave maps and electrograms of aAF and persAF. In aAF (Figure 3A), a single 'AF cycle' consists of only a few simultaneous waves, with no or few epicardial breakthroughs occurring. However in pers AF (Figure 3C), a single 'AF cycle' consists of multiple waves simultaneously present, and the occurrence of several breakthroughs. Furthermore, electrograms in persAF show more fractionation than in aAF. These results indicate the presence of a more complex $\mathrm{AF}$ substrate in the persAF group.

Table 1. Overview of AF substrate parameters. ${ }^{*} P \leq 0.05,+P<0.001$ aAF vs. pers $A F$.

\begin{tabular}{|c|c|c|c|c|c|}
\hline & $\begin{array}{l}\text { AF Cycle } \\
\text { Length (ms) }\end{array}$ & $\begin{array}{l}\text { Breakthroughs } \\
\text { per s }\end{array}$ & $\begin{array}{l}\text { Fibrillation Waves } \\
\text { per s }\end{array}$ & $\begin{array}{l}\text { Width of Fibrillation } \\
\text { Waves }(\mathrm{mm})\end{array}$ & $\begin{array}{l}\text { Conduction } \\
\text { velocity }(\mathrm{cm} / \mathrm{s})\end{array}$ \\
\hline $\operatorname{aAF}(n=6)$ & $127 \pm 15$ & $7.4 \pm 4.2$ & $41.0 \pm 14.4$ & $8.0 \pm 2.0$ & $62.6 \pm 9.04$ \\
\hline persAF $(n=5)$ & $103 \pm 20^{*}$ & $32.7 \pm 10.0 \dagger$ & $101.6 \pm 27.0 \dagger$ & $5.9 \pm 0.9^{*}$ & $53.7 \pm 6.9^{*}$ \\
\hline
\end{tabular}


Chapter 3

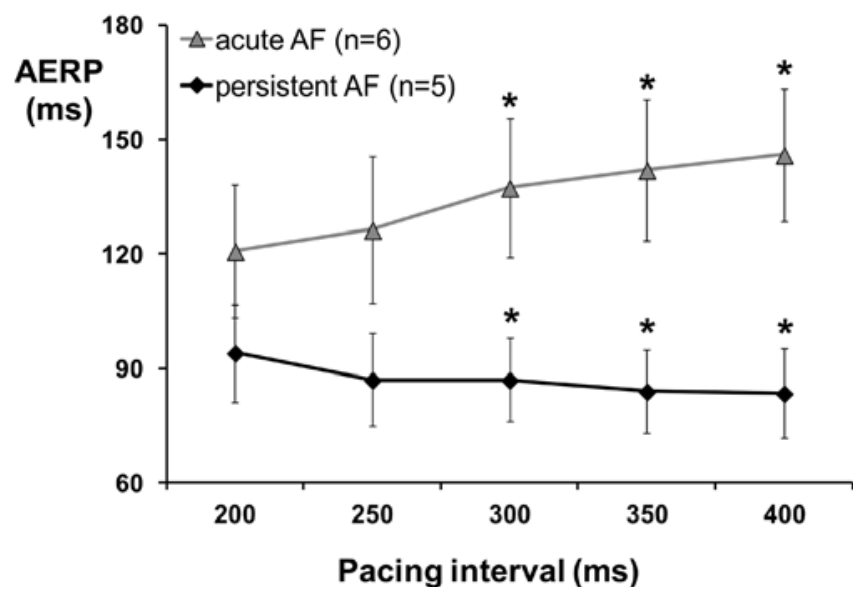

Figure 2. Atrial refractory period measurements (AERP) at different pacing cycle lengths for aAF and pers $A F$. ${ }^{*} P<0.05$ between $a A F$ and pers $A F$.

\subsection{Degree of anisotropy of conduction}

The degree of anisotropy of CV and anisotropy of conduction likelihood during pacing and AF is summarized in supplemental table 1 . During pacing, no significant differences were present in anisotropy of $\mathrm{CV}$ between aAF and persAF. Also during AF, anisotropy of $\mathrm{CV}$ was comparable in both groups. Degree of anisotropy of conduction likelihood, however, was significantly lower in persAF compared to aAF.

To study the relationship between the two aspects of anisotropic conduction, the angle differences between the fastest (direction of anisotropy of CV) and the most frequent direction (direction of anisotropy of conduction likelihood) are depicted in two rose diagrams (supplemental Figure 4). In aAF and persAF, no clear correlation between the two directions was found (both $\mathbf{R}_{\mathrm{N}}$ close to 0.5, i.e. small and large angle differences were equal in frequency), but the distribution was more uniform in aAF than in persAF $\left(P_{\text {uniform }}=0.22 \mathrm{vs}\right.$. $\left.P_{\text {uniform }}=0.02\right)$. Mean angle differences between both anisotropic directions were not different between aAF and persAF (Table 2).

\subsection{Endocardial versus epicardial bundle orientation}

To study whether AF-related remodeling is accompanied by changes in atrial bundle orientation, the direction of endocardial bundles was compared with 


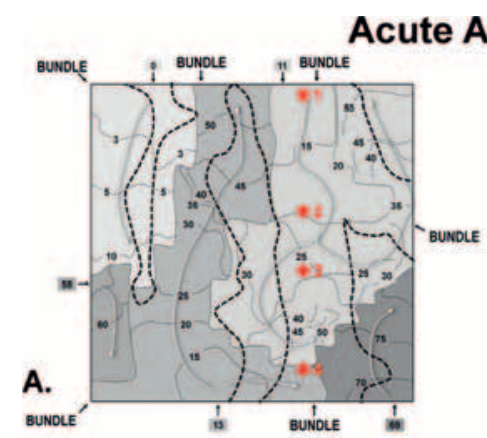

B.
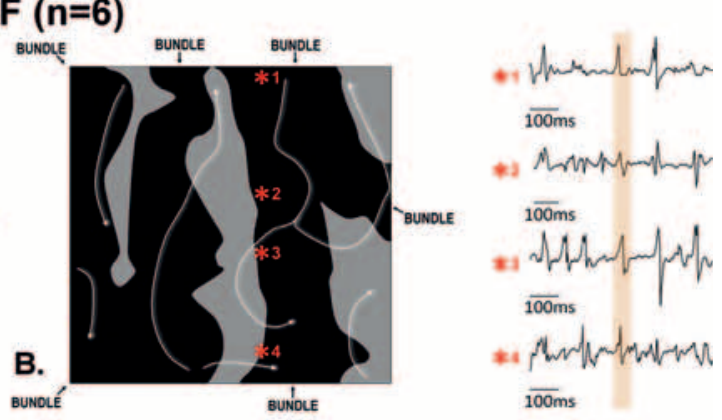

\section{Persistent AF ( $n=5)$}

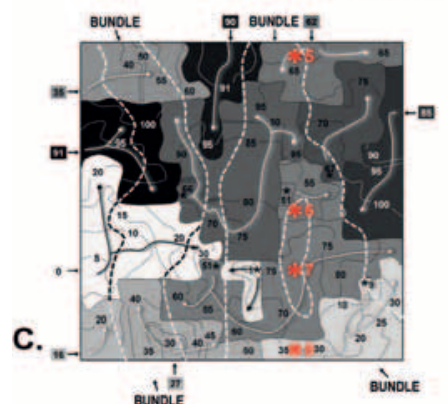

D.

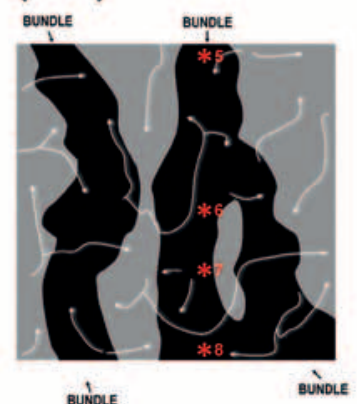

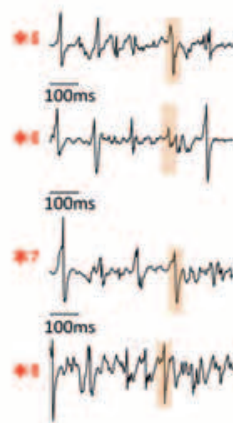

Figure 3. Representative maps and corresponding electrograms of a $A F(A, B)$ and pers $A F(C, D)$. $A$ and $C$. Representative isochrone maps of 1 beat of aAF $(A)$ and 1 beat of pers $A F(C)$. The area is activated by 5 waves in aAF $(A)$ and 13 waves in pers $A F(C)$, identified using shades of gray. Dotted lines indicate underlying endocardial bundles; arrows indicate direction of propagation. Peripheral waves are indicated by arrows. Black asterisks indicate epicardial breakthroughs. Corresponding electrograms and their location on the map (red asterisk) are depicted for aAF $\left({ }^{*} 1-{ }^{*} 4\right)$ end pers $A F\left({ }^{*} 5-{ }^{*}\right)$. As more waves are simultaneously present in pers AF compared to $a A F$, electrograms in pers $A F\left(e . g .{ }^{*} 8\right)$ show more fractionation (fractionation representing activation of surrounding waves picked up by the electrode) than electrograms in aAF (e.g. $\left.{ }^{*} 1\right)$. $B$ and D. Same maps as in $A$ and $C$ with only endocardial bundles (black) and direction of wave propagation (white arrows). In aAF, direction of propagation is mainly dominated by endocardial bundles (B). In pers $A F$, this anatomical agreement between direction of propagation and endocardial bundle pattern is lost (D).

direction of epicardial fibers in aAF and persAF (Figure 4). In aAF, endocardial bundle orientation often showed large angles to epicardial bundle orientation $\left(\mathbf{R}_{\mathrm{N}}=0.44, P_{\text {uniform }}<0.001\right.$, Figure $\left.4 \mathrm{~A}\right)$. In the persAF group, however, this was significantly more pronounced with an even larger fraction of large angles $\left(\mathbf{R}_{\mathrm{N}}=0.19, P_{\text {uniform }}<0.001, P<0.05\right.$ vs. aAF, Figure $\left.4 \mathrm{~B}\right)$, indicating that epicardial 
Chapter 3

Acute AF $(n=6)$

A.

\section{Epicardial fibers versus} endocardial bundles

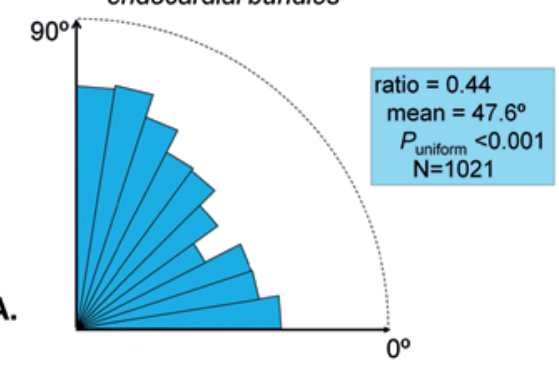

\section{Persistent AF ( $n=5)$}

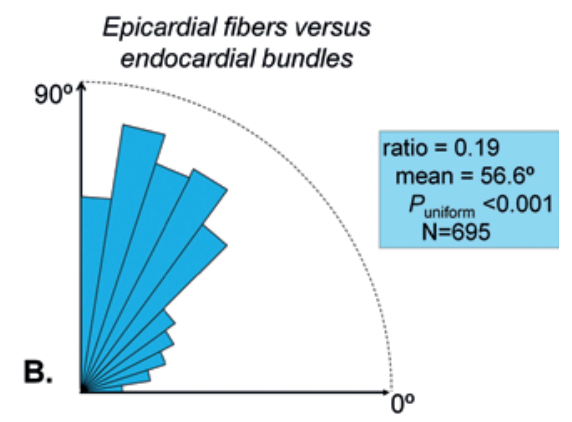

C.

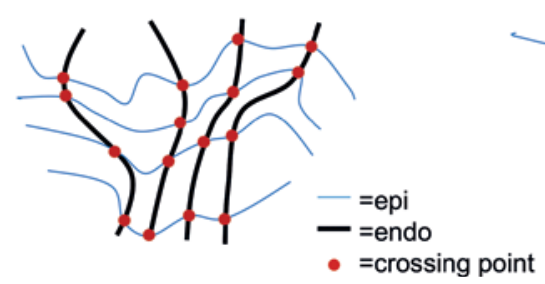

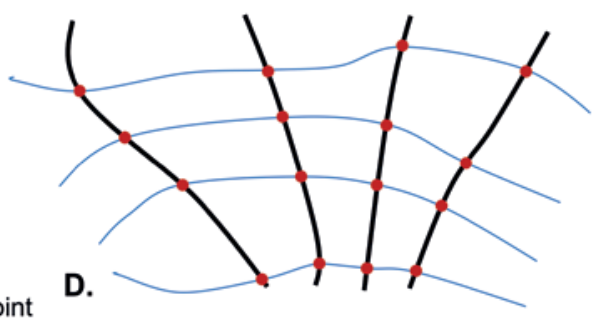

Figure 4. Spread of absolute angle differences (range $0^{\circ}$ to $90^{\circ}$ ) between direction of epicardial and endocardial bundles during $a A F(A)$ and pers $A F(B)$, see results 3.3 for explanation. Schematic representation of endocardial and epicardial bundles in $A A F(C)$ and pers $A F(D)$, see discussion 4.2 for explanation. Ratio=ratio small angle differences/(small + large angle differences); mean=mean angle difference; $P_{\text {uniform }}=$ test for uniform distribution, $N=$ number of observations.

bundles were oriented more perpendicularly to endocardial bundles than in aAF (see table 2 for mean angle differences and see supplemental results).

\subsection{Relation of anisotropy to tissue substrate}

All angle differences between the direction of anisotropy of $\mathrm{CV}$ and the direction of the endocardial and epicardial bundles are plotted in Figure 5 (A-D). In aAF, the direction of anisotropy of $\mathrm{CV}$ corresponded well with endocardial bundle direction $\left(\mathbf{R}_{\mathrm{N}}=0.67 ; P_{\text {uniform }}<0.001\right)$, while there was no correlation with the epicardial fiber direction $\left(\mathbf{R}_{\mathrm{N}}=0.54 ; P_{\text {uniform }}=0.08\right)$. In contrast, in persAF the direction of anisotropy of $\mathrm{CV}$ correlated better with epicardial bundle direction $\left(\mathbf{R}_{\mathrm{N}}=0.66 ; P_{\text {uniform }}<0.001\right)$, and was oriented predominantly perpendicularly to the endocardial bundle direction $\left(\mathbf{R}_{\mathrm{N}}=0.34 ; P_{\text {uniform }}<0.01\right)$.

The same analysis was performed for direction of anisotropy of conduction likelihood (Figure 5; E-H). For aAF, direction of anisotropy of conduction 
Table 2. Mean angle differences for comparison of different directions

\begin{tabular}{|c|c|c|c|}
\hline & $\mathrm{aAF}(\mathrm{n}=6)$ & persAF $(n=5)$ & $P$-value \\
\hline $\begin{array}{l}\text { Directions of anisotropy of conduction } \\
\text { velocity vs anisotropy of conduction } \\
\text { likelihood }\end{array}$ & $44.5^{\circ} \pm 26.4^{\circ}$ & $47.3^{\circ} \pm 27.0^{\circ}$ & 0.51 \\
\hline \multirow[t]{2}{*}{$\begin{array}{l}\text { Directions of epicardial fibers } \\
\text { vs endocardial bundles }\end{array}$} & $47.6^{\circ} \pm 26.8^{\circ}$ & $56.6^{\circ} \pm 21.9^{\circ}$ & $<0.01$ \\
\hline & $\begin{array}{l}\text { Directions of Anisotropy } \\
\text { vs Endocardial Bundles }\end{array}$ & $\begin{array}{l}\text { Directions of Anisotropy } \\
\text { vs Epicardial Bundles }\end{array}$ & $P$-value \\
\hline $\begin{array}{l}\text { aAF values for anisotropy } \\
\text { of conduction velocity }\end{array}$ & $38.3^{\circ} \pm 26.2^{\circ}$ & $43.4^{\circ} \pm 26.5^{\circ}$ & $<0.01$ \\
\hline $\begin{array}{l}\text { persAF values for anisotropy } \\
\text { of conduction velocity }\end{array}$ & $51.5^{\circ} \pm 26.4^{\circ}$ & $39.9^{\circ} \pm 26.1^{\circ}$ & $<0.01$ \\
\hline $\begin{array}{l}\text { aAF values for anisotropy } \\
\text { of conduction likelihood }\end{array}$ & $39.2^{\circ} \pm 25.7^{\circ}$ & $44.2^{\circ} \pm 25.7^{\circ}$ & $<0.01$ \\
\hline $\begin{array}{l}\text { persAF values for anisotropy } \\
\text { of conduction likelihood }\end{array}$ & $46.7^{\circ} \pm 24.9^{\circ}$ & $42.2^{\circ} \pm 25.0^{\circ}$ & $<0.01$ \\
\hline
\end{tabular}

\section{Acute AF $(n=6)$}
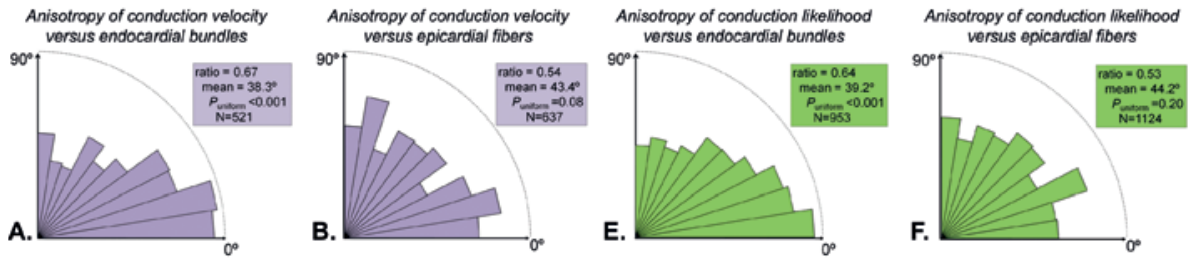

\section{Persistent AF $(n=5)$}
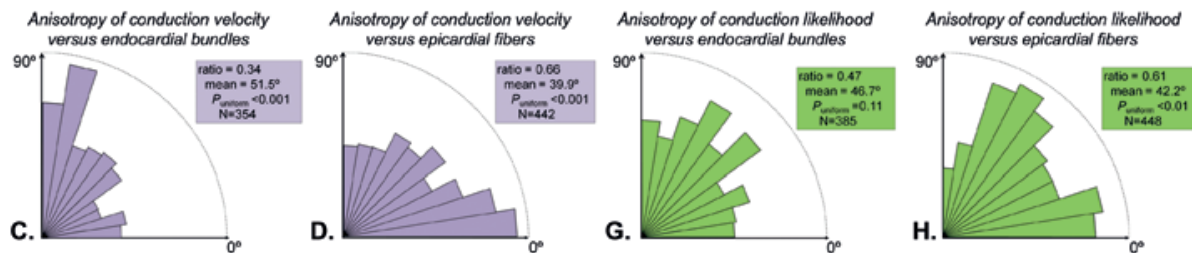

Figure 5. Spread of absolute angle differences (range $0^{\circ}$ to $90^{\circ}$ ) between anisotropy of $C V(A-D)$ or anisotropy of conduction likelihood $(E-H)$ and endocardial or epicardial bundle orientation. Data for aAF $(A, B, E, F)$ and for pers $A F(C, D, G, H)$. Ratio=ratio small angle differences/(small + large angle differences); mean= mean angle difference; $P_{\text {uniform }}=$ test for uniform distribution, $N=$ number of observations. See text for further explanation. 
likelihood corresponded with the direction of the endocardial bundles $\left(\mathbf{R}_{\mathrm{N}}=0.64 ; P_{\text {uniform }}<0.001\right)$. There was no relation with the epicardial fiber direction $\left(\mathbf{R}_{\mathrm{N}}=0.53 ; P_{\text {uniform }}=0.20\right)$. In the persAF group, direction of anisotropy of conduction likelihood showed no relationship with the endocardial bundle direction $\left(\mathbf{R}_{\mathrm{N}}=0.47 ; P_{\text {uniform }}=0.11\right)$, but a good correlation with epicardial fiber direction $\left(\mathbf{R}_{\mathrm{N}}=0.61 ; P_{\text {uniform }}<0.01\right.$, see table 2 for mean angle differences).

\subsection{Heterogeneity in anisotropy of conduction and bundle anatomy}

In supplemental Figure 5, example maps of anisotropy of CV and anisotropy of conduction likelihood are given (dark to light color indicates increasing anisotropy). The local direction of both types of conduction anisotropy is indicated by arrows (light blue). The corresponding $\mathrm{HI}$ and the $\mathrm{HI}$ of the endocardial and epicardial bundle patterns are summarized in supplemental table 2. No significant differences in HI of anisotropy of CV and in HI of anisotropy of conduction likelihood were found between aAF and persAF. However, the HI of anisotropy of conduction likelihood was significantly lower than the HI of anisotropy of CV for both groups. The HI of the epicardial bundle pattern was higher than the HI of the endocardial bundle pattern for persAF, not for aAF.

\section{Discussion}

AF persistence goes hand in hand with an increasing complexity in the fibrillatory process. ${ }^{1-6}$ With AF remodeling, the number of fibrillation waves and transmural conduction (epicardial breakthrough) increases, resulting in more complex AF propagation patterns (see Figure 3). ${ }^{2-4}$ Anisotropy of conduction is arrhythmogenic, contributing to both initiation and perpetuation of AF. ${ }^{12-16,20}$ Nevertheless, studies addressing the roles of the complex 3D atrial anatomy in fibrillatory conduction during AF are scarce. Our study demonstrates that during several months of AF in the goat, differences in endo-epicardial bundle direction increase. In non-remodeled atria, epicardial fibrillation waves propagated fastest along the direction of endocardial bundles, with little influence of epicardial fiber orientation on $\mathrm{CV}$ and conduction likelihood of epicardial fibrillation waves. In structurally remodeled atria however, epicardial fibrillation waves conducted fastest along epicardial fibers, presumably because of endo-epicardial dissociation (EED) of electrical activity and 3D conduction during $\mathrm{AF}$. 


\subsection{Anisotropy of CV}

Low epicardial macroscopic anisotropy of $\mathrm{CV}$ during sinus rhythm and pacing has been reported in experimental and clinical studies. ${ }^{18,19,21,22,27}$ Also here, epicardial macroscopic anisotropy of CV in goat LA free wall was low during pacing (mean anisotropy ratio was 1.7 in non-remodeled atria and 1.9 in remodeled atria).

Houben et al. reported low anisotropy of $\mathrm{CV}$ in the human RA during AF (median 1.2). ${ }^{20}$ Here, we also report low macroscopic anisotropy of $\mathrm{CV}$ during AF. To our surprise, the anisotropy ratio was similar in both remodeled and non-remodeled atria (mean 1.5), indicating that an increase in anisotropy of $\mathrm{CV}$ as such is not required to enhance AF stability in remodeled goat atria. Epicardial anisotropy of $\mathrm{CV}$ varies between regions in the atria, partly because of differences in underlying histo-anatomy. For example, epicardial activation in the LA free wall is relatively uniform with anisotropy ratios of 1.4 to $1.5 .^{27}$ Most of the LA endocardium consists of a smooth wall composed of overlapping layers of differently aligned myocardial fibers, with major changes in fiber orientation from the epicardial to the endocardial surface. ${ }^{23,24}$ In contrast, epicardial propagation in the posterior LA exhibits marked CV anisotropy, ranging from 1.8 to $3.2{ }^{1,4,22,25}$ The posterior LA wall is dominated by the septopulmonary bundle, where the muscle strands tend to follow a predominant direction. ${ }^{23,24,28}$ Overall, regional variability in fiber orientation together with tight electrical coupling between the fibers leads to a lower degree of anisotropy when conduction is observed on a macroscopic scale.

Interestingly, there is a pronounced discrepancy between these macroscopic findings and reports of high anisotropy at the microscopic level, ${ }^{13,16}$ which ranges from 4.5 to $9.8 .{ }^{13}$ Spach et al. were the first to demonstrate highly anisotropic propagation in human atrial bundles..$^{13}$ Development of microscopic collagenous septa ${ }^{13}$ but also redistribution of gap junctions toward cellends ${ }^{16}$ lead to reduced lateral electrical coupling between myocytes, leading to tortuous conduction pathways in the transverse direction while the longitudinal conduction may be unaffected.11-16 Moreover, fibrosis-induced tissue discontinuities can cause electrical source-to-sink mismatch along these pathways, contributing to rate-dependent local slowing of conduction or conduction block. ${ }^{14}$ Finally, AF can be associated with fibroblast proliferation and differentiation into myofibroblasts. ${ }^{29}$ Heterocellular electrotonic coupling of (myo-)fibroblasts and myocytes has been shown in native atrial tissue, ${ }^{30}$ and 
is thought to increase heterogeneity in excitability, refractoriness and electrical load ${ }^{31}$ potentially inducing heterogeneous slowing of conduction. ${ }^{32}$ These mechanisms may also contribute to microscopic 'zigzag' conduction allowing reentry to occur in regions as small as $1-2 \mathrm{~mm}^{2},{ }^{13,16}$ largely facilitating reentrant arrhythmias. ${ }^{12,15-17}$

\subsection{Rearrangement of bundle anatomy and direction of fastest conduction}

With the transition of aAF to persAF, the orientation differences between epicardial and endocardial bundles in goats become larger. This alteration in atrial bundle architecture might be related to progressive atrial dilatation, occurring during prolonged $\mathrm{AF}$ in humans ${ }^{33}$ and in goats (as much as $~ 12 \%$ dilatation during the first 5 days). ${ }^{34}$ Chronic atrial dilatation and stretch in fibrillating atria are caused by an elevation of LA pressure and increased wall stress, ${ }^{6,33}$ and loss of atrial contractility resulting in enhanced atrial compliance. $^{34}$ As shown in the schematic drawing of Figure $4 \mathrm{C}+\mathrm{D}$, atrial dilatation itself may lead to a rotation of epicardial fibers with respect to endocardial bundles, leading to a more perpendicular arrangement. This change would be most likely to occur in the thin epicardial layer, rather than in the endocardial bundles which are relatively thick and firmly anchored to the macro-anatomy.

Atrial bundle rearrangement has consequences for the observed behavior of fibrillation waves. The alignment of direction of anisotropy of CV with the endocardial and epicardial bundle directions showed marked differences in aAF and persAF. In non-remodeled atria, the direction of the fastest conduction was mainly dominated by the direction of the endocardial bundles (Figure 5A), in agreement with previous studies demonstrating that lines of block occur parallel to pectinate muscles in sheep ${ }^{18}$ and rabbit. ${ }^{27}$ This suggests that the overall activation pattern is mainly determined by the endocardial bundle network, and that this network is electrically well connected to the epicardial layer.

However, after 7 months of AF, the direction anisotropy of $\mathrm{CV}$ is primarily determined by the epicardial fiber orientation (Figure 5D). Earlier studies from our group demonstrated that perpetuation of $\mathrm{AF}$ in goat is associated with increased heterogeneity in connexin 40 expression, an increase in inter-myocyte distance (endomysial fibrosis) and myocyte hypertrophy., $4,27,35,36$ Increased interstitial fibrosis underlies electrical uncoupling of side-to-side connections between neighboring muscle bundles, ${ }^{13}$ potentially leading to 
electrical dissociation within the epicardial layer, ${ }^{1,3,4}$ but more importantly between the epicardial layer and the endocardial bundle network. ${ }^{5}$ This is in keeping with a recent report by Verheule et al. showing that AF-induced endomysial fibrosis is much more pronounced in the outer millimeter of the atrium than in the deeper layers. ${ }^{35}$ In this study, a computer simulation of endo-epicardial dissociation and conduction showed that fibrosis exclusively occurring in the epicardial layer was sufficient to increase electrical dissociation and the complexity of AF. ${ }^{35}$

\subsection{Putative AF Mechanisms and atrial anatomy}

While the role of ectopic activity originating in the pulmonary veins is well established as a mechanism of paroxysmal $\mathrm{AF}^{37}$ persistent $\mathrm{AF}$ mechanisms are still under debate. Both experimental and human studies suggest rotors and ectopic activity to drive persistent $A F .^{7-10}$ However, detailed high-density direct contact mapping studies in goat and man identified multiple wavelets, increasing longitudinal dissociation and transmural conduction (epicardial breakthrough) as dominant AF mechanisms.$^{1-5}$ In these studies, stable rotors were rare and not sustained, and breakthroughs were largely due to transmural conduction rather than to ectopic activity. ${ }^{1,2}$ The present study was not designed to clarify the mechanism of AF. Rather our data give insight into how bundle anatomy affects fibrillatory conduction in the atria independent of the mechanism driving AF.

So far, studies relating AF propagation to the underlying 3D atrial anatomy are scarce. Dyssynchrony of electrical activation between the epicardial and the endocardial layer was first demonstrated by Schuessler et al..$^{38}$ Interestingly, the observed electrical endo-epicardial differences were larger in the thick trabeculated part of the RA. Eckstein et al. confirmed these findings and reported that EED increases with AF-induced remodeling. ${ }^{5}$ Yamazaki et al. performed simultaneous epi/endocardial optical mapping and identified 'atrial scroll waves', transmural rotors that form and meander around regions of sharp transition in myocardial thickness, suggesting that wall thickness variability is an important factor for AF stabilization. ${ }^{8}$ Also in humans, fibrillatory conduction is believed to be influenced by the underlying anatomy. Allessie et al. reported interwave conduction block to be predominantly oriented parallel to the large pectinate bundles. ${ }^{1}$ Narayan et al. suggested sustained rotors and repetitive focal beats as drivers of $\mathrm{AF}$, however the relation with underlying atrial anatomy has not been studied yet. ${ }^{7}$ Our results may help to 


\section{Chapter 3}

better understand the relation between fibrillatory conduction and 3D atrial anatomy. In non-remodeled atria with extensive coupling between all layers, the large endocardial bundles prevail over thin epicardial fibers as pathways for fastest propagation of fibrillation waves. In remodeled atria, in contrast, loss of endo-epicardial coupling due to structural remodeling allows epicardial fibrillation waves to primarily propagate along the epicardial muscle bundles. As during the process of AF the latter become oriented more perpendicularly to the endocardial muscle bundles, epicardial fibrillation waves also preferentially propagate perpendicularly to the endocardial muscle bundles. Because endocardial fibrillation waves conduct along the large muscle bundles, the change in the atrial bundle architecture further enhances EED and thereby the 3D character of the histo-anatomical AF substrate.

\subsection{The relation between the two aspects of conduction anisotropy}

Anisotropy of conduction likelihood provides an additional measure of conduction anisotropy. In our study, the degree of anisotropy of conduction likelihood was strongly reduced in goats with persAF compared to goats with aAF. This observation is in agreement with the increase in complexity of AF propagation patterns over time as reported in this study and others. ${ }^{1,2,45}$ As more and narrower waves simultaneously meander over the epicardial surface, preferential pathways are less likely to coexist.

Intuitively, it may appear obvious that the direction of the fastest conduction would also be the most frequently encountered conduction direction. However, neither in aAF nor in persAF a strong correlation between the direction of the fastest and the most likely conduction was found. Potentially this is due to the low HI of anisotropy of conduction likelihood. As such, no strong correlation between the direction of anisotropy of conduction likelihood at a certain electrode and the surrounding electrodes exists. In contrast, the HI of anisotropy of $\mathrm{CV}$ is two to three times higher than the $\mathrm{HI}$ for anisotropy of conduction likelihood and - more importantly - comparable to the HI of epicardial fiber orientation. This supports the hypothesis that conduction likelihood depends more on the macroscopic atrial anatomy while CV is determined by microscopic fiber orientation. In agreement with this, we found the correlation between the direction of fastest conduction with the underlying bundle direction to be larger than the match between the direction of bundles and most likely conduction. 


\subsection{Limitations}

Caution is warranted when extrapolating results regarding the relationship between conduction anisotropy and atrial anatomy from goat to human. For example, human RA shows a strongly parallel orientation between endocardial bundles while in goat RA endocardial trabeculae follow highly variable directions. However, we believe that our general conclusions still hold. These include the observation that endocardial bundle anatomy and epicardial fiber orientation are important determinants of both the velocity and the likelihood of conduction of fibrillation waves, and that the extent and the directionality of conduction anisotropy may change with progressive structural remodeling of the atria and electrical dissociation.

\section{Clinical Relevance}

Although this study focuses on the relation between atrial bundle orientation and anisotropy of conduction, the general conclusions are relevant for clinical practice, in particular the mechanisms contributing to domestication of persAF.

\section{Relevance of the 3D substrate}

We propose that inter-individual differences in AF substrate, as observed in humans, ${ }^{1}$ are partly caused by differences in tissue architecture and thus that in an individual patient, AF characteristics are also determined by the unique underlying atrial anatomy.

\section{Relevance for computer modeling of $A F$}

It is obvious that the strong influence of the underlying atrial anatomy on fibrillatory conduction demonstrated in this study is relevant for the development of computer models of AF, and vice versa (as predictions from structure to function benefit immensely from quantitative modeling). Our data show that not only electrophysiological characteristics, but also a detailed anatomy of endocardial and epicardial muscle bundles should be implemented in realistic computer models for AF, in particular if they are to be 'individualized'. 
Chapter 3

\section{Clinical Perspective}

The architecture of the atrial wall is highly complex and characterized by thick trabeculated endocardial bundles branching out into a thin subepicardial layer. The identified correlation between the atrial bundle anatomy and the atrial fibrillatory conduction pattern has several clinical implications. In particular, our observations help to understand the occurrence of endo-epicardial dissociation of electrical activity and transmural conduction during atrial fibrillation (AF). The study provides evidence that endocardial bundle anatomy and epicardial fiber orientation are important determinants of anisotropic conduction of fibrillation waves. As in remodelled atria epicardial bundles are oriented perpendicular to the larger endocardial bundles fibrillation waves follow different paths in the two layers. Moreover, observed interindividual differences in AF substrates in man can partly be attributed to differences in the individual atrial anatomy, next to differences in electrophysiological properties, clinical risk factors or remodeling-induced structural alterations such as fibrosis. Finally, our study stresses the importance of implementing a detailed anatomy of endocardial and epicardial muscle bundles in computer models for $\mathrm{AF}$, at least if these models are developed for prediction of the efficacy of antiarrhythmic drug therapy or $\mathrm{AF}$ ablation. 


\section{Anatomy and Anisotropy of AF Conduction}

\section{References}

1. Allessie MA, de Groot NM, Houben RP, Schotten U, Boersma E, Smeets JL, Crijns HJ. Electropathological substrate of long-standing persistent atrial fibrillation in patients with structural heart disease: longitudinal dissociation. Circ Arrhythm Electrophysiol. 2010;3:606-615.

2. Eckstein J, Zeemering S, Linz D, Maesen B, Verheule S, van Hunnik A, Crijns H, Allessie MA, Schotten U. Transmural Conduction is the Predominant Mechanism of Breakthrough during Atrial Fibrillation: Evidence from Simultaneous Endo-epicardial High Density Activation Mapping. Circ Arrhythm Electrophysiol. 2013;6:334-341.

3. de Groot NM, Houben RP, Smeets JL, Boersma E, Schotten U, Schalij MJ, Crijns H, Allessie MA. Electropathological substrate of longstanding persistent atrial fibrillation in patients with structural heart disease: epicardial breakthrough. Circulation. 2010;122:1674-1682.

4. Verheule S, Tuyls E, van Hunnik A, Kuiper M, Schotten U, Allessie M. Fibrillatory Conduction in the Atrial Free Walls of Goats in Persistent and Permanent Atrial Fibrillation. Circ Arrhythm Electrophysiol. 2010;3:590-599.

5. Eckstein J, Maesen B, Linz D, Zeemering S, van Hunnik A, Verheule S, Allessie M, Schotten U. Time course and mechanisms of endo-epicardial electrical dissociation during atrial fibrillation in the goat. Cardiovasc Res. 2011;89:816-824.

6. Schotten U, Verheule S, Kirchhof P, Goette A. Pathophysiological Mechanisms of Atrial Fibrillation: A Translational Appraisal. Physiol Rev. 2011;91:265-325.

7. Narayan SM, Krummen DE, Rappel W-J. Clinical Mapping Approach To Diagnose Electrical Rotors and Focal Impulse Sources for Human Atrial Fibrillation. J Cardiovasc Electrophysiol. 2012;23:447-454.

8. Yamazaki M, Mironov S, Taravant C, Brec J, Vaquero LM, Bandaru K, Avula UM, Honjo H, Kodama I, Berenfeld O, Kalifa J. Heterogeneous atrial wall thickness and stretch promote scroll waves anchoring during atrial fibrillation. Cardiovasc Res. 2012;94:48-57.

9. Lee S, Sahadevan J, Khrestian CM, Durand DM, Waldo AL. High Density Mapping of Atrial Fibrillation During Vagal Nerve Stimulation in the Canine Heart: Restudying the Moe Hypothesis. J Cardiovasc Electrophysiol. 2012;24:328-335.

10. Jalife J, Berenfeld O, Mansour M. Mother rotors and fibrillatory conduction: a mechanism of atrial fibrillation. Cardiovasc Res. 2002;54:204-216.

11. Spach MS, Miller WT, 3d, Dolber PC, Kootsey JM, Sommer JR, Mosher CE, Jr. The functional role of structural complexities in the propagation of depolarization in the atrium of the dog. Cardiac conduction disturbances due to discontinuities of effective axial resistivity. Circ Res. 1982;50:175-191.

12. Dillon SM, Allessie MA, Ursell PC, Wit AL. Influences of anisotropic tissue structure on reentrant circuits in the epicardial border zone of subacute canine infarcts. Circ Res. 1988;63: 182-206. 


\section{Chapter 3}

13. Spach MS, Dolber PC. Relating extracellular potentials and their derivatives to anisotropic propagation at a microscopic level in human cardiac muscle. Evidence for electrical uncoupling of side-to-side fiber connections with increasing age. Circ Res. 1986;58:356-371.

14. de Jong S, van Veen TA, van Rijen HV, de Bakker JM. Fibrosis and Cardiac Arrhythmias. J Cardiovasc Pharmacol. 2011;57:630-638.

15. de Bakker JM, van Capelle FJ, Janse MJ, Tasseron S, Vermeulen JT, de Jonge N, Lahpor JR. Slow conduction in the infarcted human heart. 'Zigzag' course of activation. Circulation. 1993; 88:915-926.

16. Koura T, Hara M, Takeuchi S, Ota K, Okada Y, Miyoshi S, Watanabe A, Shiraiwa K, Mitamura H, Kodama I, Ogawa S. Anisotropic Conduction Properties in Canine Atria Analyzed by High-Resolution Optical Mapping: Preferential Direction of Conduction Block Changes From Longitudinal to Transverse With Increasing Age. Circulation. 2002;105:20922098.

17. Schalij MJ, Lammers WJ, Rensma PL, Allessie MA. Anisotropic conduction and reentry in perfused epicardium of rabbit left ventricle. Am J Physiol. 1992;263:H1466-1478.

18. Gray RA, Pertsov AM, Jalife J. Incomplete reentry and epicardial breakthrough patterns during atrial fibrillation in the sheep heart. Circulation. 1996;94:2649-2661.

19. Hansson A, Holm M, Blomstrom P, Johansson R, Lührs C, Brandt J, Olsson SB. Right atrial free wall conduction velocity and degree of anisotropy in patients with stable sinus rhythm studied during open heart surgery. Eur Heart J. 1998;19:293-300.

20. Houben RP, de Groot NM, Smeets JL, Becker AE, Lindemans FW, Allessie MA. S-wave predominance of epicardial electrograms during atrial fibrillation in humans: Indirect evidence for a role of the thin subepicardial layer. Heart Rhythm. 2004;1:639-647.

21. Sakamoto S, Yamauchi S, Yamashita H, Imura H, Maruyama Y, Ogasawara H, Hatori N, Shimizu K. Intraoperative mapping of the right atrial free wall during sinus rhythm: variety of activation patterns and incidence of postoperative atrial fibrillation. Eur J Cardiothorac Surg. 2006;30:132-139.

22. Roberts-Thomson KC, Stevenson I, Kistler PM, Haqqani HM, Spence SJ, Goldblatt JC, Sanders P, Kalman JM. The role of chronic atrial stretch and atrial fibrillation on posterior left atrial wall conduction. Heart Rhythm. 2009;6:1109-1117.

23. Wang K, Ho SY, Gibson DG, Anderson RH. Architecture of atrial musculature in humans. Br Heart J. 1995;73:559-565.

24. Ho SY, Sánchez-Quintana D. The importance of atrial structure and fibers. Clin Anat. 2009; 22:52-63.

25. Hocini M, Ho SY, Kawara T, Linnenbank AC, Potse M, Shah D, Jais P, Janse MJ, Haissaguerre M, de Bakker JM. Electrical Conduction in Canine Pulmonary Veins: Electrophysiological and Anatomic Correlation. Circulation. 2002;105:2442-2448.

26. Karnovsky MJ. A formaldehyde-glutaraldehyde fixative of high osmolality for use in electron microscopy. J Cell Biol. 1965;27:137A-138A. 


\section{Anatomy and Anisotropy of AF Conduction}

27. Eijsbouts SC, Majidi M, van Zandvoort M, Allessie MA. Effects of acute atrial dilation on heterogeneity in conduction in the isolated rabbit heart. J Cardiovasc Electrophysiol. 2003;14: 269-278.

28. Klos M, Calvo D, Yamazaki M, Zlochiver S, Mironov S, Cabrera JA, Sanchez-Quintana D, Jalife J, Berenfeld O, Kalifa J. Atrial Septopulmonary Bundle of the Posterior Left Atrium Provides a Substrate for Atrial Fibrillation Initiation in a Model of Vagally Mediated Pulmonary Vein Tachycardia of the Structurally Normal Heart. Circ Arrhythm Electrophysiol. 2008;1:175-183.

29. Rücker-Martin C, Pecker F, Godreau D, Hatem SN. Dedifferentiation of atrial myocytes during atrial fibrillation: role of fibroblast proliferation in vitro. Cardiovasc Res. 2002;55:38-52.

30. Camelliti P, Green CR, LeGrice I, Kohl P. Fibroblast Network in Rabbit Sinoatrial Node: Structural and Functional Identification of Homogeneous and Heterogeneous Cell Coupling. Circ Res. 2004;94:828-835.

31. Kohl P, Camelliti P. Fibroblast-myocyte connections in the heart. Heart Rhythm. 2012;9: 461-464.

32. Rohr S. Myofibroblasts in diseased hearts: New players in cardiac arrhythmias? Heart Rhythm. 2009;6:848-856.

33. Sanfilippo AJ, Abascal VM, Sheehan M, Oertel LB, Harrigan P, Hughes RA, Weyman AE. Atrial enlargement as a consequence of atrial fibrillation. A prospective echocardiographic study. Circulation. 1990;82:792-797.

34. Schotten U, de Haan S, Neuberger HR, Eijsbouts S, Blaauw Y, Tieleman R, Allessie MA. Loss of atrial contractility is primary cause of atrial dilatation during first days of atrial fibrillation. Am J Physiol Heart Circ Physiol. 2004;287:H2324-2331.

35. Verheule S, Tuyls E, Gharaviri A, Hulsmans S, van Hunnik A, Kuiper M, Serroyen J, Zeemering S, Kuijpers NH, Schotten U. Loss of Continuity in the Thin Epicardial Layer Because of Endomysial Fibrosis Increases the Complexity of Atrial Fibrillatory Conduction. Circ Arrhythm Electrophysiol. 2013;6:202-211.

36. van der Velden HM, Ausma J, Rook MB, Hellemons AJ, van Veen TA, Allessie MA, Jongsma HJ. Gap junctional remodeling in relation to stabilization of atrial fibrillation in the goat. Cardiovasc Res. 2000;46:476-486.

37. Haïssaguerre M, Jaïs P, Shah DC, Takahashi A, Hocini M, Quiniou G, Garrigue S, Le Mouroux A, Le Métayer P, Clémenty J. Spontaneous Initiation of Atrial Fibrillation by Ectopic Beats Originating in the Pulmonary Veins. N Engl J Med. 1998;339:659-666.

38. Schuessler RB, Kawamoto T, Hand DE, Mitsuno M, Bromberg BI, Cox JL, Boineau JP. Simultaneous epicardial and endocardial activation sequence mapping in the isolated canine right atrium. Circulation. 1993;88(1):250-263. 
Chapter 3

\section{Supplemental Material}

\subsection{Supplemental Methods}

\section{Open chest experiments and tissue harvesting Animal Model of AF}

An atrial endocardial pacemaker lead (Medtronic Capsurefix ${ }^{\circledR}$ ) was implanted in the right atrial appendage in all animals. In the persAF group, the pacemaker lead was connected to an implanted neurostimulator (Medtronic Itrel ${ }^{\circledR}$ ) and $\mathrm{AF}$ was maintained by repetitive $50 \mathrm{~Hz}$ burst pacing at 3 times threshold (first 6 weeks $1 \mathrm{~s}$ on $/ 1 \mathrm{~s}$ off, remaining weeks $1 \mathrm{~s} / \mathrm{min}$ ). Anesthesia was induced with thiopental $(10 \mathrm{mg} / \mathrm{kg}$, Inresa Arzneimittel GmbH/Germany) and further maintained using Sufentanyl ( $6 \mu \mathrm{g} / \mathrm{kg} / \mathrm{h}$, Hameln/Germany), Midazolam $(0.8$ $\mathrm{mg} / \mathrm{kg} / \mathrm{h}$, Actavis/Iceland) and Pancuronium $(0.3 \mathrm{mg} / \mathrm{kg} / \mathrm{h}$, Organon/The Netherlands). All animal procedures conformed to US National Institutes of Health guidelines and were approved by the local ethical committee of Maastricht University.

Process of mechanically fixing the mapping array to the underlying atrial tissue At the end of recording, the mapping array (supplemental Figure 1A) was mechanically fixed to the underlying left atrial tissue using 13 injection needles. The needles were inserted through holes in a transparent frame surrounding the mapping array. The mapping array was then pulled out of the transparent frame and the whole heart was excised. In supplemental Figure 1B, the excised heart and the frame mechanically fixed to the underlying left atrial tissue is depicted. Hereafter, the free wall bounded by the frame was carefully removed from the rest of the left atrium. The result is depicted in supplemental Figure 1C, which shows the endocardial aspect of the tissue underneath the recording area kept in position by the needles. Then, a counter-frame, with matching dimensions and holes to accept the needles, was placed on the endocardial side by sliding over the needles, thereby aligning counter-frame and frame. Finally, needles were removed one by one and replaced by sutures. As a result, frame and counter-frame were tied together (see Figure 1A in main manuscript).

\section{MRI acquisition protocol}

Magnetic Resonance Image Acquisition

Anatomical magnetic resonance imaging (MRI) of fixed tissue samples, held in the fixating frame and positioned in an MRI tube using low-melting point agar, was performed using a vertical-bore, 11.7T (500Mhz) MR system with a Bruker Avance console (Bruker Medical, Ettingen, Germany) running Para- 

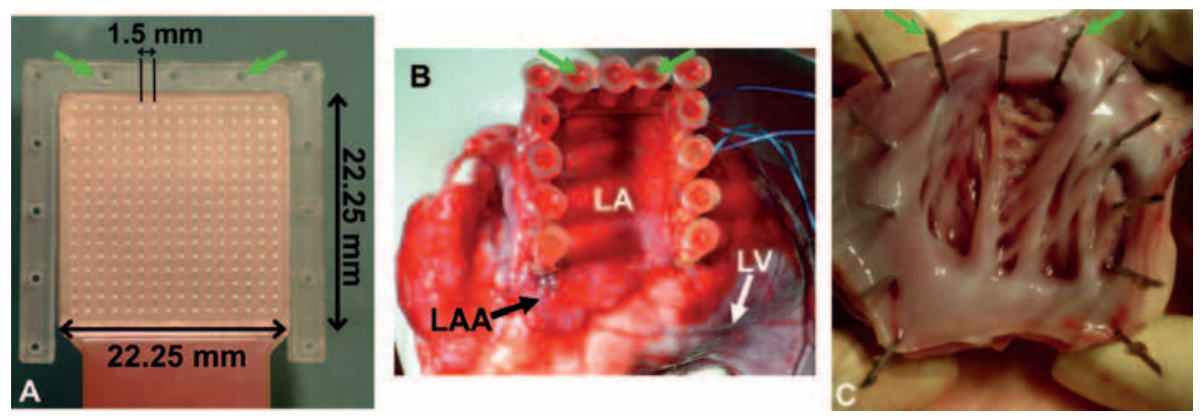

Supplemental Figure 1. 256-channel square mapping array used to record epicardial potentials. A. Contact-side of the mapping array (256 channels, interelectrode distance $1.5 \mathrm{~mm}$, array dimensions $22.5 \times 22.5 \mathrm{~mm}$ ). The array is shown inserted into a transparent frame. Green arrows point at holes used subsequently for attachment of the frame to the tissue.

$B$. Epicardial aspect of an excised heart, showing the transparent frame attached to the atrial tissue by 13 injection needles (e.g. green arrows, corresponding to locations in panel $A$ ). LAA= left atrial appendage, $L V=$ left ventricle, $L A=$ left atrium

C. Endocardial aspect of the excised tissue with points of the injection needles clearly visible.

vision 2.1.1, a 40-mm quadrature-driven birdcage coil (Rapid Biomedical, Würzburg, Germany) and a 3D fast gradient echo sequence (TE/TR 1.8/15ms; $15^{\circ}$ pulse; field of view $40 \times 40 \times 40 \mathrm{~mm}$, matrix size $512 \times 512 \times 512$; voxel size $78 \mu \mathrm{m} \times 78 \mu \mathrm{m} \times 78 \mu \mathrm{m} ; 10$ averages; total acquisition time $11 \mathrm{~h}$ ). While MRI resolution $(78 \mu \mathrm{m} \times 78 \mu \mathrm{m} \times 78 \mu \mathrm{m})$ is not sufficient to resolve individual myocytes, it is sufficient to identify atrial myobundles.

\section{Analysis of anisotropy of conduction during $A F$}

Analysis of fibrillation electrograms

Local activation times were identified by the steepest negative deflection of the electrogram $[-\mathrm{dV} / \mathrm{dt}]_{\max }$. Individual fibrillation waves were delineated by boundaries of conduction block $(\mathrm{CV}<20 \mathrm{~cm} / \mathrm{s})$. Two types of waves were identified: 'peripheral waves' and 'epicardial breakthroughs'. ${ }^{1-4}$ For each activation at each electrode, a plane was fitted to activation times at neighboring electrodes belonging to the same wave (maximum square of $5 \times 5$ electrodes). The fitted plane indicates local direction of propagation (orientation of the plane) and $\mathrm{CV}$ (reciprocal value of the steepness of the plane).

\section{Threshold of conduction block}

For the identification of the fibrillation waves in the analysis of AF electrograms, the threshold for conduction block was set to $\mathrm{CV}<20 \mathrm{~cm} / \mathrm{s}$. To inves- 
Chapter 3
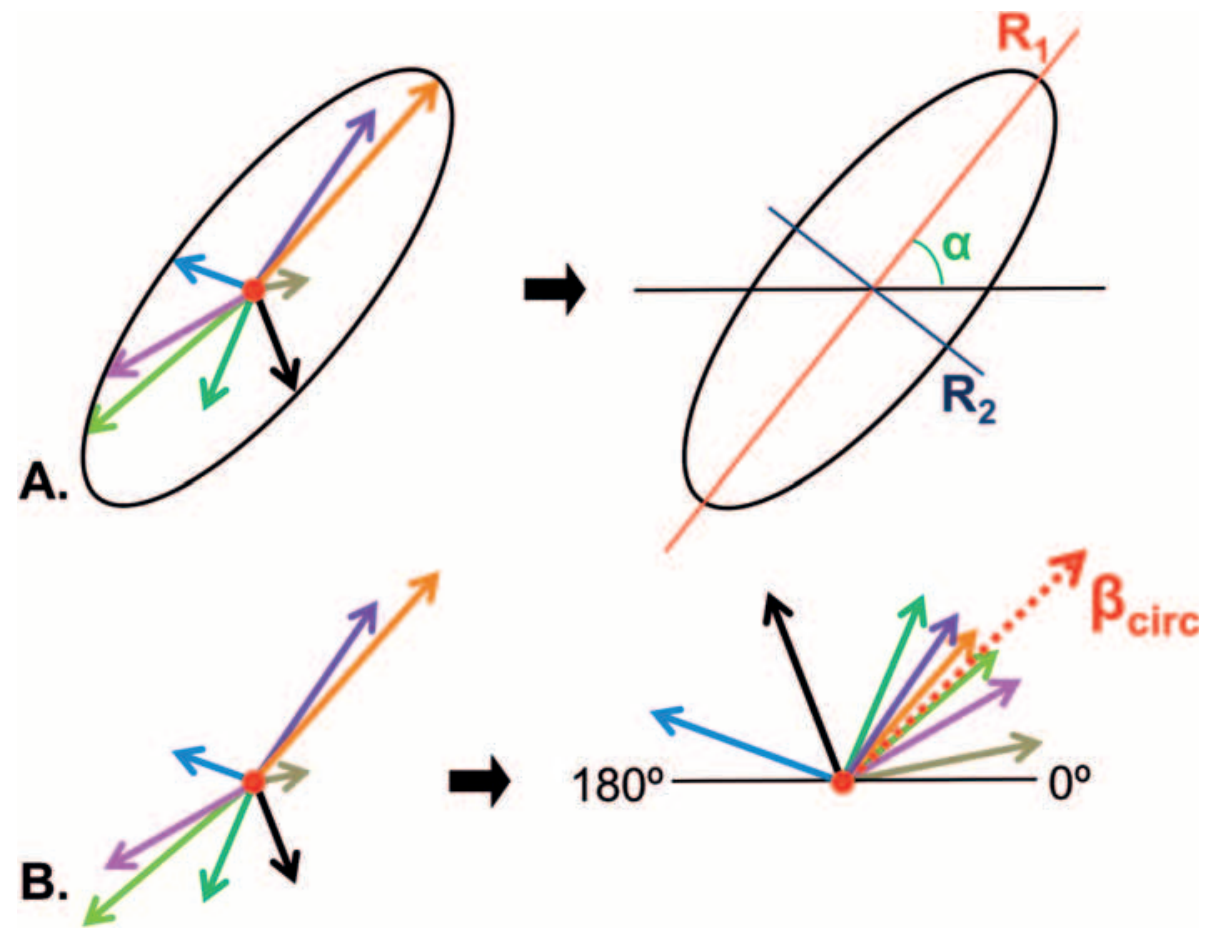

Supplemental Figure 2. A. Diagram of the quantification of anisotropy of conduction velocity for an individual electrode (red dot). An ellipse is fitted through 7 conduction vectors ( $R_{1}=$ major axis, $R_{2}=$ minor axis). The ratio $R_{1} / R_{2}$ is the degree of anisotropy of conduction velocity and $\alpha$ the direction of anisotropy of conduction velocity.

B. Quantification of anisotropy of conduction likelihood using the same 7 hypothetical conduction vectors. All conduction vectors are projected onto a circular scale from $0^{\circ}$ to $180^{\circ}\left(\beta_{\text {circ }}=\right.$ circular mean, $\sigma_{\text {circ }}^{2}=$ circular variance). The degree of anisotropy of conduction likelihood was calculated as 1-circular variance $\left(\sigma_{\text {circ }}^{2}\right)$. The direction of anisotropy of conduction likelihood is calculated as the mean of angles (circular mean $=\beta_{\text {circ }}$ ).

tigate the sensitivity of the computation of the CV direction to the conduction block threshold, the fibrillation waves and CV were determined at different conduction block thresholds. The difference in conduction velocity direction (in degrees) between directions calculated with the default conduction block threshold of $20 \mathrm{~cm} / \mathrm{s}$ and lower thresholds of $15 \mathrm{~cm} / \mathrm{s}, 10 \mathrm{~cm} / \mathrm{s}$ and $5 \mathrm{~cm} / \mathrm{s}$ was negligible in most cases (see Supplemental Table 3). The median absolute difference (p50) for $15 \mathrm{~cm} / \mathrm{s}, 10 \mathrm{~cm} / \mathrm{s}$ and $5 \mathrm{~cm} / \mathrm{s}$ was 0,0 and 2 degrees respectively. The number of direction vectors calculated to compare with the default 
conduction block threshold was 79200. These data demonstrate that there is a very small effect of the threshold for block on the vector direction.

\begin{abstract}
Anisotropy of conduction during AF
Anisotropy values were calculated as follows:

- Anisotropy of conduction velocity. For each electrode, an ellipse was fitted (minimizing the algebraic distance $)^{5}$ through all conduction vectors at that electrode during the $4 \mathrm{~s}$ recording (see supplemental Figure 2A). The degree of anisotropy of conduction velocity was calculated as the ratio of the major axis and the minor axis of the fitted ellipse. The direction of anisotropy of conduction velocity was calculated as the angle between the major axis of the fitted ellipse and the horizontal axis.
\end{abstract}

- Anisotropy of conduction likelihood. For each electrode, anisotropy of conduction likelihood was quantified based on the circular distribution of conduction vectors. Diametrically opposed conduction vectors are considered equal because they are oriented in the same direction, relatively to myocardial fiber axis. Therefore, conduction vectors were transposed to a range of $0^{\circ}$ to $180^{\circ}$. Of these transposed vectors, the circular mean $\left(\beta_{\text {circ }}\right)$ and variance $\left(\sigma_{\text {circ }}^{2}\right)$ were calculated. ${ }^{6}$ The degree of anisotropy of conduction likelihood was calculated as 1- $\sigma_{\text {circ }}^{2}$ [value between 1 (maximal degree of anisotropy of conduction likelihood) and 0 (no degree of anisotropy of conduction likelihood)]. For the direction of anisotropy of conduction likelihood, the circular mean was used (see supplemental Figure 2B).

For the total degree of anisotropy of conduction velocity and anisotropy of conduction likelihood per goat, all the degrees of anisotropy of conduction velocity and anisotropy of conduction likelihood determined at each electrode were averaged per goat. For the purpose of standardization and to exclude directions at electrodes with low and thus uncertain degree of anisotropic conduction, only directions of electrodes with a degree of anisotropy of conduction velocity $\geq 1.5$ and a degree of anisotropy of conduction likelihood $\geq 0.20$ were included in the analysis. These cut-off values have been chosen so that on average $~ 51 \%$ ( $\min .22 \%$, max. $87 \%$ ) of all vectors were included in the analysis. The technique used is capable of detecting differences between the direction of fastest conduction (anisotropy of conduction velocity) and the direction of the most likely conduction (anisotropy of conduction likelihood, see supplemental Figure 3 for a schematic example). 
A.
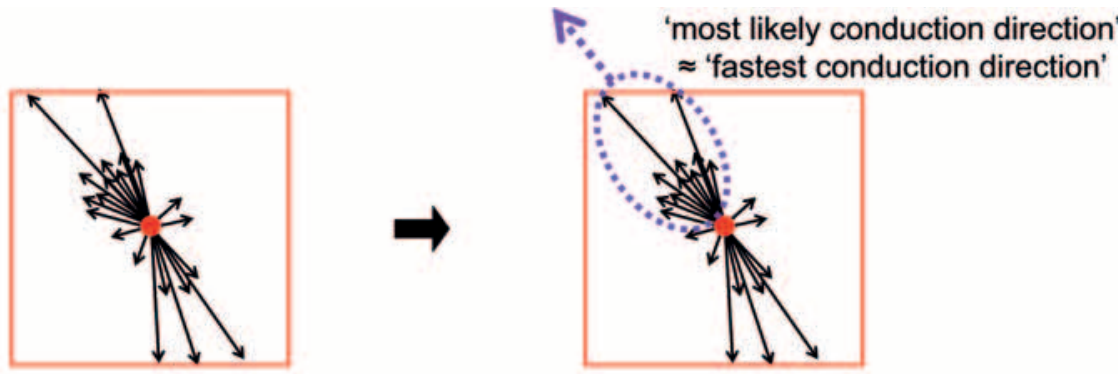

B.
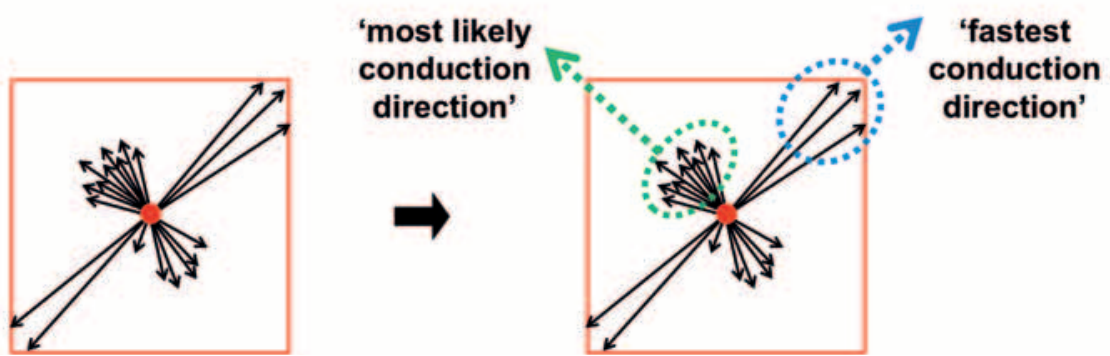

Supplemental Figure 3. Schematic examples of direction of anisotropy of conduction velocity and anisotropy of conduction likelihood. Hypothetical conduction vectors (black arrows) during 4s of AF at a single electrode (red point) are depicted. A. Calculation of the direction of anisotropy of conduction velocity and anisotropy of conduction likelihood will result approximately in the same direction (purple). B. Most small conduction vectors are orientated along the same axis, but a few large vectors are orientated along an axis perpendicular to the first axis. This will result in a direction of anisotropy of conduction velocity (blue) that is different from the direction of anisotropy of conduction likelihood (green).

\subsection{Supplemental Results}

\section{Direction of endocardial bundles versus epicardial fiber orientation}

In addition to differences between the direction of endocardial bundles and the direction of epicardial fibers in aAF and persAF, we further analyzed directional differences between epicardial fibers within the epicardial layer for aAF and persAF and differences between the endocardial bundles within the endocardial layer (Supplemental Figure 6). To illustrate the differences, results should be compared to figure 4 in the main manuscript. As mentioned in the main manuscript, epicardial fibers are oriented more perpendicularly to endocardial bundles in persAF $\left(\mathbf{R}_{\mathrm{N}}=0.19, P_{\text {uniform }}<0.001, P<0.05\right.$ vs. aAF, Figure $\left.6 \mathrm{~B}\right)$ 


\section{Acute AF}

Direction of anisotropy of conduction likelihood versus

direction of anisotropy of conduction velocity

1.

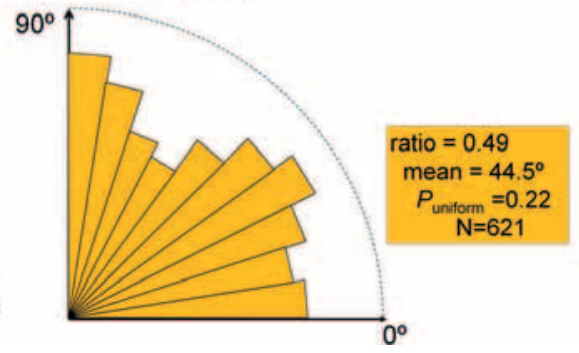

Persistent AF

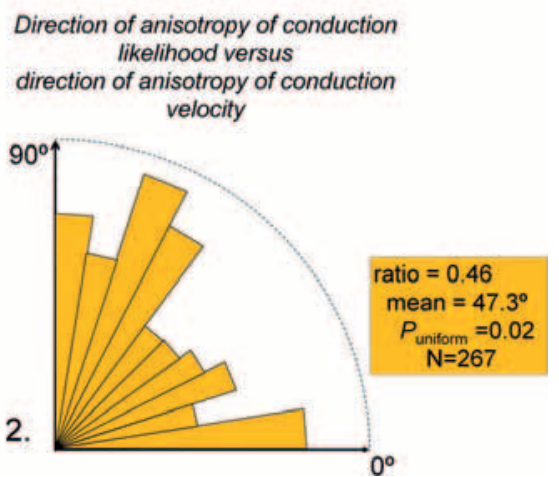

Supplemental Figure 4. Spread of absolute angle differences (range $0^{\circ}$ to $90^{\circ}$ ) between direction of anisotropy of conduction velocity and anisotropy of conduction likelihood during acute $A F(A)$ and persistent $A F(B)$. Ratio=ratio small angle differences/(small + large angle differences); mean= mean angle difference; Puniform=test for uniform distribution, $N=n u m b e r$ of observations. See text for further explanation.

than in aAF $\left(\mathbf{R}_{\mathrm{N}}=0.44, P_{\text {uniform }}<0.001\right.$, Figure $\left.6 \mathrm{~A}\right)$. Likewise, when comparing epicardial fibers within the epicardial layer, no differences were present between aAF $\left(\mathbf{R}_{\mathbf{N}}=0.96, P_{\text {uniform }}<0.001\right.$, Figure 6 C) and persAF $\left(\mathbf{R}_{\mathbf{N}}=0.96, P_{\text {uniform }}\right.$ $<0.001$, Figure 6D). When comparing endocardial bundles within the endocardial bundle network, no differences were present between aAF $\left(\mathbf{R}_{\mathrm{N}}=0.95, P_{\text {uniform }}\right.$ $<0.001$, Figure $6 \mathrm{E})$ and persAF $\left(\mathbf{R}_{\mathrm{N}}=0.99, P_{\text {uniform }}<0.001\right.$, Figure $\left.6 \mathrm{E}\right)$. Also, within the endocardial layer the differences in bundle direction were smaller than between the epicardial and the endocardial bundles These results clearly illustrate that during seven months of AF in the goat, endo-epicardial differences in direction of the bundles increase but that this is not the case within the epicardial and endocardial layers. 


\section{Chapter 3}

Supplemental Table 1. Mean degree of anisotropy of conduction during pacing and AF. ${ }^{*} P<0.001$ aAF versus pers $A F ;+P<0.01$ pacing versus $A F ; N A=$ not applicable

\begin{tabular}{lll}
\hline & $\begin{array}{l}\text { Degree of anisotropy of } \\
\text { conduction velocity }\end{array}$ & $\begin{array}{l}\text { Degree of anisotropy } \\
\text { of conduction likelihood }\end{array}$ \\
\hline aAF - Pacing $(n=6)$ & $1.68 \pm 0.19$ & NA \\
persAF - Pacing $(n=4)$ & $1.85 \pm 0.23$ & NA \\
aAF - AF $(n=6)$ & $1.55 \pm 0.07$ & $0.39 \pm 0.05$ \\
persAF - AF $(n=5)$ & $1.51 \pm 0.07 \dagger$ & $0.20 \pm 0.02^{*}$
\end{tabular}

Supplemental Table 2. Heterogeneity index of direction of anisotropy of conduction and heterogeneity index of direction of atrial bundles for the aAF group and the pers AF group. ${ }^{*} P<0.05$ between direction of anisotropy of conduction velocity and anisotropy of conduction likelihood. $+P<0.05$ between direction of epicardial and endocardial bundles.

\begin{tabular}{llc}
\hline & \multicolumn{2}{c}{ Heterogeneity Index } \\
& $\operatorname{aAF}(n=6)$ & persAF $(n=5)$ \\
\hline $\begin{array}{l}\text { Direction of anisotropy } \\
\text { of conduction velocity }\end{array}$ & $18.8 \pm 9.2$ & $28.2 \pm 16.6$ \\
$\begin{array}{l}\text { Direction of anisotropy } \\
\text { of conduction likelihood }\end{array}$ & $9.3 \pm 1.7^{*}$ & $8.4 \pm 2.4^{*}$ \\
\hline
\end{tabular}

Supplemental Table 3. Percentiles of the angle differences (in degrees) of the vectors calculated with the default conduction block threshold of 20cm/s compared to lower thresholds of $15 \mathrm{~cm} / \mathrm{s}, 10 \mathrm{~cm} / \mathrm{s}$ and $5 \mathrm{~cm} / \mathrm{s}$.

\begin{tabular}{llllllllllllllllllll}
\hline \multicolumn{11}{c}{ Percentile } \\
\hline Threshold & 5 & 10 & 15 & 20 & 25 & 30 & 35 & 40 & 45 & 50 & 55 & 60 & 65 & 70 & 75 & 80 & 85 & 90 & 95 \\
$5 \mathrm{~cm} / \mathrm{s}$ & 0 & 0 & 0 & 0 & 0 & 0 & 0 & 0 & 0 & 2.32 & 7.13 & 13.20 & 20.81 & 30.54 & 43.21 & 58.62 & 79.38 & 105.12 & 138.18 \\
$10 \mathrm{~cm} / \mathrm{s}$ & 0 & 0 & 0 & 0 & 0 & 0 & 0 & 0 & 0 & 0 & 0 & 0 & 1.10 & 5.62 & 11.73 & 20.31 & 33.31 & 52.75 & 89.38 \\
$15 \mathrm{~cm} / \mathrm{s}$ & 0 & 0 & 0 & 0 & 0 & 0 & 0 & 0 & 0 & 0 & 0 & 0 & 0 & 0 & 0.07 & 5.31 & 13.86 & 28.34 & 58.62
\end{tabular}




\section{Direction of anisotropy of conduction velocity}

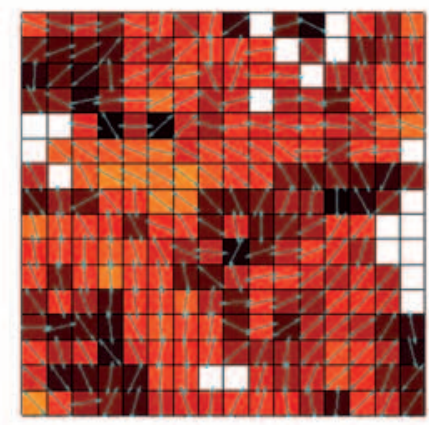

Acute $\operatorname{AF}(n=6)$

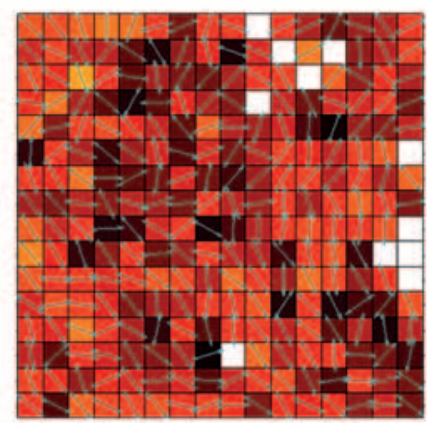

Persistent AF $(n=5)$

\section{Direction of anisotropy of conduction likelihood}

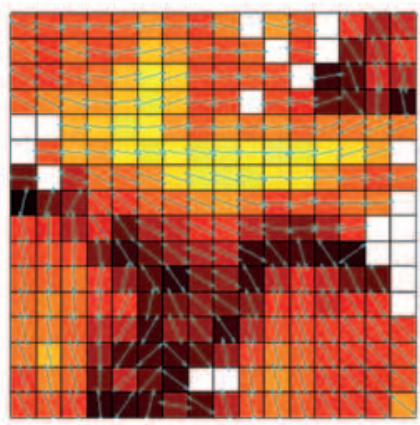

Acute $\operatorname{AF}(n=6)$

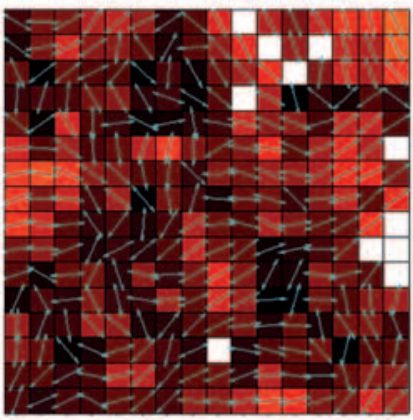

Persistent AF $(n=5)$

Low

High

Supplemental Figure 5. Example maps of anisotropy of conduction. One map consists of $16 \times 16$ squares corresponding to electrode positions on the mapping array. Dark to light color indicates increasing anisotropy (see reference bar). Direction of anisotropy of conduction velocity and anisotropy of conduction likelihood is indicated (blue arrows). 
Chapter 3

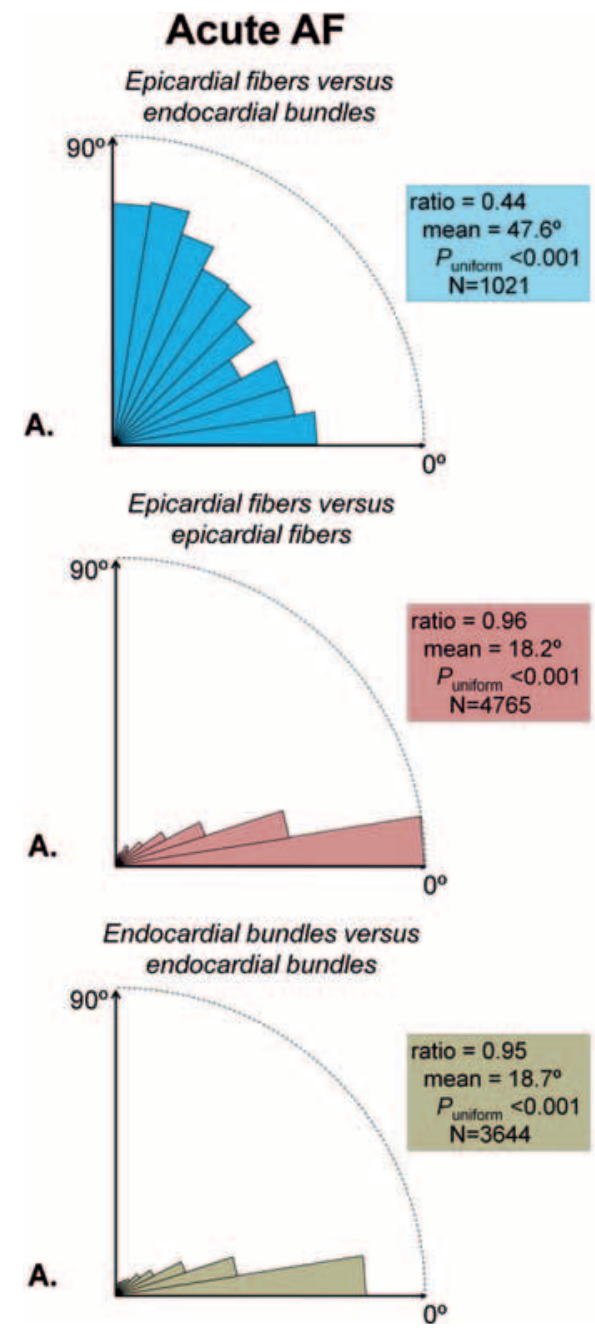

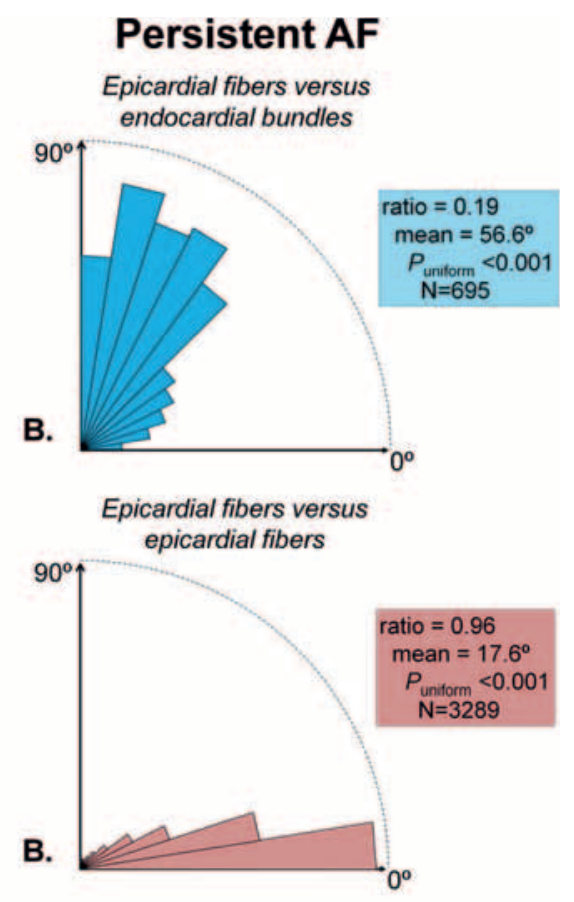

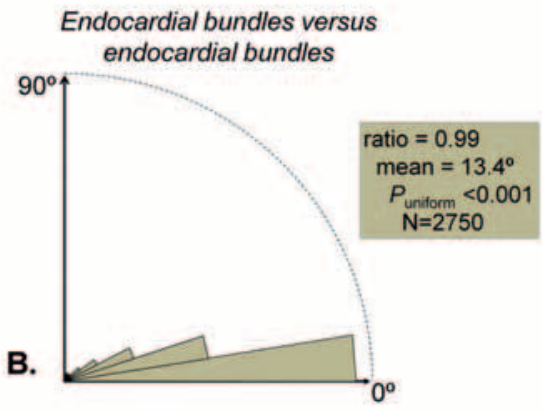

Supplemental Figure 6. Absolute angle differences (range $0^{\circ}$ to $90^{\circ}$ ) between direction of epicardial and endocardial bundles during $a A F(A)$ and pers $A F(B)$, within the epicardial layer during $a A F(C)$ and pers $A F(D)$ and within the endocardial layer during $a A F(E)$ and pers $A F(D)$. Differences in bundle direction are larger between the epicardial layer and the endocardial layer, than within the epicardial layer or within the endocardial bundle network. The differences in bundle direction between the epicardial layer and the endocardial layer increase with the persistence of AF. No differences between aAF and pers AF are observed within the epicardial or the endocardial layer. Ratio=ratio small angle differences/(small + large angle differences); mean=mean angle difference; Puniform =test for uniform distribution, $N=$ number of observations. 


\section{Anatomy and Anisotropy of AF Conduction}

\section{Supplemental References}

1. Verheule S, Tuyls E, van Hunnik A, Kuiper M, Schotten U, Allessie M. Fibrillatory Conduction in the Atrial Free Walls of Goats in Persistent and Permanent Atrial Fibrillation. Circ Arrhythm Electrophysiol. 2010;3:590-599.

2. Eckstein J, Zeemering S, Linz D, Maesen B, Verheule S, van Hunnik A, Crijns H, Allessie MA, Schotten U. Transmural Conduction is the Predominant Mechanism of Breakthrough during Atrial Fibrillation: Evidence from Simultaneous Endo-epicardial High Density Activation Mapping. Circ Arrhythm Electrophysiol. 2013;6:334-341.

3. Allessie MA, de Groot NM, Houben RP, Schotten U, Boersma E, Smeets JL, Crijns HJ. Electropathological substrate of long-standing persistent atrial fibrillation in patients with structural heart disease: longitudinal dissociation. Circ Arrhythm Electrophysiol. 2010;3:606-615.

4. de Groot NM, Houben RP, Smeets JL, Boersma E, Schotten U, Schalij MJ, Crijns H, Allessie MA. Electropathological substrate of longstanding persistent atrial fibrillation in patients with structural heart disease: epicardial breakthrough. Circulation. 2010;122:1674-1682.

5. Gander W, Golub GH, Strebel R. Least-squares fitting of circles and ellipses. BIT Numerical Math. 1994;34:558-578.

6. Berens P. A MATLAB Toolbox for Circular Statistics. J. Stat. Softw. 2009;31:1-21. 



\section{Chapter 4}

\section{Electrical and Structural}

\section{Substrates in Patients with}

Acute, Paroxysmal and

\section{Persistent Atrial Fibrillation}

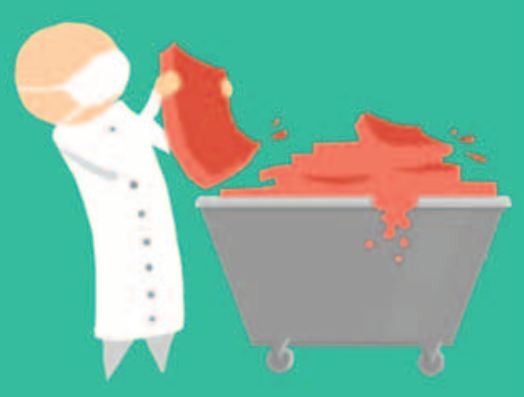

Bart Maesen, Mark La Meir, Stef Zeemering, Jan Nijs, Stijn Lumei, Dennis H. Lau, Mathieu Granier, Laurent Pison, Harry Crijns, Jos Maessen, Sander Verheule, Stefan Dhein and Ulrich Schotten In preparation of submission 


\section{Chapter 4}

\section{Abstract}

Introduction: While persistence of atrial fibrillation (AF) is characterized by high AF complexity, relative little is known about AF complexity in paroxysmal AF (pAF). Also, the relative contribution of structural alterations to conduction disturbances is not clear.

Methods: During cardiac surgery, epicardial high-density mapping was performed in patients with acutely induced AF (aAF, $n=11)$, pAF ( $n=12)$ and persistent AF (persAF, $n=9$ ) on the right atrial free wall (RA), the posterior left atrium (pLA) and the LA appendage (LAA). After unipolar AF electrogram analysis (10s), the number of waves and breakthroughs, wave width and fractionation index (FI) were quantified. In RA auricles, overall and endomysial (myocyte-myocyte distances) fibrosis, connexin 43 (Cx43) distribution and myocyte size were quantified.

Results: Overall, more and smaller waves, more breakthroughs and a higher FI were seen in persAF compared to aAF and pAF and no differences between aAF and pAF were found. The FI was consistently higher at the pLA compared to the RA. Cx43 lateralization increased with $\mathrm{AF}$ duration ( $\mathrm{aAF}=7.5 \pm 8.9 \%$, $\mathrm{pAF}=24.7 \pm 11.1 \%$, pers $A F=35.1 \pm 11.4 \%, P<0.001)$. Only endomysial fibrosis correlated with AF complexity $(\mathrm{r}=0.57, P=0.001)$. No correlation was found between overall fibrosis and AF complexity $(r=0.23, P=0.20)$.

Conclusion: AF complexity is comparable between pAF and aAF, but higher in persAF. Cx43 lateralization increases during AF progression. Endomysial fibrosis, not overall fibrosis, is the strongest determinant of atrial conduction disturbances. As such, the relevance of imaging of overall atrial fibrosis as a predictor of conduction disturbances can be questioned. 


\section{Introduction}

The pathophysiological mechanisms underlying the initiation and perpetuation of atrial fibrillation (AF) are complex and show high diversity and interindividual variability. ${ }^{1}$ Progressive atrial remodeling due to AF itself or as a consequence of underlying structural heart diseases lead to an increase in the persistence of the arrhythmia. ${ }^{2}$ Although the presence of structural heart disease like heart failure and hypertension are associated with progression of paroxysmal $\mathrm{AF}(\mathrm{pAF}$ ) to more sustained forms, the substrate alterations related to this transition remain unknown. ${ }^{3}$

The seminal description of AF initiation by ectopic focal activity in the pulmonary veins purports the importance of 'triggers' in patients with pAF. ${ }^{4}$ However, recent epicardial mapping has shown that sinus rhythm (SR) patients with structural heart disease already harbor a substrate capable of maintaining AF. Indeed, several studies have also highlighted an abnormal substrate in pAF. The results of these studies include similar atrial refractoriness and conduction velocity as compared to persistent $\mathrm{AF}$ (persAF), ${ }^{6}$ electroanatomic findings of lower left atrial voltage, slowed conduction and increased proportion of complex fractionated atrial electrograms as compared to controls, ${ }^{7,8}$ and an increased atrial fibrosis from delayed enhancement magnetic resonance imaging (DE-MRI) and histologic studies. ${ }^{9-11}$ Nevertheless, a comprehensive direct contact mapping assessment of the pAF substrate with electro-structural correlation is still lacking.

It is likely that the complex interplay between 'triggers' and 'substrate', as well as electrical and structural remodeling account for the variable manifestations of AF progression from the paroxysmal to persistent form. Recently, our group developed a wave-mapping algorithm that identified several novel factors that contribute to the stability of AF in patients with structural heart disease and longstanding persistent $\mathrm{AF}$ as well as in animal models of AF. ${ }^{2}$ Key electrophysiological elements of the AF substrate include longitudinal dissociation, epicardial breakthrough of AF waves as well as dyssynchronous endo-epicardial atrial activity. ${ }^{13-15}$ Here, we aimed to comprehensively evaluate the electro-structural substrate pertinent to the progression of AF using aforementioned direct contact $\mathrm{AF}$ wave mapping algorithms in conjunction with structural analysis of atrial appendage tissues from patients with structural heart disease undergoing cardiac surgery with SR and acutely induced AF (aAF), pAF and persAF. 
Chapter 4

\section{Methods}

\subsection{Patient population}

Patients without history of AF ( $\mathrm{n}=11, \mathrm{AF}$ was acutely induced in this group, $\mathrm{aAF})$, with a history of pAF ( $\mathrm{n}=12, \mathrm{AF}$ acutely induced if necessary) and persAF $(n=9)$, all referred for cardiac surgery, were included. Medical history, drug use and preoperative rhythm monitoring (7days) using a trans-telephonic $\mathrm{AF}$ event recorder (Vitaphone ${ }^{\mathrm{TM}}$ ) were used in the aAF group to exclude patients with preoperative AF. Different types of cardiac surgery - including cut-and-sew rhythm surgery, coronary artery bypass grafting (CABG), aortic (AVS) and mitral valve surgery (MVS) - were included resulting in a considerable variability in the degree of the underlying structural heart diseases in each group (Table 1). Approval of the local ethics committee and informed consent was obtained for each patient. This trail was registered at the Dutch Trial register, number NTR1301.

\subsection{Epicardial mapping of $A F$}

After median sternotomy and insertion of the aortic cannula, epicardial highdensity mapping of AF was performed using two different single-used square electrode grids: a 256-channel electrode $(22.5 \times 22.5 \mathrm{~mm}$, interelectrode distance $1.5 \mathrm{~mm}$ ) for mapping of the right atrial (RA) free wall and posterior left atrium (pLA, in the oblique sinus) and a 64-channel electrode $(10.5 \times 10.5 \mathrm{~mm}$, interelectrode distance $1.5 \mathrm{~mm}$ ) for the left atrial auricle (LAA, Figure 1). RA and pLA files were recorded off-pump, LAA files were, for hemodynamic reasons, acquisitioned on-pump, but with preserved atrial filling pressure. AF was induced via incremental pacing $(3.3 \mathrm{~Hz}$ to $16.7 \mathrm{~Hz})$ in patients with aAF and pAF if in SR. Recording of fibrillatory electrograms (10s; sampling rate $1 \mathrm{kHz}$; filtering bandwidth $0.5-500 \mathrm{~Hz}$ ) was started $30 \mathrm{~s}$ after induction of AF and data were stored for off-line analysis.

\subsection{Analysis of AF electrograms}

Unipolar AF electrogram analysis and wave mapping was performed using a novel fully automated analysis as described elsewhere. ${ }^{12}$ Briefly, electrogram preprocessing included filtering with a third order zero-phase Chebyshev $0.5 \mathrm{~Hz}$ high-pass filter to remove any baseline drift and removal of ventricular far-field deflections by ventricular R-wave detection followed by single-beat QRST-template cancellation. Intrinsic deflections - representing local activa- 

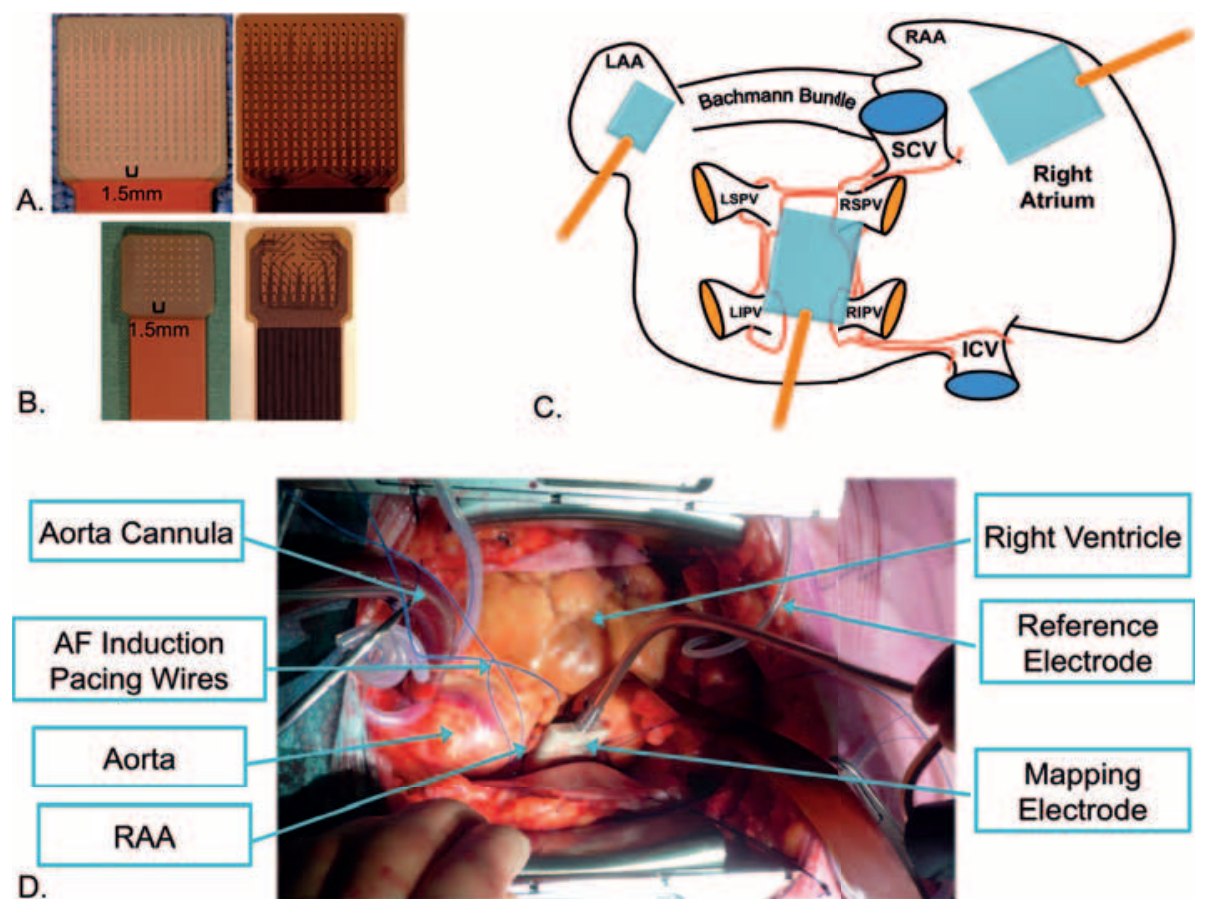

Figure 1. Representative pictures of the epicardial 256-channel (A) and 64-channel (B) electrodes (inter-electrode distance $1.5 \mathrm{~mm}$ ). C. Atrial scheme with locations of electrode application. D. Surgical view on mapping procedure.

tions underneath the electrode - were identified based on a recently validated probabilistic algorithm. ${ }^{12}$ Non-intrinsic deflections were considered to be due to far field effects causes by fibrillation waves propagating in the close vicinity of the electrode. If they were larger than $25 \%$ of the median intrinsic deflection they were counted as fractionated activity. As an additional substrate parameter, the fractionation index (FI) was defined as the ratio of non-intrinsic to intrinsic deflections.

AF wave construction consisted of three phases: (1) partial wave creation by identifying wave borders based on conduction block, i.e. conduction velocity $(\mathrm{CV})<20 \mathrm{~cm} / \mathrm{s}$; (2) determining the distribution of $\mathrm{CV}$ and conduction deviation (tortuosity) within one wave; (3) allocation of unassigned deflections to adjacent waves based on a maximum local $\mathrm{CV}$ and conduction direction probability. ${ }^{12}$ 
Chapter 4

The following electrophysiological wave parameters were determined: CV, AF cycle length (AFCL), dominant frequency (DF), number of waves and epicardial breakthroughs, wave width and FI.

\subsection{Structural Analysis}

During surgery RA auricles (RAA) were surgically excised and rapidly stored in formaldehyde $0.4 \%$.

\section{Histology}

The tissue buffered in formaldehyde $0.4 \%$ was embedded in paraffin wax for slicing. After slicing, tissue sections were fixed at $56^{\circ} \mathrm{C}$ overnight, deparaffinized, and rehydrated. Three types of staining were used:

- Sirius red staining for determination of total amount of fibrosis. To quantify the ratio fibrosis to total tissue, epicardial and perivascular fibrosis were blanked out and fibrosis was color-identified. The amount of fibrosis was averaged per patient (5-8 slides, 20xmagnification).

- Congo red staining for quantification of amyloid.

- Haematoxylin and eosin staining for determination of cardiomyocyte diameter (cellular hypertrophy) and intermyocyte distance (endomysial fibrosis). For the cell diameter, only transversely cut cells were used. All measurements were averaged per patient (5-8 slides, 40xmagnification).

All measurements were performed with ImageJ (National Institutes of Health, USA).

\section{Connexin 43 analysis}

Immunostaining for connexin 43 (Cx43) in formalin fixed right atrial tissue was performed like described elsewhere. ${ }^{16}$ Briefly, expression of Cx43 at the lateral and polar membrane of myocytes from human right atria was investigated. Per sample 2-3 sections were analyzed, and per section 5-10 cells, so that each data point is representing 100-250 cells. The Cx43-ratio ([lateral Cx43/polar Cx43] *100) was determined.

\subsection{Statistical Analysis}

All data are expressed as mean $\pm S D$ if continuous or median \pm interquartile ranges if categorical. Significance of differences in means was calculated using a student t-test or one-way analysis of variance. Significance of difference in medians was calculated with $\chi^{2}$ test. Correlation between different parameters was calculated with bivariate (overall) and partial correlation (corrected 
for underlying rhythm). All calculations were performed with SPSS (IBM). $P$ values $<0.05$ were considered statistically significant.

\section{Results}

\subsection{Patient population}

The clinical characteristics and echocardiographic data of the patients are summarized in Table 1. Patients with persAF and pAF were older than aAF patients. Other clinical characteristics were comparable between groups except for hypercholesterolemia, which was less prevalent in pAF compared to aAF. The $\mathrm{CHA}_{2} \mathrm{DS}_{2}$-Vasc score was higher in persAF compared to $\mathrm{pAF}$. Overall, type of surgery was not different between groups $\left[\chi^{2}(8, N=32)=8.34\right.$, $P=0.40]$. As expected, LA size and volume were higher in persAF compared to aAF and pAF patients and LAA flow was lower in persAF compared to pAF. Furthermore RA volume was higher in persAF than aAF and pAF. When compared with $\mathrm{pAF}$, patients with persAF more frequently used digoxin, but less frequently amiodarone or sotalol. ACE-inhibitors and angiotensin II receptor blockers were more frequently taken by persAF patients as compared to $\mathrm{aAF}$ and $\mathrm{pAF}$.

\subsection{Epicardial Mapping}

\section{Basic characteristics of $A F$}

Values for AFCL, DF and CV are summarized in Table 2. DF was higher for persAF compared to aAF and pAF in the LAA, but not in the RA or in the pLA. Per location, there were no significant differences in AFCL between the three groups. Within each group, AFCL and DF were not different between the different locations. $\mathrm{CV}$ was lower for persAF compared to aAF in the RA $(0.64 \pm 0.04 \mathrm{~m} / \mathrm{s}$ vs $0.75 \pm 0.12 \mathrm{~m} / \mathrm{s}, P=0.02)$, but not in the $\mathrm{pLA}$ or the LAA.

\section{Parameters of AF conduction pattern}

In Figure 2, representative examples of isochronal maps with separate waves colored in different shades of green for aAF, yellow for PAF and red for pers$\mathrm{AF}$ are depicted. The maps were recorded in the pLA. The number of waves and breakthroughs is much higher in persAF compared to aAF and pAF. Moreover, representative electrograms, corresponding to different locations on the map (asterisks), are shown. The depicted electrograms in persAF are clearly more fractionated than in aAF and $\mathrm{pAF}$, supporting the presence of a far more complex substrate. 


\section{Chapter 4}

Table 1. Preoperative patient characteristics.

\begin{tabular}{|c|c|c|c|}
\hline & Acute $A F(n=11)$ & Paroxysmal AF $(n=12)$ & Persistent AF $(n=9)$ \\
\hline Age (yr) & $61.6 \pm 9.3$ & $68.6 \pm 4.0^{*}$ & $69.1 \pm 5.8^{*}$ \\
\hline Male sex (\%) & 72.7 & 75.0 & 55.6 \\
\hline \multicolumn{4}{|l|}{ Clinical characteristics } \\
\hline Nicotine abuse (\%) & 18.2 & 33.3 & 44.4 \\
\hline Hypertension (\%) & 63.6 & 66.7 & 77.8 \\
\hline Diabetes (\%) & 18.2 & 8.3 & 44.4 \\
\hline Peripheral arterial disease (\%) & 27.3 & 16.7 & 22.2 \\
\hline Previous MI (\%) & 36.4 & 25.0 & 11.1 \\
\hline Hypercholesterolemia (\%) & 81.8 & $33.3^{*}$ & 44.4 \\
\hline $\mathrm{GFR}<60 \mathrm{~mL} / \mathrm{min}(\%)$ & 0 & 25.0 & 22.2 \\
\hline BMI $\left(\mathrm{kg} / \mathrm{m}^{2}\right)$ & $26.9 \pm 2.5$ & $27.5 \pm 5.1$ & $26.9 \pm 3.1$ \\
\hline NYHA class & $2[2-3]$ & $2[1-2.75]$ & $2[2-3]$ \\
\hline CHA2DS2-Vasc & $3[3-4]$ & $3[2-3.75]$ & $3[3-6]^{\S}$ \\
\hline \multicolumn{4}{|l|}{ Surgery } \\
\hline$C A B G+M V S$ & 2 & - & - \\
\hline CABG & 7 & 8 & 4 \\
\hline MVS & 2 & 1 & 2 \\
\hline AVS & - & 2 & 2 \\
\hline Lone AF & - & 1 & 1 \\
\hline \multicolumn{4}{|l|}{ Echocardiography } \\
\hline LA diameter (mm) & $43.0 \pm 7.1$ & $43.1 \pm 7.9$ & $53.1 \pm 6.1^{* \S}$ \\
\hline LA volume (cc) & $87.4 \pm 35.0$ & $79.2 \pm 26.1$ & $151.0 \pm 55.3^{\star \S}$ \\
\hline LAA flow $(\mathrm{cm} / \mathrm{s})$ & $58.9 \pm 10.9$ & $61.4 \pm 24.6$ & $37.6 \pm 13.3^{\S}$ \\
\hline RA volume (cc) & $47.9 \pm 17.0$ & $50.9 \pm 25.7$ & $102.8 \pm 32.3^{\star \S}$ \\
\hline $\operatorname{LVEDD~(mm)~}$ & $52.6 \pm 6.4$ & $52.0 \pm 4.2$ & $52.1 \pm 5.1$ \\
\hline $\operatorname{LVESD}(\mathrm{mm})$ & $37.4 \pm 8.9$ & $33.0 \pm 5.8$ & $34.9 \pm 6.8$ \\
\hline $\operatorname{LVEF}(\%)$ & $55.5 \pm 14.1$ & $64.0 \pm 8.7$ & $61.4 \pm 6.4$ \\
\hline \multicolumn{4}{|l|}{ Drug use } \\
\hline Betablocker (\%) & 72.7 & 83.3 & 77.8 \\
\hline Digoxin (\%) & - & 0 & $33.3^{\S}$ \\
\hline Amiodarone / sotalol (\%) & - & 58.3 & $11.1^{\S}$ \\
\hline ACE-inhibitor / ARB (\%) & 45.5 & 58.3 & $100^{\star \S}$ \\
\hline CCB (\%) & 18.2 & 33.3 & 33.3 \\
\hline AF duration (yr) & - & $7.0 \pm 6.9$ & $9.6 \pm 6.6$ \\
\hline Preoperative CRP (mg/L) & $3.2 \pm 2.5$ & $2.5 \pm 1.6$ & $3.2 \pm 3.7$ \\
\hline
\end{tabular}


Table 1. Legend.

$M I=$ myocardial infarction; $G F R=$ glomerular filtration rate; $B M I=b o d y$ mass index; $N Y H A=$ New York Heart Association; $C A B G=$ coronary artery bypass grafting; $M V S=$ mitral valve surgery; $A V S=$ aortic valve surgery; $L A=$ left atrial; $L A A=l$ eft atrial appendage; $R A=$ right atrial; $L V E D D=$ left ventricular end diastolic diameter; $L V E S D=$ left ventricular end systolic diameter; $L V E F=$ left ventricular ejection fraction; $A C E$ = angiotensin converting enzyme; $C C B=$ Calcium channel blocker. $C R P=c$-reactive protein .

${ }^{*} P<0.05$ vs. Acute $A F, \S P<0.05$ vs. paroxysmal $A F$.

Acute AF
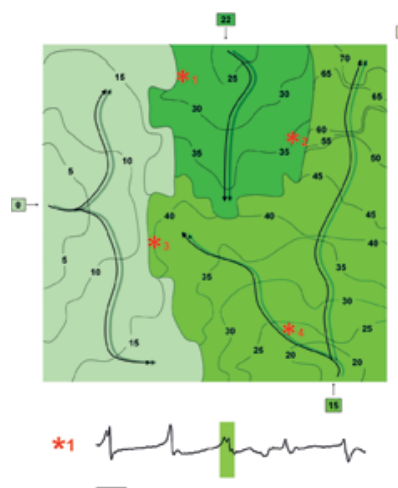

$\overline{100} \mathrm{~ms}$

*2

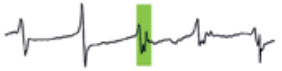

$\overline{100} \mathrm{~ms}$

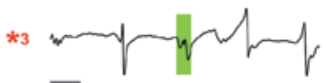

$\overline{100 \mathrm{~ms}}$

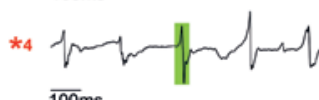

$\overline{100 \mathrm{~ms}}$
Paroxysmal AF
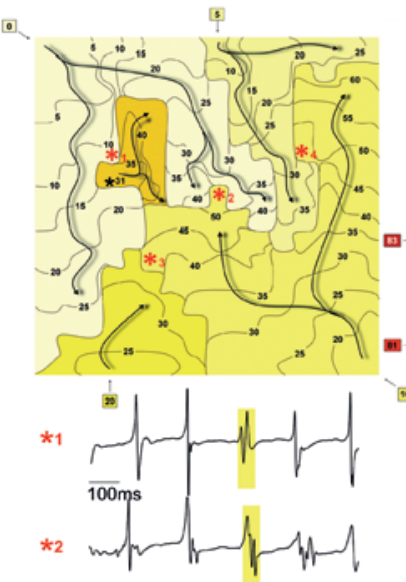

$\overline{100} \mathrm{~ms}$
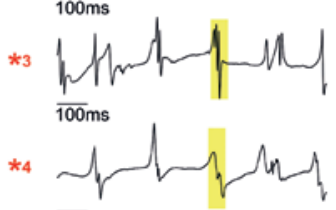

$\overline{100 \mathrm{~ms}}$

\section{Persistent AF}

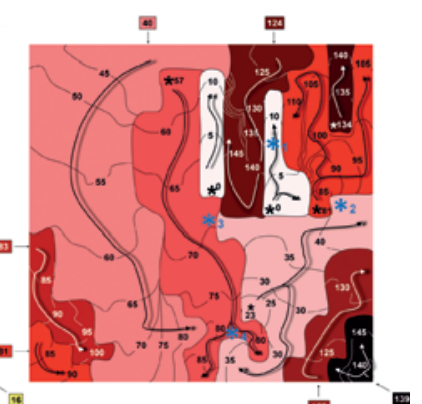

*1

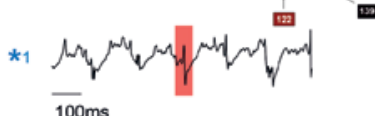

*2

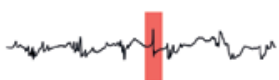

$\overline{100 \mathrm{~ms}}$
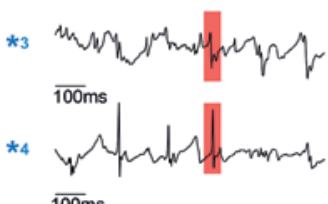

Figure 2. Representative isochrone maps in the posterior left atrium of 1 AF beat and corresponding electrograms of patients with $a A F, p A F$ and pers AF. Separate waves are colored different shades of green for $a A F$, yellow for $P A F$ and red for pers $A F$. Electrograms are preceded by an asterix that corresponds to the asterix on the map. See text for explanation.

Average complexity parameters of the AF conduction pattern are outlined in Table 3. The number of fibrillation waves per AFCL (waves/AFCL) and number of breakthroughs per AFCL (BT/AFCL) were significantly higher in persAF compared to aAF and pAF at the RA and the pLA, but not at the LAA. Importantly, there were no differences for waves per AFCL (waves/AFCL) 


\section{Chapter 4}
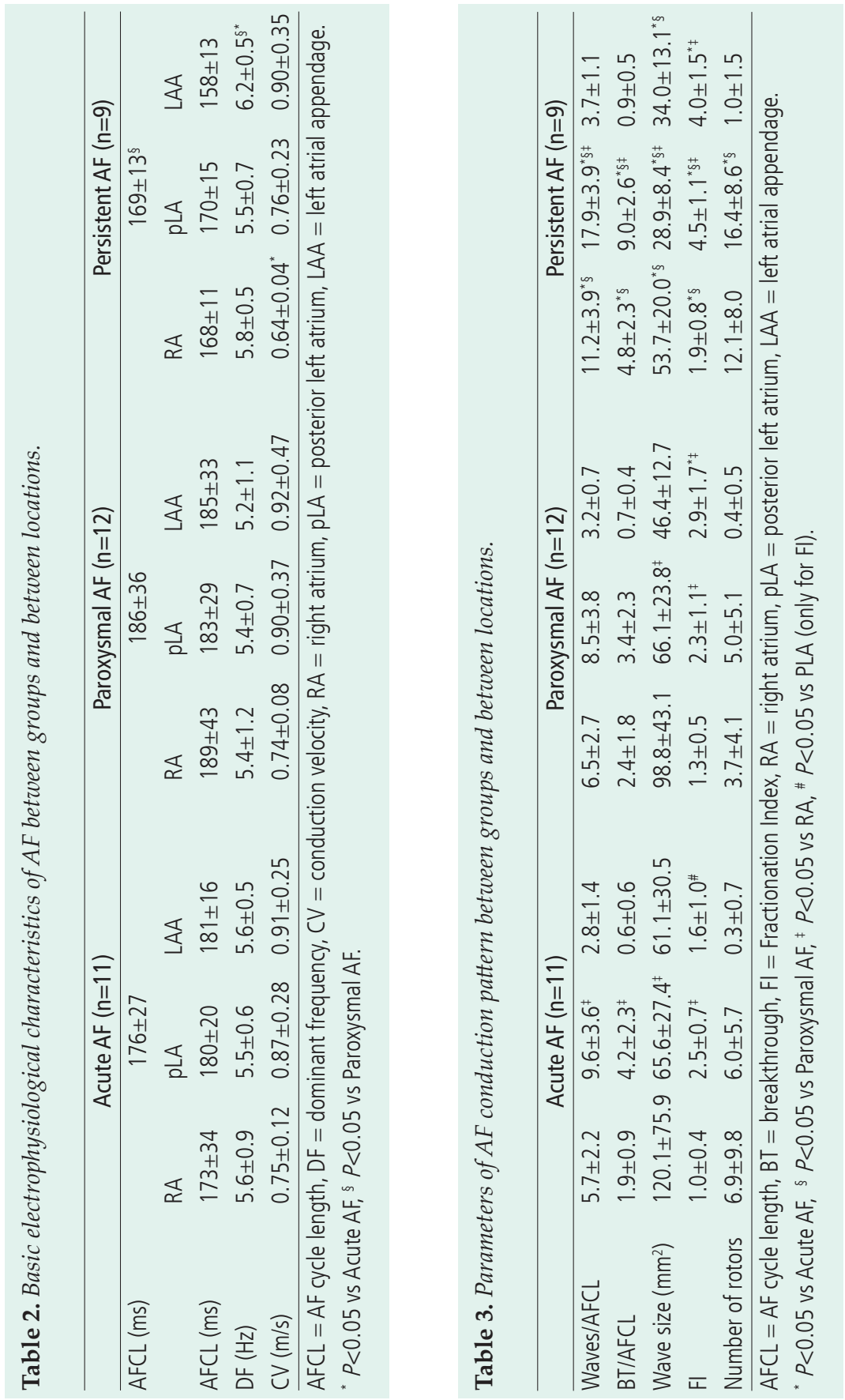
and number of breakthroughs per AFCL (BT/AFCL) between $\mathrm{pAF}$ and $\mathrm{AAF}$ at any location. Moreover, both for the aAF en the persAF group, waves/AFCL and BT/AFCL were higher at the pLA than at the RA. As a consequence, significant smaller waves were present in persAF when compared to aAF or pAF for all 3 mapping sites. Fibrillatory waves were also smaller in pLA compared to RA for all groups. Please note that the LAA was mapped with a smaller electrode. For this reason, waves/AFCL, BT/AFCL and wave sizes cannot directly be compared with the other mapping sites but only with the LAA measurement in the other patient groups.

\section{Variability of AF complexity}

To illustrate the variability of AF complexity within groups, a boxplot of AF complexity (expressed as waves/s) is depicted in Figure 3 for RA and pLA. In the RA, the coefficient of variation was $56.1 \%$ for aAF, $63.5 \%$ for $\mathrm{pAF}$ and $30.3 \%$ for persAF. In the pLA, the coefficient of variation was $36.7 \%$ for aAF, $58.4 \%$ for $\mathrm{pAF}$ and $21.0 \%$ for persAF.

\section{Electrogram fractionation}

The FI was higher in the persAF group compared to the aAF group at all 3 locations and compared to pAF at the RA and pLA (Table 3). FI was higher in the pAF group compared to the aAF group at the LAA, at other locations were no differences in FI between the aAF and the pAF group. When comparing between locations, the FI was consistently higher at the pLA when compared
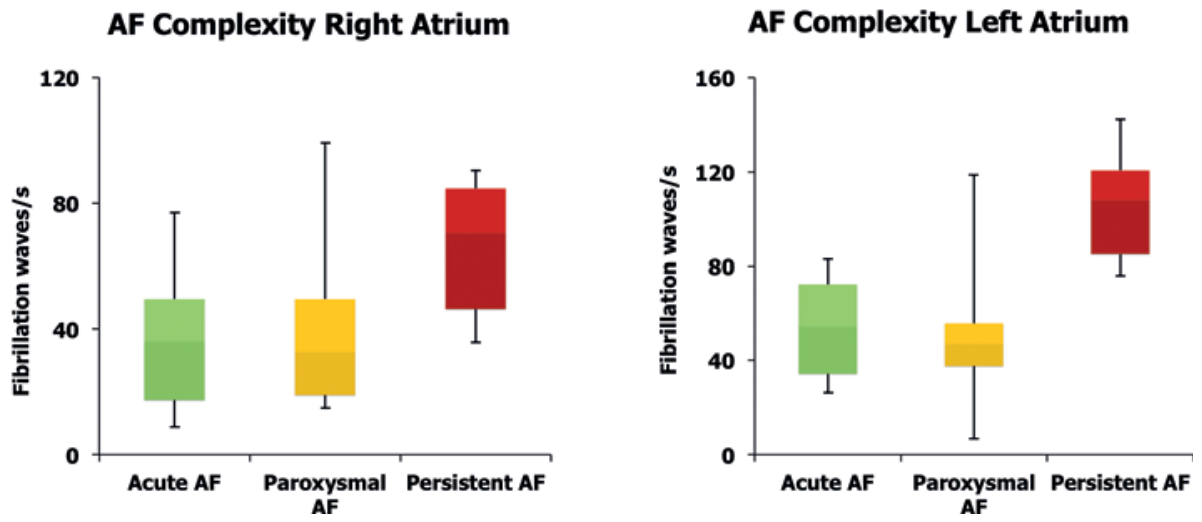

Figure 3. Boxplot diagram of $A F$ complexity (expressed as waves/AFCL) for aAF, $p A F$ and pers AF for the RA (left) and the LA (right). In both cases variability of AF complexity is highest for the $p A F$ group. 


\section{Chapter 4}

to the RA. At the LAA, the FI was higher than at the RA for the pAF and the persAF group, not for the aAF group. In the aAF group, the FI was lower at the LAA compared to the PLA. Correlation between the FI and AF complexity (expressed as waves/AFCL) was very good for RA and pLA ( $r=0.90, P<0.001$ and $\mathrm{r}=0.84, P<0.001$ respectively; Table 5$)$ and good in the LAA ( $\mathrm{r}=0.40, P=0.04$; Table 5). In RA and pLA, this correlation was still significant after correction for differences between the three patient groups (partial correlation, RA: $r=0.86$, $\mathrm{p}<0.01$, pLA: $\mathrm{r}=0.76, \mathrm{p}<0.01$, LAA: 0.29, $\mathrm{p}=0.14$; Table 5).

\subsection{Structural alterations}

\section{Amyloid}

The degree of amyloid on Congo red staining present in the RAA samples was below the detection level. None of the tissue slices showed significant amyloid staining.

\section{Cell dimensions}

Cell diameter was significantly larger in persAF compared to aAF (Table 4). Cell length was not significantly different among the three rhythm groups, although a trend towards a longer length in the persAF group compared to the aAF group was present. Cell width was significantly larger in persAF compared to aAF and pAF. None of the 3 parameters showed a significant correlation with AF complexity (Table 4). Also after correction for group differences (partial correlation) there was no correlation between cell dimensions and AF complexity (Table 5).

\section{Total amount of fibrosis}

Representative examples of Sirius red staining for patients with aAF, pAF en persAF are depicted in Figure 4A. The quantified degree of fibrosis suggests

Table 4. Cell dimensions for acute AF, paroxysmal AF and persistent AF.

\begin{tabular}{llll}
\hline & $\begin{array}{l}\text { Acute AF } \\
(\mathrm{n}=11)\end{array}$ & $\begin{array}{l}\text { Paroxysmal AF } \\
(\mathrm{n}=12)\end{array}$ & $\begin{array}{l}\text { Persistent AF } \\
(\mathrm{n}=9)\end{array}$ \\
\hline Cell diameter $(\mu \mathrm{m})$ & $12.1 \pm 2.7$ & $13.3 \pm 2.8$ & $15.3 \pm 2.5^{*}$ \\
Cell length $(\mu \mathrm{m})$ & $59.4 \pm 10.1$ & $61.6 \pm 12.2$ & $67.4 \pm 9.2$ \\
Cell width $(\mu \mathrm{m})$ & $8.9 \pm 1.3$ & $9.1 \pm 1.5$ & $10.9 \pm 1.4^{*}$ \\
\hline
\end{tabular}

$\mathrm{P}<0.05$ vs Acute $A F,{ }^{\S} \mathrm{P}<0.05$ vs Paroxysmal $A F$ 
Table 5. Partial and overall correlations between cell dimensions, endomysial and overall fibrosis, and connexin 43 on the one hand and AF complexity on the other hand.

\begin{tabular}{lll}
\hline & $\begin{array}{l}\text { Correlation with } \\
\text { waves/AFCL }\end{array}$ & $\begin{array}{l}\text { Partial Correlation with } \\
\text { waves/AFCL }\end{array}$ \\
\hline Fractionation Index RA & $r=0.90, P<0.001$ & $r=0.86, P<0.001$ \\
Fractionation Index pLA & $r=0.84, P<0.001$ & $r=0.76, P<0.001$ \\
Fractionation Index LAA & $R=0.40, P=0.04$ & $r=0.29, P=0.14$ \\
Cell diameter $(\mu \mathrm{m})$ & $r=0.15, P=0.42$ & $r=-0.14, P=0.44$ \\
Cell length $(\mu \mathrm{m})$ & $r=0.30, P=0.11$ & $r=0.16, P=0.41$ \\
Cell width $(\mu \mathrm{m})$ & $r=0.32, P=0.08$ & $r=0.03, P=0.87$ \\
\% Fibrosis (total amount) & $r=0.23, P=0.20$ & $r=0.06, P=0.76$ \\
Endomysial fibrosis & $r=0.57, P=0.001$ & $r=0.44, P=0.01$ \\
Connexin 43 & $r=0.51, P=0.003$ & $r=0.14, P=0.47$
\end{tabular}

A.

Acute AF

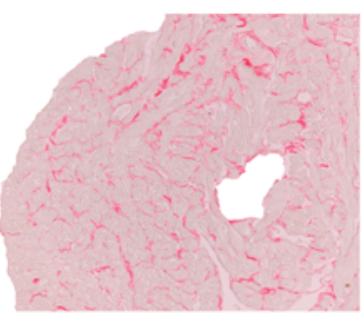

\% Fibrosis (total amount) in Right Atrial Appendage

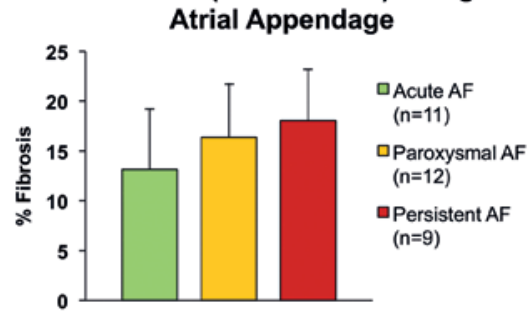

B.

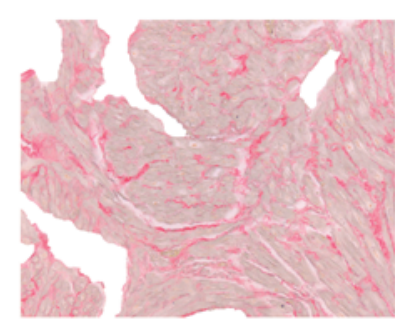

Persistent AF

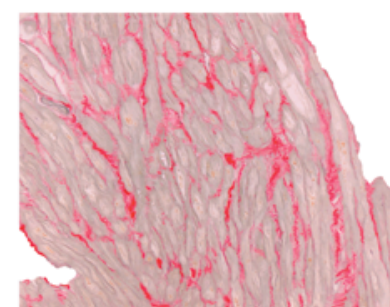

Sirius Red Staining (magnification 20x)

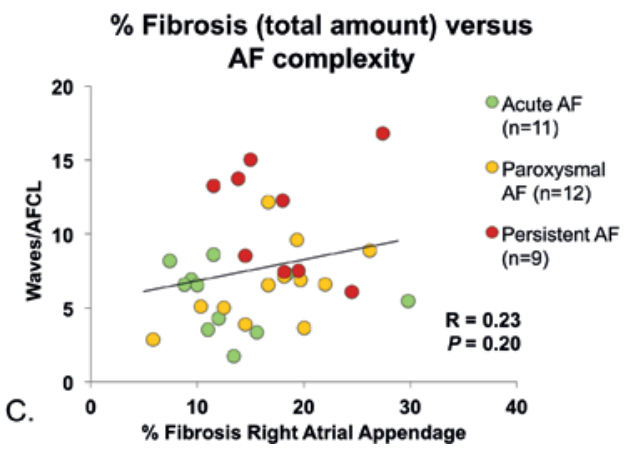

Figure 4. Representative pictures of Sirius red staining after exclusion of pericardial and perivascular fibrosis for aAF, $p A F$ and pers $A F(A)$. Total amount of fibrosis (\%) in RAA (B). Correlation between total amount of fibrosis (\%) and AF complexity (C). 
Chapter 4

a trend towards more fibrosis in the persAF compared to the aAF group (Figure 4B), however this difference was not significant (aAF=13.4 $\pm 6.3 \%$, $\mathrm{pAF}=16.6 \pm 5.5 \%$, persAF $=18.0 \pm 5.2 \%, P=0.17)$. Moreover, no correlation was present between AF complexity (expressed as waves/AFCL) and the degree of fibrosis (correlation $\mathrm{r}=0.23, P=0.20$, Figure $4 \mathrm{C}$ ). Also after correction for group differences (partial correlation) there was no correlation between total fibrosis and AF complexity (Table 5).

\section{Endomysial Fibrosis.}

Representative samples of Haematoxylin and eosin staining for endomysial fibrosis (fibrosis within bundles between cells) are depicted in Figure 5A. Again, there was a trend of increased endomysial fibrosis in the persAF group compared to the aAF group as can also be appreciated in the example stainings (Figure 5A and 5B). The difference in endomysial fibrosis among groups was almost reached statistical significance $(\mathrm{aAF}=3.1 \pm 1.4 \mu \mathrm{m}, \mathrm{pAF}=3.7 \pm 1.6 \mu \mathrm{m}$, pers $A F=5.2 \pm 2.5 \mu \mathrm{m}, P=0.054)$. There was a positive correlation between $\mathrm{AF}$

A.

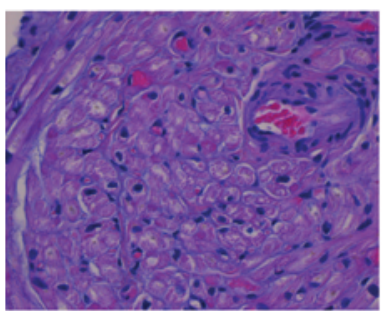

Endomysial Fibrosis in

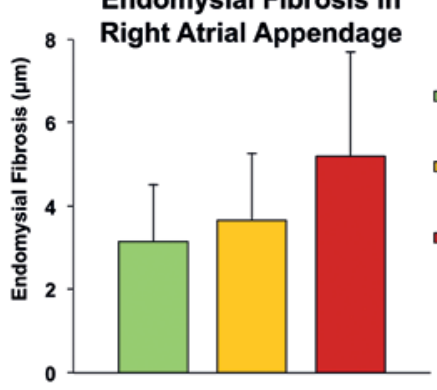

B.

Figure 5. Representative pictures of HEE staining with endomysial (cell-to-cell) fibrosis for $a A F, p A F$ and pers $A F(A)$. Endomysial fibrosis in RAA (B). Correlation between endomysial fibrosis and $A F$ complexity (C). 
complexity and the degree of endomysial fibrosis ( $\mathrm{r}=0.57, P=0.001$, Figure 5C). Importantly, this correlation was still significant after correction for group differences (partial correlation, $\mathrm{r}=0.44, \mathrm{p}=0.01$, Table 5).

\section{Cx43 expression and distribution.}

In Figure 6A, lateralization of $\mathrm{Cx} 43$ is shown in 3 representative examples of $\mathrm{C} \times 43$ immunostaining. A decreasing trend in polar $\mathrm{C} x 43$ was present between the groups $(\mathrm{aAF}=75.4 \pm 12.1 \%$, $\mathrm{pAF}=71.3 \pm 10.9 \%$, persAF $=60.7 \pm 13.7 \%, P=0.058$; Figure $6 \mathrm{~B})$. Also, both lateral $\mathrm{C} \times 43(\mathrm{aAF}=5.7 \pm 6.5 \%, \mathrm{pAF}=16.9 \pm 6.3 \%$, persAF= $20.8 \pm 7.1 \%, P<0.001)$ and the Cx43-ratio $(\mathrm{aAF}=7.5 \pm 8.9 \%, \mathrm{pAF}=24.7 \pm 11.1 \%$, persAF $=35.1 \pm 11.4 \%, P<0.001$ ) were higher in $\mathrm{pAF}$ and persAF than in aAF (Figure 6B). There was a correlation between the $\mathrm{Cx} 43$ distribution and $\mathrm{AF}$ complexity (correlation $\mathrm{r}=0.51, P=0.003$, Figure $6 \mathrm{C}$ ). However, after correction for group differences (partial correlation), this correlation was not significant anymore $(\mathrm{r}=0.14, P=0.47$, Table 5$)$.

A.

Acute AF

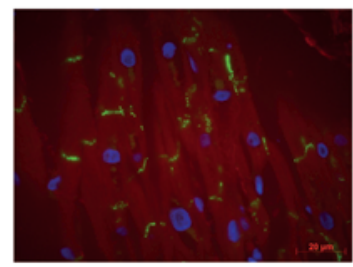

Paroxysmal AF

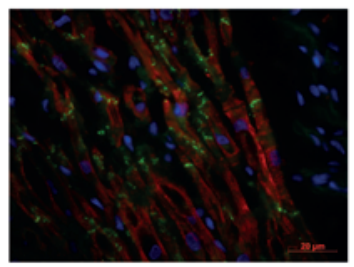

Persistent AF

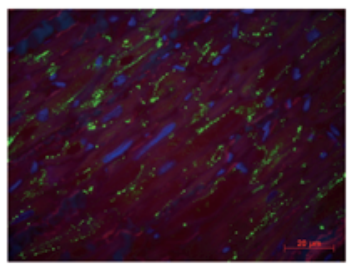

Immunostaining for connexin 43

Connexin $\mathbf{4 3}$ expression and distribution

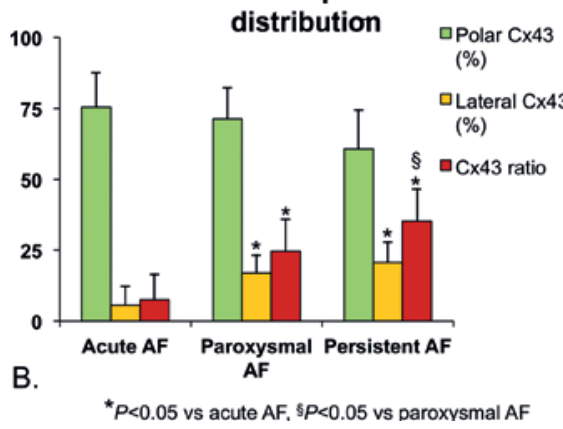

Connexin $\mathbf{4 3}$ ratio versus AF complexity

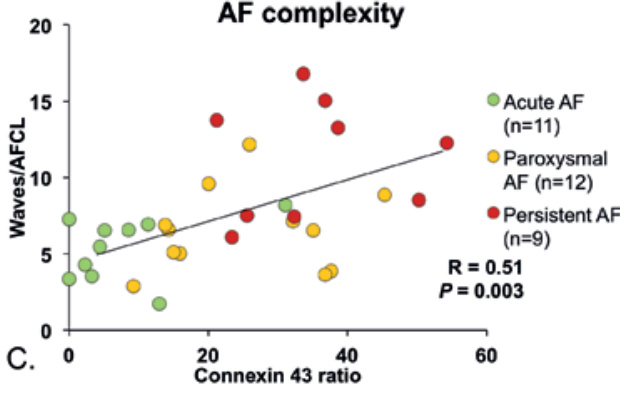

Figure 6. Representative pictures of immunostaining for $C x 43$ for $a A F, p A F$ and pers $A F(A)$. In aAF CX43 is mainly localized at the longitudinal junction between myocytes. In pers $A F$, distribution of $C x 43$ is more lateralized than in aAF. Amount of polar $C x 43$, lateral $C x 43$ and Cx43 ratio in $R A A(B)$. Correlation $C x 43$ ratio and AF complexity $(C)$. 


\section{Discussion}

\subsection{Main Findings}

With this analysis of high-density epicardial AF mapping data in patients undergoing cardiac surgery we provide a direct comparison of substrate characteristics between patients with acutely induced AF, patients with paroxysmal and patients with persistent AF enabling a cross-sectional comparison of structural and electrophysiological characteristics of human AF during all stages of the arrhythmia.

We demonstrate that AF complexity in patients with paroxysms of AF is not intermediate between patients with acutely induced AF and patients with longstanding persistent AF, but similar to AF complexity in patients with aAF. Furthermore, AF complexity is much higher in patients with persAF compared to patients with aAF and $\mathrm{pAF}$. The conduction pattern in persistent AF is characterized by multiple simultaneous fibrillation waves, a high incidence of epicardial breakthrough and highly fractionated electrograms. The conduction pattern in aAF and $\mathrm{pAF}$ is far less complex and AF electrograms are less fractionated. We also provide a direct comparison between electrophysiological properties of the right atrium and the underlying morphological changes like total and endomysial fibrosis, gap junction remodeling, amyloidosis and changes in cell dimensions. Of all investigated parameters only endomysial fibrosis, not overall fibrosis, correlates with AF complexity independently from differences between the groups.

\subsection{Paroxysmal AF in the process of AF progression}

Since the description of focal triggers located in the muscular sleeves of the pulmonary veins initiating paroxysms of $\mathrm{AF},{ }^{4}$ a huge number of patients have been treated with ablative procedures electrically isolating the pulmonary veins. To date, however, detailed high-density mapping studies addressing the substrate in human pAF are scarce. Several studies did describe specific electrophysiological changes in human pAF compared to control: prolonged signalaveraged $\mathrm{p}$-wave durations, ${ }^{17}$ increased spatial dispersion of refractoriness, ${ }^{18}$ globally shortened refractoriness with increased spatial heterogeneity, ${ }^{6}$ higher anisotropy indices ${ }^{19}$ and prolongation of conduction times and higher proportion of complex electrograms have been described. ${ }^{7,8}$ On the other hand, epicardial mapping in patients without a AF history showed electrogram prolongation indicating the presence of a substrate capable of maintaining AF. ${ }^{5}$ 
Mechanisms underlying progression of AF from paroxysms to more persistent forms are still under debate. Allessie et al. demonstrated that longstanding persistent human $\mathrm{AF}$ is characterized by electrical dissociation between neighboring atrial muscle bundles and a high incidence of epicardial breakthrough compared to SR. ${ }^{13,14}$ In a goat model of lone AF, we reported that persistence of AF goes hand in hand with an increase in endo-epicardial dissociation of electrical activity, ${ }^{15}$ in $3 \mathrm{D}$ conduction (breakthrough $)^{20}$ and with rearrangement of atrial bundle anatomy and AF conduction. ${ }^{21}$ Lee et al. performed high-density mapping of human persistent AF and found activation patterns consisting of multiple wavefronts and disorganized electrical activity, with sporadic occurrence of focal activity and only 3 transient rotational circuits. ${ }^{22}$ Unlike this anarchical organization of AF, hierarchical mechanisms such as stable rotors and focal sources have been put forward as the mechanism driving and perpetuating AF. ${ }^{23}$ Freedom of AF after ablation of these sources has been reported to be higher than with other ablation strategies. ${ }^{24}$ Remarkably, the authors reported no large differences in rotor incidence or behavior between $\mathrm{pAF}$ and persAF and no correlation with (bipolar) electrogram fractionation. ${ }^{25}$ More recently, noninvasive mapping was used to identify meandering driver locations and periodic occurrence of unstable reentries and endocardial ablation of those drivers was associated with a high degree of $\mathrm{AF}$ termination. ${ }^{26}$

In this study, we reported comparable AF complexity in terms of numbers of fibrillation waves, epicardial breakthroughs and electrogram fractionation between patients without a history of AF and patients with pAF. These data confirm the findings of Kanagaratnam et al. that also in patients without an AF history, a substrate capable of maintaining AF can be present. ${ }^{5}$ Also, as AF complexity was not different between aAF and $\mathrm{pAF}$, these data support the importance of triggers in the occurrence of pAF. ${ }^{4}$ Furthermore, AF complexity was much higher in persAF compared to aAF and $\mathrm{pAF}$, and also higher in the pLA than in the RA. Higher AF complexity in persAF compared to aAF was also reported in other high-density human mapping studies., ${ }^{5,13}$ These findings indirectly imply that the increase in AF complexity in patients with persistent AF must occur after AF has become persistent. This means that although structural heart disease may have caused significant structural alterations in the atrium before $\mathrm{AF}$ becomes persistent, ${ }^{27}$ the structural alterations responsible for the increase in incidence of conduction block actually occur as a response to sustained episodes of AF. 
Chapter 4

\subsection{Structural remodeling as determinant of conduction disturbances}

Several structural alterations have been identified as possible determinants of the 'second factor'. In an analysis of RAA of patients undergoing cardiac surgery, atrial amyloidosis was present in $16.3 \%$ and associated with prolonged p-wave duration and increased AF risk. ${ }^{28}$ In our study we could not detect appreciable amyloid levels. This might be due to its low prevalence or differences in study populations. Obviously, amyloidosis played limited role for conduction disturbances in our population.

Another relevant factor might be myocyte hypertrophy, which can also cause conduction disturbances. ${ }^{1,29}$ Both in animal and human studies, cellular hypertrophy has been associated with progression of AF.11,30,31 In our study, atrial myocyte diameter was larger in persAF patients than in aAF patients. This is in line with another study analyzing appendages removed during cox-maze surgery. ${ }^{11}$ Although myocyte hypertrophy occurs with persistence of $\mathrm{AF}$, it was not associated with an increase in AF complexity and as such seems to play a bystander role for conduction disturbances.

Atrial fibrosis is often thought to play the most important role in the structural remodeling process of $\mathrm{AF}$, however the relation between fibrosis and $\mathrm{AF}$ in experimental and human studies is not so consistent. ${ }^{1}$ For example, the canine heart failure model is known to produce a high degree of (replacement) fibrosis, yet perpetuates a rather low complexity type of $A F .{ }^{32}$ In patients, Platonov et al. found more fibrosis in AF patients than control at different atrial locations, but found no clear correlation with AF duration. ${ }^{10}$ Anné et al. showed interstitial fibrosis to be a consequence of the underlying valvular disease rather than of the presence of AF. ${ }^{31}$ More recently noninvasive DE-MRI quantification of fibrosis has been shown to correlate to pathological LA regions (low voltage zones) and AF recurrence after ablation, ${ }^{9}$ however an inverse relationship was reported between electrogram fractionation and MRI-detected fibrosis. ${ }^{33}$

In our data set, we did not find differences in total amount of fibrosis between $\mathrm{aAF}, \mathrm{pAF}$ and persAF. More importantly, we did not find any correlation between total amount of fibrosis and AF complexity (independent of classifying patients in pAF or persAF). Unlike the total amount of fibrosis, endomysial fibrosis (quantified as the distance between myocytes within bundles) is reported to better represent specific AF-related structural remodeling. ${ }^{30} \mathrm{We}$ found borderline significance for amount of endomysial fibrosis in persAF 
compared to aAF. However, endomysial fibrosis correlated very well with AF complexity. Importantly, this correlation was still present after correction for differences between the patient groups. Therefore, endomysial fibrosis rather than total amount of fibrosis seems to be a solid marker of structural remodeling of the AF substrate.

Finally, altered connexin expression might play a role in micro-reentery, however their exact contribution remains to be determined. ${ }^{1}$ In AF, translocation of Cx43 to the lateral membranes of the myocytes has been reported, while Cx43 usually localizes in the end-to-end junctional complexes. ${ }^{16}$ Also in our study, a higher $\mathrm{Cx} 43$ ratio was found in persAF compared to aAF and $\mathrm{pAF}$, and also a higher $\mathrm{C} \times 43$ ratio in $\mathrm{pAF}$ compared to aAF. Furthermore, lateralization of $\mathrm{C} \times 43$ correlated overall with AF complexity. However, as a partial correlation was not present, this is most likely the consequence of the difference in Cx43-ratio between the three groups. In theory, this changed pattern in connexin expression may reduce conduction velocity and potentially could contribute to enhanced incidence of conduction block. ${ }^{16}$

\subsection{Clinical Relevance}

Two important findings of this study are relevant for clinical practice. First, given the large variability of AF complexity in $\mathrm{pAF}$, this group harbors patients with very complex and less complex substrates. As such, pAF patients would benefit most of real-time identification of the underlying AF substrate complexity. Secondly, this study - among others - identified total amount of fibrosis as a weak factor in the structural remodeling process. Endomysial fibrosis, on the contrary, emerges as a solid and important player in the development of a substrate for AF. As a consequence, novel non-invasive methods for atrial fibrosis quantification, such as DE-MRI, may overestimate the value of overall fibrosis as a determinant of conduction disturbances in AF.

\subsection{Conclusions}

In this in-depth electrophysiological and structural analysis of human AF in patients without a history of $\mathrm{AF}$, with $\mathrm{pAF}$ and with persAF, we were able to show that the complexity of the AF substrate in patients with pAF is comparable to the complexity found in patients without history of AF. This implies that the increase of AF complexity identified in patients with persistent $\mathrm{AF}$ occurs primarily after AF has become persistent. Moreover, patients with $\mathrm{pAF}$ 


\section{Chapter 4}

exhibit a large variability in AF complexity. Together with lateralization of Cx43, endomysial but not total amount of fibrosis, plays an important role in the development of a substrate for AF.

\subsection{Limitations}

This study is performed in patients undergoing cardiac surgery for different underlying pathologies, not in 'lone- $\mathrm{AF}^{\prime}$ patients. As such, the results might be influenced by the underlying pathology. However statistical analysis did not show differences in type of surgery among groups. Recording on the LAA were performed on cardiopulmonary bypass but with preserved filling pressures. Initiation of cardiopulmonary bypass might alter cardiac pressures and therefore also AF conduction. Structural analysis was performed on right atrial appendages, which might be different of the atrial histology at the pLA. The same holds true for LAA biopsies, as electrical activation at the LAA is often very regular and less fractionated than at the pLA. It must be stressed that fibrosis, total or endomysial, is a bi-atrial disease. The activation patterns during AF in the RA also were complex with propagation of multiple simultaneous waves and a high degree of 3D conduction. As such, it is reasonable to assume that a comparable correlation between structural alterations and AF complexity is also found in the left atrium. 


\section{References}

1. Schotten U, Verheule S, Kirchhof P and Goette A. Pathophysiological mechanisms of atrial fibrillation: a translational appraisal. Physiol Rev. 2011;91:265-325.

2. Wijffels MC, Kirchhof CJ, Dorland R and Allessie MA. Atrial fibrillation begets atrial fibrillation. A study in awake chronically instrumented goats. Circulation. 1995;92:1954-68.

3. de Vos CB, Pisters R, Nieuwlaat R, Prins MH, Tieleman RG, Coelen RJ, van den Heijkant AC, Allessie MA and Crijns HJ. Progression from paroxysmal to persistent atrial fibrillation clinical correlates and prognosis. J Am Coll Cardiol. 2010;55:725-31.

4. Haissaguerre M, Jais P, Shah DC, Takahashi A, Hocini M, Quiniou G, Garrigue S, Le Mouroux A, Le Metayer P and Clementy J. Spontaneous initiation of atrial fibrillation by ectopic beats originating in the pulmonary veins. N Engl J Med. 1998;339:659-66.

5. Kanagaratnam P, Kojodjojo P and Peters NS. Electrophysiological Abnormalities Occur Prior to the Development of Clinical Episodes of Atrial Fibrillation: Observations from Human Epicardial Mapping. Pacing and Clinical Electrophysiology. 2008;31:443-453.

6. Kojodjojo P, Peters NS, Davies DW and Kanagaratnam P. Characterization of the electroanatomical substrate in human atrial fibrillation: the relationship between changes in atrial volume, refractoriness, wavefront propagation velocities, and AF burden. J Cardiovasc Electrophysiol. 2007;18:269-75.

7. Stiles MK, John B, Wong CX, Kuklik P, Brooks AG, Lau DH, Dimitri H, Roberts-Thomson KC, Wilson L, De Sciscio P, Young GD and Sanders P. Paroxysmal lone atrial fibrillation is associated with an abnormal atrial substrate: characterizing the "second factor". J Am Coll Cardiol. 2009;53:1182-91.

8. Teh AW, Kistler PM, Lee G, Medi C, Heck PM, Spence SJ, Sparks PB, Morton JB and Kalman JM. Electroanatomic remodeling of the left atrium in paroxysmal and persistent atrial fibrillation patients without structural heart disease. J Cardiovasc Electrophysiol. 2012; 23:232-8.

9. Oakes RS, Badger TJ, Kholmovski EG, Akoum N, Burgon NS, Fish EN, Blauer JJ, Rao SN, DiBella EV, Segerson NM, Daccarett M, Windfelder J, McGann CJ, Parker D, MacLeod RS and Marrouche NF. Detection and quantification of left atrial structural remodeling with delayed-enhancement magnetic resonance imaging in patients with atrial fibrillation. Circulation. 2009;119:1758-67.

10. Platonov PG, Mitrofanova LB, Orshanskaya V and Ho SY. Structural abnormalities in atrial walls are associated with presence and persistency of atrial fibrillation but not with age. J Am Coll Cardiol. 2011;58:2225-32.

11. Castonguay MC, Wang Y, Gerhart JL, Miller DV, Stulak JM, Edwards WD and Maleszewski JJ. Surgical Pathology of Atrial Appendages Removed During the Cox-Maze Procedure: A Review of 86 Cases (2004 to 2005) With Implications For Prognosis. The American Journal of Surgical Pathology. 2013;37:890-897. 


\section{Chapter 4}

12. Zeemering S, Maesen B, Nijs J, Lau DH, Granier M, Verheule S and Schotten U. Automated quantification of atrial fibrillation complexity by probabilistic electrogram analysis and fibrillation wave reconstruction. Conf Proc IEEE Eng Med Biol Soc. 2012;2012:6357-60.

13. Allessie MA, de Groot NM, Houben RP, Schotten U, Boersma E, Smeets JL and Crijns HJ. Electropathological substrate of long-standing persistent atrial fibrillation in patients with structural heart disease: longitudinal dissociation. Circ Arrhythm Electrophysiol. 2010;3:606-15.

14. de Groot NM, Houben RP, Smeets JL, Boersma E, Schotten U, Schalij MJ, Crijns H and Allessie MA. Electropathological substrate of longstanding persistent atrial fibrillation in patients with structural heart disease: epicardial breakthrough. Circulation. 2010;122:1674-82.

15. Eckstein J, Maesen B, Linz D, Zeemering S, van Hunnik A, Verheule S, Allessie M and Schotten U. Time course and mechanisms of endo-epicardial electrical dissociation during atrial fibrillation in the goat. Cardiovasc Res. 2011;89:816-24.

16. Polontchouk L, Haefliger JA, Ebelt B, Schaefer T, Stuhlmann D, Mehlhorn U, Kuhn-Regnier F, De Vivie ER and Dhein S. Effects of chronic atrial fibrillation on gap junction distribution in human and rat atria. J Am Coll Cardiol. 2001;38:883-91.

17. Fukunami M, Yamada T, Ohmori M, Kumagai K, Umemoto K, Sakai A, Kondoh N, Minamino $\mathrm{T}$ and Hoki N. Detection of patients at risk for paroxysmal atrial fibrillation during sinus rhythm by P wave-triggered signal-averaged electrocardiogram. Circulation. 1991;83:162-9.

18. Ramanna H, Hauer RN, Wittkampf FH, de Bakker JM, Wever EF, Elvan A and Robles De Medina EO. Identification of the substrate of atrial vulnerability in patients with idiopathic atrial fibrillation. Circulation. 2000;101:995-1001.

19. Wong CX, Stiles MK, John B, Brooks AG, Lau DH, Dimitri H, Kuklik P, Shipp NJ, Sullivan $\mathrm{T}$ and Sanders P. Direction-dependent conduction in lone atrial fibrillation. Heart Rhythm. 2010;7:1192-9.

20. Eckstein J, Zeemering S, Linz D, Maesen B, Verheule S, van Hunnik A, Crijns H, Allessie MA and Schotten U. Transmural conduction is the predominant mechanism of breakthrough during atrial fibrillation: evidence from simultaneous endo-epicardial high-density activation mapping. Circ Arrhythm Electrophysiol. 2013;6:334-41.

21. Maesen B, Zeemering S, Afonso C, Eckstein J, Burton RA, van Hunnik A, Stuckey DJ, Tyler D, Maessen J, Grau V, Verheule S, Kohl P and Schotten U. Rearrangement of atrial bundle architecture and consequent changes in anisotropy of conduction constitute the 3-dimensional substrate for atrial fibrillation. Circ Arrhythm Electrophysiol. 2013;6:967-75.

22. Lee G, Kumar S, Teh A, Madry A, Spence S, Larobina M, Goldblatt J, Brown R, Atkinson V, Moten S, Morton JB, Sanders P, Kistler PM and Kalman JM. Epicardial wave mapping in human long-lasting persistent atrial fibrillation: transient rotational circuits, complex wavefronts, and disorganized activity. Eur Heart J. 2014;35:86-97. 


\section{Substrate of Human AF}

23. Narayan SM, Krummen DE and Rappel WJ. Clinical mapping approach to diagnose electrical rotors and focal impulse sources for human atrial fibrillation. J Cardiovasc Electrophysiol. 2012;23:447-54.

24. Narayan SM, Baykaner T, Clopton P, Schricker A, Lalani GG, Krummen DE, Shivkumar K and Miller JM. Ablation of rotor and focal sources reduces late recurrence of atrial fibrillation compared with trigger ablation alone: extended follow-up of the CONFIRM trial (Conventional Ablation for Atrial Fibrillation With or Without Focal Impulse and Rotor Modulation). J Am Coll Cardiol. 2014;63:1761-8.

25. Narayan SM, Shivkumar K, Krummen DE, Miller JM and Rappel WJ. Panoramic electrophysiological mapping but not electrogram morphology identifies stable sources for human atrial fibrillation: stable atrial fibrillation rotors and focal sources relate poorly to fractionated electrograms. Circ Arrhythm Electrophysiol. 2013;6:58-67.

26. Haissaguerre M, Hocini M, Denis A, Shah AJ, Komatsu Y, Yamashita S, Daly M, Amraoui S, Zellerhoff S, Picat MQ, Quotb A, Jesel L, Lim H, Ploux S, Bordachar P, Attuel G, Meillet V, Ritter P, Derval N, Sacher F, Bernus O, Cochet H, Jais P and Dubois R. Driver domains in persistent atrial fibrillation. Circulation. 2014;130:530-8.

27. Kottkamp H. Human atrial fibrillation substrate: towards a specific fibrotic atrial cardiomyopathy. European Heart Journal. 2013;34:2731-2738.

28. Röcken C, Peters B, Juenemann G, Saeger W, Klein HU, Huth C, Roessner A and Goette A. Atrial Amyloidosis: An Arrhythmogenic Substrate for Persistent Atrial Fibrillation. Circulation. 2002;106:2091-2097.

29. Spach MS, Heidlage JF, Barr RC and Dolber PC. Cell size and communication: role in structural and electrical development and remodeling of the heart. Heart Rhythm. 2004;1:500-15.

30. Verheule S, Tuyls E, Gharaviri A, Hulsmans S, van Hunnik A, Kuiper M, Serroyen J, Zeemering S, Kuijpers NH and Schotten U. Loss of continuity in the thin epicardial layer because of endomysial fibrosis increases the complexity of atrial fibrillatory conduction. Circ Arrhythm Electrophysiol. 2013;6:202-11.

31. Anne W, Willems R, Roskams T, Sergeant P, Herijgers P, Holemans P, Ector H and Heidbuchel $\mathrm{H}$. Matrix metalloproteinases and atrial remodeling in patients with mitral valve disease and atrial fibrillation. Cardiovasc Res. 2005;67:655-66.

32. Li D, Fareh S, Leung TK and Nattel S. Promotion of atrial fibrillation by heart failure in dogs: atrial remodeling of a different sort. Circulation. 1999;100:87-95.

33. Jadidi AS, Cochet H, Shah AJ, Kim SJ, Duncan E, Miyazaki S, Sermesant M, Lehrmann H, Lederlin M, Linton N, Forclaz A, Nault I, Rivard L, Wright M, Liu X, Scherr D, Wilton SB, Roten L, Pascale P, Derval N, Sacher F, Knecht S, Keyl C, Hocini M, Montaudon M, Laurent F, Haissaguerre $\mathrm{M}$ and Jais P. Inverse relationship between fractionated electrograms and atrial fibrosis in persistent atrial fibrillation: combined magnetic resonance imaging and high-density mapping. J Am Coll Cardiol. 2013;62:802-12. 



\section{Chapter 5}

\section{Indices of Bipolar Complex}

\section{Fractionated Atrial}

\section{Electrograms Correlate}

Poorly with Each Other and

\section{Atrial Fibrillation Substrate}

\section{Complexity}

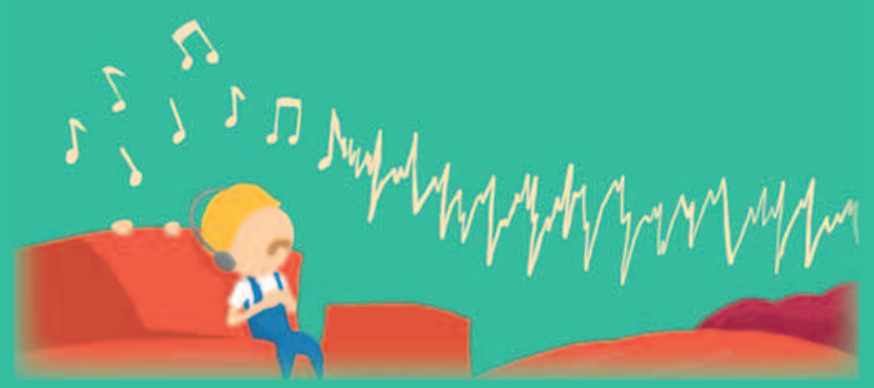

*Dennis H. Lau, *Bart Maesen, Stef Zeemering, Pawel Kuklik, Arne van Hunnik, Theodorus A. R. Lankveld, Elham Bidar, Sander Verheule, Jan Nijs, Jos Maessen, Harry Crijns, Prashanthan Sanders, Ulrich Schotten *denotes equal contribution

Published in Heart Rhythm. 2015 Jul;12(7):1415-23. 


\section{Chapter 5}

\section{Abstract}

Background: The pathophysiological relevance of complex fractionated atrial electrograms (CFAE) in atrial fibrillation (AF) remains poorly understood.

Objective: This work aims to comprehensively investigate how bipolar CFAE correlates with unipolar electrogram fractionation and the underlying electrophysiological substrate of AF.

Methods: Ten-second unipolar AF electrograms were recorded using a highdensity electrode from the left atrium of 20 (10 persistent and 10 paroxysmal) AF patients undergoing cardiac surgery. Semi-automated bipolar CFAE algorithms: complex fractionated electrogram-mean (CFE-m), interval confidence interval (ICL), continuous electrical activity (CEA), average complex interval (ACI) and shortest complex interval (SCI) were evaluated against AF substrate complexity measures following fibrillation wave reconstruction derived from local unipolar activation time. The effect of inter-electrode spacing and electrode orientation on bipolar CFAE was also examined.

Results: All five semi-automated bipolar CFAE algorithms showed poor correlation with each other and AF substrate complexity measures (conduction velocity, number of waves or breakthroughs per AF cycle and electrical dissociation). Bipolar CFAE also correlated poorly with fractionation index (FI) derived from the unipolar electrograms. Increased inter-electrode spacing resulted in an increase in bipolar CFAE detected except for the ICL algorithm. CFAE appears unaffected by bipolar electrode orientation (vertical vs. horizontal). By contrast, unipolar FI correlated well with AF substrate complexity measures and can be regarded as a marker for conduction block.

Conclusions: The lack of pathophysiological relevance of bipolar CFAE analysis may in part contribute to the divergent and limited success rates of catheter ablation strategies targeting CFAE. 


\section{Introduction}

Sites with complex fractionated atrial electrograms (CFAE) are of potential pathophysiological relevance to the atrial fibrillation (AF) substrate. ${ }^{1}$ Numerous studies have demonstrated that progressive atrial remodeling with AF persistence was associated with increasing atrial substrate complexity including electrogram fractionation. ${ }^{2-8}$ Nademanee et al were first to report high successful AF termination rate following CFAE ablation in 2004. ${ }^{9}$ However, this initial success has not been reproducible, with a recent randomized trial (STAR AF 2) demonstrating no extra benefits of additional CFAE ablation over pulmonary vein isolation alone in persistent AF patients. ${ }^{10}$

A myriad of factors may account for the variable and curtailed outcomes of CFAE ablation we have seen to date. ${ }^{11}$ We have recently highlighted that both algorithms and mapping electrode configurations may have significant impact on CFAE determinations. ${ }^{12,13}$ Further, how CFAE are related to the pathophysiological mechanisms of AF remains poorly understood. At present, CFAE can be defined using semi-automated mapping software incorporated with 3-D electroanatomical mapping systems. The CARTO (Biosense Webster, Diamond Bar, CA) system accommodates four different bipolar CFAE measures: Interval confidence level (ICL), average complex interval (ACI), shortest complex interval (SCI) and continuous electrical activity (CEA); while the EnSite NavX (St Jude Medical, St Paul, MN) system uses only one: Complex fractionated electrogram-mean (CFE-m).

In this study, our primary aim is to evaluate these bipolar CFAE algorithms against electrophysiological characteristics of the underlying atrial substrate derived from high-density activation mapping of unipolar human AF electrograms. Further, we aimed to comprehensively evaluate the impact of algorithms, inter-electrode spacing and electrode orientation on CFAE determinations. Comparative analysis of these semi-automated bipolar measures of CFAE was also undertaken with correlation to their unipolar activation.

\section{Methods}

\subsection{Study Population}

This study included 20 AF patients (10 paroxysmal and 10 persistent) undergoing cardiac surgery for coronary or valvular heart disease and/or AF at Maastricht University Medical Centre. The institutional ethics review com- 


\section{Chapter 5}

mittee approved this study protocol and all patients gave written informed consent. Intra-operative mapping was performed under general anesthesia. Following median sternotomy, a single-use custom-made high-density multiple electrode array (Flex-MEA, 256 or 64 electrodes, electrode diameter $0.1 \mathrm{~mm}$, inter-electrode spacing $1.5 \mathrm{~mm}$ ) was used for direct contact epicardial mapping. ${ }^{14}$ Incremental atrial pacing was used to induce AF if necessary. Unipolar AF electrograms were recorded from the posterior wall of the left atrium and the left atrial appendage using a custom-made 256-channel mapping amplifier (filtering bandwidth $0.1-400 \mathrm{~Hz}$, sampling rate $1 \mathrm{kHz}, \mathrm{A} / \mathrm{D}$ resolution $16 \mathrm{bits}$ ). A silver plate was secured in the thoracic cavity and acted as an indifferent electrode.

\subsection{Semi-automated CFAE Algorithms}

Unipolar atrial electrograms were first filtered (bandwidth 1-400Hz) prior to conversion to bipolar electrograms (bandpass filter 30-400 Hz) using custom software programmed in the MATLAB environment (The MathWorks Inc., Natick, MA, USA). To evaluate the effect of inter-electrode spacing and electrode orientation on CFAE determinations, bipolar electrograms were constructed from unipolar signals 1.5, 3.0, 4.5 and $6 \mathrm{~mm}$ apart in both horizontal and vertical orientations. Comparisons of CFAE between horizontal and vertical electrode configurations were facilitated by linear interpolation of each fractionation map into 961 nodes. Point-by-point correlations of CFAE determined by different algorithms were analyzed using bipolar electrograms of $1.5 \mathrm{~mm}$ inter-electrode spacing only. We used AF episodes of $10 \mathrm{~s}$ duration to ensure accurate CFAE characterization. ${ }^{15}$

Electrograms or deflections were first tagged according to the system specific amplitude and timing criteria, which were designed to avoid noise or far-field detections. For the CARTO algorithms, electrogram width was 15-30ms with amplitude range of $0.03-0.15 \mathrm{mV}$. For the EnSite NavX CFE-m algorithm, refractory period was set at $50 \mathrm{~ms}$ with minimum electrogram width of $10 \mathrm{~ms}$ and peak-to-peak sensitivity of $0.03-0.1 \mathrm{mV}$. All electrograms were verified manually to ensure accurate annotation and determination of CFAE according to the individual algorithm at factory default or previously published values using custom analysis software: ${ }^{13}$

I. Interval confidence level (ICL): ICL refers to the number of 70-120ms intervals between tagged intrinsic local activations per 2.5s of AF. CFAE is defined by ICL $\geq 5$. 
II. Average complex interval (ACI): This refers to the average of all intervals between 2 successive tagged deflections within the range of $70-500 \mathrm{~ms}$. CFAE is defined by $\mathrm{ACI} \leq 100 \mathrm{~ms}$.

III. Shortest complex interval (SCI): This refers to the shortest interval between 2 successive tagged deflections within the range of $70-500 \mathrm{~ms}$. CFAE is defined by $\mathrm{SCI} \leq 120 \mathrm{~ms}$.

IV. Continuous electrical activity (CEA): This was defined by the presence of 2 or more successive tagged deflections with interval $<50 \mathrm{~ms}$ and expressed as percentage of continuous activity. CFAE is defined by CEA $\geq 75 \%$.

$V$. Complex fractionated electrogram mean (CFE-m): This measures the mean of time intervals between the marked deflections. CFAE is defined by CFE-m $<120 \mathrm{~ms}$.

\subsection{Characterization of the Atrial Substrate by High-density Activation Mapping}

Established wave-mapping technique based on unipolar local activation time was used to compute the following substrate complexity measures: AF wave conduction velocity, number of waves per AF cycle, electrical dissociation and incidence of breakthrough waves per AF cycle. ${ }^{2-6,16}$ Detailed methods of unipolar electrogram deflection detection, $\mathrm{AF}$ wave reconstruction and computation of these substrate parameters can be found in the online supplement. Further, the automated deflection detection algorithm can differentiate local from non-local activations (Figure 1). The downstroke of a unipolar electrogram has been shown to represent local activation that coincides with the upstroke of the action potential of the underlying myocyte. ${ }^{17}$ Any additional
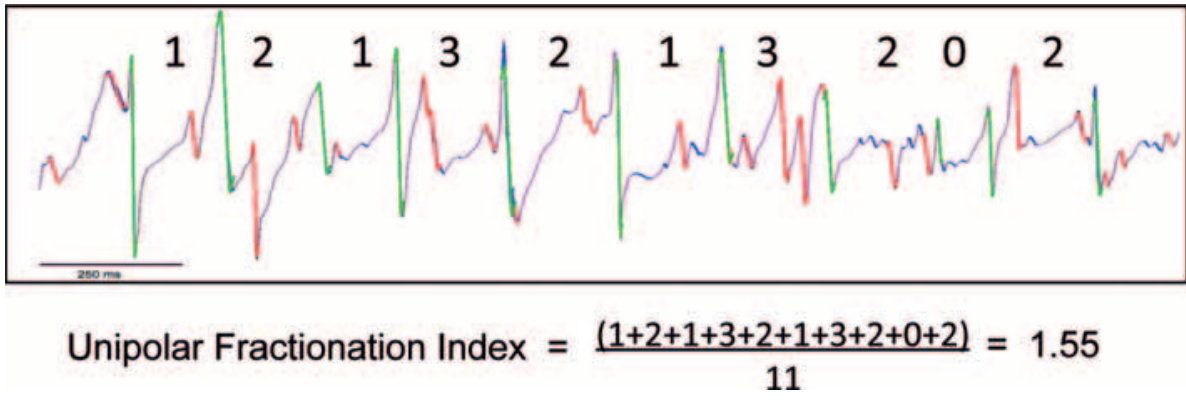

Figure 1. Fractionation index according to local unipolar activations. Both local (green) and nonlocal (red) deflections are marked by automated deflection detection algorithm. In this example, unipolar fractionation index taken as the ratio of nonlocal to local deflections is 1.55. 


\section{Chapter 5}

deflections are therefore due to fractionation or non-local activations. We therefore defined unipolar fractionation index (FI) as the ratio of non-local to local deflections. Bipolar CFAE algorithms were assessed against the fractionation index of the respective unipolar electrograms (mean FI at both unipoles) and the individual AF substrate complexity measures listed above.

\subsection{Statistical Analysis}

All continuous variables are reported as mean \pm SD. Data were compared using the Student's t-test or Wilcoxon rank sum test according to their distribution. Categorical data were compared using the Fisher's exact test. To investigate the effect of algorithm, inter-electrode spacing and electrode configuration on CFAE detection as well as the percentage of match between CFAE algorithms, a linear mixed-effects model was used. In this model, each of the above factors was entered as the dependent variable with AF type entered as fixed factor and patient ID as random factor. One-way ANOVA was used to compare bipolar CFAE across different inter-electrode spacing. Correlation analyses between various time domain algorithms and with AF complexity measures were also assessed. Statistical significance was established at $\mathrm{p}<0.05$.

\section{Results}

Both groups of patients were well matched except for larger left atrial dimension and higher $\mathrm{CHA}_{2} \mathrm{DS}_{2}$-VASc score in those with persistent AF (Table 1). All posterior left atrial mapping $(n=16)$ was performed with the 256-electrode plaque while 5 out of 15 (4 paroxysmal, 1 persistent) left atrial appendages were mapped with the 64-electrode plaque due to the smaller surface area. In total, 45,126 10s bipolar AF electrograms were used for bipolar CFAE algorithm, inter-electrode spacing and electrode configuration comparisons. CFAE correlations between various algorithms were performed using a subset of $1190010 \mathrm{~s}$ bipolar electrograms at $1.5 \mathrm{~mm}$ spacing.

\subsection{Bipolar CFAE and AF Substrate Complexity}

Figure 2A shows an example of AF wave map constructed from unipolar activation time map as described previously. ${ }^{2}$ Bipolar electrograms 1-3 are all taken along the same line of block, yet a different degree of fractionation is evident; from low amplitude highly fractionated signals in 1 and 2 to minimally fractionated signal in 3. Bipolar electrogram 4 taken from an area be- 
Table 1. Patient and Electrogram Characteristics. Values are presented as mean $\pm S D$. AF $=$ atrial fibrillation.

\begin{tabular}{llll}
\hline & $\begin{array}{l}\text { Paroxysmal AF } \\
(\mathrm{n}=10)\end{array}$ & $\begin{array}{l}\text { Persistent AF } \\
(\mathrm{n}=10)\end{array}$ & $\mathrm{P}$ \\
\hline Age (yrs) & $69 \pm 5$ & $70 \pm 6$ & 0.7 \\
Male (\%) & 80 & 60 & 0.6 \\
Body mass index $\left(\mathrm{kg} / \mathrm{m}^{2}\right)$ & $26.6 \pm 4.6$ & $27.0 \pm 3.0$ & 0.9 \\
Hypertension (\%) & 70 & 80 & 1.0 \\
Diabetes (\%) & 10 & 40 & 0.3 \\
Duration of atrial fibrillation (yrs) & $7 \pm 7$ & $9 \pm 6$ & 0.4 \\
Anti-arrhythmic drugs (\%) & 60 & 40 & 0.7 \\
Surgery Indications (\%): & & & \\
$\quad$ Coronary heart disease & 60 & 40 & 0.6 \\
$\quad$ Valvular heart disease & 30 & 50 & \\
Atrial fibrillation & 10 & 10 & 0.9 \\
Left ventricular ejection fraction (\%) & $62 \pm 8$ & $62 \pm 5$ & 0.006 \\
Left atrial size: parasternal (mm) & $43 \pm 8$ & $53 \pm 6$ & 0.03 \\
CHA $_{2}$ DS 2 -VASc score & $2.3 \pm 0.9$ & $3.8 \pm 1.7$ &
\end{tabular}

tween a line of block and waves collision also demonstrates a high degree of fractionation. In area within a wave where fractionation is not expected, both fractionated and non-fractionated signals are found at location 5 and 6 respectively. These demonstrate that the bipolar electrogram fractionation is variable and not always reflective of underlying conduction characteristics.

Overall mean bipolar CFAE measure of each 10s AF recording ( $\mathrm{n}=31$ from 20 patients) was correlated with each established AF substrate complexity measure. Examples of correlation between AF complexity as quantified by the number of AF waves per cycle with two bipolar CFAE indices are shown in Figure $2 \mathrm{~B}$ to further illustrate the discrepancy between algorithms. A wide range in the number of AF waves is seen at the same SCI of $70 \mathrm{~ms}$ with poor overall correlation (left panel), although the relationship between AF wave numbers and CFE-m was marginally better (right panel). Figure $2 \mathrm{C}$ shows the entire array of correlations between the various AF substrate characteristics and all bipolar CFAE indices. None of the bipolar CFAE measures demonstrated significant correlation with AF wave conduction velocity. Overall correlations between bipolar CFAE and AF substrate complexity measures were poor with the CEA algorithm showing the best correlation with number of AF waves 
Chapter 5
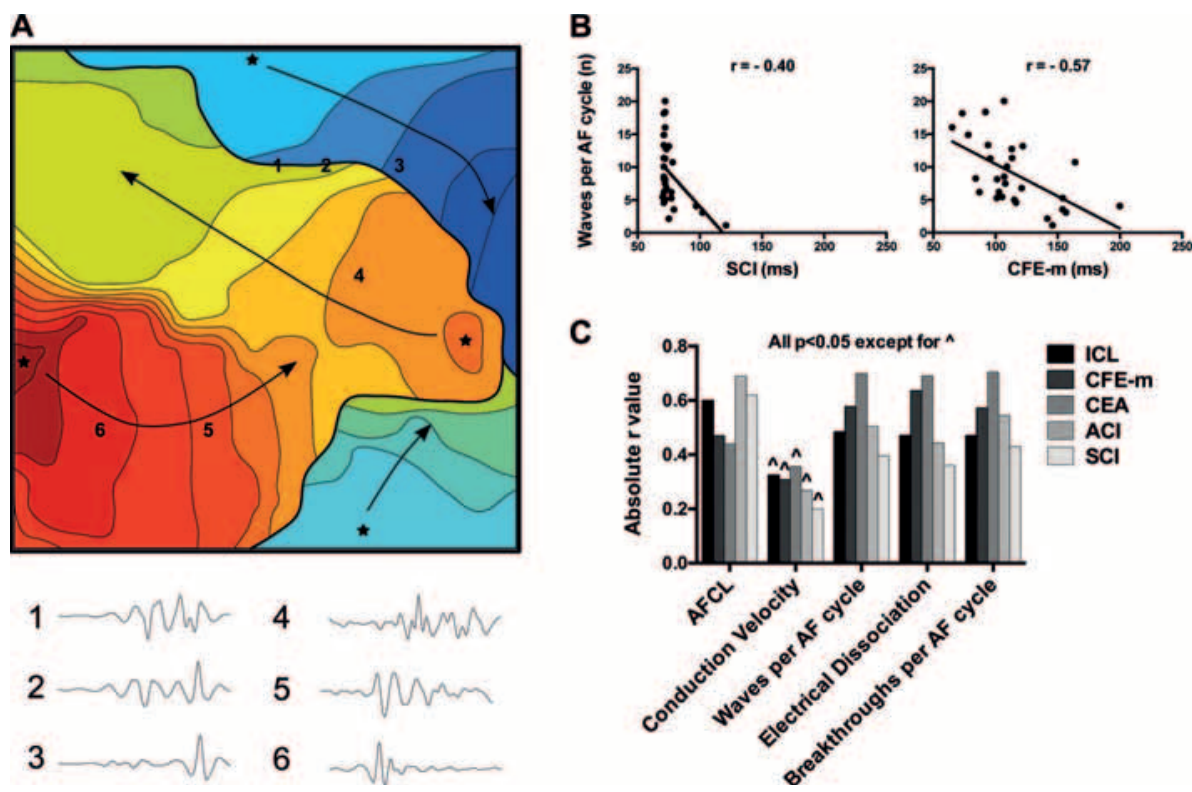

Figure 2. Bipolar CFAE and AF substrate complexity.

A: Example wave map from the posterior left atrium of a patient with paroxysmal AF. Thin arrows demonstrate wavefront propagation direction. Electrograms from sites 1-6 within the wave map demonstrate inconsistent relationship between fractionation and underlying conduction characteristics (see text).

B: Correlation graphs for CFE-m and SCI with number of AF waves per cycle.

C: Overall correlations between various AF substrate characteristics and all bipolar CFAE indices. $A C I=$ average complex interval; $A F=$ atrial fibrillation; $C E A=$ continuous electrical activity; $C F A E=$ complex fractionated atrial electrogram; $C F E-m=$ complex fractionated electrogram-mean; $I C L=$ interval confidence level; $S C I=$ shortest complex interval.

and breakthroughs per AF cycle and electrical dissociation. ( $r=0.70,0.70$ and 0.69 respectively; all $\mathrm{p}<0.0006)$ The remaining four algorithms (CFE-m, ACI, ICL and SCI) demonstrated poorer correlations with these AF substrate complexity measures. Further, poor correlations were also seen between bipolar CFAE algorithms and AFCL.

\subsection{Point-by-Point Correlations of Bipolar CFAE}

Figure 3 shows the comparison of the degree of fractionation for each individual 10s AF recording based on the different algorithms. Correlations between the ICL algorithm and the other four algorithms were poor (Figure 3, top row, 

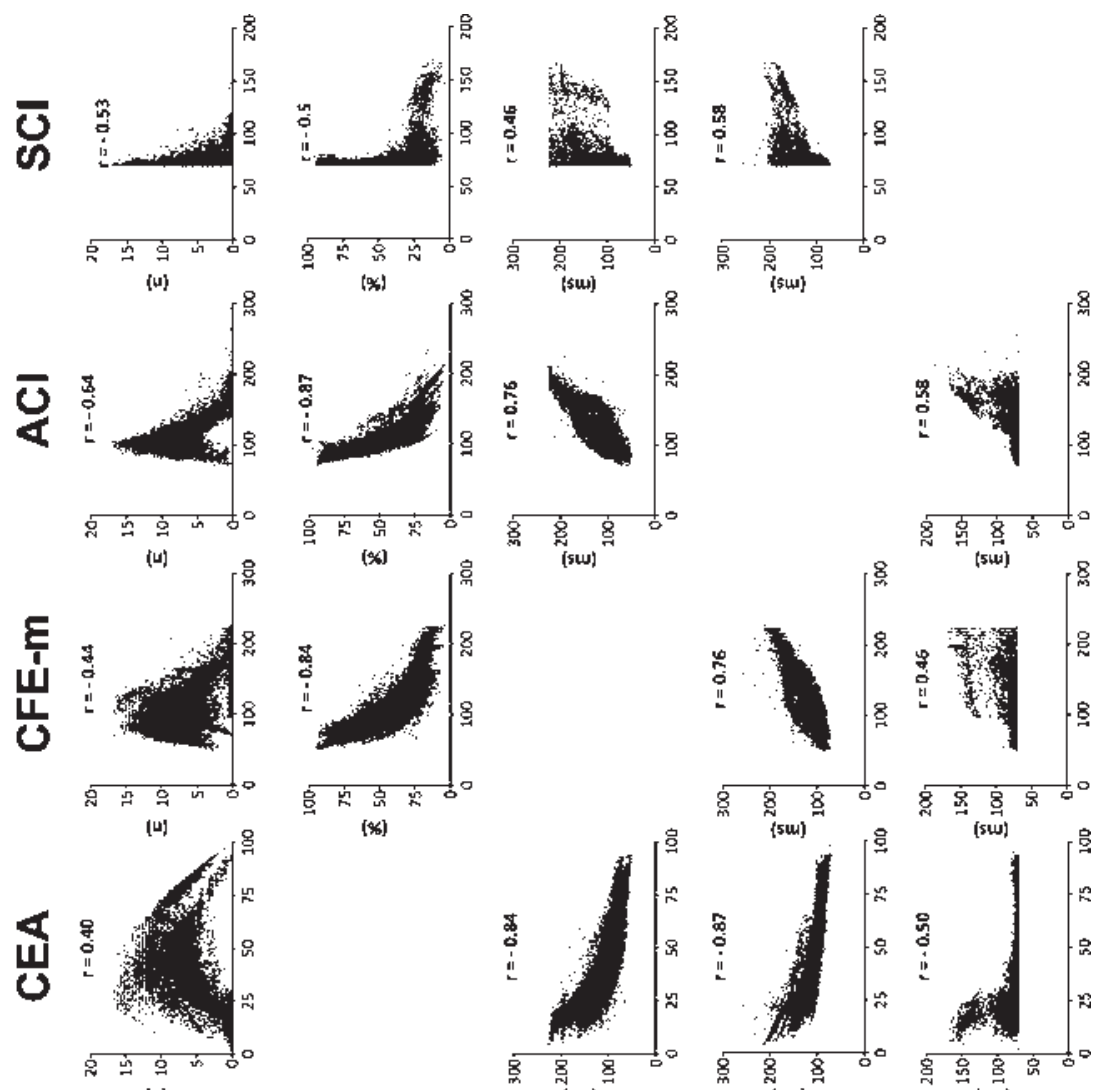

[क]
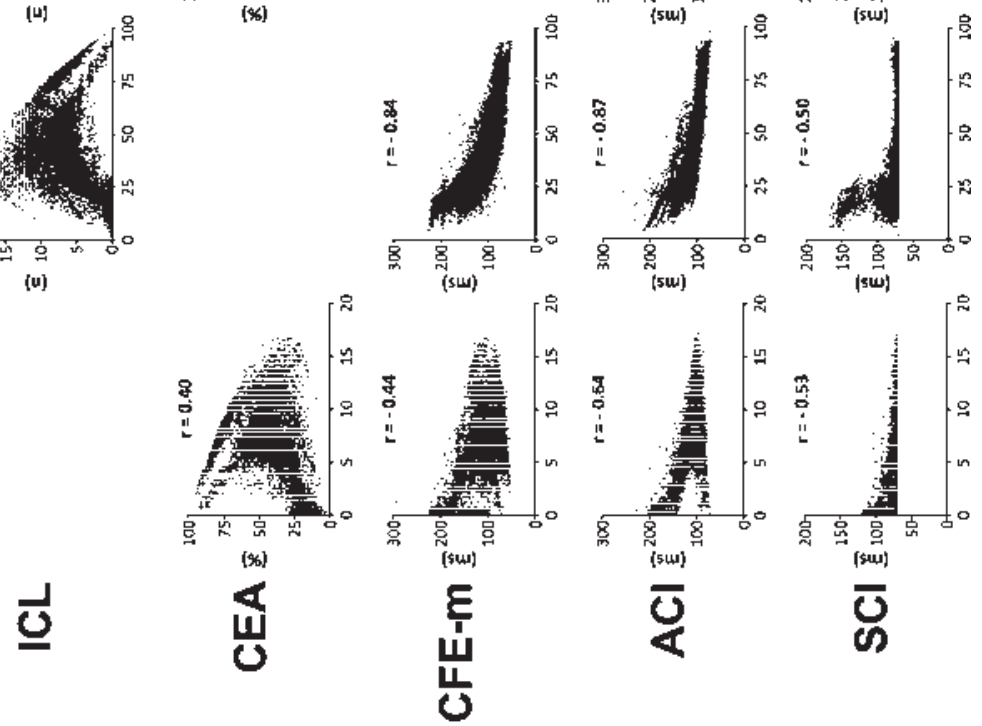

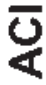

$\overline{\mathrm{s}}$

Figure 3. Point-by-point correlations of bipolar CFAE. Moderately good point-by-point correations were seen between the CEA/CFE-m/ACI algorithms (column 2, row 2 and column 3, and rows 2 and 3). However, the remaining correlations were at most fair to moderate. ACI = average complex interval; $C E A=$ continuous electrical activity; $C F A E=$ complex fractionated atrial electrogram; $C F E-m=$ complex fractionated electrogram-mean; $I C L=$ interval confidence level; SCI = shortest complex interval. 
Chapter 5

$r=0.40$ to 0.64 ; all $\mathrm{p}<0.001$ ). A paradoxical decrease in ICL was noted when fractionation was highest with CEA, CFE-m and ACI. Similarly, low ICL was seen when SCI was lowest at the cut off of $70 \mathrm{~ms}$. The correlations between SCI with all the other algorithms were also mostly poor (Figure 3, right column, $r=0.46$ to 0.58 ; all $\mathrm{P}<0.001)$. Moderate correlations were seen in the remaining CEA, CFE-m and ACI algorithms (Figure 3, $r=0.76$ to 0.87 ; all $\mathrm{P}<0.001$ ). A considerable variation in point-by-point correlations of bipolar CFAE is evident. Further, using the respective threshold for each bipolar CFAE algorithm, the resultant percentage of 10s AF electrograms detected as CFAE ranged from 11 to $88 \%$ and 23 to $97 \%$ for the paroxysmal and persistent AF group respectively (Figure 4A). Specifically, persistent AF patients demonstrated
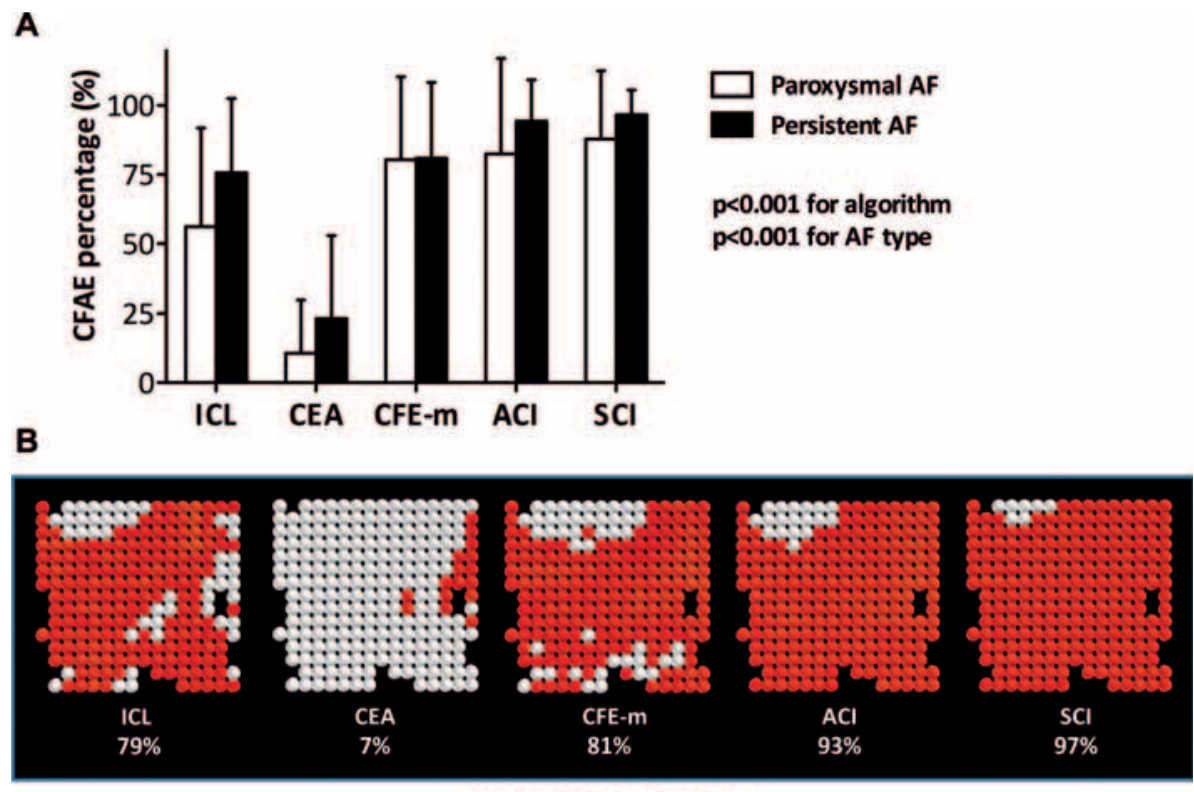

O Non-CFAE CFAE

Figure 4. CFAE detection with bipolar algorithms. A: CFAE detection differed significantly according to bipolar algorithms used. CFAE was more frequently encountered in those with persistent vs paroxysmal AF. B: 256-electrode fractionation maps of the same 10-second AF from the posterior left atrium of a patient with persistent AF. Percentage of CFAE ranged from $7 \%$ to $97 \%$. CFAE sites are denoted in red and non-CFAE sites in white. Gaps in the maps are due to removal of electrograms with insufficient quality for analysis. $A C I=$ average complex interval; $A F=$ atrial fibrillation; $C E A=$ continuous electrical activity; $C F A E=$ complex fractionated atrial electrogram; $C F E-m=$ complex fractionated electrogram-mean; $I C L=$ interval confidence level; $S C I=$ shortest complex interval. 
more fractionated atrial electrograms than those with paroxysmal AF and the CEA algorithm stood out with the lowest CFAE detection. An example of the variation in CFAE detection is shown in Figure 4B whereby the percentage of detected CFAE in the same 10 s AF recording ranged from 7 to $97 \%$, with poor agreement among all five algorithms.

\subsection{Effect of Electrode spacing and orientation on Bipolar CFAE Detection}

Increasing inter-electrode spacing from 1.5 to $6.0 \mathrm{~mm}$ resulted in a corresponding increase in the percentage of AF electrograms deemed as fractionated according to each algorithm with the exception of ICL, whereby a paradoxical decrease in CFAE was seen (Figure 5A). When the effect of increasing interelectrode spacing was analyzed within each individual algorithm, statistical significance was maintained for CEA, ACI and CFE-m (Figure 5B). The step-
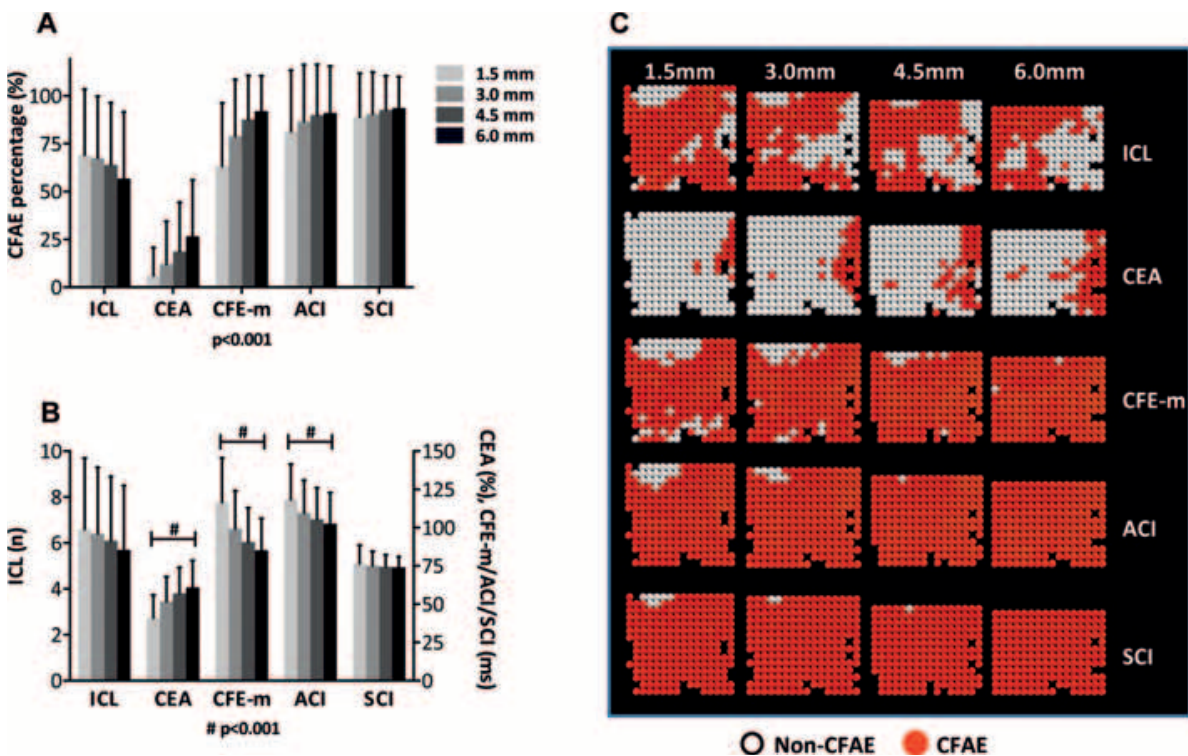

Figure 5. Interelectrode spacing and bipolar CFAE. A and B: Increased bipolar interelectrode spacing resulted in increased CFAE detection except for the ICL algorithm. C: This effect is illustrated using the same 10-second AF episode from Figure 2D. Likewise, CFAE sites are denoted in red and non-CFAE sites in white, with gaps due to data with insufficient electrogram quality. $A C I=$ average complex interval; $A F=$ atrial fibrillation; $C E A=$ continuous electrical activity; $C F A E=$ complex fractionated atrial electrogram; $C F E-m=$ complex fractionated electrogram-mean; $I C L=$ interval confidence level; $S C I=$ shortest complex interval. 


\section{Chapter 5}

wise increase in CFAE detection (except for ICL) with increasing inter-electrode spacing is further illustrated in Figure 5C. No significant differences were seen in bipolar CFAE determinations when comparing horizontal vs. vertical electrode configurations (Online Supplemental Figure 1). Overall match in CFAE detection was very good between horizontal and vertical configured

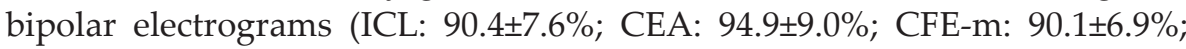
ACI: $91.9 \pm 6.2 \%$; SCI: 97.9 $\pm 7.5 \%)$.

\subsection{Correlation between Bipolar and Unipolar CFAE in relation to AF Wavefronts}

Figure 6 illustrates the differences in bipolar and unipolar fractionation in relation to conduction patterns. Clean and sharp unipolar electrograms are usually seen with broad uni-directional AF wavefront while bipolar counterparts demonstrate variable complexity (top left). With colliding wavefronts, a split or double potential is clearly seen in unipolar signals, which is not apparent in all bipolar examples (bottom left). In the case of conduction block, unipolar electrograms demonstrate fractionated potentials along the block line with sharper local deflection way from the site of block. This specificity is not as clear with bipolar recordings demonstrating more continuous fractionation (top right). Unipolar electrograms are most fractionated at the core of rotating wavefront as compared to the periphery whereas the differentiation is not as distinct with bipolar electrograms (bottom right). Figure 7 shows the correlation between unipolar and bipolar fractionation. All correlations with unipolar FI were significant. However, the correlation coefficient was poor for the ICL and SCI algorithms $(r=0.42$ and 0.44$)$ and only fair with the remaining three algorithms $(r=0.65,0.68$, and 0.68 , respectively). Interestingly, unipolar FI demonstrated very good correlations with AF substrate complexity such as the number of AF waves and breakthroughs per AF cycle and electrical dissociation (Figure 6B: $r=0.91,0.90$ and 0.92 respectively). No correlation was seen between unipolar FI and conduction velocity.

\section{Discussion}

This work provides a comprehensive electrophysiological evaluation of bipolar CFAE algorithms and the impact of mapping electrode configurations on bipolar CFAE. Our main findings are that bipolar CFAE derived from semi-automated algorithms: (i) correlate poorly with established AF substrate 
CFAE Algorithms and AF Substrate
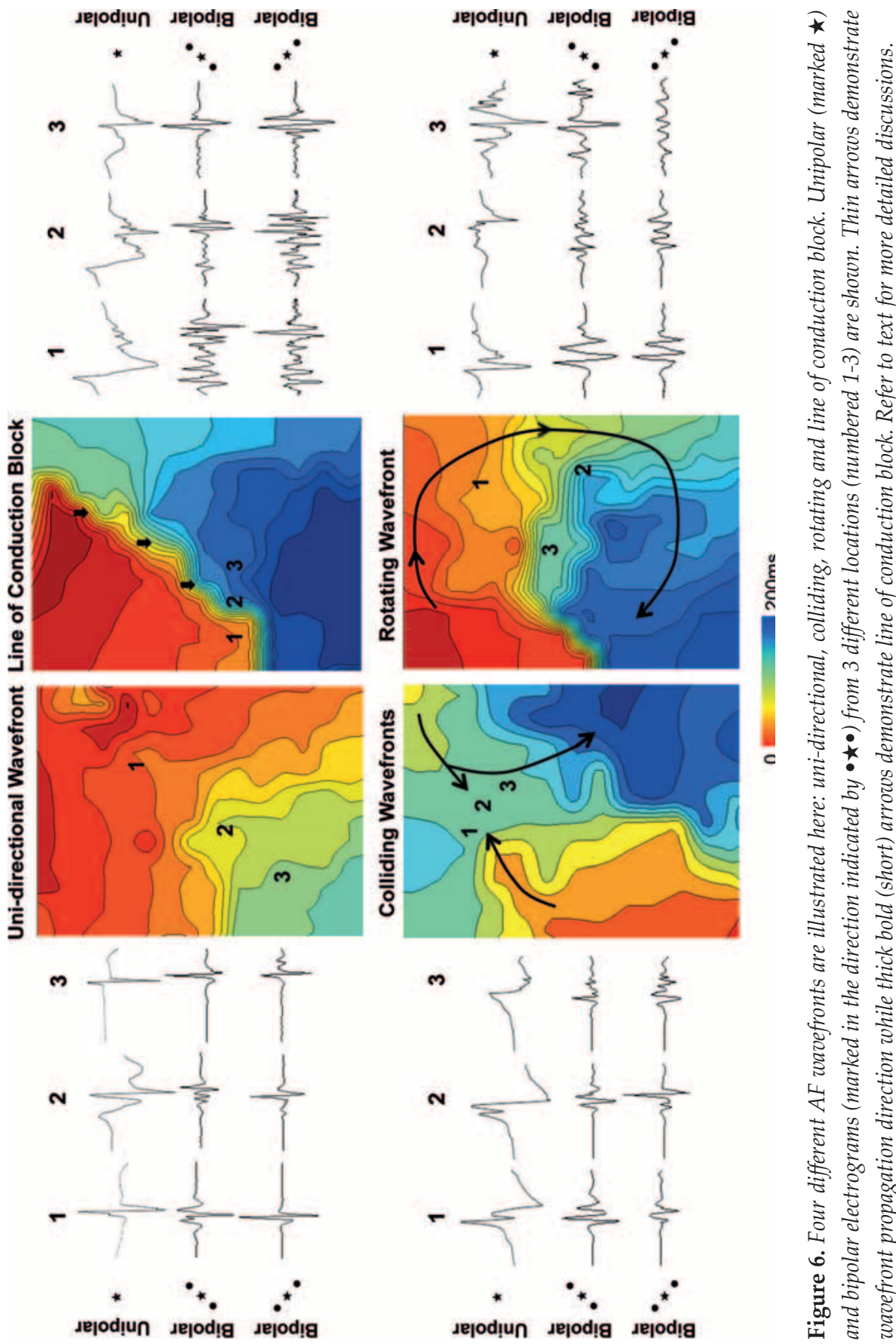
Chapter 5
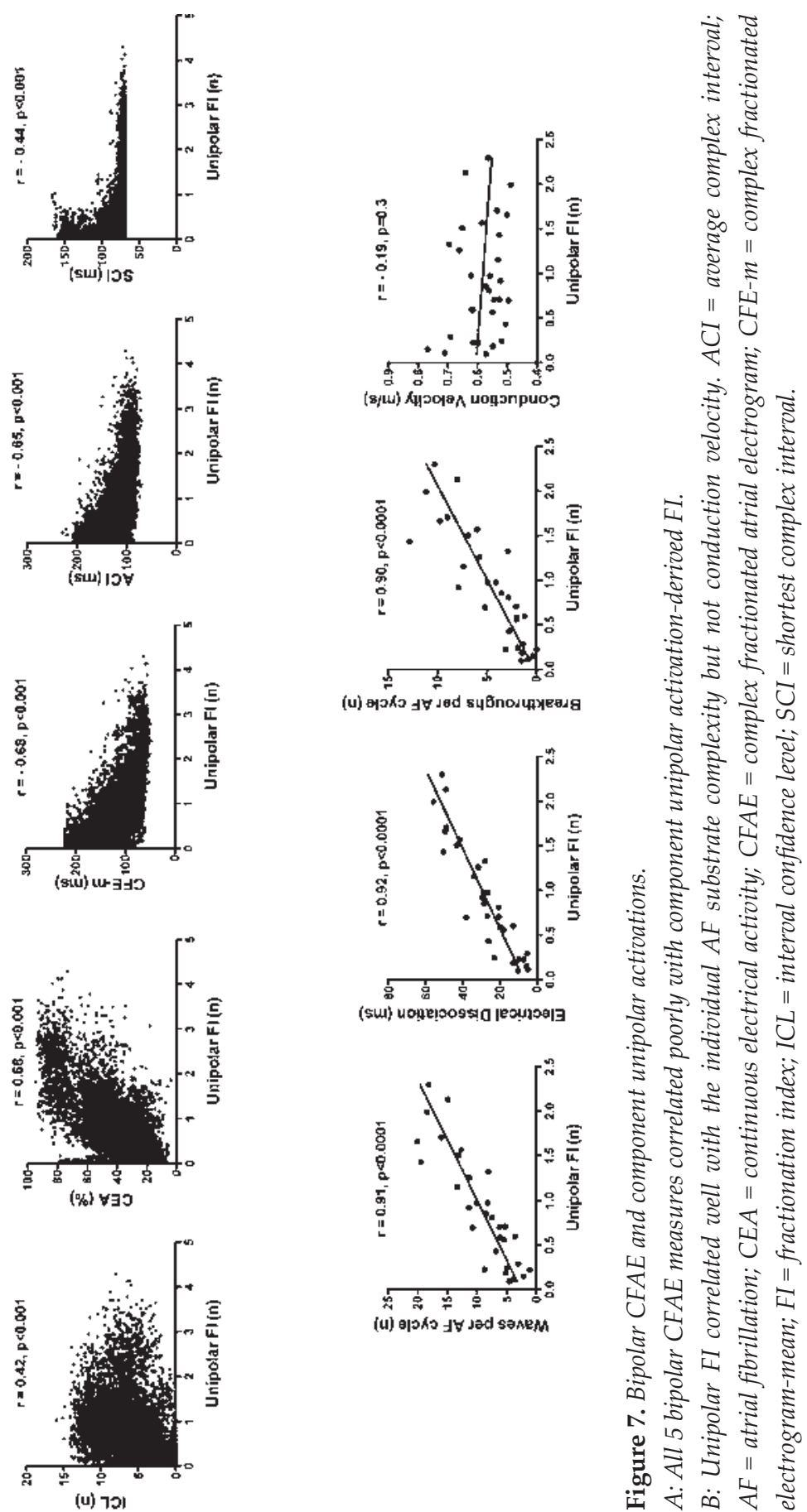
complexity measures and with each other; (ii) are sensitive to inter-electrode spacing with an increase in CFAE detected with increased inter-electrode distance; (iii) do not correlate well with their constituent unipolar activation derived fractionation index. This study indicates that CFAE determined by semi-automated bipolar algorithms are highly variable and poor markers for the underlying AF substrate.

\subsection{Variability in CFAE Determinations with Bipolar Algorithms}

Several semi-automated algorithms have been tested for their diagnostic accuracy against manual determinations. ${ }^{18-21}$ These algorithms attempt to delineate specific characteristics of AF: the ICL evaluates the repetitiveness of CFAE; the CFE-m and ACI assess the mean cycle length between deflections; the CEA identifies sites with continuous depolarizations; and the SCI locates sites with fastest activations. Although CFAE identified by different algorithms may represent different pathophysiology, this study demonstrates that the agreement amongst them was poor. This held true despite removing the subjectivity component inherent in manual classifications and previous work showing the reliability of automated algorithms. ${ }^{21}$ Perhaps, the sensitivity of time-domain algorithms to signal morphology, amplitude, non-local deflections and deflection regularity is a major limiting factor. ${ }^{22-24}$ Our findings further extend recent observation of poor anatomic overlap between CFAE sites defined manually and those with AF cycle length $<120 \mathrm{~ms} .{ }^{25}$ We also uncovered a paradoxical behavior with the ICL algorithm whereby a proportion of highly fractionated signals demonstrated low ICL scores. Furthermore, the CEA algorithm showed the lowest CFAE detection with lowest match with all other algorithms. Interestingly, recent multicenter randomized trial (SELECT-AF) demonstrated that adjuvant CFAE ablation guided by ICL yielded better outcome than selective CEA ablation. ${ }^{26}$ Taken together, it is likely that electrophysiologists have been targeting different 'substrate' sites when guided by different bipolar algorithms resulting in variable outcomes.

\subsection{Variability in Bipolar CFAE due to Electrode Configurations}

Baerman et al. elegantly demonstrated that electrogram amplitude, morphology and atrial activation rate determinations during AF were sensitive to bipolar inter-electrode spacing. ${ }^{27}$ More recently, both mapping studies and computer simulations have also demonstrated increased electrogram fractionation with increasing electrode diameter, height and inter-electrode spacing. ${ }^{28}$ ${ }^{29}$ Our work further extends these findings with higher-density mapping and 


\section{Chapter 5}

more comprehensive assessment of all bipolar CFAE algorithms. Specifically, we detected a peculiar behavior with the ICL algorithm whereby a paradoxical decrease in fractionation was seen with increasing inter-electrode spacing. We also found that CFAE did not vary significantly between vertical and horizontal bipolar electrode couplings. Perhaps the direction dependent change in bipolar electrogram was more limited to signal amplitude than degree of fractionation. Nevertheless, due considerations must be given to inter-electrode spacing of the catheters used for CFAE mapping to avoid over-detection and unnecessary ablation of non-critical sites.

\subsection{An Ideal CFAE Algorithm?}

Earlier work has correlated unipolar CFAE to pivoting waves, wave collisions, areas of slow conduction and lines of conduction block indicative of substrate complexity. ${ }^{30}$ Indeed, CFAE is more prevalent in areas with more structural remodeling. ${ }^{4,731-34}$ However, recent monophasic action potential mapping has shown that the majority of bipolar CFAE were due to non-local activations. ${ }^{35}$ In addition, bipolar CFAE have been seen in close proximity to high dominant frequency sites ${ }^{31,36}$ but not sites with stable rotors, focal sources or rotor pivot zones. ${ }^{37,38}$ The above suggests that current bipolar algorithms are not defining CFAE adequately. Lower conduction velocity, a higher number of fibrillation waves, narrower/smaller AF waves, higher electrical dissociation and higher incidence of breakthrough waves have been associated with more advanced atrial remodeling. ${ }^{2-6}$ Importantly, these were also observed in conjunction with endomysial fibrosis and myocyte hypertrophy. ${ }^{4,6,39}$ In this study, the CEA algorithm demonstrated the highest correlation with these substrate complexity indicators. However, unipolar FI demonstrated superior physiological relevance with even higher correlations with the number of fibrillation waves and breakthroughs, indicatory of a good marker for conduction block and endo-epicardial dissociation.

\subsection{Clinical Implications}

This study demonstrates a large algorithm-dependent variability in bipolar CFAE and discloses a lack of correlation of bipolar CFAE with the underlying atrial substrate. Not only were the correlations between bipolar algorithms suboptimal, paradoxical classifications of CFAE were also evident. For this reason, ablation guided by currently available algorithms might lead to erroneous targeting of AF substrate sites. ${ }^{34}$ The dynamic and temporally variable 
nature of CFAE together with our incomplete understanding of its pathophysiology renders CFAE ablation even more challenging. ${ }^{12,13}$ The unipolar FI offers an alternative activation-based classification of electrogram fractionation with more pathophysiological relevance, warranting further work to determine its role clinically.

\subsection{Study Limitations}

This study utilized direct contact mapping to facilitate assessment of semiautomated CFAE algorithms designed for endocardial mapping. We did not perform simultaneous endo-epicardial mapping to specifically confirm epicardial breakthroughs. The inter-electrode spacing of our mapping electrode is different to commonly used clinical catheters. Correlation of mapped CFAE with pre-operative non-invasive imaging to ascertain atrial scarring or fibrosis would have provided further insights. The functional significance of unipolar FI remains to be determined despite its apparent superior pathophysiological relevance as compared to bipolar CFAE measures.

\section{Conclusions}

Current bipolar algorithms correlate poorly with established AF substrate complexity measures and vary significantly in their classification of CFAE. Further work is needed to improve the current classification of CFAE to provide better identification of pathophysiological substrate sites relevant to the complex mechanisms sustaining AF. 
Chapter 5

\section{Clinical Perspective}

This work highlights the inconsistency of bipolar complex fractionated atrial electrogram (CFAE) algorithms where poor correlation was seen between them. Bipolar CFAE measures did not correlate well with underlying atrial fibrillation complexity and unipolar fractionation. The variability of these bipolar CFAE measures call for greater in-depth research regarding their pathophysiological relevance. In contrast, unipolar fractionation demonstrates better correlation with AF complexity parameters and lends itself to further catheter ablation studies to determine its role in our bid to combat this debilitating arrhythmia. 


\section{CFAE Algorithms and AF Substrate}

\section{References}

1. Schotten U, Verheule S, Kirchhof P, Goette A. Pathophysiological mechanisms of atrial fibrillation: a translational appraisal. Physiol Rev. 2011;91:265-325.

2. Allessie MA, de Groot NM, Houben RP, Schotten U, Boersma E, Smeets JL, Crijns HJ. Electropathological substrate of long-standing persistent atrial fibrillation in patients with structural heart disease: longitudinal dissociation. Circ Arrhythm Electrophysiol. 2010;3: 606-615.

3. de Groot NM, Houben RP, Smeets JL, Boersma E, Schotten U, Schalij MJ, Crijns H, Allessie MA. Electropathological substrate of longstanding persistent atrial fibrillation in patients with structural heart disease: epicardial breakthrough. Circulation. 2010;122:1674-1682.

4. Eckstein J, Maesen B, Linz D, Zeemering S, van Hunnik A, Verheule S, Allessie M, Schotten $\mathrm{U}$. Time course and mechanisms of endo-epicardial electrical dissociation during atrial fibrillation in the goat. Cardiovascular research. 2011;89:816-824.

5. Eckstein J, Zeemering S, Linz D, Maesen B, Verheule S, van Hunnik A, Crijns H, Allessie M, Schotten U. Transmural conduction is the predominant mechanism of breakthrough during atrial fibrillation: Evidence from simultaneous endo-epicardial high density activation mapping. Circ Arrhythm Electrophysiol. 2013;6:334-341.

6. Verheule S, Tuyls E, van Hunnik A, Kuiper M, Schotten U, Allessie M. Fibrillatory conduction in the atrial free walls of goats in persistent and permanent atrial fibrillation. Circ Arrhythm Electrophysiol. 2010;3:590-599.

7. Lau DH, Mackenzie L, Kelly DJ, et al. Hypertension and atrial fibrillation: evidence of progressive atrial remodeling with electrostructural correlate in a conscious chronically instrumented ovine model. Heart Rhythm. 2010;7:1282-1290.

8. Abed HS, Samuel CS, Lau DH, et al. Obesity results in progressive atrial structural and electrical remodeling: implications for atrial fibrillation. Heart Rhythm. 2013;10:90-100.

9. Nademanee K, McKenzie J, Kosar E, Schwab M, Sunsaneewitayakul B, Vasavakul T, Khunnawat C, Ngarmukos T. A new approach for catheter ablation of atrial fibrillation: mapping of the electrophysiologic substrate. J Am Coll Cardiol. 2004;43:2044-2053.

10. Verma A, Jiang C-Y, Betts TR, Chen J, Deisenhofer I, Mantovan R, Macle L, Morillo C, Sanders P. STAR AF II Investigators. Approaches to catheter ablation for persistent atrial fibrillation. N Engl J Med. 2015 May 7;372(19):1812-22.

11. Brooks AG, Stiles MK, Laborderie J, Lau DH, Kuklik P, Shipp NJ, Hsu LF, Sanders P. Outcomes of long-standing persistent atrial fibrillation ablation: a systematic review. Heart Rhythm. 2010;7:835-846.

12. Lau DH, Maesen B, Zeemering S, Verheule S, Crijns HJ, Schotten U. Stability of complex fractionated atrial electrograms: a systematic review. J Cardiovasc Electrophysiol. 2012;23: 980-987. 


\section{Chapter 5}

13. Lau DH, Zeemering S, Maesen B, Kuklik P, Verheule S, Schotten U. Catheter ablation targeting complex fractionated atrial electrogram in atrial fibrillation. J Atrial Fibrillation. 2013;6:86-92.

14. Eckstein J, Kuhne M, Osswald S, Schotten U. Mapping of atrial fibrillation - basic research and clinical applications. Swiss Med Wkly. 2009;139:496-504.

15. Stiles MK, Brooks AG, John B, et al. The effect of electrogram duration on quantification of complex fractionated atrial electrograms and dominant frequency. J Cardiovasc Electrophysiol. 2008;19:252-258.

16. Zeemering S, Maesen B, Nijs J, Lau DH, Granier M, Verheule S, Schotten U. Automated quantification of atrial fibrillation complexity by probabilistic electrogram analysis and fibrillation wave reconstruction. Conf Proc IEEE Eng Med Biol Soc. 20126357-6360.

17. de Bakker JM, Wittkampf FH. The pathophysiologic basis of fractionated and complex electrograms and the impact of recording techniques on their detection and interpretation. Circ Arrhythm Electrophysiol. 2010;3:204-213.

18. Scherr D, Dalal D, Cheema A, Cheng A, Henrikson CA, Spragg D, Marine JE, Berger RD, Calkins H, Dong J. Automated detection and characterization of complex fractionated atrial electrograms in human left atrium during atrial fibrillation. Heart Rhythm. 2007;4:1013-1020.

19. Verma A, Novak P, Macle L, Whaley B, Beardsall M, Wulffhart Z, Khaykin Y. A prospective, multicenter evaluation of ablating complex fractionated electrograms (CFEs) during atrial fibrillation (AF) identified by an automated mapping algorithm: acute effects on AF and efficacy as an adjuvant strategy. Heart Rhythm. 2008;5:198-205.

20. Scherr D, Dalal D, Cheema A, et al. Long- and short-term temporal stability of complex fractionated atrial electrograms in human left atrium during atrial fibrillation. J Cardiovasc Electrophysiol. 2009;20:13-21.

21. Hunter RJ, Diab I, Thomas G, Duncan E, Abrams D, Dhinoja M, Sporton S, Earley MJ, Schilling RJ. Validation of a classification system to grade fractionation in atrial fibrillation and correlation with automated detection systems. Europace. 2009;11:1587-1596.

22. Grzeda KR, Noujaim SF, Berenfeld O, Jalife J. Complex fractionated atrial electrograms: properties of time-domain versus frequency-domain methods. Heart Rhythm. 2009;6:14751482.

23. Berenfeld O, Ennis S, Hwang E, Hooven B, Grzeda K, Mironov S, Yamazaki M, Kalifa J, Jalife J. Time- and frequency-domain analyses of atrial fibrillation activation rate: the optical mapping reference. Heart Rhythm. 2011;8:1758-1765.

24. Ng J, Goldberger JJ. Time- and frequency-domain analysis of AF electrograms: simple approaches to a complex arrhythmia? Heart Rhythm. 2011;8:1766-1768.

25. Lee G, Roberts-Thomson K, Madry A, Spence S, Teh A, Heck PM, Kumar S, Kistler PM, Morton JB, Sanders P, Kalman JM. The relationship between complex signals, short cycle length activity and dominant frequency in patients with long lasting persistent AF: A high-density epicardial mapping study in humans. Heart Rhythm. 2011;8:1714-1719. 


\section{CFAE Algorithms and AF Substrate}

26. Verma A, Sanders P, Champagne J, Macle L, Nair GM, Calkins H, Wilber DJ. Selective Complex Fractionated Atrial Electrograms Targeting for Atrial Fibrillation Study (SELECT AF): A Multicenter, Randomized Trial. Circ Arrhythm Electrophysiol. 2014;7:55-62.

27. Baerman JM, Ropella KM, Sahakian AV, Kirsh JA, Swiryn S. Effect of bipole configuration on atrial electrograms during atrial fibrillation. PACE. 1990;13:78-87.

28. Correa de Sa DD, Thompson N, Stinnett-Donnelly J, Znojkiewicz P, Habel N, Muller JG, Bates JH, Buzas JS, Spector PS. Electrogram fractionation: the relationship between spatiotemporal variation of tissue excitation and electrode spatial resolution. Circ Arrhythm Electrophysiol. 2011;4:909-916.

29. Nagashima K, Okumura Y, Watanabe I, Nakai T, Ohkubo K, Kofune T, Kofune M, Mano H, Sonoda K, Hirayama A. Effects of inter-electrode spacing on complex fractionated atrial electrograms and dominant frequency detection. J Interv Card Electrophysiol. 2012;34:51-57.

30. Konings KT, Smeets JL, Penn OC, Wellens HJ, Allessie MA. Configuration of unipolar atrial electrograms during electrically induced atrial fibrillation in humans. Circulation. 1997;95: 1231-1241.

31. Stiles MK, Brooks AG, Kuklik P, et al. High-density mapping of atrial fibrillation in humans: relationship between high-frequency activation and electrogram fractionation. J Cardiovasc Electrophysiol. 2008;19:1245-1253.

32. Tada H, Yoshida K, Chugh A, et al. Prevalence and characteristics of continuous electrical activity in patients with paroxysmal and persistent atrial fibrillation. J Cardiovasc Electrophysiol. 2008;19:606-612.

33. Jadidi AS, Cochet $\mathrm{H}$, Shah AJ, et al. Inverse relationship between fractionated electrograms and atrial fibrosis in persistent atrial fibrillation: combined magnetic resonance imaging and high-density mapping. J Am Coll Cardiol. 2013;62:802-812.

34. Jadidi AS, Duncan E, Miyazaki S, et al. Functional nature of electrogram fractionation demonstrated by left atrial high-density mapping. Circ Arrhythm Electrophysiol. 2012;5:32-42.

35. Narayan SM, Wright M, Derval N, et al. Classifying fractionated electrograms in human atrial fibrillation using monophasic action potentials and activation mapping: evidence for localized drivers, rate acceleration, and nonlocal signal etiologies. Heart Rhythm. 2011;8: 244-253.

36. Kalifa J, Tanaka K, Zaitsev AV, et al. Mechanisms of wave fractionation at boundaries of high-frequency excitation in the posterior left atrium of the isolated sheep heart during atrial fibrillation. Circulation. 2006;113:626-633.

37. Narayan SM, Shivkumar K, Krummen DE, Miller JM, Rappel WJ. Panoramic Electrophysiological Mapping but not Electrogram Morphology Identifies Stable Sources for Human Atrial Fibrillation: Stable Atrial Fibrillation Rotors and Focal Sources Relate Poorly to Fractionated Electrograms. Circ Arrhythm Electrophysiol. 2013;6:58-67.

38. Ganesan AN, Kuklik P, Lau DH, et al. Bipolar electrogram shannon entropy at sites of rotational activation: implications for ablation of atrial fibrillation. Circ Arrhythm Electrophysiol. 2013;6:48-57. 


\section{Chapter 5}

39. Verheule S, Tuyls E, Gharaviri A, Hulsmans S, van Hunnik A, Kuiper M, Serroyen J, Zeemering S, Kuijpers NH, Schotten U. Loss of continuity in the thin epicardial layer because of endomysial fibrosis increases the complexity of atrial fibrillatory conduction. Circ Arrhythm Electrophysiol. 2013;6:202-211. 


\section{Supplemental Material}

\subsection{Automated Deflection Detection and Wave Reconstruction Algorithms}

Unipolar electrograms were first filtered with a third order zero-phase Chebyshev $0.5 \mathrm{~Hz}$ high-pass filter to remove any baseline drift prior to QRS cancellation using a modified version of the adaptive singular value decomposition method. ${ }^{2}$ Candidate deflections were detected by sensitive template matching. The AF cycle length distribution was estimated by sieving out low amplitude template matches until a clear peak was visible in the deflection interval distribution. Local deflections were assigned to maximize the joint deflection interval probability as well as the amplitude and steepness of the deflections. Further, the automated deflection detection algorithm can differentiate local (Manuscript Figure 1, marked green) from non-local activations (marked red) using minimal amplitude and steepness criteria (25\% of median local deflections) as described by Konings et al. ${ }^{3}$ The ratio of non-local to local deflections was taken as the unipolar fractionation index (FI).

Following the application of the above recently validated automated deflection detection algorithm, automated fibrillation wave reconstruction were performed using custom software in the MATLAB environment (The MathWorks Inc). ${ }^{4}$ The wave reconstruction involved creation of partial waves based on minimum conduction velocity $(20 \mathrm{~cm} / \mathrm{s})$ between two neighboring local activations in the mapping electrode grid. Any deflections that can be linked to two or more partial waves are left unassigned. These unassigned activations were then allocated to adjacent waves based on the estimated distributions of partial wave conduction velocity and conduction direction probability.

\subsection{AF Substrate Complexity}

The following atrial fibrillation (AF) substrate complexity measures were calculated after wave reconstruction: AF wave conduction velocity, number of waves per AF cycle, electrical dissociation and incidence of breakthrough waves per AF cycle.

AF wave conduction velocity is taken as the median of all conduction velocities within each wave. The local conduction velocity for each wave activation is determined by fitting a tangent plane onto the surface formed by the activation and the activations within the same wave at the directly surrounding electrodes. The conduction velocity is then computed as the reciprocal of the plane gradient vector length and the direction of conduction as the plane gradient angle. 
Chapter 5

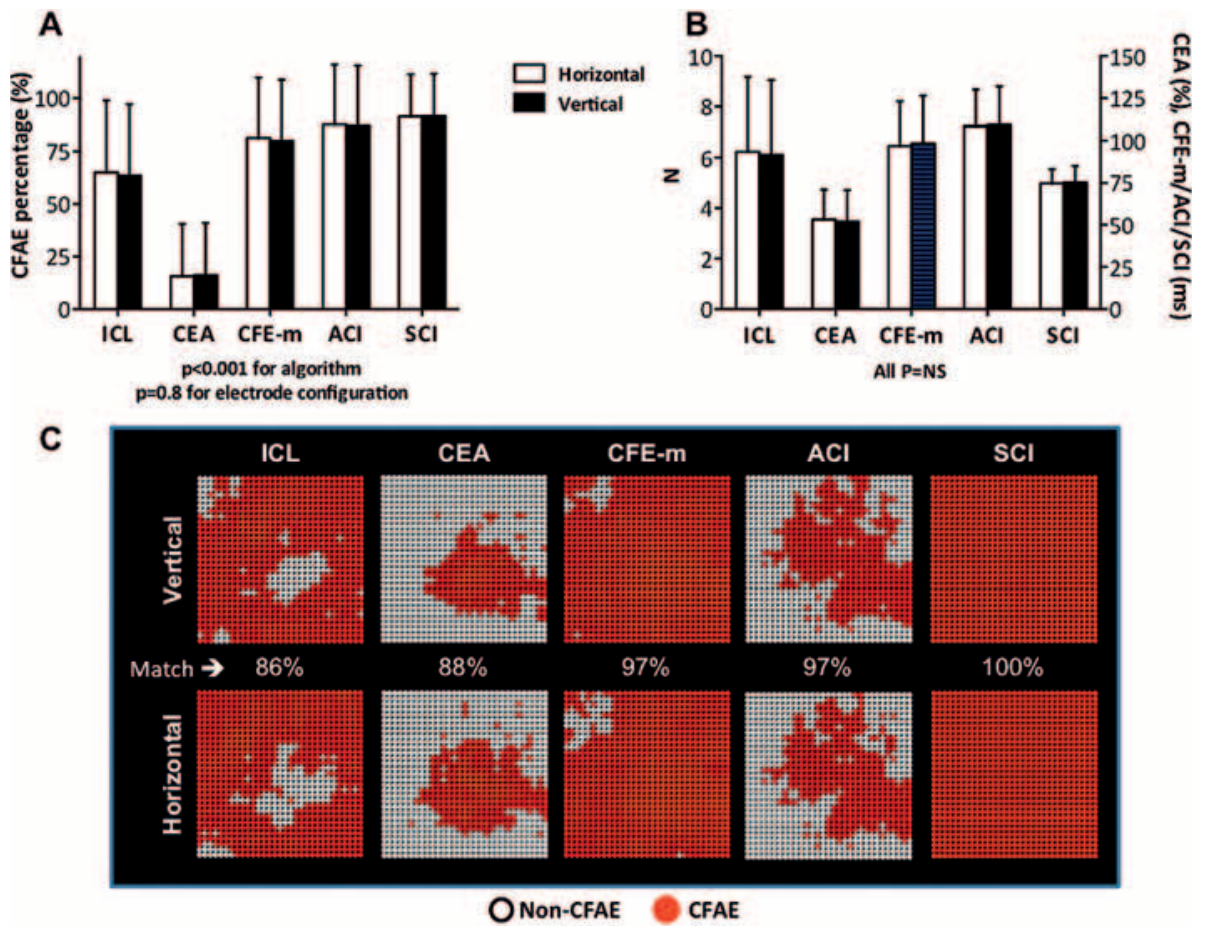

Supplemental Figure 1. Effect of Electrode Orientation on Bipolar CFAE Determinations.

$A$ and B. Horizontal vs. vertical coupling of bipolar electrode did not affect the percentage of CFAE detected nor the raw CFAE values determined by each algorithm.

C. Good match was seen in the fractionation maps with bipolar electrode in the vertical (top) and horizontal (bottom) configurations from the same 10s AF episode recorded from the posterior left atrium of a persistent AF patient. CFAE sites are denoted in red and non-CFAE sites in white.

Number of waves per AF cycle is taken as the total number of AF waves seen in the mapping area over the entire 10 s recording, normalized to the AFCL.

Electrical dissociation is taken as the median time difference between the boundaries of fibrillation waves.

Breakthrough waves are taken as waves appearing within the mapping area that cannot be accounted for by other propagating waves in the mapping field. The number of breakthrough waves was normalized to the AFCL to facilitate comparisons. 


\section{CFAE Algorithms and AF Substrate}

\section{References}

1. Lau DH, Zeemering S, Maesen B, Kuklik P, Verheule S, Schotten U. Catheter ablation targeting complex fractionated atrial electrogram in atrial fibrillation. J Atr Fibrillation. 2013;6: 86-92

2. Alcaraz R, Rieta JJ. Adaptive singular value cancelation of ventricular activity in single-lead atrial fibrillation electrocardiograms. Physiol Meas. 2008;29:1351-1369

3. Konings KT, Smeets JL, Penn OC, Wellens HJ, Allessie MA. Configuration of unipolar atrial electrograms during electrically induced atrial fibrillation in humans. Circulation. 1997;95: 1231-1241

4. Zeemering S, Maesen B, Nijs J, Lau DH, Granier M, Verheule S, Schotten U. Automated quantification of atrial fibrillation complexity by probabilistic electrogram analysis and fibrillation wave reconstruction. Conf Proc IEEE Eng Med Biol Soc. 2012;2012:6357-6360 



\section{Chapter 6}

Automated Quantification of

Atrial Fibrillation Complexity

by Probabilistic Electrogram

Analysis and Fibrillation

Wave Reconstruction

S. Zeemering, B. Maesen, J. Nijs, D. Lau, M. Granier, S. Verheule, and U. Schotten Published in Conf Proc IEEE Eng Med Biol Soc. 2012;2012:6357-60. 


\section{Chapter 6}

\section{Abstract}

The analysis of high-density activation maps of atrial fibrillation (AF) provides fundamental insights into the fibrillation wave propagation patterns and thus the mechanisms of AF. Current annotation of local activations in unipolar atrial electrograms and the construction of fibrillation waves require labor-intensive manual editing. To enhance the possibilities for spatiotemporal analysis of AF, we developed a rapid and fully automated procedure to accurately identify local, intrinsic atrial deflections and construct fibrillation waves based on these deflections. In this study, the automated procedure was validated using manually annotated electrograms and wave maps. We show that the novel procedure accurately detects intrinsic deflections (sensitivity= $87 \%$, positive predictive value $=89 \%$ ) and that reconstructed wave maps correlate well with manually edited wave maps in terms of number of waves $(\mathrm{r}=0.96)$, intra-wave conduction velocity $(\mathrm{r}=0.97)$, AF cycle length $(\mathrm{r}=0.97)$, and wave size $(\mathrm{r}=0.96)(\mathrm{p}<0.01$ in all cases). The automated procedure is therefore an adequate substitute for manual annotation. 


\section{Introduction}

Atrial fibrillation (AF) is an arrhythmia where the electrical activity in the atria is irregular instead of well organized. Multiple wavelets wander throughout the atria, instead of a single coordinated wave. ${ }^{1}$ High-density atrial contact mapping of AF provides the most direct information on the spatiotemporal complexity of AF. It allows one to describe the process of AF in its most elementary form, the separate fibrillation waves. ${ }^{2}$ From these wave propagation patterns it is possible to quantify the complexity of AF, for example in terms of the number of waves, the wave size, the wave conduction velocity or the wave source (peripheral or transmural breakthrough). Complexity of the $\mathrm{AF}$ activation pattern is a strong determinant of responsiveness to AF therapy. Assessment of the AF activation pattern might therefore be used for decisionmaking in the management of AF patients. ${ }^{3}$ Current analysis methods still involve labor-intensive manual annotation of atrial deflections and waves, which limits the amount of fibrillation data that can be analyzed within a reasonable timeframe. Manual editing also increases the risk of subjective editing, which can lead to lower inter-observer consistency. To overcome these limitations we developed a novel method that identifies atrial deflections and fibrillation waves in a rapid and fully automated way, based on estimated probabilistic properties of the recorded fibrillation process. The details of this automatic procedure are presented in this paper, as well as the results of a validation study. In the design of the new deflection detection and wave mapping method, we aimed to incorporate electrophysiological knowledge to be able to compute wave map solutions that both visually and intellectually reflect the way electrophysiologists would construct them.

\section{Methods}

\subsection{Data acquisition}

Unipolar atrial fibrillation electrograms were recorded in 15 patients during cardiac surgery using a 16x16 square grid of electrodes with an inter-electrode distance of $1.5 \mathrm{~mm}$. Acute AF was induced in 8 patients who were in sinus rhythm, 7 patients were already in AF during surgery (either paroxysmal or persistent AF). Signals were acquired from the epicardium of the right atrial free wall (RA) $(n=15)$ and the posterior left atrium (LA) $(n=11)$ with a sampling frequency of $1 \mathrm{kHz}$. Segments of 4 seconds of AF were manually annotated by three experienced electrophysiologists to determine local atrial deflections 
Chapter 6

and to identify clusters of deflections that form separate fibrillation waves, following the algorithm described. ${ }^{2}$

\subsection{Electrogram pre-processing}

The first step in processing the atrial measurements is to eliminate electrograms that exhibit a bad signal-to-noise ratio. To enable a valid comparison between the new method and manually annotated signals, the same electrograms were eliminated in both methods. Signals were then filtered with a third order zero-phase Chebyshev $0.5 \mathrm{~Hz}$ high-pass filter to remove any baseline drift. Ventricular far-field disturbances in the atrial signal were removed by ventricular R-wave detection in a synchronously recorded ventricular signal ${ }^{4}$, followed by single-beat QRST-template cancellation based on the adaptive singular value decomposition cancellation method by Alcaraz et al. ${ }^{5}$. This method determines the morphology of the QRST complex as the most significant principal component of a set of QRST windows in a single lead. We adapted this method to compute the QRST complex for a single beat in all electrograms to account for beat-to-beat QRST complex variability. In atrial electrograms these ventricular far-fields are usually relatively low in amplitude compared to the local atrial deflections, but nonetheless they can cause false positives when detecting deflections and constructing waves.

\subsection{Intrinsic deflection detection}

A single predefined deflection shape was used to detect all candidate atrial deflections in the electrograms. This template could vary in duration (5-50ms). At each time-point in an electrogram the maximum correlation was determined between the electrogram and all template durations. The local maxima in the resulting template correlogram were marked as candidate deflection positions, as shown in Figure 1a, 1b and 1c. These candidate deflections can be either 1 . true intrinsic (or local) deflections or 2. far-field deflections - fluctuations of the electrograms caused by activations remote from the electrode - or 3. deflections caused by external disturbances. To distinguish between the three types of deflections, we exploited the underlying distribution of the AF cycle length (AFCL). This distribution was estimated by iteratively increasing the minimally allowed deflection amplitude until the distribution of the remaining deflection intervals showed a clear peak. The position and shape of this peak in the interval distribution of deflections with higher amplitude reflect the interval distribution of the true intrinsic deflections. The distribution 
Automated Quantification of AF Complexity
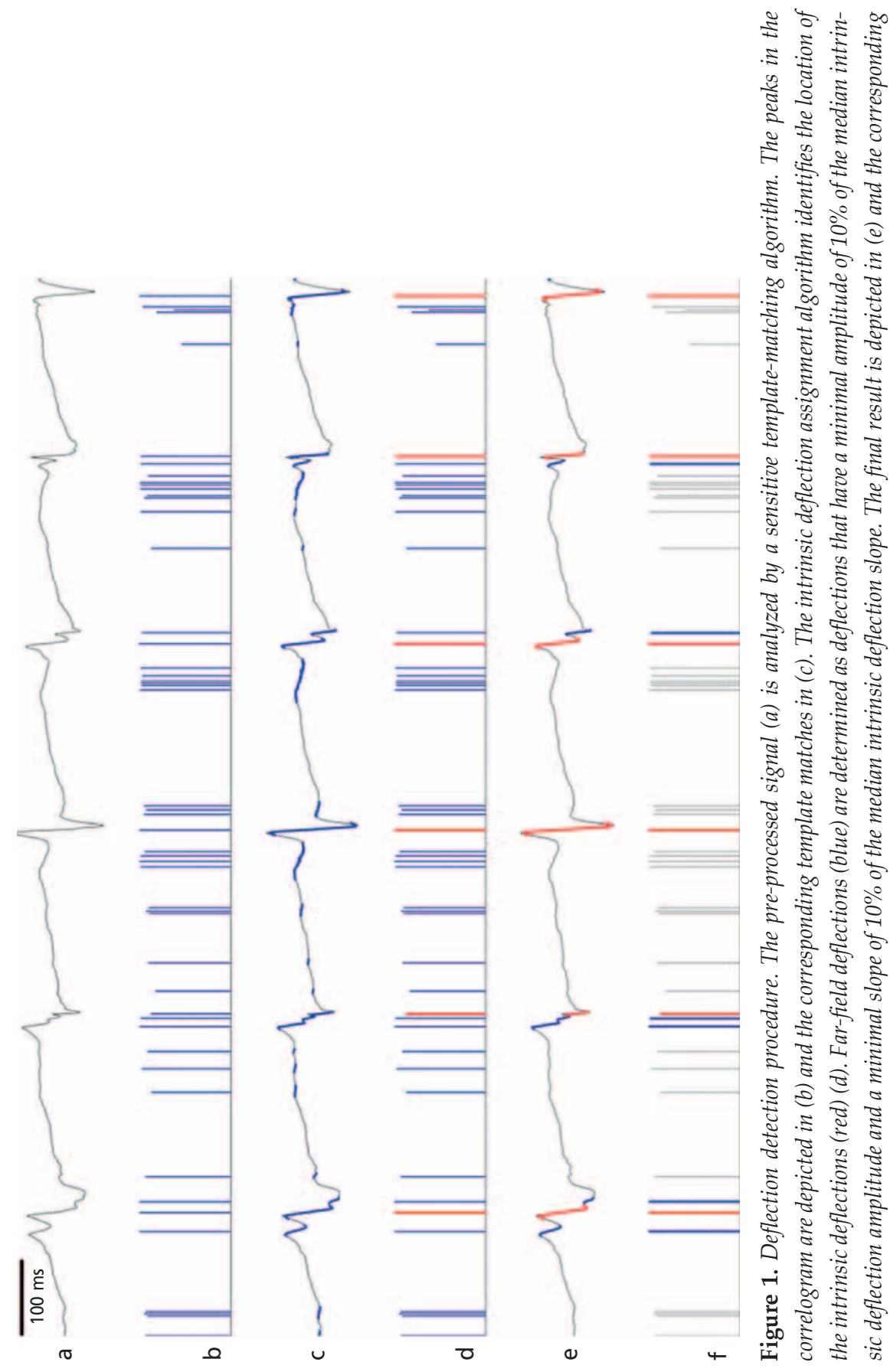

$\sqrt{2.5} \frac{2}{2} \frac{2}{2}$

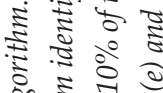

๑ 5 क

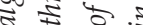

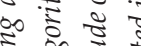

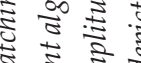

离 离

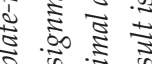

疍.

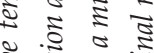

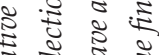

क

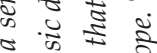

$\rightarrow \stackrel{\frac{1}{2}}{\rightarrow} \frac{5}{\infty}$

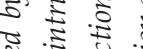

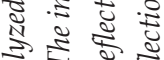

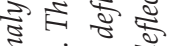

ह

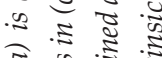

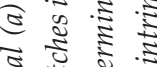

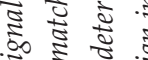

क ट है

क $\frac{5}{2} \frac{1}{2}$

खे ई ई

은

两.

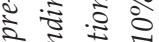

₹

स के क

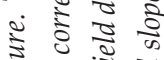

苟站 $\frac{1}{2}$

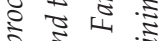

运官

. $5 \sqrt{2} \sqrt{2}$

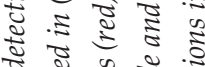

苟.

इ क

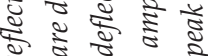

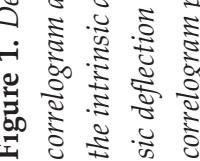




\section{Chapter 6}

estimation procedure was automated by introducing a maximum deflection interval threshold (default value $250 \mathrm{~ms}$ ). The minimally allowed deflection amplitude was increased until a maximum percentage (default value $10 \%$ ) of the remaining deflection intervals were larger than the maximum deflection interval threshold. A normal distribution with parameters $\theta_{C L}=\left(\mu_{\mathrm{CL}}, \sigma_{C L}\right)$ was fitted on the resulting deflection intervals. The procedure is illustrated in Figure 2.

Given the sequence of candidate deflections $\left\{c_{n}\right\}_{n \in\{1,2, \cdots, N\}}$ and the AFCL distribution estimate, a deflection type assignment problem is formulated, where the goal is to select a subsequence of intrinsic deflections $\left\{c_{n_{r}}\right\}_{r \in\{1,2, \ldots, k\}, n k \leq N}$ with maximum interval probability. Assuming a sequence of deflection intervals is i.i.d., the joint interval probability of a subsequence $\left\{c_{n_{r}}\right\}$ can be expressed as

$P\left(\left\{c_{n_{r}}\right\} \mid \theta_{C L}\right)=\prod_{i=1}^{k-1} f\left(t_{r_{i+1}}-t_{r_{i}} \mid \theta_{C L}\right)$

where $t_{r_{i}}$ is the central time of deflection $c_{i}$. The interval between the time $t_{r_{i}}$ of the first deflection in a subsequence and the beginning of the recording $t_{0}$ and the interval between the time $t_{r_{k}}$ of last deflection in a subsequence and the end of the recording $t_{\text {end }}$ has to be included in the joint probability of the subsequence to include the constraint that intrinsic deflections are to be found in all parts of the recording, forming a chain of deflections that are linked by probable deflection intervals.

$P\left(\left(t_{0},\left\{c_{n_{r}}\right\}, t_{\text {end }}\right) \mid \theta_{C L}\right)=\tilde{f}\left(t_{r_{1}}-t_{0} \mid \theta_{C L}\right) \cdot\left(\prod_{i=1}^{k-1} f\left(t_{r_{i+1}}-t_{r_{i}} \mid \theta_{C L}\right)\right) \ldots$

$\cdot \tilde{f}\left(t_{\text {end }}-t_{r_{k}} \mid \theta_{C L}\right)$,

where

$\tilde{f}\left(t_{j}-t_{i} \mid \theta_{C L}\right)=\left\{\begin{array}{ll}f\left(\mu_{C L} \mid \theta_{C L}\right) & \text { if } t_{j}-t_{i} \leq \mu_{C L} \\ f\left(t_{j}-t_{i} \mid \theta_{C L}\right) & \text { if } t_{j}-t_{i}>\mu_{C L}\end{array}\right.$.

A heuristic greedy algorithm finds a solution to the sequence selection problem by starting with the complete sequence of candidate deflections and trying to improve the joint deflection probability (2) by removing deflections, starting with deflection with low amplitude and slope, until the solution converges. This order of deflection deletion in this algorithm is based on the tendency of electrophysiologists to mark steep deflections with high amplitude 


\section{Automated Quantification of AF Complexity}
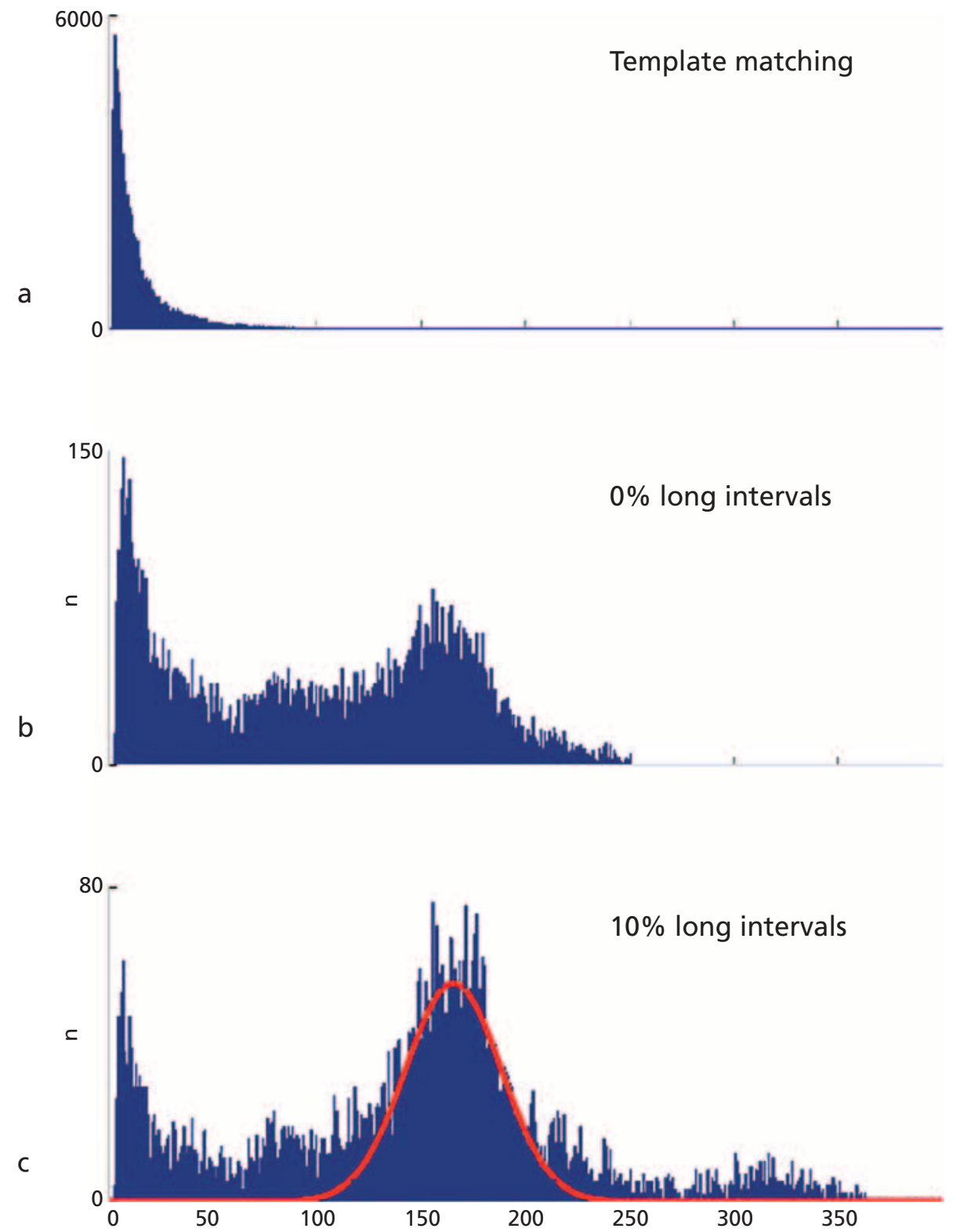

Figure 2. Estimating the intrinsic deflection interval distribution. A histogram of the intervals between the deflections found in the template matching procedure is shown in (a). Increasing the minimal amplitude of a deflection without causing long intervals, produces the histogram in (b). If a maximum of $10 \%$ long intervals are allowed, a clear peak appears, as can been seen in (c). A normal distribution is fitted onto this peak. 


\section{Chapter 6}

as intrinsic deflections and flat deflections with low amplitude as far-field deflections. An example result of an intrinsic deflection assignment solution can be seen in Figure 1d, 1e and 1f. The strength of this intrinsic deflection detection method is that it is able to adapt to substrate-specific deflection properties, such as amplitude, slope and interval distribution.

\subsection{Fibrillation wave construction}

The intrinsic deflection detection step determines the sequences of intrinsic deflections that are used to construct the fibrillation waves. The center of an intrinsic deflection is taken as the moment of local activation. Wave construction is divided into three phases. First, partial waves are created based on a minimum conduction velocity criterion (default value $20 \mathrm{~cm} / \mathrm{s}$ ) between two neighboring activations in the electrode grid. In experimental studies this threshold was identified as reasonable cut-off value for the occurrence of conduction block. ${ }^{2}$ Activations that can be linked to two or more partial waves are not yet assigned. In the second phase statistical conduction properties of these partial waves are determined. The distribution of the wave conduction velocity is estimated by computing the conduction velocity in partial waves containing at least 9 activations. The local conduction velocity for each wave activation is determined by fitting a tangent plane onto the surface formed by the activation and the activations within the same wave at the directly surrounding electrodes. The conduction velocity is then computed as the reciprocal of the plane gradient vector length and the direction of conduction as the plane gradient angle. The resulting velocity distribution is approximated by a gamma distribution with parameters $\theta_{C V}=\left(\alpha_{C V}, \theta_{C V}\right)$. Besides the velocity distribution also the distribution of the conduction deviation or tortuosity within a wave is determined by computing the mean conduction direction difference at each activation compared to the activations within the same wave at the directly surrounding electrodes. This tortuosity distribution is approximated by a normal distribution with parameters $\theta_{T O}=\left(\mu_{T O}, \sigma_{T O}\right)$. The third phase consists of assigning the unassigned activations to adjacent waves based on a maximum local conduction velocity and conduction direction probability. Given an activation $\mathrm{a}_{\mathrm{e}, \mathrm{t}}$ at electrode e at time $\mathrm{t}$ and a set of candidate waves $W$, this probability is defined as

$P\left(C V=c v_{a, w}, T O=t o_{a, w}\right)=P\left(c v_{a, w} \mid \theta_{C V}\right) \cdot P\left(t o_{a, w} \mid \theta_{T O}\right)$,

where $c v_{a, w}$ denotes the conduction velocity that results from adding activation $a_{e, t}$ to wave $w \in W$, and $t_{a, w}$ the mean conduction tortuosity. 


\subsection{Validation}

The results of the novel automated deflection detection and wave map construction procedure were validated by comparing the location of intrinsic deflections to the location manually annotated deflections. Automatically computed wave maps were compared to manually constructed maps in terms of median wave conduction velocity, median AF cycle length, number of waves per AFCL, number of breakthrough waves (BT) per AFCL and average wave size.

\section{Results and conclusions}

The sensitivity of the intrinsic deflection detection algorithm compared to the manual intrinsic deflection annotation is $87 \pm 6.7 \%$ (mean $\pm \mathrm{SD}$ ). The positive predictive value of the automated intrinsic deflection algorithm is $89 \pm 3.8 \%$. Figure 3 and Table 1 contain the comparison between the result of automated wave construction algorithm and the manually created waves. In general, the automated procedure produces very similar results to a manual annotation, most notably the wave conduction velocity and the AF cycle length. The number of waves per AFCL is only slightly overestimated, but the number of breakthrough waves per AFCL is roughly doubled by the automated procedure. An explanation for this phenomenon is that a manual editor tends to minimize the number of breakthroughs by searching for alternative activation pathways originating from the edge of the mapping array. Importantly, correlations are high, which effectively shows that the automated procedure is an adequately and valid substitute for the cumbersome manual annotation of atrial electrograms and manual atrial wave reconstruction.

\section{Discussion}

We developed and validated a novel algorithm for fast and automated spatiotemporal analysis of the substrate of atrial fibrillation. The algorithm identifies the key properties of the substrate with high accuracy. Potential applications of this technique are:

1. Assessment of spatial and temporal variability of the AF substrate. Automatic analysis of high-density maps during longer recordings will provide greater insight into the temporal variation in the behavior of the AF substrate and the recording duration required to assess AF complexity in a more reliable way. 


\section{Chapter 6}

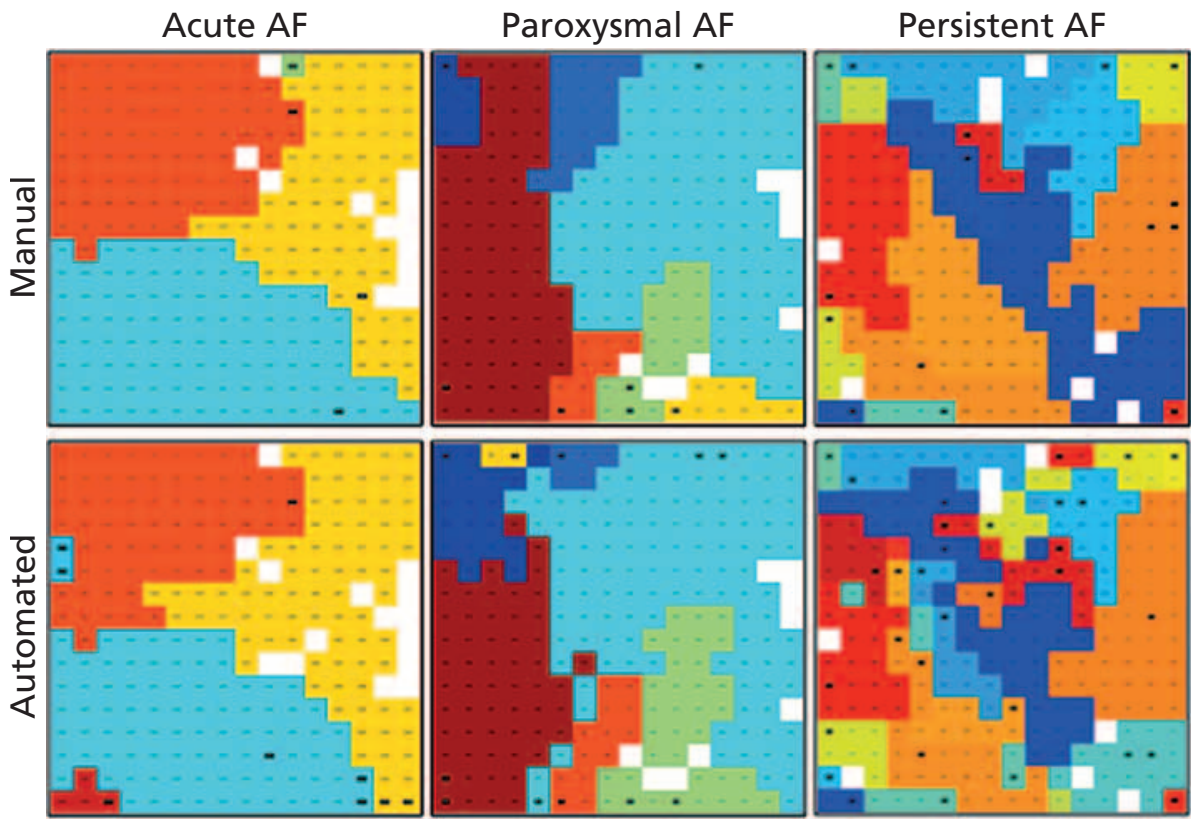

Figure 3. Examples of manually edited wave reconstructions versus wave reconstructions computed by the automated procedure. The maps show the wave reconstruction for a patient in acute $A F$, paroxysmal $A F$ and persistent $A F$. The same wave shapes can be visually identified in both the manually edited maps as well as in the computed maps, although the automated procedure tends to create more and smaller waves. This does not however affect the ranking of AF complexity.

Table 1. Comparison between automated and manual wave construction. Numbers are reported as mean $\pm S D$. All correlations are significant $(p<0.01)$.

\begin{tabular}{llll}
\hline Category & Manual & Automated & $r$ \\
\hline Number of waves / AFCL & $5.6 \pm 2.7$ & $7.8 \pm 3.3$ & 0.96 \\
Number of BT / AFCL & $1.8 \pm 1.2$ & $3.7 \pm 2.0$ & 0.94 \\
Wave conduction velocity (cm/s) & $65 \pm 12$ & $66 \pm 13$ & 0.97 \\
AFCL (ms) & $200 \pm 32$ & $204 \pm 29$ & 0.97 \\
Wave size (number of electrodes) & $53 \pm 29$ & $36 \pm 18$ & 0.96
\end{tabular}


2. Analysis of large amounts of fibrillation data in multicenter trials to establish a new classification of AF. Using the automated method, the amount of AF fibrillation electrograms that can be feasibly processed and analyzed in a short amount of time will increase, enabling larger scale data studies required to establish a classification of AF.

3. On-site AF substrate complexity assessment to tailor ablation therapy. A (quasi) real-time implementation of the automated method can provide direct information on wave conduction patterns to guide the ablation process and can give immediate feedback to assess efficacy of an ablation lesion set. 
Chapter 6 


\section{Automated Quantification of AF Complexity}

\section{References}

1. U. Schotten, S. Verheule, P. Kirchhof, and A. Goette, "Pathophysiological Mechanisms of Atrial Fibrillation: A Translational Appraisal," Physiological Reviews, vol. 91, no. 1, pp. 265-325, Jan. 2011.

2. M. A. Allessie, N. M. S. de Groot, R. P. M. Houben, U. Schotten, E. Boersma, J. L. Smeets, and H. J. Crijns, “Electropathological Substrate of Long-Standing Persistent Atrial Fibrillation in Patients With Structural Heart Disease: Longitudinal Dissociation," Circulation: Arrhythmia and Electrophysiology, vol. 3, no. 6, pp. 606-615, Dec. 2010.

3. P. Kirchhof, G. Y. H. Lip, I. C. Van Gelder, J. Bax, E. Hylek, S. Kaab, U. Schotten, et al., "Comprehensive risk reduction in patients with atrial fibrillation: emerging diagnostic and therapeutic options - a report from the 3rd Atrial Fibrillation Competence NETwork/European Heart Rhythm Association consensus conference.," Europace, vol. 14, no. 1, pp. 8-27, Jan. 2012.

4. J. Pan and W. J. Tompkins, "A Real-Time QRS Detection Algorithm," IEEE Trans. Biomed. Eng., vol. 32, no. 3, pp. 230-236, Mar. 1985.

5. R. Alcaraz and J. J. Rieta, "Adaptive singular value cancelation of ventricular activity in single-lead atrial fibrillation electrocardiograms," Physiol. Meas., vol. 29, no. 12, pp. 1351-1369, Oct. 2008 . 

Chapter $\mathbf{7}$

General Discussion 
Chapter 7 
This thesis focuses on different aspects of the development of a substrate for atrial fibrillation (AF), partly in goat but most in human. In chapter 1, both general mechanisms leading to the formation of an AF substrate and mechanistic information deducted out of current clinical practice in AF treatment is discussed. In chapter 2, postoperative AF is discussed and arguments for the presence of a pre-existing substrate capable of maintaining AF in patients without an AF history are extensively summarized. ${ }^{1}$ In chapter 3, persistence of AF is related to changes in conductance over the underlying atrial bundle anatomy. ${ }^{2}$ In-depth analysis of the substrate of patients with paroxysms of AF and comparison with patients without a history of AF and patients with longstanding persistent AF are reported in chapter 4 . In chapter 5, it is demonstrated that bipolar complex fractionated atrial electrograms (CFAE), a clinically wide-used surrogate parameter for AF substrate complexity, correlate poorly with established AF complexity measures and show no correlation with unipolar electrogram fractionation. ${ }^{3}$ In chapter 6, a novel automated method for quantifying AF substrate complexity is presented. ${ }^{4}$ The data and results presented in these chapters add, each in a specific way, to our knowledge and understanding of the development of a substrate capable of perpetuating AF.

\section{Need for Automated Analysis of the AF Substrate}

Both dominant frequency (DF) and electrogram fractionation are used to characterize the electrophysiological properties of AF. While DF has been adopted as a surrogate parameter of the $\mathrm{AFCl}$, electrogram fractionation is thought to correlate with the complexity of AF. Electrogram fractionation is the consequence of different activation times within the area sensed by the recording electrode. ${ }^{5}$ A link between substrate complexity and electrogram fractionation has been shown, for example, in high density mapping where unipolar fractionated electrograms are mostly found in areas of slow conduction or at pivot points around lines of functional block. ${ }^{6}$ Moreover, Nademanee and coworkers reported high degree of AF termination by ablating areas of bipolar CFAE. ${ }^{7}$ These results, however, were not confirmed in a randomized single-center study, ${ }^{8}$ nor in a recent report on the results of the largest randomized trial to examine outcomes of catheter ablation in patients with persistent AF (Star AF 2 trial). ${ }^{9}$ In this trial, patients were randomized to pulmonary vein isolation (PVI) alone, PVI + CFAE ablation or PVI + additional lines. ${ }^{9}$ No difference in AF freedom was reported between the 3 arms. These results might be due to the fact that the degree of fractionation - as it is currently measured - is not 


\section{Chapter 7}

necessarily a reflection of the severity of the underlying AF substrate. On the other hand, these results might also indicate that the durability of endocardial ablation lesion sets is limited.

Direct contact mapping and reconstruction of fibrillation waves allows studying the complexity of propagation patters during AF and provides better understanding of AF mechanisms. ${ }^{5,10}$ Although noise reduction of farfield potentials is much better in bipolar electrograms, unipolar electrograms have the advantage to represent more accurate local electrical activation. ${ }^{5}$

The disadvantage of, especially high-density, contact mapping is the complexity of the propagation patterns detected. Manual editing and annotation of atrial deflections and waves is a tedious work, thereby limiting the amount of fibrillation data and duration of AF recordings that can be analyzed. Also, due to the operator dependency, the risk of subjective editing can lead to lower inter-observer consistency. In chapter 6 a novel algorithm for fast and automated spatiotemporal analysis of fibrillation electrograms is presented and validated by comparing identification of local maximum negative $\mathrm{dV} / \mathrm{dt}$ by the algorithm with carefully manually annotated deflections. ${ }^{4}$ The algorithm uses the underlying distribution of the AFCL to overcome subjective deflection selection. This new technique has allowed us to analyze 10s files of highdensity (256 electrodes) epicardially mapped AF electrograms at different locations on both atria in chapter 4 and chapter 5 .

\section{Pre-existence of an AF Substrate}

AF is believed to be the consequence of the interplay of triggers initiating the arrhythmia and the presence of a substrate capable of perpetuating the arrhythmia. 5, 11 Electrical remodeling (shortening of the AF refractory period) has been identified as the first step in sustaining AF. ${ }^{12}$ To further perpetuate the arrhythmia, structural remodeling is needed to develop the substrate for AF. ${ }^{13}$

As such, patients undergoing cardiac surgery represent an interesting study population as they are capable, without having a history of AF, to develop post-surgical AF. Postoperative AF is different from so-called 'lone AF' in its self-limiting time course, generally peaking in incidence at the $2^{\text {nd }}$ postoperative day and then rapidly declining to only $6 \%$ of patients developing $\mathrm{AF}$ after the sixth postoperative day. ${ }^{14}$ On the other hand, the risk factors for POAF 
are surprisingly similar to the classical risk factors identified for AF as such (e.g. ageing, left atrial dilatation, mitral valve disease, congestive heart failure and hypertension). In chapter 2, both transient factors related to surgery as well as factors developing slowly and progressively contributing to the occurrence of POAF are summarized. ${ }^{1}$ Among the surgery-induced factors, sympathetic activation appears to be most relevant. This, however, cannot be the only mechanism responsible for AF occurrence as not all patients in whom those transient factors are active develop postoperative AF. Instead, we hypothesize the concept of the 'pre-existence of an AF substrate' in patients developing AF after cardiac surgery. Due to underlying cardiovascular diseases and remodeling, some patients already harbor a substrate capable of maintaining $\mathrm{AF}$ and post-surgical $\mathrm{AF}$ seems to unmask such a substrate. In this perspective the study of Ahlsson and coworkers is very intriguing. They were able to show that in patients with postoperative $\mathrm{AF}$ at the time of cardiac surgery, the arrhythmia occurred repeatedly during a follow-up of 5 years. ${ }^{15}$

In chapter 4 we demonstrate that patients with paroxysmal AF have the same degree of AF complexity as patients without an AF history. One can assume that some of the patients with acutely induced AF have some kind of substrate present. It is more interesting is to speculate to which degree a (pre-existing?) substrate is present in paroxysmal AF patients and how it contributes to 'de novo' AF occurrence, as generally only triggers are believed to drive paroxysmal AF. ${ }^{11}$ Of course, almost all patients in the study in chapter 4 are referred for cardiac surgery - and thus with underlying cardiovascular diseases - they are not 'lone$\mathrm{AF}^{\prime}$ patients. In any case, it is conceivable that paroxysmal $\mathrm{AF}$ is partly substrate driven. ${ }^{16}$ The spread in AF complexity reported in chapter 4, which is greatest in the paroxysmal AF group, presumably is due to underlying substrate differences. In the same context, we also looked at the relation between AF complexity and incidence of postoperative AF in chapter 4 . However, no correlation was found, probably due to small patient numbers (11 patients in the acutely induced AF group, 12 patients in the paroxysmal AF group). We did find an inverse correlation between the numbers of peroperative $\mathrm{AF}$ inductions needed, as all paroxysmal AF patients were in sinus rhythm, and AF complexity ( $\mathrm{r}=0.76, P=0.007)$.

\section{The 3-Dimensional AF Substrate}

The mechanistic relationship between trajectories of fibrillatory conduction and the complex underlying bundle anatomy is addressed in chapter 3. In Figure 1, 


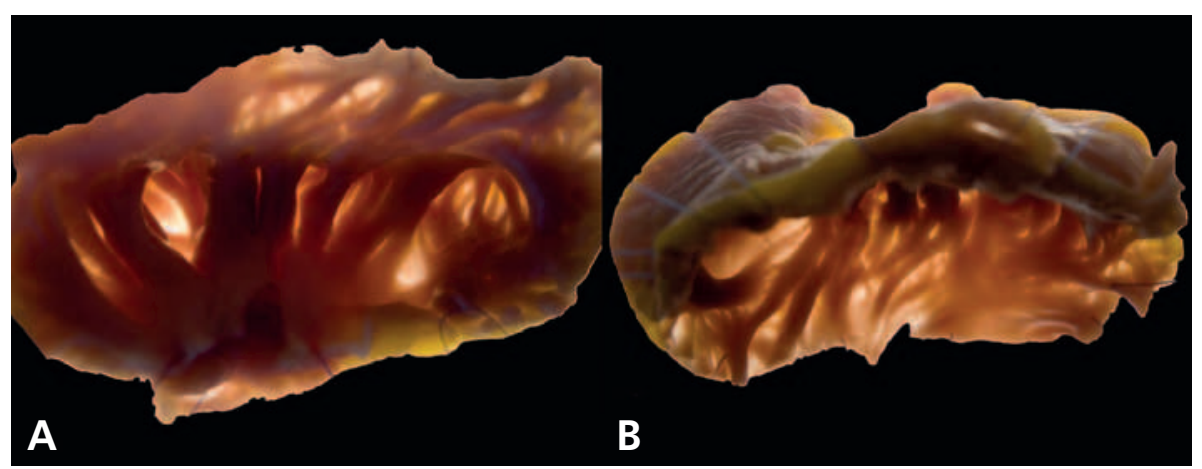

Figure 1. Transluminated views of a human left atrial appendage as seen from the endocardial $(A)$ and the epicardial $(B)$ side.

a transluminated view on the endo- and epicardium of a human left atrial appendage is depicted. As can be appreciated, the endocardial layer consists of thick endocardial bundles branching out into a thin epicardial layer. These obvious anatomical differences may play an important role in the development of the AF substrate. Indeed, in experimental studies propagation of electrical activity in the endocardial layer can markedly differ from that in the epicardial layer. ${ }^{17}$ Our group already demonstrated that endo-epicardial dissociation of electrical activity occurs and that the degree of endo-epicardial dissociation increases with AF complexity. ${ }^{18}$ In a consecutive study of our group, the majority of "breakthroughs" could be traced back to fibrillation waves propagating on the contralateral side of the atrial wall and therefore are likely to be due to transmural conduction. ${ }^{19}$

So there are strong indications for a 3-dimensional (3D) substrate of AF, but what do we know about the relationship of fibrillatory conduction with the underlying atrial anatomy? Such a link is suggested in several experimental and even in human studies. ${ }^{17,18,20-25}$ Allessie and coworkers described so-called 'cracks in the atrial wall' in human right atria. ${ }^{23}$ Those 'cracks' corresponded to lines of interwave conduction block, predominantly orientated parallel to the large pectinate muscle bundles. ${ }^{23}$ In chapter 3 , the first direct comparison between fibrillatory wave trajectories and atrial bundle anatomy reconstructed by high-resolution MRI is presented. ${ }^{2}$ First, with persistence of AF, bundle anatomy undergoes a more perpendicular rearrangement, presumably due to atrial dilatation. ${ }^{2}$ Secondly, in acutely induced AF, epicardial fibrillation waves conduct over the thick endocardial bundles. With persistence of AF, however, waves no longer follow endocardial bundles, but rather propagate over the thin epicardial muscle fibers. ${ }^{2}$ 
This finding strongly supports the loss of electrical coupling between both layers and enhances endo-epicardial dissociation. As a consequence, the AF substrate becomes a 3D process. It should be noted that this is relevant for clinical practice, as interindividual (and not only intergroup) differences in AF substrate, as observed in human (chapter 4 and other studies) ${ }^{23,26,27}$, are also determined by the unique underlying atrial anatomy.

\section{The Electrical and Structural Substrate in Human AF}

In chapter 4, electrical - based on high-density epicardial mapping of acutely induced AF, paroxysmal AF and persistent AF- and structural - based on histological analysis of right atrial appendages- properties of the human AF substrate are presented. The goal of this study was to investigate the degree of AF complexity in patients with paroxysmal AF compared to patients without an $\mathrm{AF}$ history and to patients with persistent $\mathrm{AF}$, and to explore the underlying structural remodeling in these groups. After analysis of almost 1000s of fibrillatory activation patterns using the novel algorithm presented in chapter 6, we were able to demonstrate that AF complexity in patients with paroxysmal $\mathrm{AF}$ is comparable to that of patients without an AF history. This is not in agreement with another endocardial study, where slower conduction properties and higher fractionation was reported in patients with paroxysmal AF compared to patients without an AF history. ${ }^{16}$ However, their analysis was based on low-resolution mapping, bipolar electrograms and was performed in sinus rhythm. ${ }^{16}$ Also in our study, a much higher degree of AF complexity was found in persistent $\mathrm{AF}$ compared to acutely induced $\mathrm{AF}$, as reported in other studies, 2, 6, 18, 19, 23, 26, 28-32 and to paroxysmal AF. Consistent with our findings, Stiles and coworkers also reported higher fractionation in the left compared to the right atrium and in persistent AF compared to paroxysmal $\mathrm{AF}^{33}$

It is important to notice that the highest variability of AF complexity was found in the paroxysmal AF group. This means that patients presenting with paroxysmal AF may have different complexity degrees of the underlying $\mathrm{AF}$ substrate. Non-invasive identification of the underlying substrate using surface ECG, ${ }^{34-39}$ Holter monitoring, ${ }^{40-42}$ body surface mapping, ${ }^{43,44}$ or echocardiography ${ }^{45,46}$ currently attracts a lot of attention in the scientific community. If adequate non-invasive identification of the AF substrate would be possible, patients with paroxysmal AF would likely benefit from this approach. Because of the large variability in AF complexity within this group, better 


\section{Chapter 7}

identification of patients in whom sinus rhythm can be restored and successfully maintained is needed. There is, however, a need for standardization in the ECG-based techniques used for non-invasive AF substrate assessment. ${ }^{47}$

The most important finding in the histological analysis presented in chapter 4 is the fact that there was no correlation between overall amount of fibrosis and AF complexity. It is, however, generally accepted that overall fibrosis is a good marker of the underlying AF substrate. ${ }^{48-52}$ The question remains if larger areas of fibrosis are a consequence of $\mathrm{AF}$ itself or of the underlying structural heart disease. In animal models of mitral regurgitation with consequent atrial dilatation ${ }^{53}$ or congestive heart failure ${ }^{54}$ replacement fibrosis secondary to tissue damage and cell death takes place. ${ }^{5}$ In a study of Anné and coworkers, atrial fibrosis was associated with the underlying structural heart disease rather than with AF. ${ }^{55}$ Furthermore, the high complexity of epicardial mapped propagation patterns during $\mathrm{AF}$, as presented in chapter 4, makes it hard to believe that general occurrence of fibrosis is causing conduction block between waves that sometimes only have the width of one recording electrode (i.e. $1.5 \mathrm{~mm}$ ). Endomysial fibrosis, increased transverse intermyocyte distances within bundles, resembles far more the interstitial fibrosis as reported by Spach and coworkers. ${ }^{49}$ Such type of fibrosis can produce large conduction delays perpendicular to the main fiber orientation. ${ }^{49,56}$ An increase in endomysial fibrosis has been reported to go hand in hand with the incidence of interwave conduction block and endo-epicardial dissociation of electrical activity. ${ }^{18,28}$ It can be hypothesized that endomysial fibrosis is responsible for disruption of electrical side-to-side connections not only within the epicardial layer, but as well between the epicardial and the endocardial layer. In chapter 4 , the first analysis of endomysial fibrosis in human atrial tissue is presented. Unlike the other quantified parameters (myocyte hypertrophy, overall fibrosis and connexin43), endomysial fibrosis did correlate (even after correction for underlying rhythm) with AF complexity in right atrial appendages of patients with acutely induced $\mathrm{AF}$, paroxysmal $\mathrm{AF}$ and persistent $\mathrm{AF}$. In persistent $\mathrm{AF}$, the number of fibrillation waves and the number of breakthroughs was even higher at the left atrium than at the right atrium. As such, an even larger increase in endomysial fibrosis is to be expected. This may have implications for clinical practice as detection of fibrosis by delayed enhancement MRI recently was introduced as a noninvasive method for the assessment of left atrial substrate properties. $^{57}$ 


\section{CFAE as a Surrogate for the AF Substrate}

Konings and coworkers identified unipolar CFAE in areas of slow conduction, at lines of conduction block, around pivot points and in regions where wavefronts collided. ${ }^{6}$ Activation maps during complex AF showed a high degree of electrical dissocation. Under such circumstances, mapping performed with two distant electrodes (bipolar), will frequently record different activation waves, rather than different signals of a single depolarization wave. ${ }^{6}$ Therefore, Konings and coworkers proposed the use of unipolar electrodes or closely spaced bipolar electrodes $(<1 \mathrm{~mm}){ }^{6}$ Nademanee introduced mapping of $b i$ polar CFAE using endocardial multipolar electrodes. ${ }^{7}$ The location and distribution of these bipolar CFAE remained relatively constant. ${ }^{7}$ Ablation of these CFAE was associated with a high rate of AF termination. ${ }^{7}$ The fact that these CFAE are stable in the spatiotemporal domain suggests the presence of stationary lines of block. This is not in line with epicardial high-resolution mapped AF patterns where random reentry and meandering multiple wavelets are seen and thus meandering CFAE would be expected (chapter 4 and others $)^{23,27}$. As discussed earlier, successful AF termination by CFAE ablation was not reproducible. ${ }^{8,9}$

The question arises whether these discrepancies could be explained by the usage of bipolar (rather than unipolar) electrograms with low-resolution mapping catheters. Using monophasic action potentials, Narayan and coworkers classified CFAEs and found that only in a minority CFAEs indicate localized rapid AF sites. ${ }^{58}$ The majority of CFAEs reflected far-field signals, AF acceleration, or disorganization..$^{58}$ To further explore the pathophysiological meaning of CFAE, we correlated CFAE to unipolar electrogram fractionation and to the underlying electrophysiological AF substrate (Chapter 5). By distinguishing intrinsic deflection (local activity) from farfield deflections (activity remote from the electrode) with the automated algorithm presented in chapter 6, we were able to define a robust parameter for unipolar fractionation (fractionation index, i.e. ratio of non-local to local deflections). In chapter 4, we demonstrated that unipolar electrogram fractionation correlates very well with AF complexity in the left and in the right atrium. In chapter 5, we show that bipolar CFAE derived from currently used semi-automated algorithms correlate poorly with established AF complexity parameters and do not correlate with the unipolar fractionation index. Moreover, agreement of CFAE identified by different algorithms is poor. This has important implications for clinical practice, as catheter ablation based on the currently used CFAE algorithms may lead to inappropriate targeting of AF substrate sites. 


\section{Chapter 7}

\section{Conclusion}

In this thesis we studied several aspects of the structure-function relationship of atrial fibrillation waves in goat and man. The key findings of this thesis are that (1) patients with postoperative AF often harbor a 'pre-existence substrate for $\mathrm{AF}^{\prime},(2)$ the AF substrate is influenced by and related to underlying atrial bundle anatomy, (3) patients with paroxysmal AF display a high variability of AF complexity, (4) overall fibrosis is not an important factor in the formation of an AF substrate and (5) bipolar CFAE ablation is not based on clear pathophysiological mechanisms of the AF substrate. 


\section{General Discussion}

\section{References}

1. Maesen B, Nijs J, Maessen J, Allessie M and Schotten U. Post-operative atrial fibrillation: a maze of mechanisms. Europace. 2011;14:159-74.

2. Maesen B, Zeemering S, Afonso C, Eckstein J, Burton RA, van Hunnik A, Stuckey DJ, Tyler D, Maessen J, Grau V, Verheule S, Kohl P and Schotten U. Rearrangement of atrial bundle architecture and consequent changes in anisotropy of conduction constitute the 3-dimensional substrate for atrial fibrillation. Circulation Arrhythmia and electrophysiology. 2013;6:967-75.

3. Lau DH, Maesen B, Zeemering S, Kuklik P, van Hunnik A, Lankveld TA, Bidar E, Verheule S, Nijs J, Maessen J, Crijns H, Sanders P and Schotten U. Indices of Bipolar Complex Fractionated Atrial Electrograms Correlate Poorly with Each Other and Atrial Fibrillation Substrate Complexity. Heart Rhythm. 2015.

4. Zeemering S, Maesen B, Nijs J, Lau DH, Granier M, Verheule S and Schotten U. Automated quantification of atrial fibrillation complexity by probabilistic electrogram analysis and fibrillation wave reconstruction. Conf Proc IEEE Eng Med Biol Soc. 2012;2012:6357-60.

5. Schotten U, Verheule S, Kirchhof P and Goette A. Pathophysiological mechanisms of atrial fibrillation: a translational appraisal. Physiol Rev. 2011;91:265-325.

6. Konings KT, Kirchhof CJ, Smeets JR, Wellens HJ, Penn OC and Allessie MA. High-density mapping of electrically induced atrial fibrillation in humans. Circulation. 1994;89:1665-80.

7. Nademanee K, McKenzie J, Kosar E, Schwab M, Sunsaneewitayakul B, Vasavakul T, Khunnawat $C$ and Ngarmukos T. A new approach for catheter ablation of atrial fibrillation: mapping of the electrophysiologic substrate. Journal of the American College of Cardiology. 2004;43:2044-53.

8. Oral H, Chugh A, Yoshida K, Sarrazin JF, Kuhne M, Crawford T, Chalfoun N, Wells D, Boonyapisit W, Veerareddy S, Billakanty S, Wong WS, Good E, Jongnarangsin K, Pelosi F, Jr., Bogun F and Morady F. A randomized assessment of the incremental role of ablation of complex fractionated atrial electrograms after antral pulmonary vein isolation for long-lasting persistent atrial fibrillation. Journal of the American College of Cardiology. 2009;53:782-9.

9. Verma A, Jiang CY, Betts TR, Chen J, Deisenhofer I, Mantovan R, Macle L, Morillo CA, Haverkamp W, Weerasooriya R, Albenque JP, Nardi S, Menardi E, Novak P, Sanders P and Investigators SAI. Approaches to catheter ablation for persistent atrial fibrillation. $N$ Engl J Med. 2015;372:1812-22.

10. Eckstein J, Kuhne M, Osswald S and Schotten U. Mapping of atrial fibrillation - basic research and clinical applications. Swiss Med Wkly. 2009;139:496-504.

11. Haissaguerre M, Jais P, Shah DC, Takahashi A, Hocini M, Quiniou G, Garrigue S, Le Mouroux A, Le Metayer P and Clementy J. Spontaneous initiation of atrial fibrillation by ectopic beats originating in the pulmonary veins. N Engl J Med. 1998;339:659-66.

12. Wijffels MCEF, Kirchhof CJHJ, Dorland R and Allessie MA. Atrial Fibrillation Begets Atrial Fibrillation: A Study in Awake Chronically Instrumented Goats. Circulation. 1995;92:1954-1968. 


\section{Chapter 7}

13. Allessie M, Ausma J and Schotten U. Electrical, contractile and structural remodeling during atrial fibrillation. Cardiovasc Res. 2002;54:230-246.

14. Aranki SF, Shaw DP, Adams DH, Rizzo RJ, Couper GS, VanderVliet M, Collins JJ, Jr., Cohn LH and Burstin HR. Predictors of atrial fibrillation after coronary artery surgery. Current trends and impact on hospital resources. Circulation. 1996;94:390-7.

15. Ahlsson A, Fengsrud E, Bodin L and Englund A. Postoperative atrial fibrillation in patients undergoing aortocoronary bypass surgery carries an eightfold risk of future atrial fibrillation and a doubled cardiovascular mortality. Eur J Cardiothorac Surg. 2010;37:1353-59.

16. Stiles MK, John B, Wong CX, Kuklik P, Brooks AG, Lau DH, Dimitri H, Roberts-Thomson KC, Wilson L, De Sciscio P, Young GD and Sanders P. Paroxysmal lone atrial fibrillation is associated with an abnormal atrial substrate: characterizing the "second factor". Journal of the American College of Cardiology. 2009;53:1182-91.

17. Schuessler RB, Kawamoto T, Hand DE, Mitsuno M, Bromberg BI, Cox JL and Boineau JP. Simultaneous epicardial and endocardial activation sequence mapping in the isolated canine right atrium. Circulation. 1993;88:250-63.

18. Eckstein J, Maesen B, Linz D, Zeemering S, van Hunnik A, Verheule S, Allessie M and Schotten U. Time course and mechanisms of endo-epicardial electrical dissociation during atrial fibrillation in the goat. Cardiovasc Res. 2011;89:816-24.

19. Eckstein J, Zeemering S, Linz D, Maesen B, Verheule S, van Hunnik A, Crijns H, Allessie MA and Schotten U. Transmural conduction is the predominant mechanism of breakthrough during atrial fibrillation: evidence from simultaneous endo-epicardial high-density activation mapping. Circ Arrhythm Electrophysiol. 2013;6:334-41.

20. Yamazaki M, Mironov S, Taravant C, Brec J, Vaquero LM, Bandaru K, Avula UM, Honjo H, Kodama I, Berenfeld $\mathrm{O}$ and Kalifa J. Heterogeneous atrial wall thickness and stretch promote scroll waves anchoring during atrial fibrillation. Cardiovasc Res. 2012;94:48-57.

21. Gray RA, Pertsov AM and Jalife J. Incomplete reentry and epicardial breakthrough patterns during atrial fibrillation in the sheep heart. Circulation. 1996;94:2649-61.

22. Houben RPM, de Groot NMS, Smeets JLRM, Becker AE, Lindemans FW and Allessie MA. $\mathrm{S}$-wave predominance of epicardial electrograms during atrial fibrillation in humans: Indirect evidence for a role of the thin subepicardial layer. Heart Rhythm. 2004;1:639-647.

23. Allessie MA, de Groot NM, Houben RP, Schotten U, Boersma E, Smeets JL and Crijns HJ. Electropathological substrate of long-standing persistent atrial fibrillation in patients with structural heart disease: longitudinal dissociation. Circ Arrhythm Electrophysiol. 2010;3:606-15.

24. Eijsbouts SC, Houben RP, Blaauw Y, Schotten U and Allessie MA. Synergistic action of atrial dilation and sodium channel blockade on conduction in rabbit atria. Journal of cardiovascular electrophysiology. 2004;15:1453-61.

25. Wu TJ, Doshi RN, Huang HL, Blanche C, Kass RM, Trento A, Cheng W, Karagueuzian HS, Peter CT and Chen PS. Simultaneous biatrial computerized mapping during permanent 


\section{General Discussion}

atrial fibrillation in patients with organic heart disease. Journal of cardiovascular electrophysiology. 2002;13:571-7.

26. de Groot NM, Houben RP, Smeets JL, Boersma E, Schotten U, Schalij MJ, Crijns H and Allessie MA. Electropathological substrate of longstanding persistent atrial fibrillation in patients with structural heart disease: epicardial breakthrough. Circulation. 2010;122:1674-82.

27. Lee G, Kumar S, Teh A, Madry A, Spence S, Larobina M, Goldblatt J, Brown R, Atkinson V, Moten S, Morton JB, Sanders P, Kistler PM and Kalman JM. Epicardial wave mapping in human long-lasting persistent atrial fibrillation: transient rotational circuits, complex wavefronts, and disorganized activity. European heart journal. 2014;35:86-97.

28. Verheule S, Tuyls E, van Hunnik A, Kuiper M, Schotten U and Allessie M. Fibrillatory conduction in the atrial free walls of goats in persistent and permanent atrial fibrillation. Circ Arrhythm Electrophysiol. 2010;3:590-9.

29. Verheule S, Tuyls E, Gharaviri A, Hulsmans S, van Hunnik A, Kuiper M, Serroyen J, Zeemering S, Kuijpers NH and Schotten U. Loss of continuity in the thin epicardial layer because of endomysial fibrosis increases the complexity of atrial fibrillatory conduction. Circ Arrhythm Electrophysiol. 2013;6:202-11.

30. Eckstein J, Zeemering S, Linz D, Maesen B, Verheule S, van Hunnik A, Crijns H, Allessie MA and Schotten U. Transmural Conduction is the Predominant Mechanism of Breakthrough during Atrial Fibrillation: Evidence from Simultaneous Endo-epicardial High Density Activation Mapping. Circ Arrhythm Electrophysiol. 2013;6:334-341.

31. Cuculich PS, Wang Y, Lindsay BD, Faddis MN, Schuessler RB, Damiano RJ, Jr., Li L and Rudy Y. Noninvasive characterization of epicardial activation in humans with diverse atrial fibrillation patterns. Circulation. 2010;122:1364-72.

32. Kanagaratnam P, Kojodjojo P and Peters NS. Electrophysiological abnormalities occur prior to the development of clinical episodes of atrial fibrillation: observations from human epicardial mapping. Pacing Clin Electrophysiol. 2008;31:443-53.

33. Stiles MK, Brooks AG, Kuklik P, John B, Dimitri H, Lau DH, Wilson L, Dhar S, RobertsThomson RL, Mackenzie L, Young GD and Sanders P. High-density mapping of atrial fibrillation in humans: relationship between high-frequency activation and electrogram fractionation. Journal of cardiovascular electrophysiology. 2008;19:1245-53.

34. Jones AR, Krummen DE and Narayan SM. Non-invasive identification of stable rotors and focal sources for human atrial fibrillation: mechanistic classification of atrial fibrillation from the electrocardiogram. Europace. 2013;15:1249-58.

35. Bollmann A, Husser D, Mainardi L, Lombardi F, Langley P, Murray A, Rieta JJ, Millet J, Olsson SB, Stridh M and Sornmo L. Analysis of surface electrocardiograms in atrial fibrillation: techniques, research, and clinical applications. Europace. 2006;8:911-26.

36. Holm M, Pehrson S, Ingemansson M, Sornmo L, Johansson R, Sandhall L, Sunemark M, Smideberg B, Olsson C and Olsson SB. Non-invasive assessment of the atrial cycle length 


\section{Chapter 7}

during atrial fibrillation in man: introducing, validating and illustrating a new ECG method. Cardiovascular research. 1998;38:69-81.

37. Husser D, Stridh M, Cannom DS, Bhandari AK, Girsky MJ, Kang S, Sornmo L, Bertil Olsson $\mathrm{S}$ and Bollmann A. Validation and clinical application of time-frequency analysis of atrial fibrillation electrocardiograms. Journal of cardiovascular electrophysiology. 2007;18:41-6.

38. Alcaraz R, Hornero F and Rieta JJ. Noninvasive time and frequency predictors of longstanding atrial fibrillation early recurrence after electrical cardioversion. Pacing Clin Electrophysiol. 2011;34:1241-50.

39. Nault I, Lellouche N, Matsuo S, Knecht S, Wright M, Lim KT, Sacher F, Platonov P, Deplagne A, Bordachar P, Derval N, O’Neill MD, Klein GJ, Hocini M, Jais P, Clementy J and Haissaguerre M. Clinical value of fibrillatory wave amplitude on surface ECG in patients with persistent atrial fibrillation. Journal of interventional cardiac electrophysiology: an international journal of arrhythmias and pacing. 2009;26:11-9.

40. Alcaraz R and Rieta JJ. The application of nonlinear metrics to assess organization differences in short recordings of paroxysmal and persistent atrial fibrillation. Physiological measurement. 2010;31:115-30.

41. Nilsson F, Stridh M, Bollmann A and Sornmo L. Predicting spontaneous termination of atrial fibrillation using the surface ECG. Medical engineering \& physics. 2006;28:802-8.

42. Alcaraz R, Sandberg F, Sornmo L and Rieta JJ. Classification of paroxysmal and persistent atrial fibrillation in ambulatory ECG recordings. IEEE Trans Biomed Eng. 2011;58:1441-9.

43. Bonizzi P, Guillem Mde L, Climent AM, Millet J, Zarzoso V, Castells F and Meste O. Noninvasive assessment of the complexity and stationarity of the atrial wavefront patterns during atrial fibrillation. IEEE Trans Biomed Eng. 2010;57:2147-57.

44. Guillem MS, Climent AM, Castells F, Husser D, Millet J, Arya A, Piorkowski C and Bollmann A. Noninvasive mapping of human atrial fibrillation. Journal of cardiovascular electrophysiology. 2009;20:507-13.

45. Duytschaever M, Heyse A, de Sutter J, Crijns H, Gillebert T, Tavernier R and Tieleman R. Transthoracic tissue Doppler imaging of the atria: a novel method to determine the atrial fibrillation cycle length. Journal of cardiovascular electrophysiology. 2006;17:1202-9.

46. Merckx KL, De Vos CB, Palmans A, Habets J, Cheriex EC, Crijns HJ and Tieleman RG. Atrial activation time determined by transthoracic Doppler tissue imaging can be used as an estimate of the total duration of atrial electrical activation. Journal of the American Society of Echocardiography: official publication of the American Society of Echocardiography. 2005;18:940-4.

47. Schotten U, Maesen B and Zeemering S. The need for standardization of time- and frequencydomain analysis of body surface electrocardiograms for assessment of the atrial fibrillation substrate. Europace. 2012;14:1072-5.

48. Nattel S. Defining "culprit mechanisms" in arrhythmogenic cardiac remodeling. Circ Res. 2004;94:1403-5. 


\section{General Discussion}

49. Spach MS and Boineau JP. Microfibrosis Produces Electrical Load Variations Due to Loss of Side-to-Side Cell Connections; A Major Mechanism of Structural Heart Disease Arrhythmias. Pacing and Clinical Electrophysiology. 1997;20:397-413.

50. Boldt A, Wetzel U, Lauschke J, Weigl J, Gummert J, Hindricks G, Kottkamp H and Dhein S. Fibrosis in left atrial tissue of patients with atrial fibrillation with and without underlying mitral valve disease. Heart. 2004;90:400-5.

51. Kostin S, Klein G, Szalay Z, Hein S, Bauer EP and Schaper J. Structural correlate of atrial fibrillation in human patients. Cardiovascular research. 2002;54:361-79.

52. Saito T, Tamura K, Uchida D, Togashi M, Nitta T and Sugisaki Y. Histopathological features of the resected left atrial appendage as predictors of recurrence after surgery for atrial fibrillation in valvular heart disease. Circ J. 2007;71:70-8.

53. Verheule S, Wilson E, Everett TIV, Shanbhag S, Golden C and Olgin J. Alterations in Atrial Electrophysiology and Tissue Structure in a Canine Model of Chronic Atrial Dilatation Due to Mitral Regurgitation. Circulation. 2003;107:2615-2622.

54. Li D, Fareh S, Leung TK and Nattel S. Promotion of atrial fibrillation by heart failure in dogs: atrial remodeling of a different sort. Circulation. 1999;100:87-95.

55. Anne W, Willems R, Roskams T, Sergeant P, Herijgers P, Holemans P, Ector H and Heidbuchel $\mathrm{H}$. Matrix metalloproteinases and atrial remodeling in patients with mitral valve disease and atrial fibrillation. Cardiovascular research. 2005;67:655-66.

56. Koura T, Hara M, Takeuchi S, Ota K, Okada Y, Miyoshi S, Watanabe A, Shiraiwa K, Mitamura H, Kodama I and Ogawa S. Anisotropic Conduction Properties in Canine Atria Analyzed by High-Resolution Optical Mapping: Preferential Direction of Conduction Block Changes From Longitudinal to Transverse With Increasing Age. Circulation. 2002;105: 2092-2098.

57. Oakes RS, Badger TJ, Kholmovski EG, Akoum N, Burgon NS, Fish EN, Blauer JJ, Rao SN, DiBella EV, Segerson NM, Daccarett M, Windfelder J, McGann CJ, Parker D, MacLeod RS and Marrouche NF. Detection and quantification of left atrial structural remodeling with delayed-enhancement magnetic resonance imaging in patients with atrial fibrillation. Circulation. 2009;119:1758-67.

58. Narayan SM, Wright M, Derval N, Jadidi A, Forclaz A, Nault I, Miyazaki S, Sacher F, Bordachar P, Clementy J, Jais P, Haissaguerre M and Hocini M. Classifying fractionated electrograms in human atrial fibrillation using monophasic action potentials and activation mapping: evidence for localized drivers, rate acceleration, and nonlocal signal etiologies. Heart Rhythm. 2011;8:244-53. 



\section{Summary}

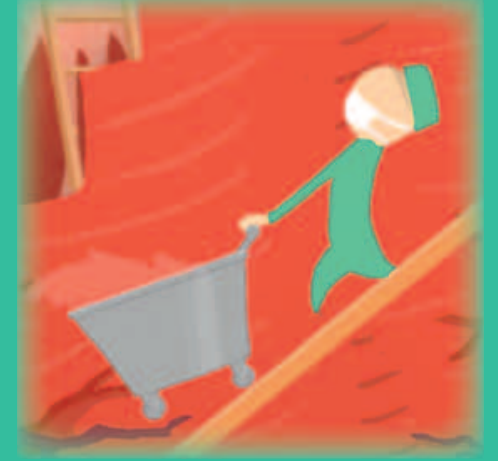


Summary 
This thesis discusses the relationship between the structure (atrial anatomy, structural remodeling processes) and the function (propagation of fibrillatory conduction) of atrial fibrillation (AF) waves both in goat and man. AF is characterized by complex conduction patterns and by an increase in AF complexity with the duration of the arrhythmia. The highly complex 3-dimensional atrial anatomy consists of thick endocardial bundles branching out into a thin epicardial layer. Moreover, different structural alterations take place with the persistence of AF. This complex interplay works in both ways, as the observed electrical activity is strongly related to the underlying anatomy, but also atrial anatomy as such is altered by the occurrence and persistence of AF. In this thesis, we focus on different aspects of this structure-function relationship and on its implications for the mechanisms driving AF.

In chapter 1, different mechanisms identified by mapping of AF in both experimental animal models and human are summarized. By reviewing mapping studies published so far, it is clear that the exact pathophysiological mechanism responsible for persistence of AF is still incompletely understood. Multiple reentrant wavelets, ectopic activity, stable and unstable rotors all have been identified depending on the mapping technique and the model that has been used or studied. There are however strong indications that AF is a 3dimensional process and that specific conduction disturbances occur in close relation with the underlying anatomy.

In chapter 2, we zoom in on a special subtype of AF that typically occurs after (cardiac) surgery; postoperative AF (POAF). In this chapter we hypothesize that many patients already have a pre-existing substrate for $\mathrm{AF}$ at the time of surgery and that this substrate is unmasked by occurrence of acute factors increasing the activity of pro-arrhythmic factors in the perioperative period. Indeed, factors associated with the occurrence of POAF can be divided in factors directly related to the surgical procedure and chronic factors related to structural heart disease and ageing of the heart. Among the surgery-induced factors, sympathetic activation seems to be more relevant than inflammation and oxidative stress. These factors, however, are also clearly active in postoperative patients not developing POAF. So besides acute factors, occurrence of POAF seems strongly determined by long-lasting structural remodeling processes leading to a pre-existing substrate of AF. These structural changes prior to the onset of the arrhythmia are also reflected by the risk factors for POAF. 


\section{Summary}

The effect of AF on atrial bundle architecture and consequent changes in AF conduction is studied in chapter 3 . In a rapid pacing model of AF in the goat, high resolution MRI-analysis of the atrial wall after high density mapping of AF was performed. Reconstruction of the endo- and epicardial bundle anatomy demonstrated that after 7 months of AF epicardial fibers are rotated more perpendicular towards endocardial bundles than in acutely induced AF. Moreover, it was shown that in non-remodeled atria, epicardial fibrillation waves propagate fastest along the direction of endocardial bundles, while in structurally remodeled atria the conduction of epicardial fibrillation waves was fastest along epicardial fibers. In remodeled atria, this mechanism is likely contributes to the occurrence of endo-epicardial dissociation of electrical activity.

A comprehensive analysis of the development of the electro-structural substrate with the persistence of AF in man is performed in chapter 4. Epicardial mapping of AF was performed in patients with acutely induced AF, paroxysmal AF and persistent AF and in-depth analysis of right atrial appendages was performed. Analysis of fibrillation electrograms demonstrated that AF complexity is much higher in patients with persistent AF, but comparable in patients with paroxysmal AF and patients without an AF history. On the contrary, the spread of AF complexity was highest in paroxysmal AF. Structural analysis revealed that endomysial fibrosis, but not overall fibrosis, correlated well with AF complexity. As a consequence, new techniques for atrial fibrosis quantification, such as DE-MRI, may overestimate the role of fibrosis as a determinant of conduction disturbances in AF.

In chapter 5, the pathophysiological relevance of complex fractionated atrial electrograms (CFAE) in AF is studied. Semi-automated bipolar CFAE algorithms, used in daily clinical practice, correlated poorly with each other and with AF complexity measures such as conduction velocity, number of waves or breakthroughs per AF cycle and electrical dissociation. Moreover, bipolar CFAE also correlated poorly with the fractionation index derived from the unipolar electrograms. The lack of pathophysiological relevance of bipolar CFAE analysis may in part contribute to the divergent and limited success rates of catheter ablation strategies targeting CFAE.

In chapter 6, a rapid and fully automated procedure by probabilistic electrogram analysis to accurately identify local, intrinsic atrial deflections and construct fibrillation waves based on these deflections is presented. Also, this 
novel analysis is validated using manually annotated electrograms and wave maps and is therefore an adequate substitute for manual annotation.

Finally, a general discussion of the results and findings in this thesis and an explanation of their implications are stated in chapter 7. 

Samenvatting

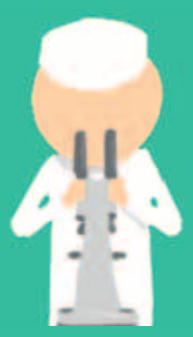


Samenvatting 
Dit proefschrift behandelt de relatie tussen de structuur (atriale anatomie, structurele remodeling processen) en de functie (de geleiding) van atriale fibrillatiegolven in de geit en de mens. Enerzijds bestaat atriumfibrilleren (AF) uit complexe geleidingspatronen en is het gekenmerkt door een toename in complexiteit bij een langere duur van de aritmie. Anderzijds is de complexe driedimensionale atriale anatomie opgebouwd uit dikke endocardiale bundels die uitwaaieren in een dunne epicardiale laag. Daarnaast treden er verschillende structurele veranderingen op door het voortbestaan van AF. Deze complexe interactie werkt in twee richtingen. De elektrische activiteit is sterk verbonden met de onderliggende anatomie en door het optreden van AF verandert ook de anatomie van het atrium. In dit proefschrift gaan we dieper in op verschillende aspecten van deze relatie tussen structuur en functie, maar ook op de implicaties voor de mechanismen van AF.

Hoofdstuk 1 van dit proefschrift vormt een samenvatting van de verschillende mechanismen van $\mathrm{AF}$, aangetoond door het mappen van $\mathrm{AF}$ in zowel dierexperimentele modellen als in de mens. Uit de samenvatting van alle tot op heden gepubliceerde mapping studies wordt duidelijk dat het precieze pathofysiologische mechanisme, verantwoordelijk voor het voortbestaan van $\mathrm{AF}$, nog niet volledig doorgrond is. Afhankelijk van de toegepaste mappingtechniek of het gekozen AF-model worden verschillende mechanismen zoals de aanwezigheid van meerdere gelijktijdige fibrillatiegolven, ectopische activiteit, stabiele en onstabiele rotoren aangetoond. Desalniettemin zijn er meerdere aanwijzingen dat $\mathrm{AF}$ een driedimensionaal proces is en dat het optreden van specifieke geleidingsstoornissen sterk afhankelijk is van de onderliggende anatomie.

In hoofdstuk 2 gaan we dieper in op een subtype van AF dat meestal voorkomt na (hart)chirurgie, namelijk postoperatief AF (POAF). We onderbouwen de hypothese dat veel patiënten reeds over een 'vooraf bestaand substraat voor $\mathrm{AF}^{\prime}$ beschikken ten tijde van chirurgie. De aanwezigheid van dit substraat wordt onthuld door zogenaamde 'acute factoren' die pro-aritmische effecten hebben in de peri-operatieve periode. Factoren, geassocieerd met het ontstaan van POAF, kunnen opgedeeld worden in acute factoren, die direct terug te brengen zijn tot de chirurgische ingreep, en chronische factoren, die een gevolg zijn van structureel hartlijden en van het verouderen van het hart. Van de chirurgisch geïnduceerde factoren blijkt sympathische activatie een belangrijkere rol te spelen bij het optreden van POAF dan inflammatie of oxidatieve stress. Al deze factoren zijn echter ook duidelijk actief in patiënten die 
Samenvatting

geen POAF ontwikkelen. Het ontstaan van POAF lijkt dus ook in belangrijke mate bepaald door langdurige structurele 'remodeling' processen die aanleiding geven tot dergelijk 'vooraf bestaand substraat voor AF'.

Het effect van AF op de atriale anatomie en de daarop volgende veranderingen in AF-geleiding zijn het onderwerp van hoofdstuk 3. Deze studie hebben we gedaan in een geitenmodel waarin AF werd opgewekt door tachypacing. In dit model hebben we een hoge resolutie MRI-analyse van de atriale wand gemaakt nadat eerst mapping van AF was verricht. Na de reconstructie van de endo- en epicardiale bundelanatomie hebben we kunnen aantonen dat na 7 maanden van AF de epicardiale vezels meer loodrecht gedraaid zijn ten aanzien van de endocardiale bundels dan in acuut geïnduceerd AF. Tevens hebben we kunnen aantonen dat in normale atria epicardiale golven het snelst geleiden in de richting van de endocardiale bundels. In structureel geremodelleerde atria bleken deze epicardiale golven echter meer in de richting van de epicardiale vezels te geleiden. In geremodelleerde atria is het optreden van endo-epicardiale dissociatie van elektrische activiteit waarschijnlijk mede toe te schrijven aan dit mechanisme.

Een uitgebreide analyse van de ontwikkeling van het elektrostructurele substraat ten gevolge van het voortbestaan van AF is terug te vinden in hoofdstuk 4. In deze studie hebben we epicardiale mapping van AF verricht in patiënten met acuut opgewekt AF, patiënten met paroxysmaal AF en patiënten met persistent AF. Daarnaast hebben we een structurele analyse van de rechter hartoortjes uitgevoerd. Na analyse van de AF electrogrammen hebben we aangetoond dat de complexiteit van AF veel hoger is in patiënten met persistent $\mathrm{AF}$, maar vergelijkbaar in patiënten met paroxysmaal $\mathrm{AF}$ en patiënten zonder AF in de voorgeschiedenis. De spreiding van de complexiteit van AF was wel het grootst in de groep van paroxysmaal AF. De structurele analyse toonde dat endomysiale fibrose, in tegenstelling tot algehele fibrose, goed overeenkomt met de complexiteit van AF. Dit heeft implicaties voor het gebruik van nieuwere technieken voor de kwantificatie van atriale fibrose, zoals DE-MRI, omdat deze technieken de rol van algehele fibrose als parameter voor geleidingsstoornissen mogelijks overschatten.

De pathofysiologische relevantie van complexe gefractioneerde electrogrammen, ook CFAE genoemd, wordt uitgediept in hoofdstuk 5. Hieruit blijkt dat de semi-automatische bipolaire CFAE algoritmen, die in de dagelijkse klinische praktijk gebruikt worden, slecht correleren met elkaar maar ook met 
parameters van de complexiteit van AF zoals geleidingssnelheid, het aantal golven of 'breakthroughs' per AF cycluslengte en elektrische dissociatie. Daarenboven correleren bipolaire CFAE ook zeer zwak met de fractionatieindex die afgeleid is van unipolaire elektrogrammen. Dit klaarblijkelijke gebrek aan pathofysiologische relevantie van bipolaire CFAE draagt mogelijk bij tot de uiteenlopende resultaten en eerder beperkt succes van katheter ablatiestrategieën gericht op CFAE.

Hoofdstuk 6 gaat over de ontwikkeling van een snelle en volautomatische analyse, gebaseerd op probabilistische elektrogramanalyse. Deze analyse identificeert de correcte lokale intrinsieke atriale deflecties en stelt fibrillatiegolven samen gebaseerd op deze geïdentificeerde deflecties. Ook toetsen we deze nieuwe analyse aan manueel geannoteerde electrogrammen. Aldus vormt deze geautomatiseerde analyse een substituut voor manuele annotatie van $\mathrm{AF}$ electrogrammen.

Tenslotte worden alle resultaten en bevindingen van dit proefschrift en de mogelijke implicaties besproken in een algemene discussie in hoofdstuk 7 . 

Valorization

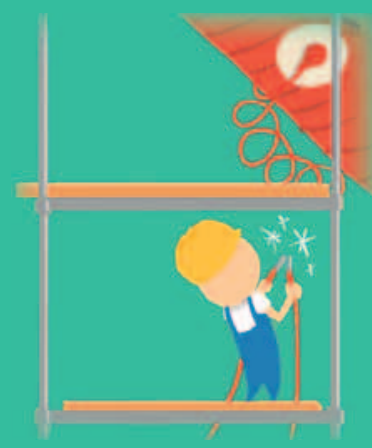


Valorization 


\section{Social relevance and need for further research}

Atrial fibrillation (AF) is the most common arrhythmia with an estimated prevalence in the developed world of approximately $1.5-2 \%$ of the general population. ${ }^{1}$ The prevalence of AF increases with age, so with the ageing of the general population, AF prevalence is estimated to at least double in the next 50 years. ${ }^{2}$ In a large Dutch population-based prospective cohort study among 6808 subjects aged 55 years and above, the overall AF prevalence was $5.5 \%$, rising from $0.7 \%$ in the age group $55-59$ years to $17.8 \%$ in those aged 85 years and above. ${ }^{3}$ Although AF prevalence and incidence are higher in men, the absolute number of men and women with AF is about equal as women have a longer life expectancy. ${ }^{4}$ In the Framingham Heart Study the lifetime risk for developing $\mathrm{AF}$ at the age of 40 years was $26.0 \%$ for men and $23.0 \%$ for women. ${ }^{5}$

The arrhythmia goes hand in hand with an important increase in mortality and morbidity; AF is associated with a doubled death rate (independent of other mortality predictors), an increased stroke risk (approximately every fifth stroke is due to AF), frequent hospitalizations, a reduced quality of life and exercise capacity and left ventricular dysfunction. ${ }^{2,6-9}$ As a consequence, $\mathrm{AF}$ attributes to an extensive economic and public health burden. ${ }^{10,}{ }^{11}$ Also, screening for AF might reduce the economic burden as patients with undiagnosed AF have greater medical costs than patients with similar observable characteristics without AF. ${ }^{12}$

It is clear that the medical and socio-economic impact of AF on the health system worldwide is huge and warrants further research. First, research on methods enabling prediction of AF or prevention of AF by treating risk factors is important. For example, recently it has been shown that sustained weight loss can reduce AF burden and even maintain sinus rhythm. ${ }^{13,14}$ Secondly, we need optimization and individualization of new and current AF treatment options. To do so, algorithms to rapidly identify AF complexity and further understanding of underlying mechanisms driving AF are necessary.

\section{Target groups and innovation}

This thesis presents information that might not only be interesting for researchers in the field of AF, but also for clinicians treating patients with $\mathrm{AF}$ 
(e.g. cardiologists, electrophysiologists, cardiac surgeons, etc.), for mathematicians in the field of AF modeling and even for (treatment) of AF patients. The data and findings presented in this thesis contribute to the understanding of $\mathrm{AF}$ and might help to improve AF therapy in different ways.

\section{AF complexity analysis}

The novel algorithm presented in chapter 6 provides rapid and automated analysis of AF electrograms. It can not only be used to study AF mechanisms in different settings, but also to identify AF complexity using non-invasive diagnostic tools to facilitate the development of patient-tailored treatment.

\section{Atrial Anatomy}

The correlation - presented in chapter 3 - between the atrial bundle anatomy and AF conduction patterns helps to understand the occurrence of endo-epicardial dissociation of electrical activity and transmural conduction during $\mathrm{AF}$, both mechanisms that are believed to be important in AF perpetuation. Furthermore, based on the findings in chapter 3, we hypothesize that observed inter-individual differences in atrial fibrillation substrates in humans can partly be attributed to differences in the individual atrial anatomy. Research on and identification of the underlying atrial anatomy in AF patients has been underexplored so far.

\section{Human Paroxysmal AF}

Based on detailed analysis of AF conduction patterns in chapter 4, we show that AF complexity is comparable between patients with paroxysmal AF and patients without a history of AF. As such, the increase of AF complexity identified in patients with persistent AF occurs primarily after AF has become persistent. This helps to explain why AF treatment is much more successful in paroxysmal than in persistent $\mathrm{AF}$ and might validate aggressive AF treatment in paroxysmal AF patients to prevent deterioration to persistent AF. In this context the large variability in AF complexity in patients with paroxysmal AF is important, as these patients would benefit most of real-time identification of the underlying AF substrate complexity.

\section{Endomysial fibrosis}

The occurrence of endomysial fibrosis has already been correlated to AF complexity in the goat model of AF by our group. ${ }^{15}$ In chapter 4 , endomysial fibrosis, not overall fibrosis, is also identified in human AF as the only structural marker correlating with AF complexity. Off course reproducing these find- 
ings in further studies is needed, but the relevance of imaging overall atrial fibrosis as a predictor of conduction disturbances can be questioned.

\section{Complex Fractionated Electrograms}

The importance of targeting complex fractionated electrograms in AF ablation is still not fully understood. However, the inconsistency in bipolar complex fractionated atrial electrogram (CFAE) algorithms and the poor correlation of these algorithms with underlying AF complexity and unipolar fractionation might explain the limited success rates of CFAE ablation. Based on the findings in chapter 5 , we can postulate that ablation guided by currently available algorithms might lead to erroneous targeting of AF substrate sites.

\section{What is next?}

Early detection and treatment of AF can possibly help to reduce the AF burden in the general population. Development of non-invasive diagnostic tools to identify AF complexity is needed to enable patient-tailored, and thus substrate-based, treatment of AF. Also, identification of patients how will but also will not benefit from a specific AF treatment can help us to optimize AF treatment. Next to animal models, direct contact mapping studies in humans are still needed to further study mechanisms underlying AF, as no animal model can mimic the plethora of different pathological processes active in the ageing human heart. Finally, the continued development of relevant AF computer models that enable us to test the efficacy of antiarrhythmic drug therapy or AF ablation strategies is needed so that research in animal models can be maximally minimized. 
Valorization 


\section{References}

1. Camm AJ, Lip GY, De Caterina R, Savelieva I, Atar D, Hohnloser SH, Hindricks G, Kirchhof P, Guidelines-CPG ESCCfP, Document R. 2012 focused update of the ESC Guidelines for the management of atrial fibrillation: an update of the 2010 ESC Guidelines for the management of atrial fibrillation--developed with the special contribution of the European Heart Rhythm Association. Europace. 2012; 14: 1385-1413.

2. Camm AJ, Kirchhof P, Lip GY, Schotten U, Savelieva I, Ernst S, Van Gelder IC, Al-Attar N, Hindricks G, Prendergast B, Heidbuchel H, Alfieri O, Angelini A, Atar D, Colonna P, De Caterina R, De Sutter J, Goette A, Gorenek B, Heldal M, Hohloser SH, Kolh P, Le Heuzey JY, Ponikowski P, Rutten FH, Vahanian A, Auricchio A, Bax J, Ceconi C, Dean V, Filippatos G, Funck-Brentano C, Hobbs R, Kearney P, McDonagh T, Popescu BA, Reiner Z, Sechtem U, Sirnes PA, Tendera M, Vardas PE, Widimsky P, Agladze V, Aliot E, Balabanski T, BlomstromLundqvist C, Capucci A, Crijns H, Dahlof B, Folliguet T, Glikson M, Goethals M, Gulba DC, Ho SY, Klautz RJ, Kose S, McMurray J, Perrone Filardi P, Raatikainen P, Salvador MJ, Schalij MJ, Shpektor A, Sousa J, Stepinska J, Uuetoa H, Zamorano JL, Zupan I. Guidelines for the management of atrial fibrillation: the Task Force for the Management of Atrial Fibrillation of the European Society of Cardiology (ESC). Europace. 2010; 12: 1360-1420.

3. Heeringa J, van der Kuip DA, Hofman A, Kors JA, van Herpen G, Stricker BH, Stijnen T, Lip GY, Witteman JC. Prevalence, incidence and lifetime risk of atrial fibrillation: the Rotterdam study. European heart journal. 2006; 27: 949-953.

4. Feinberg WM, Blackshear JL, Laupacis A, Kronmal R, Hart RG. Prevalence, age distribution, and gender of patients with atrial fibrillation. Analysis and implications. Archives of internal medicine. 1995; 155: 469-473.

5. Lloyd-Jones DM, Wang TJ, Leip EP, Larson MG, Levy D, Vasan RS, D’Agostino RB, Massaro JM, Beiser A, Wolf PA, Benjamin EJ. Lifetime Risk for Development of Atrial Fibrillation: The Framingham Heart Study. Circulation. 2004; 110: 1042-1046.

6. Wolf PA, Abbott RD, Kannel WB. Atrial fibrillation as an independent risk factor for stroke: the Framingham Study. Stroke. 1991; 22: 983-988.

7. Wang TJ, Larson MG, Levy D, Vasan RS, Leip EP, Wolf PA, D'Agostino RB, Murabito JM, Kannel WB, Benjamin EJ. Temporal Relations of Atrial Fibrillation and Congestive Heart Failure and Their Joint Influence on Mortality: The Framingham Heart Study. Circulation. 2003; 107: 2920-2925.

8. Ott A, Breteler MM, de Bruyne MC, van Harskamp F, Grobbee DE, Hofman A. Atrial fibrillation and dementia in a population-based study. The Rotterdam Study. Stroke. 1997; 28: 316-321.

9. Benjamin EJ, Wolf PA, D'Agostino RB, Silbershatz H, Kannel WB, Levy D. Impact of atrial fibrillation on the risk of death: the Framingham Heart Study. Circulation. 1998; 98: 946-952. 


\section{Valorization}

10. Ball J, Carrington MJ, McMurray JJ, Stewart S. Atrial fibrillation: profile and burden of an evolving epidemic in the 21st century. Int J Cardiol. 2013; 167: 1807-1824.

11. Sheikh A, Patel NJ, Nalluri N, Agnihotri K, Spagnola J, Patel A, Asti D, Kanotra R, Khan H, Savani C, Arora S, Patel N, Thakkar B, Patel N, Pau D, Badheka AO, Deshmukh A, Kowalski M, Viles-Gonzalez J, Paydak H. Trends in Hospitalization for Atrial Fibrillation: Epidemiology, Cost, and Implications for the Future. Prog Cardiovasc. Dis 2015.

12. Turakhia MP, Shafrin J, Bognar K, Goldman DP, Mendys PM, Abdulsattar Y, Wiederkehr D, Trocio J. Economic Burden of Undiagnosed Nonvalvular Atrial Fibrillation in the United States. Am J Cardiol. 2015; 116: 733-739.

13. Abed HS, Wittert GA, Leong DP, Shirazi MG, Bahrami B, Middeldorp ME, Lorimer MF, Lau DH, Antic NA, Brooks AG, Abhayaratna WP, Kalman JM, Sanders P. Effect of weight reduction and cardiometabolic risk factor management on symptom burden and severity in patients with atrial fibrillation: a randomized clinical trial. Jama. 2013; 310: 2050-2060.

14. Pathak RK, Middeldorp ME, Meredith M, Mehta AB, Mahajan R, Wong CX, Twomey D, Elliott AD, Kalman JM, Abhayaratna WP, Lau DH, Sanders P. Long-Term Effect of GoalDirected Weight Management in an Atrial Fibrillation Cohort: A Long-Term Follow-Up Study (LEGACY). Journal of the American College of Cardiology. 2015; 65: 2159-2169.

15. Verheule S, Tuyls E, Gharaviri A, Hulsmans S, van Hunnik A, Kuiper M, Serroyen J, Zeemering S, Kuijpers NH, Schotten U. Loss of continuity in the thin epicardial layer because of endomysial fibrosis increases the complexity of atrial fibrillatory conduction. Circ Arrhythm Electrophysiol. 2013; 6: 202-211. 
Valorization 

Dankwoord 
Dankwoord 
Eindelijk. Het 'boekje' is af. Of bijna af. Het dankwoord nog. Het dankwoord is best wel een belangrijk onderdeel van 'het boekje', er zijn veel mensen die me geholpen hebben om mijn doel te bereiken.

Graag begin ik met dank aan alle patiënten die hebben deelgenomen aan de MAPAC studie. Zonder hun bereidwilligheid en onbaatzuchtigheid zou ik nooit de prachtige data in hoofdstuk 4, 5 en 6 kunnen voorstellen. Ook de proefdieren ben ik dankbaar voor de unieke mogelijkheid om een diepgaande anatomische analyse te verrichten.

Professor Schotten, beste Uli, ik ben je enorm dankbaar voor al wat je me de laatste jaren hebt geleerd en het vertrouwen dat je steeds in mij had. Ik herinner me onze eerste ontmoeting. Ik kwam langs uw bureau voor een 'sollicitatie gesprek' en u zat helemaal enthousiast achter uw blazende Windowslaptop (nog in uw pre-á tijd) naar 2 rijen electrogrammen te kijken. U wees me op een epicardiale breakthrough die vanuit het endocard leek te komen. Ik had toen geen flauw idee wat ik eigenlijk moest zien, maar ik begreep al dat het PhD traject een uitdagend avontuur zou worden! Het is een veeleisende, maar fantastische samenwerking geweest en ik hoop uit de grond van mijn hart dat we deze kunnen verderzetten in de nabije toekomst.

Professor Maessen, beste Jos, ik bewonder uw gedrevenheid voor onderzoek. Graag bedank ik u om me binnen te loodsen in de groep van Uli en mij de kans te geven helemaal voor mijn onderzoek te gaan. Dank ook voor de 'ochtendmomenten' waarop ik steeds even met u kon/kan overleggen. Ik herinner me mijn vreugde toen $u$ me na een onderzoekspresentatie op de 'Tscore' een opleidingsplek aanbood. Bij het lezen van de brief diende ik wel even in het woordenboek te duiken om 'Ijs en weder dienende' juist te kunnen interpreteren.

Dr. Verheule, beste Sander, mijn co-promotor! Steeds weer stond je deur open om uitleg te geven over zowat alles waar je vragen over kan stellen: een pas uitgekomen paper, $\boldsymbol{k}$, zelf software knutselen, fotograferen, Amerika, zakmessen en andere zeer excentrieke survivalgadgets. Bedankt voor al die (tot minuscule toe) veranderingen aan teksten en figuren tot ze echt helemaal perfect waren. You are the 'master of readability'. Daarnaast wil ik je graag bedanken voor alle fijne momenten buiten het werk. 


\section{Dankwoord}

Professor Allessie, beste Maurits, we hebben maar een korte tijd samen kunnen werken. Samen met u over onderzoek praten is als door een TGV van ideeën omver geblazen worden, heel indrukwekkend. Dank voor die korte maar krachtige momenten.

Professor Crijns, beste Harry, ik herinner me de 'brainstorm sessies' waar u 's avonds na een overvolle klinische werkdag vol enthousiasme onze onderzoekpraatjes aanhoorde en feedback gaf. Dank voor al die leerrijke momenten.

Graag had ik de leden van de beoordelingscommissie, professor Frits Prinzen, professor Tammo Delhaas, professor Filip Rega en professor Mattias Duytschaever bedankt voor de tijd die ze aan de beoordeling en lezen van het proefschrift hebben gespendeerd. Jammer dat $\mathrm{u}$ niet bij de promotie zal zijn Mattias, ik had u graag als opponent in de corona ontmoet.

Er zijn veel mensen bij de (elektro)fysiologie die me gedurende mijn onderzoeksperiode fantastisch geholpen hebben. Arne, wat had ik al die jaren zonder jou gedaan? Je hebt me veilig door de elektrofysiologische jungle geleid! Daarnaast ben je een geweldige vriend geworden. Samen op congres in de USA gaat steeds gepaard met fantastische outdoor- en indoor(lees: lekker eten)momenten. Bedankt kerel. Jens, wat een warm iemand ben je toch. Je hebt me leren 'pacemappen', maar eigenlijk heb je me vooral bijgebracht te genieten van je gezin, zelfs al is het leven superdruk. Je bent dan ook gezegend met een geweldige thuis. Arne en Jens, ik ben trots dat jullie mijn paranimfen zijn. Dominik, heerlijk om te zien hoe jij als onderzoeker en als arts helemaal tot de top aan het doorstomen bent, impressionant! Ben je dankbaar voor alle gesprekken, bbq's en leuke momenten (op werk, op congres of gewoon thuis) die we tot nu toe hebben gehad. Maura, bedankt voor al de momenten waarop we onze frustratie even kwijt konden bij elkaar. Stef, bedankt voor je eindeloos geduld ten aanzien van alle softwareproblematiek. Zonder jouw toewijding was dit alles niet gelukt. Dennis, thanks for your scientific advice and your help with analyzing and writing. I enjoyed your cheerfulness a lot. Your jokes and laughter were always very welcome. I especially liked the wine tastings. Theo, Ione, Ron en Cees, de 'klinische AF-kant', het was steeds fijn samenwerken met jullie. Marion, bedankt voor je geduld en toewijding tijdens de pacemakerimplantaties en alle metingen op OK. Stijn, bedankt voor al het ondersteunende werk dat je hebt verricht. Thanks to Ali, Kelly, Benoît-Gilles, Mathieu, Pawel and Hussein for the nice company during breaks and trips. Beste Sonja, Viviane en Bianca, dank voor het regelen van 1000 en 1 dingen. 
During my PhD trajectory, I had the opportunity to work together with a group of very motivated people at Oxford, UK. Professor Kohl, dear Peter, impressive how such great work can come from such a small office. Thanks for all your revisions and your hospitality. Dear Rebecca, Carlos, Vicente, Damian and Daniel, it was a pleasure to meet and work with you all! Our cooperation has ended in a nice (and very complex) publication. The trips to Oxford were always very much appreciated.

Ook in het ziekenhuis van Maastricht zijn er veel mensen die meegewerkt hebben om alles tot een goed einde te brengen. Nathalie, jij hebt me in Riemst en bij de ctc wegwijs gemaakt, iets waarvoor ik je nog steeds dankbaar ben. Uiteindelijk ben ik ook blij dat het werken bij Uli niets voor jou was, anders was deze thesis er nooit gekomen. Graag wil ik ook de hartchirurgen bedanken die alle mapping op OK hebben verricht: Jan, Mark, Gijs, professor Mochtar en Jerôme, bedankt voor de moeite en het geduld tijdens de metingen (als AF wederom overging in sinusritme of als de electrode niet perfect stond). Jan, je hebt het leeuwendeel van de mapping voor je genomen. Bedankt voor alle leuke momenten tussendoor, wetenschappelijk en minder wetenschappelijk. Ik drink nog steeds koffie uit een soepkom! Professor La Meir, best Mark, je bent ondertussen mijn mentor geworden. Prachtig om te zien hoe gepassioneerd je bent door AF! Bedankt voor al het vertrouwen en alle kansen. Professor Mochtar, beste Bas, steeds weer wees $\mathrm{u}$ me op het belang van promoveren. Dank voor alle raad en advies. Beste Gijs, je deed het toch maar, dat mappen, ook al had je geen hoge pet op van al dat onderzoek. Bedankt voor alle leermomenten en het fijne gezelschap (let's keep on walking). Leen en Thomas, dank voor al die gezellige momenten buiten het werk waarbij onderzoek en andere zaken besproken werden. Laurent, dank voor je geduld tijdens experimentele metingen bij de hybride AF-ablatie. Het is erg aangenaam om nu in de kliniek met je te mogen samenwerken. Beste Anja, Sylvia, Nicole en Lucienne, dank voor de flexibiliteit bij het inplannen van de MAPAC patiënten en de ontspannende gesprekken tussendoor (recent nog over de dubbele garage).

Beste Miel en Jos, bedankt voor alle gedetailleerde echo's die jullie bij de MAPAC patiënten gemaakt hebben. Ook dank aan de cardio-anaesthesisten van het MUMC+, die nooit mopperden toen ik weer AF wou induceren op OK voor de metingen. Tenslotte ook veel dank aan de 'cardiozusters' op OK, die het begin van een hartoperatie koelbloedig wisten te combineren met het monteren en aansluiten van de electroden. 


\section{Dankwoord}

Dank aan Youri Curfs, Jos Aarts, Ralf Raumanns Vincent Franssen, Paul Verjans en Frank Nijpels bij IDEE voor alle gezamenlijke projecten die we tot een goed einde hebben gebracht. Het was fijn samenwerken met jullie. Dank aan de mensen bij de dienst sterilisatie MUMC+ die de tijd en de moeite namen om het steriliseren van electrodes te testen en te doen.

Dan ben ik bijna 'uitgedankt'. Rest me mijn vrienden te bedanken omdat ze accepteerden dat ons contact op een lager pitje stond gezien het vele werk en mijn familie voor hun begrip als ik er weer eens niet bij was of mijn laptop meenam omdat ik 'moest werken'. Aan de westvlaamse kant, dank voor jullie vertrouwen en interesse. Mooi hoe jullie ernstig luisterden terwijl ik enthousiast over AF en mijn onderzoek vertelde. Sofie, klein zusje, je hebt vanaf het begin in me geloofd en me steeds gesteund. Dat apprecieer ik enorm! Mamma en papa, jullie hebben heel veel mogelijk gemaakt voor mij. De hele periode vanaf de studie geneeskunde tot het promotiefeest toe zijn jullie steeds prominent aanwezig geweest, op allerlei manieren, om er mee voor te zorgen dat mijn thesis vandaag werkelijkheid is. Ik ben jullie daar zeer erkentelijk voor. Jullie hebben me steeds geholpen op moeilijke momenten.

Tenslotte rest er me nog één iemand te bedanken. Mien, lieve schat, je was er steeds. Steeds. 'Werk maar verder' zei je dan 'ik doe de rest wel'. En 'al die rest' was en is redelijk letterlijk te nemen. Zonder jou geen onderzoek, zonder jou geen carrière, zonder jou geen thesis. Dank daarvoor. Ik hou van je, maar dat weet je wel. 
Dankwoord 

About the author

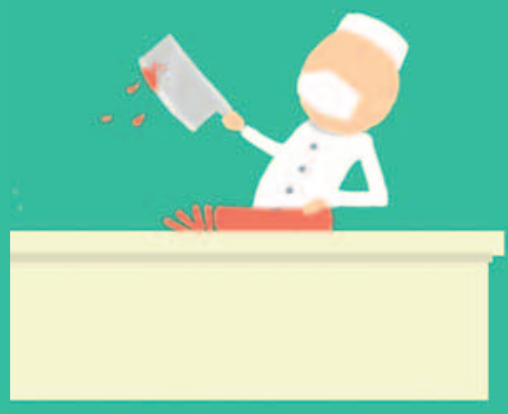


About the author 


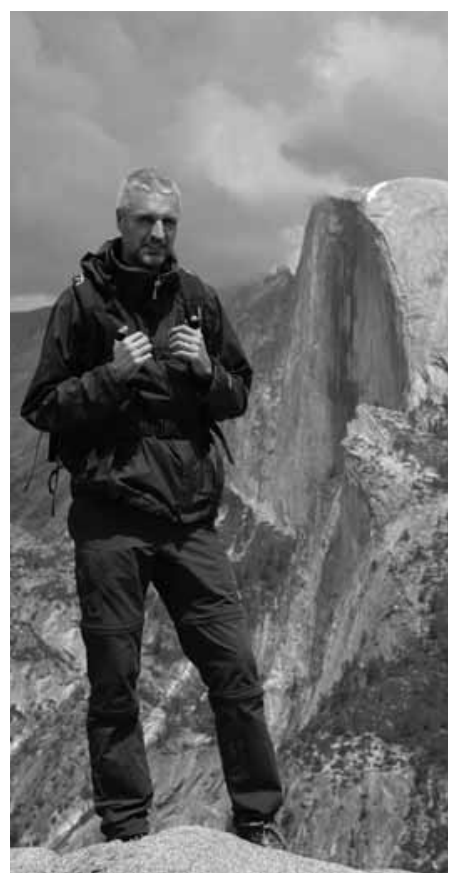

Bart Maesen was born on January 28, 1979 in Turnhout, Belgium. In 1997 he obtained his secondary school diploma (Latin-Greek) at the 'Sint-Gummaruscollege Lier' (Belgium).

He studied medicine at the University of Antwerp (Belgium) and obtained his medical degree in 2004. He then worked in the research group of prof. dr. Dirk Ysebaert at the Department of Experimental Surgery, studying early detection of ischemia/reperfusion injury in the kidney.

By the end of 2006 he moved to Maastricht University Medical Center and started as an intern in the Department of Cardiothoracic Surgery under supervision of prof. dr. Jos Maessen. As his interest in research continued to grow, he joined the electrophysiology research group at the Department of Physiology at Maastricht University under supervision of prof. dr. Uli Schotten. During a PhD trajectory of 4 years, he studied different aspects of the substrate of atrial fibrillation in goat and human. Together with prof. dr. Uli Schotten and IDEE (Maastricht University) he developed a high-density mapping electrode suitable for human epicardial mapping. During his PhD trajectory, he had the opportunity to collaborate with the research group of prof. dr. Peter Kohl at Oxford University.

The acquired research data resulted in several publications in peer-reviewed journals and a patent (Non-invasive classification of atrial fibrillation by probabilistic interval analysis of a transesophageal electrocardiogram, EP2713866A1, EP2713866B1, US20150038863, WO2012160066A1) together with Stef Zeemering and prof. dr. Uli Schotten. He presented his work at several international and national congresses and won the poster prize at the Belgian Heart Rhythm Meeting in 2012. By the end of 2011 he started his training in cardiothoracic surgery under supervision of prof. dr. Jos Maessen and dr. Suzanne Kats. His interests are minimal invasive cardiac and lung surgery, (minimal invasive) rhythm surgery and aortic surgery. 

List of publications

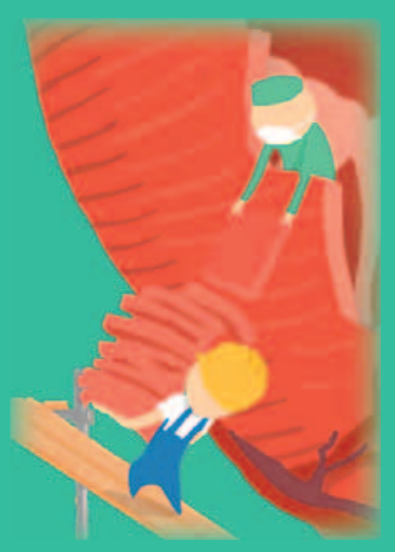


List of publications 
Eckstein J, Maesen B, Linz D, Zeemering S, van Hunnik A, Verheule S, Allessie $\mathrm{M}$, Schotten U. Time course and mechanisms of endo-epicardial electrical dissociation during atrial fibrillation in the goat. Cardiovasc Res. 2011 Mar 1;89(4): 816-24.

Maesen B, Nijs J, Maessen J, Allessie M, Schotten U. Post-operative atrial fibrillation: a maze of mechanisms. Europace. 2012 Feb;14(2):159-74.

Schotten U, Maesen B, Zeemering S. The need for standardization of timeand frequency-domain analysis of body surface electrocardiograms for assessment of the atrial fibrillation substrate. Europace. 2012 Aug;14(8):1072-5

Lau DH, Maesen B, Zeemering S, Verheule S, Crijns HJ, Schotten U. Stability of Complex Fractionated Atrial Electrograms: A Systematic Review. J Cardiovasc Electrophysiol. 2012 Sep;23(9):980-7

Zeemering S, Maesen B, Nijs J, Lau DH, Granier M, Verheule S, Schotten U. Automated quantification of atrial fibrillation complexity by probabilistic electrogram analysis and fibrillation wave reconstruction. Conf Proc IEEE Eng Med Biol Soc. 2012 Aug;2012:6357-60

Eckstein J, Zeemering S, Linz D, Maesen B, Verheule S, van Hunnik A, Crijns $\mathrm{H}$, Allessie MA, Schotten U. Transmural Conduction is the Predominant Mechanism of Breakthrough during Atrial Fibrillation: Evidence from Simultaneous Endo-epicardial High Density Activation Mapping. Circ Arrhythm Electrophysiol. 2013; 6: 334-341

Bidar E, Bramer S, Maesen B, Maesen J, Schotten U. Post-operative Atrial Fibrillation - Pathophysiology, Treatment and Prevention. JAFIB: Journal of Atrial Fibrillation. 2013 Apr/May, Vol. 5, Issue 6: p136-145.

Lau D. H., Zeemering S., Maesen B., Kuklik P., Verheule S., Schotten U. Catheter Ablation Targeting Complex Fractionated Atrial Electrogram in Atrial Fibrillation. JAFIB: Journal of Atrial Fibrillation. 2013 Oct/Nov, Vol. 6, Issue 3: p86-92.

Maesen B, Zeemering S, Afonso C, Eckstein J, Burton RA, van Hunnik A, Stuckey DJ, Tyler D, Maessen J, Grau V, Verheule S, Kohl P, Schotten U. Rearrangement of atrial bundle architecture and consequent changes in anisotropy of conduction constitute the 3-dimensional substrate for atrial fibrillation. Circ Arrhythm Electrophysiol. 2013 Oct 1;6(5):967-75 
List of publications

Bidar E, Maesen B, Nieman F, Verheule S, Schotten U, Maessen JG. A prospective randomized controlled trial on the incidence and predictors of late phase post-operative atrial fibrillation up to 30 days and the preventive value of bi-atrial pacing. Heart Rhythm. 2014 Jul;11(7):1156-62.

Verheule S, Eckstein J, Linz D, Maesen B, Bidar E, Gharaviri A, Schotten U. Role of endo-epicardial dissociation of electrical activity and transmural conduction in the development of persistent atrial fibrillation. Prog Biophys Mol Biol. 2014 Aug;115(2-3):173-85.

Kuklik P, Zeemering S, Maesen B, Maessen J, Crijns H, Verheule S, Schotten U. Reconstruction of instantaneous phase of unipolar atrial contact electrogram using a concept of sinusoidal recomposition and Hilbert transform. IEEE Trans Biomed Eng. 2015 Jan;62(1):296-302

Kumar N, Bonizzi P, Pison L, Phan K, Lankveld T, Maesen B, La Meir M, Gelsomino S, Maessen J, Crijns H. Impact of hybrid procedure on $\mathrm{P}$ wave duration for atrial fibrillation ablation. J Interv Card Electrophysiol. 2015 Mar; 42(2):91-9.

Lau DH, Maesen B, Zeemering S, Kuklik P, Hunnik AV, Lankveld TA, Bidar E, Verheule S, Nijs J, Maessen J, Crijns H, Sanders P, Schotten U. Indices of bipolar complex fractionated atrial electrograms correlate poorly with each other and atrial fibrillation substrate complexity. Heart Rhythm. $2015 \mathrm{Jul} ; 12$ (7): 1415-23 
List of publications 

List of abbreviations

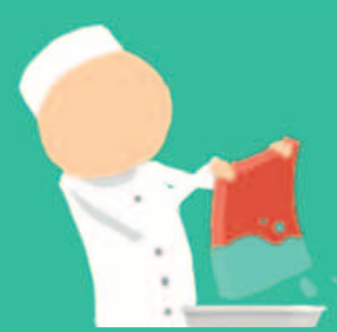


List of abbreviations 
2D 2-Dimensional

3D 3-Dimensional

aAF Acute AF

ACE-I Angiotensin-converting enzyme inhibitor

ACI Average complex interval

AERP Atrial effective refractory period

AF Atrial fibrillation

AFCL Atrial fibrillation cycle length

AFL atrial flutter

APD Action potential duration

AVR Aortic valve replacement

AVS Aortic Valve Surgery

BMI Body mass index

BSM Body surface mapping

BT Breakthrough

CABG Coronary artery bypass grafting

cAMP Cyclic adenosine monophosphate

CCB Calcium channel blocker

CEA Continuous electrical activity

CFAE Complex fractionated atrial electrogram

CFE-m Complex fractionated electrogram-mean

$\mathrm{CHF} \quad$ Chronic heart failure

COPD Chronic obstructive pulmonary disease

CPB Cardiopulmonary bypass

CRP C-reactive protein

$\mathrm{CV} \quad$ Conduction velocity

Cx43 Connexin 43

DF Dominant frequency

ECG Electrocardiogram

Endo Endocardial

Epi Epicardial

FI Fractionation index

GFR Glomerular filtration rate

HI Heterogeneity index

HRV Heart rate variability

$\mathrm{Hz} \quad$ Hertz

ICL Interval confidence level

LA Left atrial/atrium

LAA Left atrial appendage 
List of abbreviations

LV Left ventricle

LVEDD Left ventricular end diastolic diameter

LVEF Left ventricular ejection fraction

LVESD Left ventricular end systolic diameter

MEA Multielectrode array

MI Myocardial infarction

MRI Magnetic resonance imaging

MVR Mitral valve replacement

MVS Mitral Valve Surgery

NADPH Nicotinamide adenine dinucleotide phosphate

NO Nitric oxide

NYHA New York Heart Association functional classification

OPCAB Off-pump coronary artery bypass

pAF Paroxysmal AF

PAT Paroxysmal atrial tachycardia

persAF Persistent AF

pLA Posterior left atrium

POAF Postoperative atrial fibrillation

PVI Pulmonary vein isolation

RA Right atrial/atrium

RAA Right atrial appendage

RAP Rapid atrial pacing

RCA Right coronary artery

RF Radiofrequency

SCI Shortest complex interval

SNP Sodium nitroprusside 